\title{
Lipid droplet coat proteins, skeletal muscle lipid metabolism \& insulin sensitivity
}

Citation for published version (APA):

Bosma, M. (2013). Lipid droplet coat proteins, skeletal muscle lipid metabolism \& insulin sensitivity.

[Doctoral Thesis, Maastricht University]. Uitgeverij BOXPress. https://doi.org/10.26481/dis.20130301mb

Document status and date:

Published: 01/01/2013

DOI:

10.26481/dis.20130301mb

Document Version:

Publisher's PDF, also known as Version of record

\section{Please check the document version of this publication:}

- A submitted manuscript is the version of the article upon submission and before peer-review. There can be important differences between the submitted version and the official published version of record.

People interested in the research are advised to contact the author for the final version of the publication, or visit the DOI to the publisher's website.

- The final author version and the galley proof are versions of the publication after peer review.

- The final published version features the final layout of the paper including the volume, issue and page numbers.

Link to publication

\footnotetext{
General rights rights.

- You may freely distribute the URL identifying the publication in the public portal. please follow below link for the End User Agreement:

www.umlib.nl/taverne-license

Take down policy

If you believe that this document breaches copyright please contact us at:

repository@maastrichtuniversity.nl

providing details and we will investigate your claim.
}

Copyright and moral rights for the publications made accessible in the public portal are retained by the authors and/or other copyright owners and it is a condition of accessing publications that users recognise and abide by the legal requirements associated with these

- Users may download and print one copy of any publication from the public portal for the purpose of private study or research.

- You may not further distribute the material or use it for any profit-making activity or commercial gain

If the publication is distributed under the terms of Article $25 \mathrm{fa}$ of the Dutch Copyright Act, indicated by the "Taverne" license above, 


\section{LIPID DROPLET COAT PROTEINS, SKELETAL MUSCLE LIPID METABOLISM \& INSULIN SENSITIVITY}




\section{îtín}

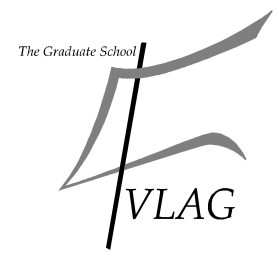

The study presented in this thesis was performed within NUTRIM, School for Nutrition, Toxicology and Metabolism, which participates in the Graduate School VLAG (Food Technology, Agrobiotechnology, Nutrition and Health Sciences), accredited by the Royal Netherlands Academy of Arts and Sciences. The research presented in this thesis was financially supported by VLAG and NUTRIM.

Cover design: Madeleen Bosma, Siebe Bosma en Yvonne van de Grint Cover photo: Chameleon's tail, (C) Mark Bridger Layout: Madeleen Bosma

ISBN: 9789088915758

(C) Copyright Madeleen Bosma, Maastricht 2013

Printed by: Proefschriftmaken.nl II Uitgeverij BOXPress

Financial support by the Dutch Diabetes Research Foundation, Novo Nordisk, Progen Biotechnik and Greiner Bio-One for printing of this thesis is gratefully acknowledged.

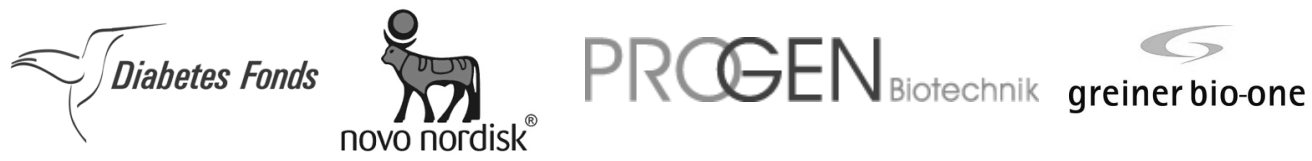




\section{LIPID DROPLET COAT PROTEINS, SKELETAL MUSCLE LIPID METABOLISM \& INSULIN SENSITIVITY}

\section{PROEFSCHRIFT}

ter verkrijging van de graad van doctor aan de Universiteit Maastricht, op gezag van de Rector Magnificus, Prof. dr. L.L.G. Soete volgens het besluit van het College van Decanen, in het openbaar te verdedigen op vrijdag 1 maart 2013 om 16.00 uur

door

\section{Magdalena Bosma}

Geboren te Heerenveen op 16 november 1984 


\section{PROMOTORES}

Prof. dr. L.P.A.J. Schrauwen

Prof. dr. M.K.C. Hesselink

Prof. dr. ir. A.H. Kersten (Wageningen Universiteit)

\section{BEOORDELINGSCOMMISSSIE}

Prof. dr. J.F.C. Glatz (voorzitter)

Prof. dr. ir. E.A.L. Biessen

Prof. dr. ir. L. Havekes (Leids Universitair Medisch Centrum)

Prof. dr. F. Karpe (University of Oxford, United Kingdom)

Dr. R.S. Shiri-Sverdlov 


\section{TABLE OF CONTENTS}

$\begin{array}{lll}\text { Chapter } 1 \text { General Introduction } & 7\end{array}$

Chapter 2 Re-evaluating lipotoxic triggers in skeletal muscle: 17

Relating intramyocellular lipid metabolism to insulin sensitivity

Chapter 3 Increased intramyocellular lipid storage capacity is associated

with lower fasting-induced insulin resistance

Chapter 4 Reduced incorporation of fatty acids into triacylglycerol in myotubes established from obese individuals with type 2 diabetes

Chapter 5 Perilipin 2 improves insulin sensitivity in skeletal muscle despite elevated intramuscular lipid levels

Chapter 6 The lipid droplet coat protein perilipin 5 also localizes to muscle mitochondria

Chapter 7 Overexpression of PLIN5 in skeletal muscle promotes oxidative gene expression and intramyocellular lipid content without compromising insulin sensitivity

Chapter 8 Modifying the myocellular lipid droplet phenotype by exercise training in obese and type 2 diabetic subjects contributes to metabolic flexibility

Chapter 9 General Discussion

Appendices

Summary

Samenvatting

Dankwoord

List of Publications

Curriculum Vitae 



\section{CHAPTER 1}

General introduction 


\section{The obesity epidemic}

Western style diets, excess calorie intake and low physical activity levels have resulted in an obesity epidemic. This epidemic is currently affecting 500 million adults worldwide, more than one in ten of the world's population, with percentages approaching 20 percent in Europe and 30 percent in the USA [1]. The obesity epidemic is expanding dramatically in adults as well as in children [1,2]. Obesity can be considered a whole-body distortion of metabolism; frequent comorbidities include cardiovascular disease, liver disease, chronic obstructive pulmonary disease (COPD), cancer, musculoskeletal disorders and type 2 diabetes mellitus [3]. Therefore, the obesity trend implies a major health burden affecting quality of life and imposes a large economic burden on the health care system.

\section{Obesity and type 2 diabetes mellitus}

One of the major complications of obesity is impaired glucose tolerance. A sedentary lifestyle and obesity are considered the main determinants in the etiology of impaired glucose tolerance, which is characterized by reduced insulin secretion by the pancreas and insulin resistance. Insulin resistance is defined as an impaired ability of the hormone insulin to stimulate glucose disposal by skeletal muscle and liver and to inhibit hepatic glucose production. Impaired glucose tolerance may deteriorate towards type 2 diabetes (T2D), which is characterized by $\beta$-cell dysfunction and hyperglycemia, reflecting the disability of the pancreatic $\beta$-cells to compensate for the peripheral insulin resistance. Approximately 90 percent of type 2 diabetics are overweight [4]. Weight loss and exercise can alleviate the symptoms and may even reverse insulin resistance $[5,6]$. Yet, the fact that 'only' approximately 30 percent of obese people have T2D [7] indicates that genetic and/or epigenetic predisposition plays an important role in the etiology of obesityassociated insulin resistance and progression towards T2D.

Several hypotheses have been put forward trying to explain the relationship between obesity and type 2 diabetes, including theories on lipid oversupply, endocrine disorders, proinflammatory states, mitochondrial dysfunction and endoplasmic reticulum (ER) stress $[8,9]$. There is no uniform single etiology; several pathologies lead to T2D and these paths are highly interrelated and involve multiple organs, in particular the adipose tissue, pancreas, liver and skeletal muscle. Most likely lipid, endocrine and inflammatory parameters in addition to mitochondrial and ER function together determine susceptibility and development towards insulin resistance, $\beta$-cell failure and ultimately T2D. One causal factor may trigger other parameters inducing a cascade of deterioration.

\section{Lipid overflow}

In this thesis, the focus is on the lipid overflow hypothesis, which is considered the major explanation for obesity-associated insulin resistance. The lipid overflow hypothesis considers T2D to result from a general state of increased lipid levels. When adipose tissue is no longer capable of providing sufficient storage capacity for lipids in situations of lipid oversupply, lipids will accumulate in nonadipose tissues such as liver, heart and skeletal 
muscle. Thus, ectopic lipid accumulation has been considered causative in obesityassociated insulin resistance and T2D (reviewed in $[8,10]$ ). In this thesis I will concentrate on lipid accumulation in skeletal muscle, which is quantitatively a major contributor to whole body glucose handling. The muscle accounts for more than 80 percent of postprandial whole body glucose disposal. Initially, impaired skeletal muscle glucose disposal, as seen in obesity, was explained by the Randle cycle; elevated intramyocellular fatty acid (FA) oxidation was considered to increase acetyl-CoA/CoA and NADH/NAD ${ }^{+}$ ratios thereby inducing a cascade of events inhibiting the glucose catabolic enzymes pyruvate dehydrogenase, phosphofructokinase and hexokinase resulting in reduced glucose utilization $[11,12]$. However, subsequent studies showed that intramyocellular glucose-6-phosphate levels were decreased rather than increased upon lipid infusion and were decreased in insulin resistant subjects compared to insulin sensitive controls without a compensatory increase in intracellular glucose levels [13-16]. This indicated that the Randle cycle cannot fully explain the effects of elevated circulating free fatty levels on glucose disposal. Thus, glucose uptake, rather than the subsequent glucose phosphorylation/ utilization, was identified as the rate-limiting determinant for skeletal muscle glucose disposal. After the discovery of the glucose transporter GLUT4 [17, 18], which translocates from the cytosol to the plasma membrane upon insulin stimulation, interest shifted towards lipid-related factors that have the potential to interfere with the insulin-dependent pathways involved in GLUT4 translocation to the sarcolemma as potential causes for obesity-associated skeletal muscle insulin resistance [19].

Skeletal muscle lipid levels - intramyocellular lipids (IMCL) - correlate negatively with insulin sensitivity in a sedentary population [20-24] and hence were considered predictive for insulin resistance and causative in obesity-associated insulin resistance. However, endurance athletes also have high IMCL levels despite being highly insulin sensitive [2527] and exercise training in obese and T2D subjects (which alleviates insulin resistance) increases rather than decreases IMCL levels $[6,28]$. This so-called athlete's paradox gave new insight into the role of skeletal muscle lipid accumulation in insulin resistance and indicated that neutral IMCL accumulation per se does not lead to insulin resistance. Lipidinduced insulin resistance in skeletal muscle probably depends on the intramyocellular lipid composition and subcellular distribution. Thus, the athlete's paradox has been explained by differential effects of training and diabetes on IMCL turnover, accumulation of lipid intermediates, and oxidative capacity. Proper balancing between skeletal muscle lipid influx and fat oxidative capacity as well as an efficient rate of lipid turnover (i.e. lipid depletion and efficient resynthesis to prevent lipid intermediate build-up) have been suggested to be beneficial for insulin sensitivity [28-31].

\section{Lipid intermediates}

In contrast to neutral lipids, i.e. triacylglycerol (TAG), certain lipid subspecies - lipid intermediates - are considered to interfere with the insulin signaling cascade, thereby impairing insulin sensitivity. Following FA uptake, FAs can be channeled directly towards mitochondrial $\beta$-oxidation, but the majority of FAs will first be utilized as building blocks 


\section{General introduction}

for TAG synthesis. TAGs serve as a neutral intracellular lipid storage form for later use as a substrate for energy production. Subsequent lipolysis can liberate FAs for downstream catabolic metabolism. Lipid intermediate accumulation can result from an imbalance between FA uptake and TAG (re)synthesis capacity and/or from a mismatch between lipolysis and FA oxidation. To date, the lipid intermediates diacylglycerol (DAG), ceramide, fatty acyl-CoAs (FA-CoAs) and acylcarnitines are considered potentially lipotoxic (reviewed in [31-35]).

\section{Skeletal muscle oxidative capacity}

Oxidative capacity, the capability to burn substrates, is considered an important determinant for lipid-induced insulin resistance. Oxidative capacity is determined by mitochondrial density, mitochondrial function and oxidative catabolism-related enzyme capacities. Obese and/or diabetic subjects have an increased supply of lipids to the skeletal muscle [21] in addition to a lower oxidative capacity and impaired mitochondrial function [36-38]. Consequently, FAs may accumulate in the form of toxic lipid intermediates. Strategies to improve skeletal muscle oxidative capacity and mitochondrial function have been shown to improve insulin sensitivity [39-41]. In addition to increased oxidative rates due to increased energy demand, the explanation for the improvements in insulin sensitivity upon improvements in mitochondrial function and oxidative capacity may lay in a better coupling of lipolysis, $\beta$-oxidation, the TCA cycle and oxidative phosphorylation thus lowering intermediate accumulation (reviewed in [42]). Paradoxically, increased oxidative capacity and energy demand are associated with increased (neutral) IMCL storage [40, 43-45], indicating that these two processes are tightly interrelated.

\section{Intramyocellular lipid droplets and lipid droplet coat proteins}

Lipid droplets are the main storage sites for intracellular lipids, providing lipid reservoirs in the hydrophilic environment. Besides storage in lipid droplets (LDs), lipid species can accumulate at other subcellular locations like the plasma membrane, mitochondria and the endoplasmic reticulum (ER), where accumulation of lipids is potentially toxic. Therefore, LDs represent a neutral lipid storage site - consisting mainly of TAG - that, very importantly, also serves as the interface for intracellular lipid metabolism. Therefore, LDs are highly dynamic organelles; they are continuously synthesized and degraded, they traffic within the cell and they interact with other organelles like the ER and mitochondria [reviewed in 46, 47]. The neutral lipid core is surrounded by a phospholipid monolayer decorated with LD coat proteins that modulate lipid droplet dynamics (Figure 1). Londos and colleagues were the first to identify a LD coat protein, perilipin 1, in 1991 [48]. Since then, numerous other LD coat proteins have been characterized, while a large proportion of the protein coat remains uncharacterized to date. The first and best-characterized family of LD coat proteins is the perilipin protein family, consisting of five proteins. Perilipin 1 (PLIN1) is specific for adipose tissue and is considered to be an important 
regulator of lipolysis. PLIN1 restrains basal lipolysis and facilitates hormone-stimulated lipolysis [48-52]. PLINs 2-4 are ubiquitously expressed [53]. PLIN2 (adipophilin, ADRP) function was mainly studied in fibroblasts, macrophages and liver, it is considered to be involved in both LD biogenesis and inhibition of lipolysis [54-57]. PLIN3 (TIP47) was implicated to be involved in LD biogenesis [58]. Little is known about PLIN4 (S3-12) function, except for its localization to nascent (i.e. early in development) LDs [59]. PLIN5 (OXPAT, MLDP, LSDP5) is expressed in cells with a high oxidative capacity like type 1 muscle fibers, brown fat and liver. Based on research in hepatocytes and cardiomyocytes, PLIN5 is considered to facilitate stimulated lipolysis [60-65]. Information on the role of perilipins in skeletal muscle is still limited.

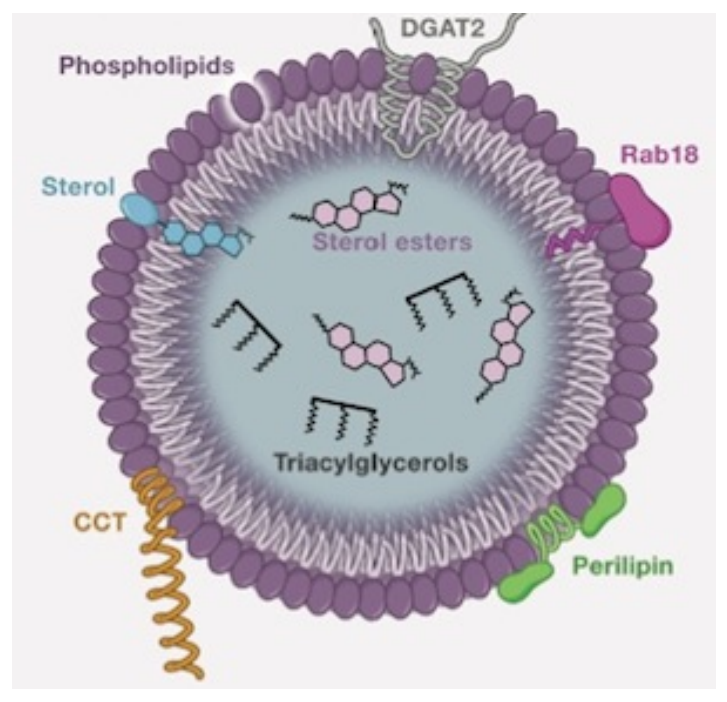

Figure 1. Illustration of the organization of an LD. LD coat proteins like perilipin are conditionally present in the LD coat, dependent on the cellular energy status and the metabolic fate of the LD. Adapted from [66].

Most research in the field of LD coat proteins has focused on adipose tissue and liver. Moreover, most knowledge is based on in vitro studies. Skeletal muscle is very distinct from adipose tissue given its high metabolic rate, which is accelerated during exercise. Therefore, intramyocellular lipid metabolism needs to be tightly controlled. A recent paper on the skeletal muscle LD proteome identified 324 proteins to localize to LDs [67]. The regulation of lipid droplet dynamics is therefore highly complex and individual pathways involved can barely be studied separately. Twenty percent of the proteins in the LD fraction were shown to be associated with mitochondria [67]. Furthermore, electron microscopy imaging shows close proximity of LDs to mitochondria in skeletal muscle [68, $69]$, indicating close interactions of these organelles. Furthermore, interventions resulting in increased energy demand and oxidative capacity are paralleled with increased intramyocellular LD storage [40,43-45], indicating a close interrelationship between these parameters that together may be the major determinants for alleviation of obesityassociated insulin resistance. By modulating lipid storage capacity and LD dynamics, LD coat proteins may be regulatory factors in lipid-induced insulin resistance. Hence, 


\section{General introduction}

interindividual variation in perilipin expression and function and interventions targeted at improving perilipin capacity and function can be considered important determinants for susceptibility to and prevention of lipid-induced insulin resistance.

\section{Outline of this thesis}

In this PhD project the role of lipid droplet coat proteins in skeletal muscle lipid metabolism and insulin sensitivity was investigated. A translational approach was used; a combination of cell, animal and human studies, as well as in vitro, ex vivo and in vivo approaches. Given their high expression levels in skeletal muscle, the LD coat proteins perilipin 2 and 5 were selected as the primary focus.

Chapter 2 provides an overview of the current literature regarding lipid-induced insulin resistance in skeletal muscle. The major parameters involved are discussed, including lipid metabolism, lipid intermediate accumulation, and LD dynamics. This chapter reviews evidence from human studies, linked with supporting information from mechanistic studies.

Intramyocellular neutral lipid storage capacity and LD coat protein expression may determine susceptibility to lipid-induced insulin resistance. In chapter 3 the effects of increased lipid supply on insulin sensitivity, intramyocellular lipid accumulation and expression of LD coat proteins was investigated. Two models for lipid oversupply in humans are reported: fasting for $60 \mathrm{~h}$ and consumption of a high fat diet for 3 weeks.

To determine whether impaired IMCL storage and/or a reduced fat oxidative capacity may characterize T2D subjects, we used a translational approach to elucidate differences in lipid metabolism and mitochondrial function in T2D subjects and BMI-matched controls in vivo, ex vivo and in vitro (chapter 4). In this study, an extensive in vivo phenotyping of the subjects was performed and lipid metabolism and oxidative capacity were studied in detail in muscle biopsy tissue and muscle cells cultured from the biopsies obtained. Cultured muscle cells are derived from satellite cells, which mainly represent the genetic and epigenetic characteristics of the donor. Therefore, this study allowed us to study both primary defects (predisposition) as well as acquired defects in lipid metabolism. In vitro pulse-chase experiments were utilized to study individual components of lipid metabolism, such as lipid synthesis, lipolysis and oxidation of LD-derived FAs.

LD coat proteins were recently characterized as important modulators of lipid metabolism. Chapter 5 focuses on the role of PLIN2 in skeletal muscle lipid metabolism, lipotoxicity and insulin sensitivity. The function of PLIN2 was extensively studied using in vitro knockdown and overexpression in muscle cells and in vivo overexpression in rat skeletal muscle. PLIN5 is a LD coat protein expressed specifically in tissues with a high fatoxidative capacity. PLIN5 may have a role in facilitating fatty acid oxidation. In chapter 6 the subcellular localization of PLIN5 was identified and effects of PLIN5 overexpression on fatty acid oxidative capacity and mitochondrial function were investigated. Chapter 7 
builds on the previous chapter and further identifies effects of PLIN5 overexpression on skeletal muscle lipid accumulation, insulin sensitivity and transcriptomic profiles.

Insulin-sensitizing strategies may involve adaptations in intramyocellular LD dynamics. Endurance training is an intervention that improves skeletal muscle oxidative capacity and insulin sensitivity. In chapter 8 the effects of a 12-week endurance training program on IMCL storage and perilipin protein expression are described. Finally, chapter 9 summarizes and integrates the major findings of this thesis project and places my findings in the light of recent advances in the field.

\section{REFERENCES}

1. WHO. Obesity and overweight Fact sheet $N^{\circ} 311.2011 ;$ www.who.int/mediacentre/factsheets/fs311.

2. Anastasiou CA, Kavouras SA, Lentzas Y, Gova A, Sidossis LS, and Melidonis A. Moderate weight loss depletes intramyocellular triglycerides but has no effect on diglycerides in type II diabetes. Eur J Clin Nutr 2010; 64: 328-330.

3. Schelbert KB. Comorbidities of obesity. Prim Care 2009; 36: 271-285.

4. Kumanyika S, Jeffery RW, Morabia A, Ritenbaugh C, and Antipatis VJ. Obesity prevention: the case for action. Int J Obes Relat Metab Disord 2002; 26: 425-36.

5. Dubé J, Amati F, Toledo F, Stefanovic-Racic M, Rossi A, Coen P, and Goodpaster B. Effects of weight loss and exercise on insulin resistance, and intramyocellular triacylglycerol, diacylglycerol and ceramide. Diabetologia 2011; 54: 1147-1156.

6. Meex RCR, Schrauwen-Hinderling VB, Moonen-Kornips E, Schaart G, Mensink M, Phielix E, van de Weijer T, Sels JP, Schrauwen P, and Hesselink MKC. Restoration of muscle mitochondrial function and metabolic flexibility in type 2 diabetes by exercise training is paralleled by increased myocellular fat storage and improved insulin sensitivity. Diabetes 2010; 59: 572-579.

7. Nguyen N, Nguyen XM, Lane J, and Wang P. Relationship between obesity and diabetes in a US Adult population: findings from the national health and nutrition examination survey, 1999-2006. Obes Surg 2011; 21: 351-355.

8. Eckel RH, Kahn SE, Ferrannini E, Goldfine AB, Nathan DM, Schwartz MW, Smith RJ, and Smith SR. Obesity and type 2 diabetes: what can be unified and what needs to be individualized? J Clin Endocrinol Metab 2011; 96: 1654-1663.

9. Lee DE, Kehlenbrink $S$, Lee $H$, Hawkins $M$, and Yudkin JS. Getting the message across: mechanisms of physiological cross talk by adipose tissue. Am J Physiol Endocrinol Metab 2009; 296: E1210-E1229.

10. Goodpaster $\mathrm{BH}$ and Wolf D. Skeletal muscle lipid accumulation in obesity, insulin resistance, and type 2 diabetes. Pediatr Diabetes 2004; 5: 219-226.

11. Randle PJ, Garland PB, Hales CN, and Newsholme EA. The glucose fatty-acid cycle. Its role in insulin sensitivity and the metabolic disturbances of diabetes mellitus. Lancet 1963; 1: 785-9.

12. Randle PJ, Garland PB, Newsholmet EA, and Hales CN. The glucose fatty acid cycle in obesity and maturity onset diabetes mellitus Ann N Y Acad Sci 1965; 131: 324-333.

13. Cline GW, Petersen KF, Krssak M, Shen J, Hundal RS, Trajanoski Z, Inzucchi S, Dresner A, Rothman DL, and Shulman GI. Impaired glucose transport as a cause of decreased insulin-stimulated muscle glycogen synthesis in type 2 diabetes. N Engl J Med 1999; 341: 240-246.

14. Dresner A, Laurent D, Marcucci M, Griffin ME, Dufour S, Cline GW, Slezak LA, Andersen DK, Hundal RS, Rothman DL, Petersen KF, and Shulman GI. Effects of free fatty acids on glucose transport and IRS-1associated phosphatidylinositol 3-kinase activity. J Clin Invest 1999; 103: 253-259.

15. Rothman DL, Shulman RG, and Shulman GI. 31P nuclear magnetic resonance measurements of muscle glucose-6-phosphate. Evidence for reduced insulin-dependent muscle glucose transport or phosphorylation activity in non-insulin-dependent diabetes mellitus. J Clin Invest 1992; 89: 1069-1075. 


\section{General introduction}

16. Shulman GI, Rothman DL, Jue T, Stein P, DeFronzo RA, and Shulman RG. Quantitation of muscle glycogen synthesis in normal subjects and subjects with non-insulin-dependent diabetes by $13 \mathrm{C}$ nuclear magnetic resonance spectroscopy. N Engl J Med 1990; 322: 223-228.

17. James DE, Brown R, Navarro J, and Pilch PF. Insulin-regulatable tissues express a unique insulin-sensitive glucose transport protein. Nature 1988; 333: 183-185.

18. James DE, Strube M, and Muecdler M. Molecular cloning and characterization of an insulin-regulatable glucose transporter. Nature 1989; 338: 83-87.

19. Shulman GI. Cellular mechanisms of insulin resistance. J Clin Invest 2000; 106: 171-6.

20. Aguer C, Foretz M, Lantier L, Hebrard S, Viollet B, Mercier J, and Kitzmann M. Increased FAT/CD36 cycling and lipid accumulation in myotubes derived from obese type 2 diabetic patients. PLOS ONE 2011; 6: e28981.

21. Goodpaster BH, Theriault R, Watkins SC, and Kelley DE. Intramuscular lipid content is increased in obesity and decreased by weight loss. Metabolism 2000; 49: 467-472.

22. Krssak M, Falk Petersen K, Dresner A, DiPietro L, Vogel SM, Rothman DL, Roden M, and Shulman GI. Intramyocellular lipid concentrations are correlated with insulin sensitivity in humans: a $1 \mathrm{H} N M R$ spectroscopy study. Diabetologia 1999; 42: 113-6.

23. Pan DA, Lillioja S, Kriketos AD, Milner MR, Baur LA, Bogardus C, Jenkins AB, and Storlien LH. Skeletal muscle triglyceride levels are inversely related to insulin action. Diabetes 1997; 46: 983-8.

24. Perseghin G, Scifo P, De Cobelli F, Pagliato E, Battezzati A, Arcelloni C, Vanzulli A, Testolin G, Pozza G, Del Maschio A, and Luzi L. Intramyocellular triglyceride content is a determinant of in vivo insulin resistance in humans: a $1 \mathrm{H}-13 \mathrm{C}$ nuclear magnetic resonance spectroscopy assessment in offspring of type 2 diabetic parents. Diabetes 1999; 48: 1600-1606.

25. Goodpaster BH, He J, Watkins S, and Kelley DE. Skeletal muscle lipid content and insulin resistance: evidence for a paradox in endurance-trained athletes. J Clin Endocrinol Metab 2001; 86: 5755-5761.

26. Van Loon LC and Goodpaster B. Increased intramuscular lipid storage in the insulin-resistant and endurance-trained state. Pflügers Arch 2006; 451: 606-616.

27. Van Loon LJC, Koopman R, Manders R, van der Weegen W, van Kranenburg GP, and Keizer HA. Intramyocellular lipid content in type 2 diabetes patients compared with overweight sedentary men and highly trained endurance athletes. Am J Physiol Endocrinol Metab 2004; 287: E558-E565.

28. Dubé JJ, Amati F, Stefanovic-Racic M, Toledo FGS, Sauers SE, and Goodpaster BH. Exercise-induced alterations in intramyocellular lipids and insulin resistance: the athlete's paradox revisited. Am J Physiol Endocrinol Metab 2008; 294: E882-888.

29. Amati F, Dube JJ, Alvarez-Carnero E, Edreira MM, Chomentowski P, Coen PM, Switzer GE, Bickel PE, Stefanovic-Racic M, Toledo FGS, and Goodpaster BH. Skeletal muscle triglycerides, diacylglycerols, and ceramides in insulin resistance: another paradox in endurance-trained athletes? Diabetes 2011; 60: 25882597.

30. Bergman BC, Perreault L, Hunerdosse DM, Koehler MC, Samek AM, and Eckel RH. Increased intramuscular lipid synthesis and low saturation relate to insulin sensitivity in endurance-trained athletes. J Appl Physiol 2010; 108: 1134-1141.

31. Bosma M, Kersten S, Hesselink MKC, and Schrauwen P. Re-evaluating lipotoxic triggers in skeletal muscle: Relating intramyocellular lipid metabolism to insulin sensitivity. Prog Lipid Res 2012; 51: 36-49.

32. Moro C, Bajpeyi S, and Smith SR. Determinants of intramyocellular triglyceride turnover: implications for insulin sensitivity. Am J Physiol Endocrinol Metab 2008; 294: E203-13.

33. Muoio DM. Intramuscular triacylglycerol and insulin resistance: guilty as charged or wrongly accused? Biochim Biophys Acta 2009; 1801: 281-288.

34. Samuel VT and Shulman GI. Mechanisms for insulin resistance: common threads and missing links. Cell 2012; 148: 852-871.

35. Summers SA. Ceramides in insulin resistance and lipotoxicity. Prog Lipid Res 2006; 45: 42-72.

36. Hulver MW, Berggren JR, Cortright RN, Dudek RW, Thompson RP, Pories WJ, MacDonald KG, Cline GW, Shulman GI, Dohm GL, and Houmard JA. Skeletal muscle lipid metabolism with obesity. Am J Physiol Endocrinol Metab 2003; 284: E741-E747. 
37. Kelley DE, He J, Menshikova EV, and Ritov VB. Dysfunction of mitochondria in human skeletal muscle in type 2 diabetes. Diabetes 2002; 51: 2944-2950.

38. Patti ME, Butte AJ, Crunkhorn S, Cusi K, Berria R, Kashyap S, Miyazaki Y, Kohane I, Costello M, Saccone R, Landaker EJ, Goldfine AB, Mun E, DeFronzo R, Finlayson J, Kahn CR, and Mandarino LJ. Coordinated reduction of genes of oxidative metabolism in humans with insulin resistance and diabetes: Potential role of PGC1 and NRF1. Proc Natl Acad Sci U S A 2003; 100: 8466-8471.

39. Benton CR, Nickerson JG, Lally J, Han XX, Holloway GP, Glatz JFC, Luiken JJFP, Graham TE, Heikkila JJ, and Bonen A. Modest PGC-1 $\alpha$ overexpression in muscle in vivo is sufficient to increase insulin sensitivity and palmitate oxidation in subsarcolemmal, not intermyofibrillar, mitochondria. J Biol Chem 2008; 283: 42284240 .

40. Timmers S, Konings E, Bilet L, Houtkooper Riekelt $H$, van de Weijer T, Goossens Gijs H, Hoeks J, van der Krieken S, Ryu D, Kersten S, Moonen-Kornips E, Hesselink Matthijs KC, Kunz I, SchrauwenHinderling Vera B, Blaak EE, Auwerx J, and Schrauwen P. Calorie restriction-like effects of 30 days of resveratrol supplementation on energy metabolism and metabolic profile in obese humans. Cell Metab 2011; 14: 612-622.

41. Toledo FGS, Menshikova EV, Ritov VB, Azuma K, Radikova Z, DeLany J, and Kelley DE. Effects of physical activity and weight loss on skeletal muscle mitochondria and relationship with glucose control in type 2 diabetes. Diabetes 2007; 56: 2142-2147.

42. Muoio Deborah $\mathrm{M}$ and Neufer PD. Lipid-induced mitochondrial stress and insulin action in muscle. Cell Metab 2012; 15: 595-605.

43. Espinoza DO, Boros LG, Crunkhorn S, Gami H, and Patti M-E. Dual modulation of both lipid oxidation and synthesis by peroxisome proliferator-activated receptor- $\gamma$ coactivator- $1 \alpha$ and $-1 \beta$ in cultured myotubes. FASEB J 2010; 24: 1003-1014.

44. Mormeneo E, Jimenez-Mallebrera C, Palomer X, De Nigris V, Vázquez-Carrera M, Orozco A, Nascimento A, Colomer J, Lerín C, and Gómez-Foix AM. PGC-1 $\alpha$ induces mitochondrial and myokine transcriptional programs and lipid droplet and glycogen accumulation in cultured human skeletal muscle cells. PLoS ONE 2012; 7: e29985.

45. Summermatter S, Baum O, Santos G, Hoppeler H, and Handschin C. Peroxisome proliferator-activated receptor $y$ coactivator $1 \alpha$ (PGC-1 $\alpha$ ) promotes skeletal muscle lipid refueling in vivo by activating de novo lipogenesis and the pentose phosphate pathway. J Biol Chem 2010; 285: 32793-32800.

46. Beller $M$, Thiel $K$, Thul PJ, and Jäckle H. Lipid droplets: A dynamic organelle moves into focus. FEBS Lett 2010; 584: 2176-82.

47. Walther TC and Farese Jr RV. The life of lipid droplets. Biochim Biophys Acta 2009; 1791: 459-66.

48. Greenberg AS, Egan JJ, Wek SA, Garty NB, Blanchette-Mackie EJ, and Londos C. Perilipin, a major hormonally regulated adipocyte-specific phosphoprotein associated with the periphery of lipid storage droplets. J Biol Chem 1991; 266: 11341-11346.

49. Brasaemle DL, Rubin B, Harten IA, Gruia-Gray J, Kimmel AR, and Londos C. Perilipin A increases triacylglycerol storage by decreasing the rate of triacylglycerol hydrolysis. J Biol Chem 2000; 275: 3848638493.

50. Gandotra S, Lim K, Girousse A, Saudek V, O'Rahilly S, and Savage DB. Human frame shift mutations affecting the carboxyl terminus of perilipin increase lipolysis by failing to sequester the adipose triglyceride lipase (ATGL) coactivator AB-hydrolase-containing 5 (ABHD5). J Biol Chem 2011; 286: 34998-35006.

51. Granneman JG, Moore HPH, Krishnamoorthy R, and Rathod M. Perilipin controls lipolysis by regulating the interactions of AB-hydrolase containing 5 (Abhd5) and adipose triglyceride lipase (Atgl). J Biol Chem 2009; 284: 34538-34544.

52. Miyoshi H, Souza SC, Zhang H-H, Strissel KJ, Christoffolete MA, Kovsan J, Rudich A, Kraemer FB, Bianco AC, Obin MS, and Greenberg AS. Perilipin promotes hormone-sensitive lipase-mediated adipocyte lipolysis via phosphorylation-dependent and -independent mechanisms. J Biol Chem 2006; 281: 15837-15844.

53. Bickel PE, Tansey JT, and Welte MA. PAT proteins, an ancient family of lipid droplet proteins that regulate cellular lipid stores. Biochim Biophys Acta 2009; 1791: 419-440. 


\section{General introduction}

54. Chang BH, Li L, Paul A, Taniguchi S, Nannegari V, Heird WC, and Chan L. Protection against fatty liver but normal adipogenesis in mice lacking adipose differentiation-related protein. Mol Cell Biol 2006; 26: 106376.

55. Imamura M, Inoguchi T, Ikuyama S, Taniguchi S, Kobayashi K, Nakashima N, and Nawata H. ADRP stimulates lipid accumulation and lipid droplet formation in murine fibroblasts. Am J Physiol Endocrinol Metab 2002; 283: E775-783.

56. Listenberger LL, Ostermeyer-Fay AG, Goldberg EB, Brown WJ, and Brown DA. Adipocyte differentiationrelated protein reduces the lipid droplet association of adipose triglyceride lipase and slows triacylglycerol turnover. J Lipid Res 2007; 48: 2751-2761.

57. Robenek H, Hofnagel O, Buers I, Robenek MJ, Troyer D, and Severs NJ. Adipophilin-enriched domains in the ER membrane are sites of lipid droplet biogenesis. J Cell Sci 2006; 119: 4215-4224.

58. Bulankina AV, Deggerich A, Wenzel D, Mutenda K, Wittmann JG, Rudolph MG, Burger KNJ, and Honing S. TIP47 functions in the biogenesis of lipid droplets. J Cell Biol 2009; 185: 641-655.

59. Wolins NE, Skinner JR, Schoenfish MJ, Tzekov A, Bensch KG, and Bickel PE. Adipocyte protein S3-12 coats nascent lipid droplets. J Biol Chem 2003; 278: 37713-21.

60. Dalen KT, Dahl T, Holter E, Arntsen B, Londos C, Sztalryd C, and Nebb HI. LSDP5 is a PAT protein specifically expressed in fatty acid oxidizing tissues. Biochim Biophys Acta 2007; 1771: 210-27.

61. Granneman JG, Moore HPH, Mottillo EP, Zhu Z, and Zhou L. Interactions of perilipin-5 (PLIN5) with adipose trigylceride lipase (ATGL). J Biol Chem 2011; 286: 5126-5135.

62. Granneman JG, Moore HP, Mottillo EP, and Zhu Z. Functional interactions between MLDP (LSDP5) and ABHD5 in the control of intracellular lipid accumulation. J Biol Chem 2009; 284: 3049-57.

63. Wang H, Bell M, Sreenevasan U, Hu H, Liu J, Dalen K, Londos C, Yamaguchi T, Rizzo MA, Coleman R, Gong D, Brasaemle D, and Sztalryd C. Unique regulation of adipose triglyceride lipase (ATGL) by perilipin 5 , a lipid droplet-associated protein. J Biol Chem 2011; 286: 15707-15.

64. Wolins NE, Quaynor BK, Skinner JR, Tzekov A, Croce MA, Gropler MC, Varma V, Yao-Borengasser A, Rasouli $\mathrm{N}$, Kern PA, Finck BN, and Bickel PE. OXPAT/PAT-1 is a PPAR-induced lipid droplet protein that promotes fatty acid utilization. Diabetes 2006; 55: 3418-28.

65. Yamaguchi T, Matsushita S, Motojima K, Hirose F, and Osumi T. MLDP, a novel PAT family protein localized to lipid droplets and enriched in the heart, is regulated by peroxisome proliferator-activated receptor $\alpha$. J Biol Chem 2006; 281: 14232-40.

66. Krahmer N, Guo Y, Farese RV, and Walther TC. SnapShot: Lipid droplets. Cell 2009; 139: 1024-1024.e1.

67. Zhang H, Wang Y, Li J, Yu J, Pu J, Li L, Zhang H, Zhang S, Peng G, Yang F, and Liu P. Proteome of skeletal muscle lipid droplet reveals association with mitochondria and apolipoprotein A-I. J Proteome Res 2011; 10: 4757-4768.

68. Hoppeler $\mathrm{H}$, Luthi $\mathrm{P}$, Claassen $\mathrm{H}$, Weibel ER, and Howald $\mathrm{H}$. The ultrastructure of the normal human skeletal muscle. A morphometric analysis on untrained men, women and well-trained orienteers. Pflugers Arch 1973; 344: 217-32.

69. Tarnopolsky MA, Rennie CD, Robertshaw HA, Fedak-Tarnopolsky SN, Devries MC, and Hamadeh MJ. Influence of endurance exercise training and sex on intramyocellular lipid and mitochondrial ultrastructure, substrate use, and mitochondrial enzyme activity. Am J Physiol Regul Integr Comp Physiol 2007; 292: R1271-1278. 


\section{CHAPTER 2}

Re-evaluating lipotoxic triggers in skeletal muscle: Relating intramyocellular lipid metabolism to insulin sensitivity

Madeleen Bosma, Sander Kersten, Matthijs K.C. Hesselink, Patrick Schrauwen

Progress in Lipid Research 2012; 51: 36-49 


\begin{abstract}
Ectopic fat accumulation has been linked to lipotoxic events, including the development of insulin resistance in skeletal muscle. Indeed, intramyocellular lipid storage is strongly associated with the development of type 2 diabetes. Research during the last two decades has provided evidence for a role of lipid intermediates like diacylglycerol and ceramide in the induction of lipid-induced insulin resistance. However, recently novel data has been gathered that suggest that the relation between lipid intermediates and insulin resistance is less straightforward than has been previously suggested, and that there are several routes towards lipid-induced insulin resistance. For example, research in this field has shifted towards imbalances in lipid metabolism and lipid droplet dynamics. Next to imbalances in key lipogenic and lipolytic proteins, lipid droplet coat proteins appear to be essential for proper intramyocellular lipid storage, turnover and protection against lipidinduced insulin resistance.

Here, we discuss the current knowledge on lipid-induced insulin resistance in skeletal muscle with a focus on the evidence from human studies. Furthermore, we discuss the available data that provides supporting mechanistic information.
\end{abstract}




\section{INTRODUCTION}

Obesity is a growing public health problem, with a prevalence of at least 500 million people worldwide [1]. Although obesity will not always result in metabolic abnormalities, most severely obese persons suffer from metabolic comorbidities. Likewise, obesity is the number one risk factor for the development of insulin resistance, which may eventually result in type 2 diabetes. The etiology of type 2 diabetes is complex, with a broad range of organs involved. Several hypotheses have been put forward trying to explain the relationship between obesity and diabetes, including lipid, endocrine and inflammatory hypotheses [2]. In this review we will focus on the lipid overflow hypothesis, which considers type 2 diabetes to result from a general state of increased lipid levels. Lipids will overflow into the circulation as a result of impaired storage capacity in adipose tissue and as a consequence lipids may accumulate ectopically in tissues like skeletal muscle, liver and heart. The link between ectopic lipid accumulation in obesity and the development of insulin resistance was first demonstrated in the early nineties [3] and had a great impact on our understanding of the etiology of type 2 diabetes (T2D). Since then, numerous animal and cellular experiments have provided evidence for the link between lipid intermediates and insulin resistance. On the other hand, data from human studies are less straightforward and have pointed towards multiple factors that may be involved in lipidinduced insulin resistance, including lipid intermediates, lipid metabolism and lipid droplet dynamics. Here we will review these data with a focus on human studies.

\section{Intramyocellular lipids and insulin sensitivity}

Obesity is associated with increased lipid supply to skeletal muscle. Intramyocellular lipid (IMCL) accumulation correlates with BMI, waist-to-hip ratio, central adiposity, and percentage body fat [4-8]. Skeletal muscle is quantitatively the major contributor to whole body insulin-mediated glucose disposal. Fat accumulation in muscle negatively impacts insulin mediated glucose uptake. In insulin resistant subjects, the negative correlation between IMCL accumulation and insulin sensitivity has been firmly established in multiple studies [9-11]. Furthermore, diet-induced weight loss results in decreased IMCL storage in parallel with improvements in insulin sensitivity [12-16]. Also, lipid infusion impairs insulin sensitivity concurrent with increased IMCL levels [17]. However, despite the strong correlation of IMCL levels with insulin resistance, the exact mechanistic link between IMCL accumulation and impairment of insulin sensitivity is unclear. Furthermore, IMCL levels are similar in obese normoglycemic and obese type 2 diabetic subjects [18, 19], indicating that total IMCL levels per se do not induce diabetes.

An important finding that has shed some light into the role of IMCL in insulin resistance comes from exercise studies. Exercise training has been shown to increase IMCL levels, and endurance-trained athletes, who are highly insulin-sensitive, have increased $\mathrm{IMCL}$ compared with lean sedentary controls, with levels even exceeding those of diabetics $[18,20]$. In addition, 12-16 weeks of exercise training in obese subjects improved insulin sensitivity in conjunction with increased IMCL levels $[21,22]$. This so-called 
athlete's paradox gave new insight in the role of IMCL in insulin resistance and indicated that IMCL accumulation per se does not lead to insulin resistance. The athlete's paradox has been explained by differential effects of training and diabetes on lipid subspecies, oxidative capacity and IMCL turnover. Proper balancing between lipid influx and fat oxidative capacity as well as an efficient rate of lipid turnover (i.e. lipid depletion and efficient resynthesis) have been suggested to be beneficial for insulin sensitivity $[18,20]$. It is still unclear, however, how IMCL can become harmful. In this review, we will discuss the current knowledge on lipid-induced insulin resistance in skeletal muscle with a focus on the evidence from human studies, combined with supporting information of the mechanisms involved from animal and cell studies.

\section{LIPID INTERMEDIATES}

It was demonstrated in multiple studies that intramyocellular lipid levels are increased in obese type 2 diabetics versus lean controls [9-11]. The observation that IMCL storage is increased in athletes and mainly consists of intramyocellular triacylglycerol (TAG) [23] strongly indicated that neutral lipid storage in the form of TAG per se does not impair insulin sensitivity. However, increased intramyocellular TAG might be paralleled with increased levels of lipid intermediates with lipotoxic potential. Lipotoxicity is defined as the accumulation of excess lipids in non-adipose tissues leading to cell dysfunction or cell death [24]. Enhancing the partitioning of fatty acids (FAs) entering the muscle towards TAG synthesis prevents lipotoxicity $[25,26]$. Under conditions of increased lipid influx, lack of TAG storage capacity, or uncontrolled lipolysis, FAs might be converted to lipid metabolites other than TAG.

The array of lipid intermediates with insulin desensitizing properties includes diacylglycerols (DAGs), long chain fatty acyl-CoAs (LCFA-CoAs), acylcarnitines, and ceramides (Fig. 1) all differing in chain length, level of saturation and/ or stereo specificity. At this moment there is a lack of consensus on the primary lipotoxic intermediate. These intermediates all have the potential to reduce insulin-mediated glucose disposal in in vitro and animals studies, partly via selective interference with insulin signaling. However, most if not all available data from in vitro and animal studies are merely correlative, as it is impossible to alter intracellular levels of one single lipotoxic intermediate. Therefore, interpretation of causality is difficult, especially with regard to their implication in obesityassociated insulin resistance in humans. Most attention has been given to DAG and ceramide. Table 1 gives an overview of the human studies in which DAG and/or ceramides were measured in skeletal muscle biopsies of obese, type 2 diabetic and/or lean controls.

\section{Diacylglycerol}

DAG is an intermediate in TAG synthesis and breakdown. In addition, DAG and its metabolite phosphatidic acid (PA) are important intracellular second messengers involved in metabolic and mitogenic responses and are important metabolites in de novo synthesis 
of phospholipids [27, 28]. Hence, fluctuations in DAG levels can lead to impaired intracellular signaling. Animal and cell studies have sought to unravel the mechanisms involved in DAG-induced insulin resistance [29, 30]. In muscle, elevated DAG levels are associated with increased activities of PKCO and PKCE [31, 32]. DAG-activated PKCs inactivate insulin receptor substrate 1 (IRS-1) by phosphorylation of one or more of its inhibitory serine residues and by direct association of PKC $\varepsilon$ with IRS-1, thereby reducing its kinase activity. Through this mechanism, DAG reduces insulin-induced tyrosine phosphorylation of IRS-1 and suppressing the activity of its downstream targets PI3-kinase and PKB/Akt, leading to impaired insulin-induced GLUT4-translocation and glucose uptake [33]. Several DAG-subspecies exist that differ in FA composition and the position of the FA on the glycerol backbone (1,3-DAG, 2,3-DAG, and 1,2-DAG). Only 1,2-DAG accumulates in membranes and is capable of activating PKCs [34-36], 2,3-DAG and 1,3-DAG can arise from TAG hydrolysis at the lipid droplet.

Intramuscular DAG levels are increased in several animal models of obesity $[37,38]$. However, evidence is lacking on the importance of intramyocellular DAG levels in the development of obesity-associated insulin resistance in humans. Although lipid infusion in humans induces insulin resistance in parallel with increased intramyocellular DAG levels [39], the support for a role of skeletal muscle DAG accumulation in the development of type 2 diabetes is inconsistent (Table 1). Two studies identified the DAG level as an important predictor for insulin resistance using multivariate regression analyses $[40,41]$. However, the remainder of the studies did not find differences in total skeletal muscle DAG levels between obese and lean subjects $[42,43]$ and between obese normal glucose tolerant (NGT) and obese insulin resistant subjects [44-46]. Perreault et al. showed intergender differences in intramuscular DAG accumulation, with prediabetic women having higher DAG levels, while being more insulin sensitive compared with prediabetic men [47]. Strategies that resulted in improved insulin sensitivity did not consistently reduce DAG levels, which indicates that the role of DAG in insulin resistance in humans is not yet clear. DAG levels decreased with weight loss and exercise in several studies [21, 48, 49] (Table 2), while pioglitazone treatment [50] and $10 \%$ diet-induced weight loss [51] did not show a decrease in DAG levels. Moreover, while Dubé et al. showed that total intramyocellular DAG decreased with weight loss and exercise, there was no correlation between changes in DAG and improvements in insulin sensitivity suggesting that DAG is not the sole mediator of insulin action [49]. 
Table 1. Lipid intermediates in lean, obese and T2D subjects.

\begin{tabular}{|c|c|c|c|c|}
\hline $\begin{array}{l}\text { Author and } \\
\text { reference }\end{array}$ & Population & $\begin{array}{l}\text { Association } \\
\text { DAG } \\
\text { with IS }\end{array}$ & $\begin{array}{l}\text { Association } \\
\text { ceramides } \\
\text { with IS }\end{array}$ & Outcomes \\
\hline $\begin{array}{l}\text { Van Hees et al. } \\
2011[52]\end{array}$ & $\begin{array}{l}30 \text { male subjects with the } \\
\text { metabolic syndrome, } 15 \text { insulin } \\
\text { resistant subjects and } 15 \text { controls }\end{array}$ & - & n.i. & $\begin{array}{l}\text { Increased saturation of DAG } \\
\text { is associated with insulin } \\
\text { resistance }\end{array}$ \\
\hline $\begin{array}{l}\text { Perreault et al. } \\
2010 \text { [47] }\end{array}$ & $\begin{array}{l}\text { Obese NGT ( } n=7 \text { men and } n=12 \\
\text { women) and prediabetics ( } n=13 \\
\text { men and } n=7 \text { women) }\end{array}$ & - & n.i. & $\begin{array}{l}\text { Turnover of DAG is more } \\
\text { important than the DAG } \\
\text { level, DAG level the same in } \\
\text { NGT and prediabetics }\end{array}$ \\
\hline $\begin{array}{l}\text { Jocken et al. } \\
2010[42]\end{array}$ & $\begin{array}{l}\text { Lean }(n=13) \text { and obese }(n=10) \\
\text { men (study } 1) \text { and nonobese T2D } \\
(n=11) \text {, obese } \\
\text { T2D (n=11), and lean male } \\
\text { controls }(n=11) \text { (study } 2)\end{array}$ & - & n.i. & $\begin{array}{l}\text { Lower DAG in obese men } \\
\text { versus lean controls }\end{array}$ \\
\hline $\begin{array}{l}\text { Coen et al. } \\
2009[45]\end{array}$ & $\begin{array}{l}\text { Insulin sensitive } \quad(n=10) \text { and } \\
\text { insulin resistant }(n=12) \text { obese } \\
\text { women }\end{array}$ & - & + & $\begin{array}{l}\text { No difference in DAG, } \\
\text { increased ceramides in } \\
\text { insulin resistance }\end{array}$ \\
\hline $\begin{array}{l}\text { Bergman et al. } \\
2010[23]\end{array}$ & $\begin{array}{l}\text { Endurance-trained male athletes } \\
(n=11) \text { and sedentary male } \\
\text { controls }(n=11)\end{array}$ & + & n.i. & $\begin{array}{l}\text { Saturation of DAG is of } \\
\text { importance, no differences } \\
\text { in total DAG }\end{array}$ \\
\hline $\begin{array}{l}\text { Thrush et al. } \\
2009[43]\end{array}$ & $\begin{array}{l}\text { Lean }(n=8) \text { and obese }(n=15) \\
\text { women }\end{array}$ & - & + & $\begin{array}{l}\text { No role for DAG, ceramides } \\
\text { increased in obese }\end{array}$ \\
\hline $\begin{array}{l}\text { Moro et al. } \\
2009 \text { [7] }\end{array}$ & $\begin{array}{l}48 \text { subjects with a wide range of } \\
\text { BMI (m/f: } 24 / 24)\end{array}$ & + & + & $\begin{array}{l}\text { Increased DAG and } \\
\text { ceramides in obese and } \\
\text { type } 2 \text { diabetic subjects. } \\
\text { DAG is the main predictor } \\
\text { for insulin resis-tance, } \\
\text { lipolytic enzymes determine } \\
\text { DAG levels }\end{array}$ \\
\hline $\begin{array}{l}\text { Anastasiou et } \\
\text { al. } 2009 \text { [44] }\end{array}$ & $\begin{array}{l}\text { Nondiabetic obese }(n=19 \text {, } \\
\text { male/female: } 9 / 10) \text { and diabetic } \\
\text { obese }(n=11, m / f: 2 / 9)\end{array}$ & - & n.i. & No role for DAG \\
\hline $\begin{array}{l}\text { Skovbro et al. } \\
2008 \text { [67] }\end{array}$ & $\begin{array}{l}\text { Type } 2 \text { diabetics }(n=8) \text {, IGT }(n=9) \text {, } \\
\text { healthy controls } \quad(n=8) \text {, } \\
\text { endurance-trained athletes }(n=8) \\
\text { (all male subjects) }\end{array}$ & n.i. & - & No role for ceramides \\
\hline $\begin{array}{l}\text { Serlie et al. } \\
2007 \text { [66] }\end{array}$ & $\begin{array}{l}\text { Lean }(n=8, m / f: 7 / 1) \text { and obese } \\
(n=6, m / f: 4 / 2) \text { subjects }\end{array}$ & n.i. & - & No difference in ceramides \\
\hline $\begin{array}{l}\text { Straczkowski et } \\
\text { al. } 2007 \text { [41] }\end{array}$ & $\begin{array}{l}\text { Male lean, obese, type } 2 \\
\text { diabetics and offspring of type } 2 \\
\text { diabetics ( } n=12 \text { per group) }\end{array}$ & + & + & $\begin{array}{l}\text { DAG and ceramides inde- } \\
\text { pendently determine insulin } \\
\text { resistance }\end{array}$ \\
\hline $\begin{array}{l}\text { Adams et al. } \\
2004 \text { [65] }\end{array}$ & $\begin{array}{l}\text { Obese insulin resistant }(n=10 \text {, } \\
m / f: 5 / 5) \text { and lean controls } \\
(n=10, m / f: 6 / 4)\end{array}$ & n.i. & + & $\begin{array}{l}\text { Increased ceramides in } \\
\text { obese insulin resistant } \\
\text { subjects }\end{array}$ \\
\hline
\end{tabular}

IS: insulin sensitivity, $\mathrm{m} / \mathrm{f}$ : male/female ratio, n.i. = not investigated. 
Based on the data summarized above, it can be concluded that total DAG levels do not necessarily mirror insulin resistance. Recent evidence suggests that it is not total DAG per se but rather specific DAG-subspecies that may be important. In the study of Dubé et al. [49], it was shown that exercise caused greater reductions in specific FAs in the DAG fraction compared to diet-induced weight loss [49]. Exercise lowered the content of all DAG species examined to a greater degree than diet-induced weight loss, which only reduced the content of all DAG C14:0 species, and of DAG C16:0/18:0, C16:0/18:1, C16:1/18:1, di-C16:0 and di-C18:1 [49]. Moreover, it was demonstrated that athletes have a lower saturation of the DAG-fraction compared to sedentary controls or an increased proportion of C18:1 and C18:2 in the DAG fraction [23]. Recently, Van Hees et al. investigated the FA composition of intramyocellular DAG and TAG in men with the metabolic syndrome, either with or without insulin resistance. While total DAG and TAG levels were similar in both groups, insulin resistant men had a higher degree of saturation of skeletal muscle DAG compared to controls [52], consistent with the study of Bergman et al [23]. This higher degree of saturation was largely explained by a higher percentage of palmitic acid and a lower percentage of oleic acid [52].

Next to differences in FA-composition, DAG-subspecies can differ in the position of the FA-binding to the glycerol backbone (1,3-DAG, 2,3-DAG, and 1,2-DAG). 1,2-DAG accumulates in membranes and only this isoform is capable of activating PKCs [36]. No human study performed to date has examined specifically the accumulation of 1,3-, 2,3and 1,2-DAG in insulin resistant and insulin sensitive subjects. Moreover, the fact that DAG can be present at different subcellular locations, including cell membranes, ER and lipid droplets (LDs) [53], may complicate the relationship between DAG levels and insulin resistance. The DAG membrane-to-cytosol ratio has been used as a measure for DAGinduced PKC activation [54-56], but data from human studies is lacking.

In summary, total DAG levels are not consistently associated with insulin resistance in humans. While it is apparent that increased DAG levels per se do not promote insulin resistance, lipid-induced insulin resistance may be dependent on the accumulation of bioactive DAG species at specific intracellular sites, including the plasma membrane for PKC-mediated interferences with insulin signaling. However, few data are available in humans and further research is needed to investigate the relationship between various DAG species and their intracellular localization, and insulin resistance in skeletal muscle.

\section{Sphingolipids}

Another group of lipid intermediates that has received a lot of attention are the ceramides, which belong to the sphingolipids. Ceramides are structural components of biological membranes and can be deacetylated, phosphorylated and glycosylated [57]. Ceramides are important membrane building blocks and intracellular messengers that are believed to interfere with insulin signaling. Sphingolipid production mainly depends on de novo biosynthesis. In as much as long chain saturated FAs like palmitate are precursors for ceramide synthesis, rates of ceramide synthesis depend on the availability of those FAs. Consistent with this notion, incubation of muscle cells with palmitate promotes ceramide 
accumulation [29] and diets high in saturated fats induce intramyocellular ceramide accumulation [58]. In addition to FAs serving as precursors for ceramide synthesis, FAs, inflammatory agonists and glucocorticoids have been shown to increase ceramide biosynthesis via upregulation of serine palmitoyltransferase, the limiting enzyme for ceramide synthesis [57, 59-61]. Evidence abounds that accumulation of ceramides can impair insulin signaling (reviewed in [57]). Indeed, ceramide was identified as an essential intermediate linking saturated FAs to insulin resistance [62]. According to some reports, ceramides inactivate IRS-1, leading to blockage of PI3-kinase. However, the majority of studies suggest that ceramide inhibits phosphorylation and activation of Akt/PKB via protein phosphatase 2A (PP2A) and PKCZ, independent of potential effects on IRS-1 [57]. Additionally, glycosylceramides have been shown to interact with the insulin receptor, thereby displacing it from the caveola thus preventing downstream signaling [63]. Interestingly, Novgorodov et al. recently showed that next to ER-derived ceramide, ceramides are also produced in mitochondria by the coupled activities of mitochondrial thioesterase, which hydrolyses palmitoyl-CoA to CoA and palmitate, and neutral ceramidase (NCDase), which utilizes sphingosine and released palmitate in a reverse reaction to produce ceramide [64]. Thus, increased FA-CoA levels in or near the mitochondria might result in increased ceramide production thus impairing mitochondrial function and eventually inducing apoptosis [64].

Inhibition of ceramide synthesis was shown to improve insulin sensitivity in rodents [59]. Consistent with a role for ceramide in insulin resistance in humans, the majority of human studies found increased ceramide levels in skeletal muscle of type 2 diabetic subjects (Table 1). Most [7, 41, 43,65], but not all [66, 67] studies observed increased accumulation of ceramides in skeletal muscle of obese subjects compared to lean controls. Furthermore, ceramides were shown to be higher in insulin resistant obese subjects compared to insulin sensitive obese subjects $[41,45]$, indicating a potential role of ceramides in insulin resistance. Two reports did not show increased ceramides in obese IGT [66] and obese diabetics versus lean controls [67]. Moro et al. found increased ceramides in T2D, but identified DAG as the key mediator of lipid-induced insulin resistance based on multivariate stepwise regression analyses [7]. Interestingly, acute and chronic exercise interventions have been shown to decrease ceramide levels $[48,68]$ (Table 2). As the sphingolipid family consists of a range of different subspecies (different ceramides and non-ceramide sphingolipids), (total) ceramide levels might not reflect levels of bioactive sphingolipid subspecies appropriately. Likewise, saturated ceramides were shown to be increased in obese compared to lean subjects [7, 43, 65] and type 2 diabetes patients versus NGT BMI-matched controls [45]. Furthermore, Dubé et al. showed that dihydroceramides increased with both diet-induced weight loss and exercise training, whereas sphingosines and total ceramide species were decreased with exercise, while only C14:0, C20:0 and C24:0 ceramides were decreased with diet-induced weight loss [49], indicating that certain bioactive ceramide subspecies, rather than total ceramide levels, may be causative in obesity-associated insulin resistance. 


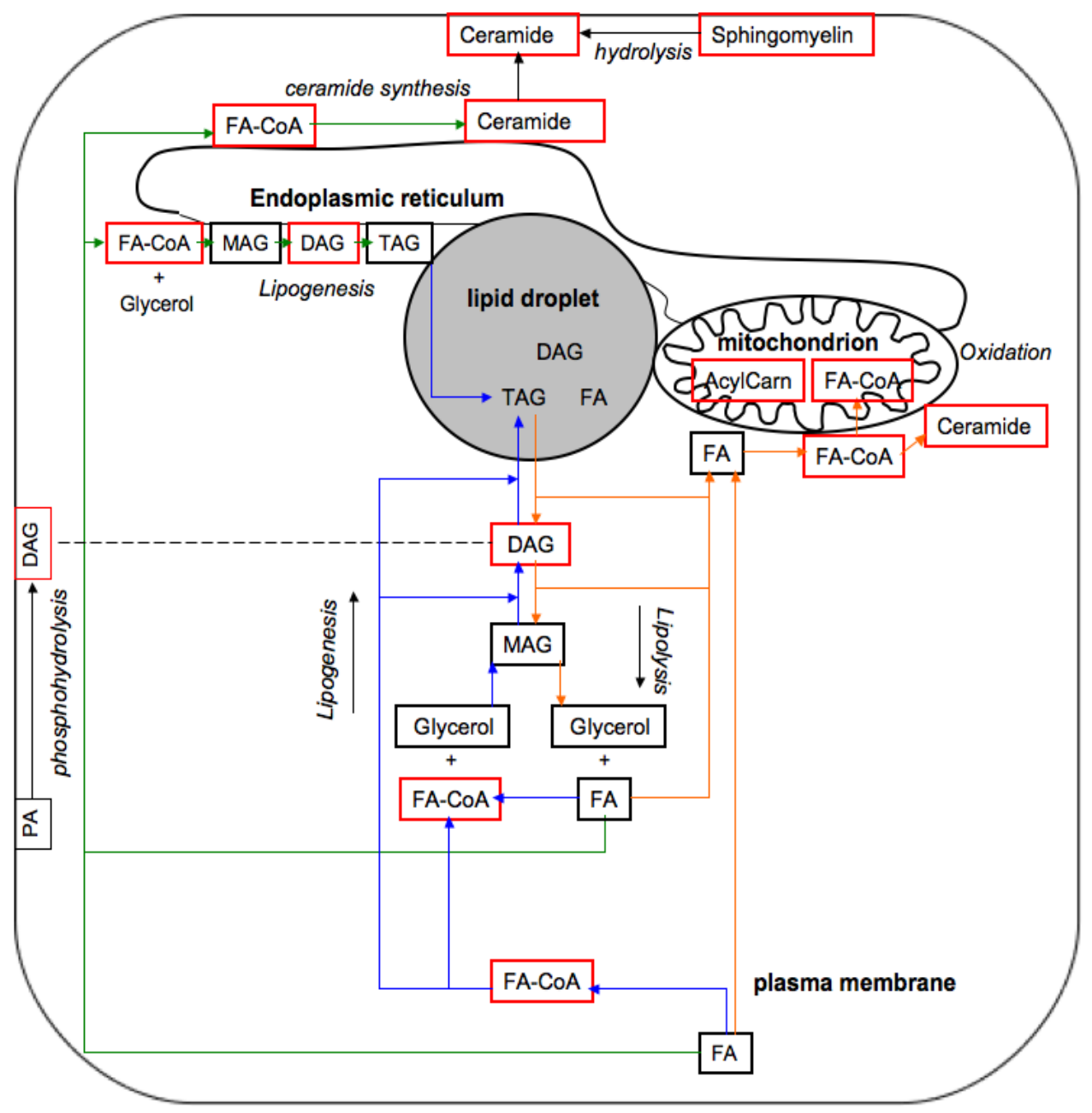

Figure 1. Lipid intermediate metabolism and subcellular localization. Potential lipotoxic intermediates are indicated with a red box. Blue arrows: routes towards storage in the lipid droplet; green: routes towards lipid synthesis on the ER, orange: routes related to lipolysis and $\beta$-oxidation in the mitochondria, black: membrane-related processes.

AcylCarn: acylcarnitines, DAG: diacylglycerol, FA: fatty acid, FA-CoA: fatty acyl-CoA, MAG: monoacylglycerol, PA: phosphatidic acid, TAG: triacylglycerol. 
Table 2. Interventions.

\begin{tabular}{llll}
\hline $\begin{array}{l}\text { Author and } \\
\text { reference }\end{array}$ & Population and intervention & Association & Association Outcomes \\
& DAG & ceramides \\
& with IS & with IS
\end{tabular}

Dubé et al. Male $(n=7)$ and female $(n=9)$ 2011 [49] overweight (IGT and NGT) subjects, 16 week diet or exercise intervention ( $n=8$ per group)

Hoeg et al. Young healthy men $(n=8)$ and 2011 [69] women ( $n=8)$, lipid infusioninduced insulin resistance

Anastasiou et A weight loss program in obese al. 2010 [51] women $(n=5)$

Bajaj et al. Pioglitazone treatment in 2010 [50] diabetics ( $n=24$; both male and female)

Dubé et al. Exercise program in obese men $2008[21] \quad(n=9)$ and women $(n=16)$

Vistisen et al. Obese women and men ( $n=8$ per 2008 [71] group), lipid infusion-induced insulin resistance

Schenk et al. Acute exercise in non-obese 2007 [72] women ( $n=8)$, followed by an overnight lipid infusion-induced insulin resistance

Serlie et al. Lean ( $n=8$, both sexes) and obese 2007 [66] ( $n=6)$ subjects, lipid infusion and Acipimox treatment (6h)

Bruce et al. Exercise intervention with obese 2006 [48] subjects ( $n=9$; both sexes)

Straczkowski Healthy male subjects $(n=10)$, et al. 2004 lipid infusion-induced insulin [70] resistance

Itani et al. Healthy male subjects $(n=12)$, 2002 [39] lipid infusion-induced insulin resistance
No correlation of changes in DAG

and ceramides and

improvements in insulin sensitivity. Differences in DAG and ceramide subspecies. Ceramides decreased only with the exercise training.

- $\quad$ Intralipid infusion did not lead to accumulation of DAG or ceramides, while inducing insulin resistance.

n.i. TAG was depleted upon weight loss, DAG was unchanged

n.i. FA-CoA was decreased and associated with improvements in insulin sensitivity, no differences in DAG

Decreased DAG and ceramides after the exercise intervention period

- The lipid-induced inhibition of glucose disposal is similar in obese females and males. DAG and ceramides were similar between sexes.

1 exercise session completely reversed FA-induced insulin resistance, decreased DAG and ceramides

n.i. $\quad$ - No differences in ceramides at baseline and no differences after 6h lipid infusion or Acipimox treatment

$+\quad$ Exercise decreases ceramides and DAG, in parallel with improved IS

n.i. $\quad+\quad$ A 4 h intralipid infusion increased ceramide levels concurrent with the induction of insulin resistance.

Increased DAG levels with lipidinduced insulin resistance, no changes in ceramides

IS: insulin sensitivity, n.i. = not investigated. 
Several studies investigated the effects of lipid infusion-induced insulin resistance on the accumulation of ceramides in skeletal muscle [39, 66, 69-71]. A 4-6h lipid infusion (intralipid) in four out of five studies did not result in increased levels of ceramides, despite inducing insulin resistance $[39,66,69,71]$. Only Straczkowski et al. did observe increased ceramide levels [70]. However, as intralipid mainly consists of unsaturated fats (20\% triglyceride emulsion, generally safflower- and soy-oil), ceramides might not play a main role in acute lipid-infusion mediated insulin resistance. Holland et al. tested this hypothesis of different fatty acids inducing insulin resistance in muscle via distinct mechanisms by infusing either a lard-oil based solution (mainly saturated fats) versus a soy-based cocktail (mainly unsaturated fats) into rats [59]. Indeed, while both lipid infusions resulted in insulin resistance, only the lard-oil infusion induced ceramide accumulation. Thus, ceramide accumulation may be involved in saturated fat-induced but not intralipid-induced insulin resistance in human skeletal muscle. Further investigation into sphingolipid subspecies and their intracellular localization could provide more information on the mechanisms involved.

\section{Fatty acyl-CoA}

Lipid intermediates that have received less attention so far are fatty acyl-CoAs and acylcarnitines. Upon entry into muscle cell either by diffusion or FA-transporters, fatty acids are trapped within the cell after a CoA group is bound by acyl-CoA synthetase. If fatty acid uptake exceeds the capacity for fatty acid channeling towards lipid synthesis or $\beta$-oxidation, FA-CoA will accumulate in the cell, either in the cytosol or in mitochondria. Indeed, rats fed a high fat diet showed an increased accumulation of long chain FA-CoAs (LC-CoAs) in skeletal muscle [72]. Currently, the importance of FA-CoA in insulin resistance remains unclear. In a number of human studies, LC-CoA levels, like other lipid intermediates, were observed to be elevated in insulin resistant muscle. LC-CoA levels were increased in skeletal muscle biopsies from obese subjects [73] and correlated negatively with whole body insulin action (i.e. glucose infusion rates during a hyperinsulinemic euglycemic clamp) [72]. Furthermore, LC-CoA levels were increased upon short-term (4-6h) lipid infusion in parallel with PKC-mediated inhibition of insulin signaling [74, 75] and insulin-sensitizing strategies were described to lower intramuscular LC-CoA levels $[50,76,77]$. In contrast, in the study of Bruce et al., both basal and insulinstimulated skeletal muscle LC-CoA content were similar between young trained, young sedentary subjects, type 2 diabetics and obese controls [78].

It is unclear whether FA-CoAs as such are interfering with the insulin signaling cascade. There are indications for PKC activation by FA-CoA, but it is unclear whether this is a direct or an indirect effect (via DAG) [79]. Next to being substrates for TAG synthesis and energy production, FA-CoAs are used as substrates for protein acylation reactions. Interestingly, Jenkins et al. recently showed that LC-COA is capable of inhibiting phosphofructokinase-1 (PFK1) activity by reversible acylation, resulting in a lowered glycolytic flux under high intracellular ATP conditions [80]. Intracellular accumulation of LC-CoA may thus inhibit glycolysis downstream of insulin signaling, without affecting non- 
oxidative glucose disposal [80]. LC-CoAs are also substrates for synthesis of phospholipids, TAG, DAG and ceramides. Hence, accumulation of LC-CoAs can lead to increased formation of lipid intermediates with the potential to impair insulin signaling. Additionally, intramitochondrial accumulation of acyl-CoAs, as a result of a disbalance in mitochondrial FA transport and downstream oxidative metabolism, and their metabolites ceramides [64] and acylcarnitines [81] might contribute to mitochondrial failure. Based on available evidence, it is too early to draw conclusions about the importance of FA-CoA in the etiology of insulin resistance in skeletal muscle. Information on intracellular localization and verification of its inhibitory effects on glucose metabolism is warranted.

\section{Acylcarnitines}

Upon entrance into the mitochondria, FA-CoAs are degraded during $\beta$-oxidation, which yields one acetyl-CoA molecule in each successive cycle. When $\beta$-oxidation rates outpace the capacity of the TCA cycle, CRAT lowers short-chain acetyl-CoA levels by coupling of a carnitine moiety thus producing acylcarnitines. CPT2, present in the inner-mitochondrial membrane, is best known for its capacity to convert acylcarnitines to carnitine plus FACoA. However, CPT2 has a dual role; the enzyme can operate in the reverse direction generating medium and long-chain acylcarnitines produced from intramitochondrial acylCoAs and transporting those to the cytoplasm [82]. A sustained mitochondrial FA oversupply and incomplete fatty acid oxidation therefore results in mitochondrial accumulation of FA-CoAs and acylcarnitines. In contrast to FA-CoAs, acylcarnitines can cross membranes and end up in the cytoplasm or in the blood.

Incomplete FA oxidation resulting in intramyocellular accumulation of (C6 to C22)acylcarnitines and other intermediates has been demonstrated to be increased in obesity [83-86]. Furthermore, blood plasma acylcarnitine levels were increased in obese subjects compared to lean controls $[87,88]$ and in type 2 diabetes patients compared to BMImatched controls $[89,90]$. Additionally, exercise training improved rates of complete $\beta$ oxidation in parallel with improved insulin sensitivity in mice [91] and in obese humans subjected to caloric restriction [92]. It was therefore suggested that mitochondria are very vulnerable to substrate overloads and therefore might serve as the principal lipid sensor in skeletal muscle [81]. In contrast, Boyle et al. observed lower levels of short and medium chain acylcarnitines in obese compared to lean subjects, long chain acylcarnitines were similar [84]. Interestingly though, following a 5 day high fat diet the obese subjects showed increased short and medium chain acylcarnitines compared to the lean controls [84].

The association of acylcarnitine levels with insulin resistance is based on observational studies and might be a reflection of lipid overload rather than that acylcarnitines are causative in lipid-induced impairments in insulin signaling. Further research is warranted to identify the importance of mitochondrial acylcarnitine species in insulin resistance. 


\section{Lipid intermediates and insulin resistance; concluding remarks}

Taken together, human studies are far from consistent with regard to lipid intermediate accumulation in skeletal muscle of type 2 diabetes patients. The inconsistencies in the study outcomes could be explained by differences in analytical tools, differences in the timing of the biopsies, age of the subjects, inter-gender variation [47, 69], and interindividual (genetic) variation. Ceramides, acyl-CoAs and DAG have the potential to interfere with insulin signaling. The prevailing importance of one over the other may well be related to specific (experimental) circumstances. For example, lipid infusion-induced insulin resistance seems to be predominantly associated with increased DAG levels, whereas ceramides are mainly associated with saturated fat intake. It deserves mention though, that although lipid infusion is often used to mimic lipid-induced insulin resistance, it is questionable whether the effects of the supraphysiological plasma FFA levels due to a short-term infusion of a lipid mixture reflect the mechanisms involved in obesity-induced insulin resistance.

Exercise interventions generally decrease both intramyocellular DAG and ceramide levels. Acylcarnitine levels seem to be important indicators of substrate overload, but evidence for a role in lipid-induced insulin resistance is limited. Support for a role of FACoA on insulin signaling is most limited, but is also the least examined option. Nevertheless, FA-CoA accumulation may well be involved in blunting oxidative glucose disposal by inhibiting glycolysis without an effect on non-oxidative glucose disposal. However, in general total skeletal muscle DAG, ceramide or FA-CoA levels are not consistently elevated in insulin resistant subjects. It is therefore questionable whether one of these lipid intermediates has a causal role in obesity-associated insulin resistance. However, given the lipotoxic potential of these lipid intermediates, it is likely that there are several routes towards lipid-induced insulin resistance. Further specification of the lipotoxic intermediates by (de)saturation [7, 23, 48, 93], chain length [45, 49], stereo specific isomers, and intracellular localization could give further insight into the lipotoxic mechanisms involved in the development of type 2 diabetes in obese subjects.

\section{INTRAMYOCELLULAR LIPID DYNAMICS}

Although research in the last decades has focused primarily on levels of lipid intermediates to explain muscular insulin resistance, more recent data also suggest that intramyocellular lipid dynamics may play an important role in regulating insulin sensitivity. Next to alterations in myocellular lipid influx, an altered rate of lipid turnover, either a decreased triglyceride synthesis, or increased lipolysis (not matched by increased fatty acid oxidation), and reductions in oxidative capacity have been suggested to be the underlying causes for lipid-induced insulin resistance. 


\section{TAG synthesis}

Upon entrance of fatty acids into the muscle cell, fatty acids can be incorporated into IMCL for storage and/or can be directed to mitochondria for oxidation. One hypothesis explaining the athlete's paradox says that as long as fatty acids are efficiently directed towards storage as TAG, there is no interference with insulin signaling. Based on this notion it could be argued that the expression of enzymes involved in lipid synthesis may be an important determinant of obesity-induced insulin resistance.

Initiation of lipid synthesis requires coupling of fatty acids to a glycerol backbone. Glycerol 3-phosphate acyltransferase (GPAT) and diacylglycerol acyltransferase (DGAT) are important rate limiting enzymes in this process. Multiple acyltransferase isoforms exist, including GPATs 1-4 and DGAT1 and DGAT2. GPATs 1 and 2 are present in the outer mitochondrial membrane, GPATs 3 and 4 localize to the ER [94]. At least $90 \%$ of the GPAT activity in skeletal muscle is contributed by GPAT1 [95]. DGAT1 resides in the ER [96], whereas DGAT2 localizes to ER, mitochondria and lipid droplets [53, 97, 98]. Both DGAT1 and DGAT2 are present in skeletal muscle $[99,100]$, but DGAT1 is the predominant skeletal muscle DGAT isoform [99]. Little is known about the expression of glyceride synthesis enzymes in human skeletal muscle of healthy, obese and diabetic subjects. Two reports on lipogenic enzyme expression in skeletal muscle of obese subjects failed to find differences in skeletal muscle GPAT and DGAT1 protein expression between lean and obese subjects $[43,101]$. On the other hand, acute exercise increased GPAT and DGAT1 protein expression while preventing lipid-induced insulin resistance [102]. GPAT and DGAT1 protein expression levels are dynamic, albeit only in the short-term. Eight [103] or sixteen weeks [49] of aerobic exercise or diet-induced weight loss [49], conditions associated with an increase and a decrease in intramyocellular TAG levels respectively, did not alter DGAT1 expression in obese subjects, indicating that at least DGAT1 mRNA and protein expression levels are not major determinants of IMCL levels in human skeletal muscle. Moreover, DGAT1 mRNA expression is similar in endurance-trained athletes and sedentary controls [104] and a lipid infusion following one exercise session increased GPAT activity without affecting DGAT activity [105]. In contrast to the limited evidence from human studies, animal studies showed beneficial effects of DGAT1 overexpression on insulin sensitivity $[25,26,106]$. We showed that a short-term (1 week) overexpression of DGAT1 in the tibialis anterior muscle of rats increased both TAG and DAG levels indicating that increasing lipid turnover by means of DGAT1 overexpression protects against insulin resistance [26].

Another enzyme that has received interest in the synthesis of TAG in muscle is SCD1. SCD1 is a member of the family of stearoyl-CoA desaturases (SCDs). Four isoforms exist in mice (SCD1-4) and two isoforms in humans (SCD1 and SCD5) [107]. Both SCD1 and SCD5 localize to the ER [108]. SCD1 and SCD5 desaturate fatty acids at the delta 9 position [108]. Little is known about the function of SCD5. SCD1 is predominantly expressed in liver, adipose tissue and skeletal muscle [107] and functions as a rate-limiting enzyme in the biosynthesis of monounsaturated fatty acids; it desaturates stearate and palmitate to 
generate the less toxic monounsaturated FAs oleate and palmitoleate. Unsaturated FAs are the preferred substrates for TAG synthesis. SCD1 is upregulated with exercise training $[23,49,109]$ and protects against saturated fat-induced insulin resistance in myotubes in vitro $[110,111]$. On the other hand, SCD1 protein expression was similar in obese and lean subjects in the study of Thrush et al. [43] and was even shown to be increased in severely obese subjects the study of Hulver et al. [112]. Nevertheless, the beneficial effects of DGAT1 and SCD1 overexpression further support the notion that channeling FAs to TAG synthesis is beneficial for insulin sensitivity. Yet while increasing the TAG synthesis capacity by, for example, training has been shown to improve insulin sensitivity, there is no evidence for a causative role of impaired TAG synthesis capacity in the development of obesity-associated insulin resistance.

\section{TAG breakdown}

Lipid turnover is not only determined by TAG synthesis but also by TAG lipolysis. In skeletal muscle, two major lipases have been identified that are responsible for complete TAG lipolysis: ATGL and HSL. Adipose triglyceride lipase (ATGL) hydrolyses TAG to form DAG [113], whereas HSL mainly acts on DAG $[114,115]$. When increased ATGL activity is not counterbalanced by increased hormone-sensitive lipase (HSL) or DGAT activity, intermediates will accumulate. In vivo microdialysis studies have demonstrated impaired lipolysis in skeletal muscle of obese subjects [116], suggesting that disturbances in the regulation of lipolysis may contribute to the development of obesity-associated comorbidities. In addition, several observational studies have shown alterations in the expression of proteins involved in lipolysis in skeletal muscle of obese and type 2 diabetic subjects. Jocken et al. measured lipase expression levels in insulin-resistant obese subjects compared with lean controls and showed that HSL was decreased while ATGL was increased without changes in CGI-58, a cofactor for ATGL activity. These changes concurrent with a lower DAG hydrolase activity may be a manifestation of incomplete lipolysis [42]. Surprisingly, the DAG level was decreased in the insulin-resistant obese subjects compared with the lean controls, indicating that the decreased DAG hydrolase and normal TAG hydrolase activity in obese subjects did not result in increased DAG. This absence of an effect on DAG accumulation raises the question whether the ratio of DAG to TAG hydrolase activity is of physiological importance for lipid-induced insulin resistance. Moreover, compensation by TAG-synthesis related proteins like DGAT might balance out intracellular DAG and TAG levels, thus protecting from accumulation of lipotoxic DAG species. Moro et al. determined DAG and TAG levels as well as lipase activities in skeletal muscle biopsies from lean, obese and type 2 diabetic subjects. In contrast to the study of Jocken et al. [42], DAG levels were increased. Additionally, a direct association with the ratio of DAG hydrolase to TAG hydrolase activity (an index of incomplete triacylglycerol hydrolysis) was observed, which explained $54 \%$ of the variance in DAG [7]. TAG hydrolase activity was increased only in female obese and type 2 diabetic subjects compared to lean controls [7]. Although Jocken et al. [42] only used male subjects, gender differences most likely do not explain the differences in DAG levels between the two studies, as no 
differences in DAG levels between males and females have been observed before [7]. Coen et al. showed decreased ATGL and HSL gene expression in obese insulin resistant compared with BMI-matched insulin sensitive controls, while DAG levels were similar [45]. In contrast to these studies, Li et al. showed that ATGL and HSL protein levels were not altered in skeletal muscle of obese women compared with lean women and that there were no differences in phosphorylation of specific sites known to affect HSL activity [101]. Recently, Badin et al. showed an imbalance between ATGL and HSL protein expression and activity in obese diabetics versus lean controls [117], consistent with the studies of Moro et al. [7] and Jocken et al. [42]. Furthermore, it was shown that an imbalance of ATGL relative to $H S L$ promotes DAG accumulation and leads to insulin resistance at least in part through the DAG-induced PKC activity [117]. However, in this study only obese type 2 diabetics and not NGT obese subjects displayed alterations in lipase protein content, in contrast with the data of Jocken et al [42]. It was suggested that these differences in study outcomes could be explained by age differences, since Badin et al. included younger obese subjects [117]. This age-effect deserves further attention.

Thus, studies in which lipase levels and activity were measured in obese and/or type 2 diabetic persons do not show consistent results. If the suggested importance of the ratio of TAG to DAG hydrolysis would be true, one could reason that TAG hydrolase activity is not as strictly regulated as DAG hydrolase activity, which may lead to a mismatch and incomplete lipolysis in obese subjects with excess IMCL. However, intramyocellular TAG and DAG hydrolysis capacity was measured in homogenates derived from frozen samples $[7,42]$ and therefore represents maximal capacity as opposed to physiological lipase activity. Cell studies showed that ATGL and HSL activity is tightly regulated by coactivation and repression by regulatory proteins. ATGL activity is dependent on CGI-58 (activator), GOS2 (suppressor) and perilipins for docking on the LD and the regulation of lipolysis upon protein kinase A (PKA) stimulation [118-121]. Thus, endogenous intracellular lipase activity is not only dependent on ATGL and HSL expression and enzyme activity, but is highly dependent on subcellular localization and the presence and activation of other proteins. Therefore, lipase protein expression and enzyme activity alone presumably do not give enough information to draw conclusion about the importance of disturbances in skeletal muscle lipolysis in lipid-induced insulin resistance. Moreover, it is currently unknown whether ATGL-mediated lipolysis gives rise to 1,2-DAG, which is considered the lipotoxic DAG intermediate capable of activity PKC [36]. The stereospecificity of the ATGL reaction needs to be elucidated. Taken together, it is still unclear whether the ratio of ATGL and HSL activity is involved in the development of lipid-induced insulin resistance.

\section{Lipid turnover and balances with oxidative capacity}

The aim of intramyocellular lipid dynamics in normal physiology is to provide intracellular fatty acids for oxidation when needed. In endurance-trained athletes, elevated IMCL storage serves as an important fuel store for prolonged exercise bouts and coincides with a high capacity to oxidize these fatty acids [122, 123]. Interestingly, type 2 diabetic 
patients have impaired mitochondrial function compared to obese NGT while having similar IMCL levels [19]. Therefore, a proper balance between IMCL storage and the myocellular oxidative capacity appears important to prevent detrimental effects of IMCL accumulation. Indeed, studies using stable isotope tracer technology to study usage of $I M C L$ during exercise revealed that IMCL was an important substrate during exercise [122, 123]. Moreover, the increased IMCL storage in endurance-trained athletes $[18,20]$ indicates an increased $\mathrm{IMCL}$ resynthesis capacity. It could be reasoned that lipid droplets in skeletal muscle of sedentary subjects have a low turnover rather than being frequently degraded and resynthesized, which might affect the subcellular distribution, organelle interactions and lipotoxic events. It is unclear to date whether IMCL usage and turnover is indeed impaired in obese and type 2 diabetic subjects. While Standl et al. [124] did not find any differences in IMCL use during exercise between type 2 diabetics and healthy lean controls, IMCL usage was demonstrated to be low in obese and type 2 diabetic subjects during exercise $[122,125]$. The beneficial effects of exercise training for type 2 diabetics, improved insulin sensitivity paralleled with increased IMCL storage [21, 22], indicate that a balance in FA uptake, IMCL storage and resynthesis, and oxidative metabolism improves insulin sensitivity. Interestingly, FFA-induced insulin resistance via lipid infusion was completely reversed by a single exercise session [102], further supporting the importance of exercise-induced IMCL resynthesis in the prevention of lipid-induced insulin resistance. Increased lipid turnover on the long term, for example as a result of exercise training, is usually paralleled by fiber type switches towards the more oxidative slow-twitch type I fibers $[45,77,126,127]$, increased oxidative capacity and increased intramyocellular TAG synthesis. Thus, elevated lipid turnover and $\mathrm{IMCL}$ resynthesis are components of the physiological adaptation to training and increased metabolic capacity. Proper balance between IMCL synthesis, lipolysis and oxidative metabolism is important for the protection against lipotoxicity. The importance of the rate of lipid turnover per se on subcellular distribution and buildup of lipotoxic intermediates requires further research.

\section{IMCL dynamics; concluding remarks}

Skeletal muscle lipid turnover is disturbed in obese and type 2 diabetic subjects. However, the mechanisms involved deserve further investigation. The regulation of lipid synthesis and lipolysis in skeletal muscle and its role in lipid-induced insulin resistance is complex and dependent on the interplay of different proteins. Disturbing this balance might lead to accumulation of lipid intermediates that have the potential to impair insulin signaling. Measurements of enzyme levels in skeletal muscle biopsies, however, represent static snap shots of the situation, while lipid metabolism is a highly dynamic process. Therefore, further research is warranted. Tracer studies and primary myotube cultures could provide valuable information on skeletal muscle lipid dynamics. 


\section{LIPID DROPLETS \& LIPID DROPLET COATING PROTEINS}

As outlined above, lipid accumulation in the form of lipid droplets (LDs) in muscle is a dynamic process that is heavily regulated by TAG synthetases and lipases. Since the recognition of LDs as dynamic organelles as opposed to being merely silent components of a cell, lipid droplet coat proteins have gained attention. LDs are composed of a neutral lipid core surrounded by a phospholipid monolayer and a protein coat. Cells contain a heterogeneous population of LDs with differences in lipid composition and protein coating. The protein coat of LDs contains a variety of different proteins involved in LD dynamics, including proteins involved in TAG metabolism, LD synthesis and breakdown, fusion and fission of LDs, intracellular trafficking and interorganelle interactions [128-131]. Research in this field is still in its infancy, but mounting evidence suggests a role for LDcoat proteins in protecting against lipotoxicity and insulin resistance. The lipid core contains DAG, TAG, cholesterolesters and free FAs [132]. One could hypothesize that storage of lipids in the LD is not harmful as opposed to accumulation of lipids elsewhere in the cell. High expression levels of LD-coat proteins might therefore provide a depot for intracellular lipids, thus sequestering (toxic) lipid species in LDs. Moreover, the lipid droplet coat is an important interface for lipid metabolism determining rates of lipid synthesis and lipolysis.

\section{Lipid droplet coat proteins: perilipins}

The best-characterized group of LD coat proteins is the perilipin (PLIN) protein family. PLIN1 (perilipin) is specific for adipose tissue, PLIN2 (ADRP, adipophilin) [133-135], PLIN3 (TIP47) [135], PLIN4 (S3-12) [136] and PLIN5 (OXPAT, MLDP, LSDP5) [133, 137-139] are expressed in muscle. Perilipins have been demonstrated to interact with key players in lipid metabolism [119-121], indicating that the protein coat of the LD is the interface for intracellular lipid metabolism. Little is known about the specific roles of the perilipins in skeletal muscle, but it could be suggested that the abundance of perilipin proteins might facilitate the creation of a depot for intracellular lipids and might modulate TAG synthesis and breakdown. Studies performed in vitro and in vivo in tissues other than muscle have demonstrated that perilipins increase intracellular lipid levels by inhibiting lipolysis and facilitating LD synthesis, while protecting against lipotoxic events [138, 140, 141], providing additional support for the hypothesis that neutral lipid storage per se does not induce lipotoxicity. Moreover, sequestering lipid intermediates towards storage in LDs rather than accumulation in/near the membranes or at other intracellular locations could prevent lipotoxicity without altering total intermediate storage. However, little is known about the exact composition of lipid droplets and this, therefore, deserves further attention.

Interestingly, in a human study in which no differences were found regarding the protein expression of TAG synthesis or lipolysis-related proteins, protein abundance of PLIN3 was lower in muscle of obese versus lean controls when expressed relative to 
intramyocellular TAG content [101]. Moreover, PLIN2 gene expression levels were lower in insulin resistant obese subjects versus BMI-matched insulin sensitive controls, with PLIN2 levels correlating positively with the rate of glucose disposal [45]. Additionally, although no differences were found in PLIN2 protein expression in diabetic versus obese control subjects, both weight loss and insulin-sensitizing drugs (troglitazone or metformin) resulted in increased protein expression of PLIN2 [134]. In a study performed in our group, we found no differences in skeletal muscle PLIN2 protein content when comparing type 2 diabetes patients with BMI-matched controls, two groups with similar IMCL levels. The same was true for PLIN5. However, an 8 week treatment with the PPAR $\gamma$ agonist rosiglitazone decreased PLIN2 and PLIN5 expression without changes in IMCL [133], which might be explained by a starting shift towards less ectopic fat accumulation and does not rule out a potential beneficial effect of perilipins. A $16 \mathrm{~h}$ lipid infusion after a 90 minute exercise session did not affect expression of perilipins 2-5 in skeletal muscle of lean women, while IMCL was increased with 30\% [105], indicating that short-term elevation of $\mathrm{IMCL}$ storage is not necessarily accompanied by increased perilipin protein expression. Information on the adaptations of PLIN activities upon long term increased fatty acid availability in humans is lacking.

We and others $[142,143]$ have recently shown that next to its presence in the lipid droplet coat, PLIN5 is present at the interface of LDs with mitochondria, as well as in the mitochondria. Furthermore, PLIN5 induces interactions of lipid droplets with mitochondria. Besides, PLIN5 regulates lipolysis by inhibiting ATGL activity under basal conditions and stimulating lipolysis upon PKA stimulation [119-121]. Therefore, PLIN5 potentially is a very important regulator of oxidative metabolism in muscle matching intracellular lipid load with downstream mitochondrial metabolism. Its exact role in mitochondria and lipid droplet dynamics requires further study.

Reports describing phenotypes of animal models of overexpression, knockdown or inhibition of perilipins are limited. PLIN2 knockout or inhibition showed contradictory results with respect to whole body or liver insulin sensitivity [140, 144-146]. That is, lowering of PLIN2 activity was demonstrated to improve liver insulin sensitivity in mice models of PLIN2 inhibition [145, 146], while siRNA-mediated knockdown of PLIN2 plus PLIN3 in liver cells impaired insulin sensitivity [140]. It should be noted that in the latter study, PLIN2 knockdown coincided with compensatory increased PLIN3 expression at the LD surface. Therefore, effects of knockdown of both PLIN3 and PLIN2 on insulin signaling was investigated [140]. In the first two studies [145, 146], potential compensation by other PLIN members at the LD surface in combination with lower intracellular lipid storage might have resulted in the beneficial effects of PLIN2 knockdown. PLIN2 knockouts crossed with ob/ob mice showed improved insulin sensitivity in both liver and muscle compared with ob/ob-PLIN2 ${ }^{+/+}$mice [144]. We recently overexpressed PLIN2 in tibialis anterior of rats by means of gene-electrotransfer. This intervention appeared to improve skeletal muscle insulin sensitivity despite increased intramyocellular lipid storage (unpublished data). 
Thus, based on present knowledge we cannot conclude whether perilipins might have the potential to protect against lipid-induced insulin resistance. Moreover, expression levels of perilipins might reflect adaptations in the cellular adaptation towards increased or decreased lipid load, thus following the pattern of myocellular fat storage. Nevertheless, based on the information from transgenic animal models and cell studies, genetic variation in LD-coat proteins (single nucleotide polymorphisms), as was described for PLIN1 in human DNA [147-149] and PLIN2 in pig DNA [150], might be one of the factors determining genetic predisposition for development of obesity and type 2 diabetes. However, further human genetic characterization studies and gain- and loss of function animal and cell models are warranted to further characterize the role of PLIN polymorphisms in (ectopic) fat storage and lipid-induced insulin resistance.

\section{Lipid droplet dynamics; future perspectives}

\section{Lipid droplet coat proteins other than the perilipins}

Other LD-coat proteins shown to be present in muscle include members of the CIDE (cell death-inducing DFF45-like effector) family, in particular Cidec/FSP27 [151-153], FIT1 and 2 [154, 155], and SNARE proteins [156-159], but not a lot is known about their function. Interestingly, while total SNAP-23 protein levels were increased in T2D patients [160, 161], the amount of SNAP-23 in skeletal muscle plasma membranes was lower in type 2 diabetes patients compared to controls and the amount of membrane SNAP-23 correlated with systemic insulin sensitivity $[160,161]$. Exocytosis of GLUT4 vesicles with the plasma membrane of insulin sensitive tissues as well as LD fusion are SNARE-mediated processes and high-jacking of SNAP-23 by LDs has been suggested to limit SNAP-23 availability for GLUT4 translocation $[160,162,163]$ but is beyond the scope of this review. Moreover, this list of muscular LD coat proteins is expected to expand because this field is still in its infancy.

\section{Lipid droplet size}

LD size might be a parameter influencing IMCL-storage induced lipotoxicity. An increased surface to volume ratio, i.e. smaller lipid droplets, would result in a greater LD coating area, potentially resulting in an increased capacity to mobilize lipids, which might be beneficial. However, this would also result in an increased binding surface area for lipases, perhaps resulting in increased lipid intermediates. Not a lot is known about the importance of lipid droplet size regarding lipotoxic potential. A weight loss and exercise program resulted in decreased LD size as determined by confocal microscopy paralleled by changes in insulin sensitivity [164]. Furthermore, rosiglitazone improved insulin sensitivity in parallel with smaller LDs [165], and large LDs were demonstrated to be associated with the development of diabetes in a study in which LD size was determined with electron microscopy (EM) [166]. On the other hand, no differences in LD size were observed after a seven week endurance training period in lean untrained men and women using EM [167]. Furthermore, in the study of Van Loon et al. [18] no differences in LD size were found 
when comparing trained, obese sedentary and obese diabetics nor in another study comparing obese subjects with lean controls [168]. A limitation of these two studies is the use of standard immunofluorescent microscopy, which is - in contrast to confocal microscopy - suboptimal to determine true LD size as the 2-dimensional section plane does not necessarily reflect the middle, largest diameter of all LDs. Basically, the same limitation holds true for EM determinations of LD size. Further research is needed to identify whether LD size is an important parameter in lipid-induced insulin resistance.

\section{Intracellular localization and organelle interactions}

Intramyocellular LDs are mainly localized in between the myofibers, in close contact with mitochondria (Fig. 2) and are less prominently present in the subsarcolemmal region. Malenfant et al. described a more central localization of LDs (i.e. less LDs in the subsarcolemmal region compared with the peripheral areas) in myofibers of NGT obese subjects compared to lean individuals [168]. Yet, in a study of Nielsen et al., it was concluded that subsarcolemmal LDs storage was increased in type 2 diabetics when compared to BMI-matched controls, using the more accurate method of ultrastructural determinations with electron microscopy [169]. Thus, LDs storage might shift from the interior towards the subsarcolemma during the transition from obesity towards overt type 2 diabetes. However, data is limited to firmly conclude on the importance of subcellular LD localization in the development of insulin resistance.

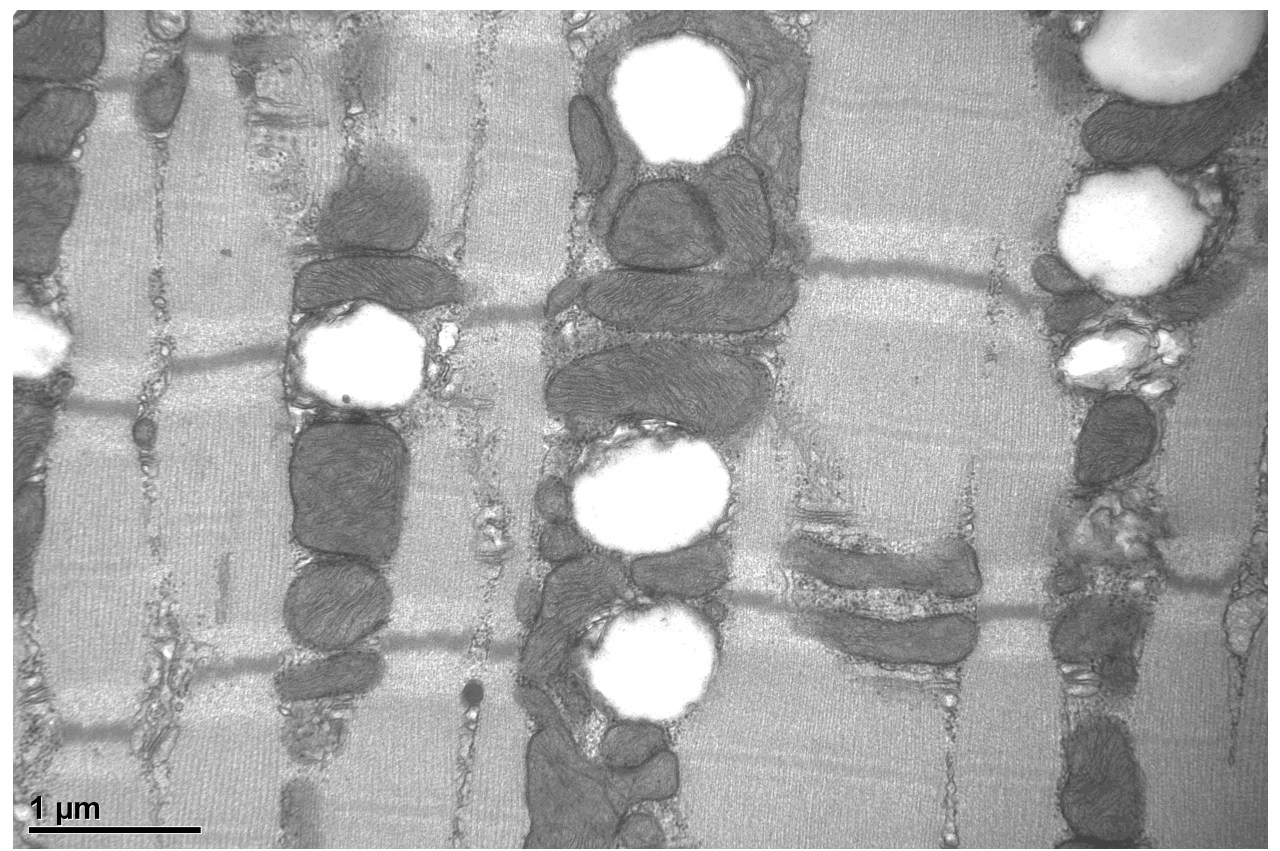

Figure 2. Transmission electron microscopy image of rat tibialis anterior muscle showing intermyofibrillar lipid droplets and adjacent mitochondria. 
The effects of subcellular localization of LDs on insulin sensitivity might be mediated by interactions of LDs with other subcellular compartments like mitochondria, the plasma membrane, and the sarcoplasmic reticulum (SR, the muscle-specific type of smooth $E R$ ). An oversupply of lipids to organelles might impair organelle function. On the other hand, it could be reasoned that a close apposition to SR or mitochondria might be beneficial for lipid handling. Complexes of SR, mitochondria and LDs might be the intracellular interface for lipid metabolism. The tubular invaginations of the sarcolemma ensure that the SR is in direct contact with the extracellular space of the muscle. These tubular invaginations are found on both sides of the z-line. Intermyofibrillar lipid droplets and mitochondria are usually found near these z-lines. The close apposition of LDs and mitochondria was already demonstrated in the early seventies by Hoppeler and colleagues [170]. They suggested that the contact surface area of LDs was the transfer site for fatty acids towards oxidative metabolism and that a larger contact surface area would be beneficial for the efficiency of lipid oxidative metabolism [171, 172]. Tarnapolsky et al. showed that a 7-week endurancetraining period in lean untrained men and women significantly increased the number of LDs in contact with mitochondria [167]. One could hypothesize that lipid droplets that are interacting with mitochondria are metabolically active LDs with a well-regulated rate and timing of lipolysis matched with downstream metabolism. That is, a close interaction between LDs and mitochondria ensures efficient utilization of lipolysis-derived FAs in situations of increased energy demand, thereby preventing high intracellular FA levels. Thus, interactions of LDs with SR and mitochondria might ensure controlled lipid metabolism and loss of interactions or a higher ratio of LDs to mitochondria might potentially be one of the intermediate steps in the development of lipotoxicity-induced insulin resistance. Moreover, proteins present on the mitochondrial outermembrane and/or in the LD coat are presumably needed for interorganelle interactions. However, so far no evidence is available for a role of LD-mitochondria interactions in determining insulin sensitivity of skeletal muscle and clearly further research in this area is warranted to unravel the dynamics of interorganelle interactions.

\section{CONCLUSIONS AND PERSPECTIVES}

The importance of intramyocellular lipid accumulation in the development of type 2 diabetes is firmly established and can be attributed to a disbalance in skeletal muscle lipid influx, lipid metabolism, and oxidative capacity. The mechanisms involved in lipid-induced insulin resistance, however, are still not fully unraveled. In animal and cell studies, lipid intermediates like DAG, ceramides, LC-FA-CoA and acylcarnitines all have the potential to induce insulin resistance. However, human studies show conflicting results, and are if anything not pointing towards one mechanism that can be held responsible for the muscular insulin resistance in type 2 diabetes. Rather, the strong interindividual variation and the inconsistencies in the broad array of studies performed so far indicate that there are several routes towards lipid-induced insulin resistance. Furthermore, it should not be 
ignored that the available data are merely correlative, describe snap shots and focus on one or a few parameters, while lipid metabolism is a highly complex and dynamic process. Based on available evidence, we conclude that total levels of DAG, ceramides and LC-FACoA are not appropriate predictors of obesity-associated insulin resistance.

Nevertheless, given the fact that these lipid species have the potential of impairing insulin signaling, it appears that the consequences of its accumulation in human skeletal muscle are multifactorial and dependent on specific characteristics, the latter might include the degree of saturation, chain length, stereo specificity and intracellular localization. Recently, research in this field has shifted towards the packaging of lipids into lipid droplets and the related lipid droplet dynamics. The heterogeneity and dynamic nature of lipid droplets indicate that lipid droplet characteristics and expression of lipid droplet-coat proteins are determinants of intramyocellular lipotoxicity. Information on this issue is still limited albeit promising, and definitely deserves further attention for our understanding of obesity-related diabetes and might provide targets for prevention.

\section{REFERENCES}

1. WHO. Obesity and overweight - Fact sheet $\mathrm{N}^{\circ} 311$. 2011. www.who.int/mediacentre/factsheets/fs311.

2. Lee DE, Kehlenbrink S, Lee $H$, Hawkins $M$, and Yudkin JS. Getting the message across: mechanisms of physiological cross talk by adipose tissue. Am J Physiol Endocrinol Metab 2009; 296: E1210-E1229.

3. McGarry JD. What if Minkowski had been ageusic? An alternative angle on diabetes. Science 1992; 258: 766-770.

4. Forouhi NG, Jenkinson G, Thomas EL, Mullick S, Mierisova S, Bhonsle U, McKeigue PM, and Bell JD. Relation of triglyceride stores in skeletal muscle cells to central obesity and insulin sensitivity in European and South Asian men. Diabetologia 1999; 42: 932-935.

5. Machann J, Bachmann OP, Brechtel K, Dahl DB, Wietek B, Klumpp B, Häring H-U, Claussen CD, Jacob S, and Schick F. Lipid content in the musculature of the lower leg assessed by fat selective MRI: intra- and interindividual differences and correlation with anthropometric and metabolic data. J Magn Reson Imaging 2003; 17: 350-357.

6. Misra A, Sinha S, Kumar M, Jagannathan NR, and Pandey RM. Proton magnetic resonance spectroscopy study of soleus muscle in non-obese healthy and type 2 diabetic Asian Northern Indian males: high intramyocellular lipid content correlates with excess body fat and abdominal obesity. Diabet Medicine 2003; 20: 361-367.

7. Moro C, Galgani JE, Luu L, Pasarica M, Mairal A, Bajpeyi S, Schmitz G, Langin D, Liebisch G, and Smith SR. Influence of gender, obesity, and muscle lipase activity on intramyocellular lipids in sedentary individuals. J Clin Endocrinol Metab 2009; 94: 3440-3447.

8. Sinha R, Dufour S, Petersen KF, LeBon V, Enoksson S, Ma Y-Z, Savoye M, Rothman DL, Shulman GI, and Caprio S. Assessment of skeletal muscle triglyceride content by $1 \mathrm{H}$ nuclear magnetic resonance spectroscopy in lean and obese adolescents. Diabetes 2002; 51: 1022-1027.

9. Aguer C, Mercier J, Yong Wai Man C, Metz L, Bordenave S, Lambert K, Jean E, Lantier L, Bounoua L, Brun J, Raynaud de Mauverger E, Andreelli F, Foretz M, and Kitzmann M. Intramyocellular lipid accumulation is associated with permanent relocation ex vivo and in vitro of fatty acid translocase (FAT)/CD36 in obese patients. Diabetologia 2010; 53: 1151-1163.

10. Goodpaster BH, Theriault R, Watkins SC, and Kelley DE. Intramuscular lipid content is increased in obesity and decreased by weight loss. Metabolism 2000; 49: 467-472.

11. Pan DA, Lillioja S, Kriketos AD, Milner MR, Baur LA, Bogardus C, Jenkins AB, and Storlien LH. Skeletal muscle triglyceride levels are inversely related to insulin action. Diabetes 1997; 46: 983-8.

12. Gray RE, Tanner CJ, Pories WJ, MacDonald KG, and Houmard JA. Effect of weight loss on muscle lipid 


\section{Re-evaluating lipotoxic triggers in skeletal muscle}

content in morbidly obese subjects. Am J Physiol Endocrinol Metab 2003; 284: E726-E732.

13. Jazet I, Schaart G, Gastaldelli A, Ferrannini E, Hesselink M, Schrauwen P, Romijn J, Maassen J, Pijl H, Ouwens $D$, and Meinders $A$. Loss of $50 \%$ of excess weight using a very low energy diet improves insulinstimulated glucose disposal and skeletal muscle insulin signalling in obese insulin-treated type 2 diabetic patients. Diabetologia 2008; 51: 309-319.

14. Solomon TPJ, Sistrun SN, Krishnan RK, Del Aguila LF, Marchetti CM, O'Carroll SM, O'Leary VB, and Kirwan JP. Exercise and diet enhance fat oxidation and reduce insulin resistance in older obese adults. J Appl Physiol 2008; 104: 1313-1319.

15. Tamura Y, Tanaka Y, Sato F, Choi JB, Watada H, Niwa M, Kinoshita J, Ooka A, Kumashiro N, Igarashi Y, Kyogoku S, Maehara T, Kawasumi M, Hirose T, and Kawamori R. Effects of diet and exercise on muscle and liver intracellular lipid contents and insulin sensitivity in type 2 diabetic patients. J Clin Endocrinol Metab 2005; 90: 3191-6.

16. Toledo FGS, Menshikova EV, Azuma K, Radiková Z, Kelley CA, Ritov VB, and Kelley DE. Mitochondrial capacity in skeletal muscle is not stimulated by weight loss despite increases in insulin action and decreases in intramyocellular lipid content. Diabetes 2008; 57: 987-994.

17. Bachmann OP, Dahl DB, Brechtel K, Machann J, Haap M, Maier T, Loviscach M, Stumvoll M, Claussen CD, Schick F, Häring HU, and Jacob S. Effects of intravenous and dietary lipid challenge on intramyocellular lipid content and the relation with insulin sensitivity in humans. Diabetes 2001; 50: 2579-2584.

18. Van Loon LJC, Koopman R, Manders R, van der Weegen W, van Kranenburg GP, and Keizer HA. Intramyocellular lipid content in type 2 diabetes patients compared with overweight sedentary men and highly trained endurance athletes. Am J Physiol Endocrinol Metab 2004; 287: E558-E565.

19. Schrauwen-Hinderling V, Kooi M, Hesselink M, Jeneson J, Backes W, van Echteld C, van Engelshoven J, Mensink $M$, and Schrauwen P. Impaired in vivo mitochondrial function but similar intramyocellular lipid content in patients with type 2 diabetes mellitus and BMI-matched control subjects. Diabetologia 2007; 50: 113-120.

20. Goodpaster BH, He J, Watkins S, and Kelley DE. Skeletal muscle lipid content and insulin resistance: evidence for a paradox in endurance-trained athletes. J Clin Endocrinol Metab 2001; 86: 5755-5761.

21. Dubé JJ, Amati F, Stefanovic-Racic M, Toledo FGS, Sauers SE, and Goodpaster BH. Exercise-induced alterations in intramyocellular lipids and insulin resistance: the athlete's paradox revisited. Am J Physiol Endocrinol Metab 2008; 294: E882-888.

22. Meex RCR, Schrauwen-Hinderling VB, Moonen-Kornips E, Schaart G, Mensink M, Phielix E, van de Weijer T, Sels JP, Schrauwen P, and Hesselink MKC. Restoration of muscle mitochondrial function and metabolic flexibility in type 2 diabetes by exercise training is paralleled by increased myocellular fat storage and improved insulin sensitivity. Diabetes 2010; 59: 572-579.

23. Bergman BC, Perreault L, Hunerdosse DM, Koehler MC, Samek AM, and Eckel RH. Increased intramuscular lipid synthesis and low saturation relate to insulin sensitivity in endurance-trained athletes. J Appl Physiol 2010; 108: 1134-1141.

24. Schaffer JE. Lipotoxicity: when tissues overeat. Curr Opin Lipidol 2003; 14: 281-7.

25. Liu L, Shi X, Choi CS, Shulman GI, Klaus K, Nair KS, Schwartz GJ, Zhang Y, Goldberg IJ, and Yu Y-H. Paradoxical coupling of triglyceride synthesis and fatty acid oxidation in skeletal muscle overexpressing DGAT1. Diabetes 2009; 58: 2516-2524.

26. Timmers S, de Vogel-van den Bosch J, Hesselink MKC, van Beurden D, Schaart G, Ferraz MJ, Losen M, Martinez-Martinez P, De Baets MH, Aerts JMFG, and Schrauwen P. Paradoxical increase in TAG and DAG content parallel the insulin sensitizing effect of unilateral DGAT1 overexpression in rat skeletal muscle. PLoS ONE 2011; 6: e14503.

27. Chibalin AV, Leng Y, Vieira E, Krook A, Björnholm M, Long YC, Kotova O, Zhong Z, Sakane F, Steiler T, Nylén C, Wang J, Laakso M, Topham MK, Gilbert M, Wallberg-Henriksson H, and Zierath JR. Downregulation of diacylglycerol kinase delta contributes to hyperglycemia-induced insulin resistance. Cell 2008; 132: 375386.

28. van Blitterswijk WJ and Houssa B. Properties and functions of diacylglycerol kinases. Cell Signal 2000; 12: 595-605.

29. Chavez JA and Summers SA. Characterizing the effects of saturated fatty acids on insulin signaling and 
ceramide and diacylglycerol accumulation in 3T3-L1 adipocytes and C2C12 myotubes. Arch Biochem Biophys 2003; 419: 101-109.

30. Montell E, Turini M, Marotta M, Roberts M, Noe V, Ciudad CJ, Mace K, and Gomez-Foix AM. DAG accumulation from saturated fatty acids desensitizes insulin stimulation of glucose uptake in muscle cells. Am J Physiol Endocrinol Metab 2001; 280: E229-37.

31. Idris I, Gray S, and Donnelly R. Protein kinase C activation: isozyme-specific effects on metabolism and cardiovascular complications in diabetes. Diabetologia 2001; 44: 659-673.

32. Samuel VT, Petersen KF, and Shulman GI. Lipid-induced insulin resistance: unravelling the mechanism. The Lancet 2010; 375: 2267-2277.

33. Turban S and Hajduch E. Protein kinase C isoforms: Mediators of reactive lipid metabolites in the development of insulin resistance. FEBS Lett 2011; 585: 269-274.

34. Boni LT and Rando RR. The nature of protein kinase $C$ activation by physically defined phospholipid vesicles and diacylglycerols. J Biol Chem 1985; 260: 10819-10825.

35. Goñi FM and Alonso A. Structure and functional properties of diacylglycerols in membranes. Prog Lipid Res 1999; 38: 1-48.

36. Wakelam MJO. Diacylglycerol - when is it an intracellular messenger? Biochim Biophys Acta 1998; 1436: 117-126.

37. Saha AK, Kurowski TG, Colca JR, and Ruderman NB. Lipid abnormalities in tissues of the KKAy mouse: effects of pioglitazone on malonyl-CoA and diacylglycerol. Am J Physiol Endocrinol Metab 1994; 267: E95E101.

38. Turinsky J, O'Sullivan DM, and Bayly BP. 1,2-Diacylglycerol and ceramide levels in insulin-resistant tissues of the rat in vivo. J Biol Chem 1990; 265: 16880-16885.

39. Itani SI, Ruderman NB, Schmieder F, and Boden G. Lipid-induced insulin resistance in human muscle is associated with changes in diacylglycerol, protein kinase C, and IkBa. Diabetes 2002; 51: 2005-2011.

40. Moro C, Bajpeyi S, and Smith SR. Determinants of intramyocellular triglyceride turnover: implications for insulin sensitivity. Am J Physiol Endocrinol Metab 2008; 294: E203-13.

41. Straczkowski M, Kowalska I, Baranowski M, Nikolajuk A, Otziomek E, Zabielski P, Adamska A, Blachnio A, Gorski J, and Gorska M. Increased skeletal muscle ceramide level in men at risk of developing type 2 diabetes. Diabetologia 2007; 50: 2366-2373.

42. Jocken JWE, Moro C, Goossens GH, Hansen D, Mairal A, Hesselink MKC, Langin D, van Loon LJC, and Blaak EE. Skeletal muscle lipase content and activity in obesity and type 2 diabetes. J Clin Endocrinol Metab 2010; jc.2010-0776.

43. Thrush AB, Brindley DN, Chabowski A, Heigenhauser GJ, and Dyck DJ. Skeletal muscle lipogenic protein expression is not different between lean and obese individuals: a potential factor in ceramide accumulation. J Clin Endocrinol Metab 2009; 94: 5053-5061.

44. Anastasiou CA, Kavouras SA, Lentzas Y, Gova A, Sidossis LS, and Melidonis A. Diabetes mellitus is associated with increased intramyocellular triglyceride, but not diglyceride, content in obese humans. Metabolism 2009; 58: 1636-1642.

45. Coen PM, Dubé JJ, Amati F, Stefanovic-Racic M, Ferrell RE, Toledo FGS, and Goodpaster BH. Insulin resistance is associated with higher intramyocellular triglycerides in type I but not type II myocytes concomitant with higher ceramide content. Diabetes 2009; 59: 80-8.

46. Perreault L, Bergman BC, Hunerdosse DM, Playdon MC, and Eckel RH. Inflexibility in intramuscular triglyceride fractional synthesis distinguishes prediabetes from obesity in humans. Obesity 2010; 18: 15241531.

47. Perreault L, Bergman BC, Hunerdosse DM, and Eckel RH. Altered intramuscular lipid metabolism relates to diminished insulin action in men, but not women, in progression to diabetes. Obesity 2010; 18: 2093-2100.

48. Bruce CR, Thrush AB, Mertz VA, Bezaire V, Chabowski A, Heigenhauser GJF, and Dyck DJ. Endurance training in obese humans improves glucose tolerance and mitochondrial fatty acid oxidation and alters muscle lipid content. Am J Physiol Endocrinol Metab 2006; 291: E99-E107.

49. Dubé J, Amati F, Toledo F, Stefanovic-Racic M, Rossi A, Coen P, and Goodpaster B. Effects of weight loss and exercise on insulin resistance, and intramyocellular triacylglycerol, diacylglycerol and ceramide. Diabetologia 2011; 54: 1147-1156. 


\section{Re-evaluating lipotoxic triggers in skeletal muscle}

50. Bajaj M, Baig R, Suraamornkul S, Hardies LJ, Coletta DK, Cline GW, Monroy A, Koul S, Sriwijitkamol A, Musi $\mathrm{N}$, Shulman $\mathrm{GI}$, and DeFronzo RA. Effects of pioglitazone on intramyocellular fat metabolism in patients with type 2 diabetes mellitus. J Clin Endocrinol Metab 2010; 95: 1916-1923.

51. Anastasiou CA, Kavouras SA, Lentzas Y, Gova A, Sidossis LS, and Melidonis A. Moderate weight loss depletes intramyocellular triglycerides but has no effect on diglycerides in type II diabetes. Eur J Clin Nutr 2010; 64: 328-330.

52. Van Hees AMJ, Jans A, Hul GB, Roche HM, Saris WHM, and Blaak EE. Skeletal muscle fatty acid handling in insulin resistant men. Obesity 2011; 19: 1350-9.

53. Kuerschner L, Moessinger C, and Thiele C. Imaging of lipid biosynthesis: How a neutral lipid enters lipid droplets. Traffic 2008; 9: 338-352.

54. Bruce CR, Hoy AJ, Turner N, Watt MJ, Allen TL, Carpenter K, Cooney GJ, Febbraio MA, and Kraegen EW. Overexpression of carnitine palmitoyltransferase-1 in skeletal muscle is sufficient to enhance fatty acid oxidation and improve high fat diet-induced insulin resistance. Diabetes 2009; 58: 550-558.

55. Choi CS, Befroy DE, Codella R, Kim S, Reznick RM, Hwang YJ, Liu ZX, Lee HY, Distefano A, Samuel VT, Zhang D, Cline GW, Handschin C, Lin J, Petersen KF, Spiegelman BM, and Shulman GI. Paradoxical effects of increased expression of PGC-1alpha on muscle mitochondrial function and insulin-stimulated muscle glucose metabolism. Proc Natl Acad Sci 2008; 105: 19926-19931.

56. Choi CS, Fillmore JJ, Kim JK, Liu ZX, Kim S, Collier EF, Kulkarni A, Distefano A, Hwang YJ, Kahn M, Chen Y, Yu C, Moore IK, Reznick RM, Higashimori T, and Shulman GI. Overexpression of uncoupling protein 3 in skeletal muscle protects against fat-induced insulin resistance. J Clin Invest 2007; 117: 1995-2003.

57. Summers SA. Ceramides in insulin resistance and lipotoxicity. Prog Lipid Res 2006; 45: 42-72.

58. Blachnio-Zabielska A, Baranowski M, Zabielski P, and Gorski J. Effect of high fat diet enriched with unsaturated and diet rich in saturated fatty acids on sphingolipid metabolism in rat skeletal muscle. J Cell Physiol 2010; 225: 786-791.

59. Holland WL, Brozinick JT, Wang L-P, Hawkins ED, Sargent KM, Liu Y, Narra K, Hoehn KL, Knotts TA, Siesky A, Nelson DH, Karathanasis SK, Fontenot Greg K, Birnbaum MJ, and Summers SA. Inhibition of ceramide synthesis ameliorates glucocorticoid-, saturated-fat-, and obesity-induced insulin resistance. Cell Metab 2007; 5: 167-179.

60. Merrill AH. De novo sphingolipid biosynthesis: a necessary, but dangerous, pathway. J Biol Chem 2002; 277: 25843-25846.

61. Summers SA. Sphingolipids and insulin resistance: the five Ws. Curr Opin Lipidol 2010; 21: 128-35.

62. Chavez JA, Knotts TA, Wang L-P, Li G, Dobrowsky RT, Florant GL, and Summers SA. A role for ceramide, but not diacylglycerol, in the antagonism of insulin signal transduction by saturated fatty acids. J Biol Chem 2003; 278: 10297-10303.

63. Kabayama K, Sato T, Saito K, Loberto N, Prinetti A, Sonnino S, Kinjo M, Igarashi Y, and Inokuchi J. Dissociation of the insulin receptor and caveolin-1 complex by ganglioside GM3 in the state of insulin resistance. Proc Natl Acad Sci 2007; 104: 13678-13683.

64. Novgorodov SA, Wu BX, Gudz TI, Bielwaski J, Ovchinnikova TV, Hannun YA, and Obeid LM. Novel pathway of ceramide production in mitochondria: Thioesterase and neutral ceramidase produce ceramide from sphingosine and acyl-COA. J Biol Chem 2011; 286: 25352-62.

65. Adams JM, Pratipanawatr T, Berria R, Wang E, DeFronzo RA, Sullards MC, and Mandarino LJ. Ceramide content is increased in skeletal muscle from obese insulin-resistant humans. Diabetes 2004; 53: 25-31.

66. Serlie MJ, Meijer AJ, Groener JE, Duran M, Endert E, Fliers E, Aerts JM, and Sauerwein HP. Short-term manipulation of plasma free fatty acids does not change skeletal muscle concentrations of ceramide and glucosylceramide in lean and overweight subjects. J Clin Endocrinol Metab 2007; 92: 1524-1529.

67. Skovbro M, Baranowski M, Skov-Jensen C, Flint A, Dela F, Gorski J, and Helge J. Human skeletal muscle ceramide content is not a major factor in muscle insulin sensitivity. Diabetologia 2008; 51: 1253-1260.

68. Nordby P, Prats C, Kristensen D, Ekroos K, Forsberg G, Andersen J, Ploug T, Dela F, Storlien L, and Helge J. Muscle ceramide content in man is higher in type I than type II fibers and not influenced by glycogen content. Eur J Appl Physiol 2010; 109: 935-943.

69. Hoeg LD, Sjoberg KA, Jeppesen J, Jensen TE, Frosig C, Birk JB, Bisiani B, Hiscock N, Pilegaard H, Wojtaszewski JFP, Richter EA, and Kiens $B$. Lipid-induced insulin resistance affects women less than men 
and is not accompanied by inflammation or impaired proximal insulin signaling. Diabetes 2011; 60: 64-73.

70. Straczkowski M, Kowalska I, Nikolajuk A, Dzienis-Straczkowska S, Kinalska I, Baranowski M, ZendzianPiotrowska M, Brzezinska Z, and Gorski J. Relationship between insulin sensitivity and sphingomyelin signaling pathway in human skeletal muscle. Diabetes 2004; 53: 1215-1221.

71. Vistisen B, Hellgren LI, Vadset T, Scheede-Bergdahl C, Helge JrW, Dela F, and Stallknecht B. Effect of gender on lipid-induced insulin resistance in obese subjects. Eur J Endocrinol 2008; 158: 61-68.

72. Ellis BA, Poynten A, Lowy AJ, Furler SM, Chisholm DJ, Kraegen EW, and Cooney GJ. Long-chain acyl-CoA esters as indicators of lipid metabolism and insulin sensitivity in rat and human muscle. Am J Physiol Endocrinol Metab 2000; 279: E554-E560.

73. Hulver MW, Berggren JR, Cortright RN, Dudek RW, Thompson RP, Pories WJ, MacDonald KG, Cline GW, Shulman GI, Dohm GL, and Houmard JA. Skeletal muscle lipid metabolism with obesity. Am J Physiol Endocrinol Metab 2003; 284: E741-E747.

74. Chalkley SM, Hettiarachchi M, Chisholm DJ, and Kraegen EW. Five-hour fatty acid elevation increases muscle lipids and impairs glycogen synthesis in the rat. Metabolism 1998; 47: 1121-1126.

75. Yu C, Chen Y, Cline GW, Zhang D, Zong H, Wang Y, Bergeron R, Kim JK, Cushman SW, Cooney GJ, Atcheson $B$, White MF, Kraegen EW, and Shulman GI. Mechanism by which fatty acids inhibit insulin activation of insulin receptor substrate-1 (IRS-1)-associated phosphatidylinositol 3-kinase activity in muscle. J Biol Chem 2002; 277: 50230-50236.

76. Bajaj M, Suraamornkul S, Romanelli A, Cline GW, Mandarino L, Shulman GI, and DeFronzo RA. Effect of a sustained reduction in plasma free fatty acid concentration on intramuscular long-chain fatty acyl-CoAs and insulin action in type 2 diabetic patients. Diabetes 2005; 54: 3148-3153.

77. Houmard JA, Tanner CJ, Yu C, Cunningham PG, Pories WJ, MacDonald KG, and Shulman GI. Effect of weight loss on insulin sensitivity and intramuscular long-chain fatty acyl-CoAs in morbidly obese subjects. Diabetes 2002; 51: 2959-2963.

78. Bruce CR, Anderson MJ, Carey AL, Newman DG, Bonen A, Kriketos AD, Cooney GJ, and Hawley JA. Muscle oxidative capacity is a better predictor of insulin sensitivity than lipid status. J Clin Endocrinol Metab 2003; 88: 5444-5451.

79. Faergeman NJ and Knudsen J. Role of long-chain fatty acyl-CoA esters in the regulation of metabolism and in cell signalling. Biochem J 1997; 323 ( Pt 1): 1-12.

80. Jenkins CM, Yang J, Sims HF, and Gross RW. Reversible high affinity inhibition of phosphofructokinase-1 by acyl-CoA. J Biol Chem 2011; 286: 11937-11950.

81. Koves TR, Ussher JR, Noland RC, Slentz D, Mosedale M, Ilkayeva O, Bain J, Stevens R, Dyck JRB, Newgard $\mathrm{CB}$, Lopaschuk GD, and Muoio DM. Mitochondrial overload and incomplete fatty acid oxidation contribute to skeletal muscle insulin resistance. Cell Metab 2008; 7: 45-56.

82. Violante S, Ijlst L, van Lenthe H, de Almeida IT, Wanders RJ, and Ventura FV. Carnitine palmitoyltransferase 2: New insights on the substrate specificity and implications for acylcarnitine profiling. Biochim Biophys Acta 2010; 1802: 728-732.

83. Bell JA, Reed MA, Consitt LA, Martin OJ, Haynie KR, Hulver MW, Muoio DM, and Dohm GL. Lipid partitioning, incomplete fatty acid oxidation, and insulin signal transduction in primary human muscle cells: effects of severe obesity, fatty acid incubation, and fatty acid translocase/CD36 overexpression. J Clin Endocrinol Metab 2010; jc.2009-1596.

84. Boyle KE, Canham JP, Consitt LA, Zheng D, Koves TR, Gavin TP, Holbert D, Neufer PD, Ilkayeva O, Muoio DM, and Houmard JA. A high-fat diet elicits differential responses in genes coordinating oxidative metabolism in skeletal muscle of lean and obese individuals. J Clin Endocrinol Metab 2010; jc.2010-2253.

85. Gaster M. Reduced lipid oxidation in myotubes established from obese and type 2 diabetic subjects. Biochem Biophys Res Commun 2009; 382: 766-770.

86. Wensaas AJ, Rustan AC, Just M, Berge RK, Drevon CA, and Gaster M. Fatty acid incubation of myotubes from humans with type 2 diabetes leads to enhanced release of \{beta\}-oxidation products because of impaired fatty acid oxidation: effects of tetradecylthioacetic acid and eicosapentaenoic Acid. Diabetes 2009; 58: 527-535.

87. Huffman KM, Shah SH, Stevens RD, Bain JR, Muehlbauer M, Slentz CA, Tanner CJ, Kuchibhatla M, Houmard $J A$, Newgard CB, and Kraus WE. Relationships between circulating metabolic intermediates and insulin 


\section{Re-evaluating lipotoxic triggers in skeletal muscle}

action in overweight to obese, inactive men and women. Diabetes Care 2009; 32: 1678-1683.

88. Newgard CB, An J, Bain JR, Muehlbauer MJ, Stevens RD, Lien LF, Haqq AM, Shah SH, Arlotto M, Slentz CA, Rochon J, Gallup D, Ilkayeva O, Wenner BR, Yancy Jr WS, Eisenson H, Musante G, Surwit RS, Millington DS, Butler MD, and Svetkey LP. A branched-chain amino acid-related metabolic signature that differentiates obese and lean humans and contributes to insulin resistance. Cell Metab 2009; 9: 311-326.

89. Adams SH, Hoppel CL, Lok KH, Zhao L, Wong SW, Minkler PE, Hwang DH, Newman JW, and Garvey WT. Plasma acylcarnitine profiles suggest incomplete long-chain fatty acid beta-oxidation and altered tricarboxylic acid cycle activity in type 2 diabetic African-American women. J Nutr 2009; 139: 1073-1081.

90. Mihalik SJ, Goodpaster BH, Kelley DE, Chace DH, Vockley J, Toledo FGS, and DeLany JP. Increased levels of plasma acylcarnitines in obesity and type 2 diabetes and identification of a marker of glucolipotoxicity. Obesity 2010; 18: 1695-1700.

91. Koves TR, Li P, An J, Akimoto T, Slentz D, Ilkayeva O, Dohm GL, Yan Z, Newgard CB, and Muoio DM. Peroxisome proliferator-activated receptor- $\gamma$ co-activator $1 \alpha$-mediated metabolic remodeling of skeletal myocytes mimics exercise training and reverses lipid-induced mitochondrial inefficiency. J Biol Chem 2005; 280: 33588-33598.

92. Redman LM, Huffman KM, Landerman LR, Pieper CF, Bain JR, Muehlbauer MJ, Stevens RD, Wenner BR, Kraus VB, Newgard CB, Kraus WE, and Ravussin E. Effect of caloric restriction with and without exercise on metabolic intermediates in nonobese men and women. J Clin Endocrinol Metab 2011; 96: E312-E321.

93. Velan SS, Said N, Durst C, Frisbee S, Frisbee J, Raylman RR, Thomas MA, Rajendran VM, Spencer RG, and Alway SE. Distinct patterns of fat metabolism in skeletal muscle of normal-weight, overweight, and obese humans. Am J Physiol Regul Integr Comp Physiol 2008; 295: R1060-R1065.

94. Gimeno RE and Cao J. Thematic review series: Glycerolipids. Mammalian glycerol-3-phosphate acyltransferases: new genes for an old activity. J Lipid Res 2008; 49: 2079-2088.

95. Park H, Kaushik VK, Constant S, Prentki M, Przybytkowski E, Ruderman NB, and Saha AK. Coordinate regulation of malonyl-CoA decarboxylase,sn-glycerol-3-phosphate acyltransferase, and acetyl-CoA carboxylase by AMP-activated protein kinase in rat tissues in response to exercise. J Biol Chem 2002; 277: 32571-32577.

96. Wurie HR, Buckett L, and Zammit VA. Evidence that diacylglycerol acyltransferase-1 (DGAT-1) has dual membrane-topology in the endoplasmic reticulum of HePG2 cells. J Biol Chem 2011; 286: 36238-36247.

97. McFie PJ, Banman SL, Kary S, and Stone SJ. Murine diacylglycerol acyltransferase-2 (DGAT2) can catalyze triacylglycerol synthesis and promote lipid droplet formation independent of its localization to the endoplasmic reticulum. J Biol Chem 2011;

98. Stone SJ, Levin MC, Zhou P, Han J, Walther TC, and Farese RV, Jr. The endoplasmic reticulum enzyme DGAT2 is found in mitochondria-associated membranes and has a mitochondrial targeting signal that promotes its association with mitochondria. J Biol Chem 2009; 284: 5352-5361.

99. Cases S, Smith SJ, Zheng Y-W, Myers HM, Lear SR, Sande E, Novak S, Collins C, Welch CB, Lusis AJ, Erickson SK, and Farese RV. Identification of a gene encoding an acyl CoA:diacylglycerol acyltransferase, a key enzyme in triacylglycerol synthesis. Proc Natl Acad Sci 1998; 95: 13018-13023.

100. Cases S, Stone SJ, Zhou P, Yen E, Tow B, Lardizabal KD, Voelker T, and Farese RV. Cloning of DGAT2, a second mammalian diacylglycerol acyltransferase, and related family members. J Biol Chem 2001; 276: 38870-38876.

101. Li M, Paran C, Wolins NE, and Horowitz JF. High muscle lipid content in obesity is not due to enhanced activation of key triglyceride esterification enzymes or to the suppression of lipolytic proteins. Am J Physiol Endocrinol Metab 2011; 300: E699-707.

102. Schenk S and Horowitz JF. Acute exercise increases triglyceride synthesis in skeletal muscle and prevents fatty acid-(0)induced insulin resistance. J Clin Invest 2007; 117: 1690-1698.

103. Alsted TJ, Nybo L, Schweiger M, Fledelius C, Jacobsen P, Zimmermann R, Zechner R, and Kiens B. Adipose triglyceride lipase in human skeletal muscle is upregulated by exercise training. Am J Physiol Endocrinol Metab 2008; 90912.2008.

104. Schmitt B, Fluck M, Decombaz J, Kreis R, Boesch C, Wittwer M, Graber F, Vogt M, Howald H, and Hoppeler $\mathrm{H}$. Transcriptional adaptations of lipid metabolism in tibialis anterior muscle of endurance-trained athletes. Physiol Genomics 2003; 15: 148-57. 
105. Newsom SA, Schenk S, Li M, Everett AC, and Horowitz JF. High fatty acid availability after exercise alters the regulation of muscle lipid metabolism. Metabolism 2010; 60: 852-9.

106. Liu L, Yu S, Khan RS, Ables GP, Bharadwaj KG, Hu Y, Huggins LA, Eriksson JW, Buckett LK, Turnbull AV, Ginsberg HN, Blaner WS, Huang L-S, and Goldberg IJ. Diacylglycerol acyl transferase 1 deficiency decreases PPAR expression and does not lead to lipotoxicity in cardiac and skeletal muscle. J Lipid Res 2010; 52: 732 44.

107. Dobrzyn $P$, Jazurek $M$, and Dobrzyn A. Stearoyl-CoA desaturase and insulin signaling â( What is the molecular switch? Biochim Biophys Acta 2010; 1797: 1189-1194.

108. Wang J, Yu L, Schmidt RE, Su C, Huang X, Gould K, and Cao G. Characterization of HSCD5, a novel human stearoyl-CoA desaturase unique to primates. Biochem Biophys Res Commun 2005; 332: 735-742.

109. Dobrzyn P, Pyrkowska A, Jazurek M, Szymanski K, Langfort J, and Dobrzyn A. Endurance training-induced accumulation of muscle triglycerides is coupled to upregulation of stearoyl-CoA desaturase 1 . J Appl Physiol 2010; 109: 1653-1661.

110. Peter A, Weigert C, Staiger H, Machicao F, Schick F, Machann J, Stefan N, Thamer C, Häring H, and Schleicher E. Individual stearoyl-CoA desaturase 1 expression modulates endoplasmic reticulum stress and inflammation in human myotubes and is sssociated with skeletal muscle lipid storage and insulin sensitivity in vivo. Diabetes 2009; 58: 1757-1765.

111. Pinnamaneni S, Southgate R, Febbraio M, and Watt M. Stearoyl CoA desaturase 1 is elevated in obesity but protects against fatty acid-induced skeletal muscle insulin resistance in vitro. Diabetologia 2006; 49: $3027-$ 3037.

112. Hulver MW, Berggren JR, Carper MJ, Miyazaki M, Ntambi JM, Hoffman EP, Thyfault JP, Stevens R, Dohm GL, Houmard JA, and Muoio DM. Elevated stearoyl-CoA desaturase-1 expression in skeletal muscle contributes to abnormal fatty acid partitioning in obese humans. Cell Metab 2005; 2: 251-261.

113. Zimmermann R, Strauss JG, Haemmerle G, Schoiswohl G, Birner-Gruenberger R, Riederer M, Lass A, Neuberger G, Eisenhaber F, Hermetter A, and Zechner R. Fat mobilization in adipose tissue is promoted by adipose triglyceride lipase. Science 2004; 306: 1383-1386.

114. Fredrikson $\mathrm{G}$ and Belfrage P. Positional specificity of hormone-sensitive lipase from rat adipose tissue. J Biol Chem 1983; 258: 14253-6.

115. Haemmerle G, Zimmermann R, Hayn M, Theussl C, Waeg G, Wagner E, Sattler W, Magin TM, Wagner EF, and Zechner R. Hormone-sensitive lipase deficiency in mice causes diglyceride accumulation in adipose tissue, muscle, and testis. J Biol Chem 2002; 277: 4806-4815.

116. Blaak E, Schiffelers S, Saris W, Mensink M, and Kooi M. Impaired $\beta$-adrenergically mediated lipolysis in skeletal muscle of obese subjects. Diabetologia 2004; 47: 1462-1468.

117. Badin P-M, Louche K, Mairal A, Liebisch G, Schmitz G, Rustan AC, Smith SR, Langin D, and Moro C. Altered skeletal muscle lipase expression and activity contribute to insulin resistance in humans. Diabetes 2011; 60: $1734-42$.

118. Granneman JG, Moore H-PH, Krishnamoorthy R, and Rathod M. Perilipin controls lipolysis by regulating the interactions of $A B$-hydrolase containing 5 (Abhd5) and adipose triglyceride lipase (Atgl). J Biol Chem 2009; 284: 34538-34544.

119. Granneman JG, Moore H-PH, Mottillo EP, Zhu Z, and Zhou L. Interactions of perilipin-5 (PLIN5) with adipose trigylceride lipase (ATGL). J Biol Chem 2011; 286: 5126-5135.

120. Granneman JG, Moore HP, Mottillo EP, and Zhu Z. Functional interactions between MLDP (LSDP5) and ABHD5 in the control of intracellular lipid accumulation. J Biol Chem 2009; 284: 3049-57.

121. Wang H, Bell M, Sreenevasan U, Hu H, Liu J, Dalen K, Londos C, Yamaguchi T, Rizzo MA, Coleman R, Gong $D$, Brasaemle D, and Sztalryd C. Unique regulation of adipose triglyceride lipase (ATGL) by perilipin 5, a lipid droplet-associated protein. J Biol Chem 2011; 286: 15707-15.

122. Van Loon LJC. Use of intramuscular triacylglycerol as a substrate source during exercise in humans. J Appl Physiol 2004; 97: 1170-1187.

123. Stellingwerff T, Boon H, Jonkers RAM, Senden JM, Spriet LL, Koopman R, and van Loon LJC. Significant intramyocellular lipid use during prolonged cycling in endurance-trained males as assessed by three different methodologies. Am J Physiol Endocrinol Metab 2007; 292: E1715-E1723.

124. Standl E, Lotz N, Dexel T, Janka H, and Kolb H. Muscle triglycerides in diabetic subjects. Diabetologia 1980; 
18: 463-469.

125. Van Loon LJC and Goodpaster B. Increased intramuscular lipid storage in the insulin-resistant and endurance-trained state. Pflügers Arch 2006; 451: 606-616.

126. Bassel-Duby R and Olson EN. Signaling pathways in skeletal muscle remodeling. Annu Rev Biochem 2006; 75: 19-37.

127. Lillioja S, Young AA, Culter CL, Ivy JL, Abbott WG, Zawadzki JK, Yki-Jarvinen H, Christin L, Secomb TW, and Bogardus C. Skeletal muscle capillary density and fiber type are possible determinants of in vivo insulin resistance in man. J Clin Invest 1987; 80: 415-24.

128. Beller M, Thiel K, Thul PJ, and Jäckle H. Lipid droplets: A dynamic organelle moves into focus. FEBS Lett 2010; 584: 2176-82.

129. Farese RV and Walther TC. Lipid Droplets Finally Get a Little R-E-S-P-E-C-T. Cell 2009; 139: 855-860.

130. Thiele $C$ and Spandl J. Cell biology of lipid droplets. Curr Opin Cell Biol 2008; 20: 378-385.

131. Walther TC and Farese Jr RV. The life of lipid droplets. Biochim Biophys Acta 2009; 1791: 459-66.

132. DiAugustine RP, Schaefer JM, and Fouts JR. Hepatic lipid droplets. Isolation, morphology and composition. Biochem J 1973; 132: 323-7.

133. Minnaard R, Schrauwen P, Schaart G, Jorgensen JA, Lenaers E, Mensink M, and Hesselink MKC. Adipocyte differentiation-related protein and OXPAT in rat and human skeletal muscle: involvement in lipid accumulation and type 2 diabetes mellitus. J Clin Endocrinol Metab 2009; 94: 4077-85.

134. Phillips SA, Choe CC, Ciaraldi TP, Greenberg AS, Kong AP, Baxi SC, Christiansen L, Mudaliar SR, and Henry RR. Adipocyte differentiation-related protein in human skeletal muscle: relationship to insulin sensitivity. Obes Res 2005; 13: 1321-9.

135. Prats C, Donsmark M, Qvortrup K, Londos C, Sztalryd C, Holm C, Galbo H, and Ploug T. Decrease in intramuscular lipid droplets and translocation of HSL in response to muscle contraction and epinephrine. J Lipid Res 2006; 47: 2392-9.

136. Wolins NE, Skinner JR, Schoenfish MJ, Tzekov A, Bensch KG, and Bickel PE. Adipocyte protein S3-12 coats nascent lipid droplets. J Biol Chem 2003; 278: 37713-21.

137. Dalen KT, Dahl T, Holter E, Arntsen B, Londos C, Sztalryd C, and Nebb HI. LSDP5 is a PAT protein specifically expressed in fatty acid oxidizing tissues. Biochim Biophys Acta 2007; 1771: 210-27.

138. Wolins NE, Quaynor BK, Skinner JR, Tzekov A, Croce MA, Gropler MC, Varma V, Yao-Borengasser A, Rasouli $\mathrm{N}$, Kern PA, Finck BN, and Bickel PE. OXPAT/PAT-1 is a PPAR-induced lipid droplet protein that promotes fatty acid utilization. Diabetes 2006; 55: 3418-28.

139. Yamaguchi T, Matsushita S, Motojima K, Hirose F, and Osumi T. MLDP, a novel PAT family protein localized to lipid droplets and enriched in the heart, is regulated by peroxisome proliferator-activated receptor $\alpha$. J Biol Chem 2006; 281: 14232-40.

140. Bell M, Wang H, Chen H, McLenithan JC, Gong D-W, Yang R-Z, Yu D, Fried SK, Quon MJ, Londos C, and Sztalryd C. Consequences of lipid droplet coat protein downregulation in liver cells: abnormal lipid droplet metabolism and induction of insulin resistance. Diabetes 2008; 57: 2037-2045.

141. Miyoshi H, Souza SC, Endo M, Sawada T, Perfield JW, II, Shimizu C, Stancheva Z, Nagai S, Strissel KJ, Yoshioka N, Obin MS, Koike T, and Greenberg AS. Perilipin overexpression in mice protects against dietinduced obesity. J Lipid Res 2009; 51: 975-82.

142. Bosma M, Minnaard R, Sparks LM, Schaart G, Losen M, De Baets MH, Duimel H, Kersten S, Bickel PE, Schrauwen $P$, and Hesselink MKC. The lipid droplet coat protein perilipin 5 also localizes to muscle mitochondria. Histochem Cell Biol 2012; 137: 205-216.

143. Wang H, Sreenevasan U, Hu H, Saladino A, Polster BM, Lund LM, Gong D-W, Stanley WC, and Sztalryd C. Perilipin 5, a lipid droplet associated protein, provides physical and metabolic linkage to mitochondria. J Lipid Res 2011; 52: 2159-2168.

144. Chang BH-J, Li L, Saha P, and Chan L. Absence of adipose differentiation related protein upregulates hepatic VLDL secretion, relieves hepatosteatosis and improves whole body insulin resistance in leptindeficient mice. J Lipid Res 2010; 51: 2132-42.

145. Imai Y, Varela GM, Jackson MB, Graham MJ, Crooke RM, and Ahima RS. Reduction of hepatosteatosis and lipid levels by an adipose differentiation-related protein antisense oligonucleotide. Gastroenterology 2007; 132: 1947-54. 
146. Varela GM, Antwi DA, Dhir R, Yin X, Singhal NS, Graham MJ, Crooke RM, and Ahima RS. Inhibition of ADRP prevents diet-induced insulin resistance. Am J Physiol Gastrointest Liver Physiol 2008; 295: G621-8.

147. Corella D, Qi L, Tai ES, Deurenberg-Yap M, Tan CE, Chew SK, and Ordovas JM. Perilipin gene variation determines higher susceptibility to insulin resistance in Asian women when consuming a high-saturated fat, low-carbohydrate diet. Diabetes Care 2006; 29: 1313-1319.

148. Jang Y, Kim OY, Lee JH, Koh SJ, Chae JS, Kim JY, Park S, Cho H, Lee JE, and Ordovas JM. Genetic variation at the perilipin locus is associated with changes in serum free fatty acids and abdominal fat following mild weight loss. Int J Obes 2006; 30: 1601-1608.

149. Qi L, Corella D, Sorlí JV, Portolés O, Shen H, Coltell O, Godoy D, Greenberg AS, and Ordovas JM. Genetic variation at the perilipin (PLIN) locus is associated with obesity-related phenotypes in White women. Clin Genet 2004; 66: 299-310.

150. Davoli R, Gandolfi G, Braglia S, Comella M, Zambonelli P, Buttazzoni L, and Russo V. New SNP of the porcine Perilipin 2 (PLIN2) gene, association with carcass traits and expression analysis in skeletal muscle. Mol Biol Rep 2011; 38: 1575-83.

151. Matsusue K, Kusakabe T, Noguchi T, Takiguchi S, Suzuki T, Yamano S, and Gonzalez FJ. Hepatic steatosis in leptin-deficient mice is promoted by the PPARY target gene Fsp27. Cell Metab 2008; 7: 302-311.

152. Puri V, Konda S, Ranjit S, Aouadi M, Chawla A, Chouinard M, Chakladar A, and Czech MP. Fat-specific protein 27, a novel lipid droplet protein that enhances triglyceride storage. J Biol Chem 2007; 282: 3421334218.

153. Wang ZQ, Yu Y, Zhang XH, Floyd EZ, and Cefalu WT. Human adenovirus 36 decreases fatty acid oxidation and increases de novo lipogenesis in primary cultured human skeletal muscle cells by promoting Cidec/FSP27 expression. Int J Obes 2010;

154. Gross DA, Snapp EL, and Silver DL. Structural insights into triglyceride storage mediated by fat storageinducing transmembrane (FIT) protein 2. PLoS ONE 2010; 5: e10796.

155. Kadereit B, Kumar P, Wang WJ, Miranda D, Snapp EL, Severina N, Torregroza I, Evans T, and Silver DL. Evolutionarily conserved gene family important for fat storage. Proc Natl Acad Sci 2008; 105: 94-99.

156. Boström P, Andersson L, Rutberg M, Perman J, Lidberg U, Johansson BR, Fernandez-Rodriguez J, Ericson J, Nilsson T, Borén J, and Olofsson S-O. SNARE proteins mediate fusion between cytosolic lipid droplets and are implicated in insulin sensitivity. Nat Cell Biol 2007; 9: 1286-1293.

157. Jägerström S, Polesie S, Wickström Y, Johansson BR, Schröder HD, Højlund K, and Boström P. Lipid droplets interact with mitochondria using SNAP23. Cell Biol Int 2009; 33: 934-940.

158. Schlaepfer IR, Pulawa LK, Ferreira LDMCB, James DE, Capell WH, and Eckel RH. Increased expression of the SNARE accessory protein Munc18c in lipid-mediated insulin resistance. J Lipid Res 2003; 44: 1174-1181.

159. Sollner TH. Lipid droplets highjack SNAREs. Nat Cell Biol 2007; 9: 1219-1220.

160. Boström P, Andersson L, Li L, Perkins R, Højlund K, Borén J, and Olofsson SO. The assembly of lipid droplets and its relation to cellular insulin sensitivity. Biochem Soc Trans 2009; 037: 981-985.

161. Boström $P$, Andersson $L$, Vind $B$, Håversen $L$, Rutberg $M$, Wickström $Y$, Larsson $E$, Jansson PA, Svensson MK, Brånemark R, Ling C, Beck-Nielsen $\mathrm{H}$, Borén J, Højlund $\mathrm{K}$, and Olofsson SO. The SNARE protein SNAP23 and the SNARE-interacting protein Munc18c in human skeletal muscle are implicated in insulin resistance/type 2 diabetes. Diabetes 2010; 59: 1870-1878.

162. Ducharme NA and Bickel PE. Lipid droplets in lipogenesis and lipolysis. Endocrinology 2008; 149 : $942-9$.

163. Olofsson SO, Andersson L, Håversen L, Olsson C, Myhre S, Rutberg M, Mobini R, Li L, Lu E, Borén J, and Boström P. The formation of lipid droplets: possible role in the development of insulin resistance/type 2 diabetes. Prostaglandins Leukot Essent Fatty Acids 2011; 85: 215-218.

164. He J, Goodpaster BH, and Kelley DE. Effects of weight loss and physical activity on muscle lipid content and droplet size. Obesity 2004; 12: 761-769.

165. Molero JC, Lee S, Leizerman I, Chajut A, Cooper A, and Walder K. Effects of rosiglitazone on intramyocellular lipid accumulation in Psammomys obesus. Biochim Biophys Acta 2010; 1802: 235-9.

166. Fraenkel M, Weiss R, Leizerman I, Anaby D, Golomb E, Leibowitz G, and Kaiser N. Scanning electron microscopic analysis of intramyocellular lipid droplets in an animal model of type 2 diabetes. Obesity 2008; 16: 695-699.

167. Tarnopolsky MA, Rennie CD, Robertshaw HA, Fedak-Tarnopolsky SN, Devries MC, and Hamadeh MJ. 


\section{Re-evaluating lipotoxic triggers in skeletal muscle}

Influence of endurance exercise training and sex on intramyocellular lipid and mitochondrial ultrastructure, substrate use, and mitochondrial enzyme activity. Am J Physiol Regul Integr Comp Physiol 2007; 292: R1271-1278.

168. Malenfant $P$, Joanisse DR, Theriault R, Goodpaster BH, Kelley DE, and Simoneau JA. Fat content in individual muscle fibers of lean and obese subjects. Int J Obes Relat Metab Disord 2001; 25: 1316-21.

169. Nielsen J, Mogensen M, Vind BF, Sahlin K, Højlund K, Schrøder HD, and Ørtenblad N. Increased subsarcolemmal lipids in type 2 diabetes: effect of training on localization of lipids, mitochondria, and glycogen in sedentary human skeletal muscle. Am J Physiol Endocrinol Metab 2009; 298: E706-E713.

170. Hoppeler $H$, Luthi $P$, Claassen $H$, Weibel ER, and Howald $H$. The ultrastructure of the normal human skeletal muscle. A morphometric analysis on untrained men, women and well-trained orienteers. Pflugers Arch 1973; 344: 217-32.

171. Taylor CR, Weibel ER, Weber JM, Vock R, Hoppeler H, Roberts TJ, and Brichon G. Design of the oxygen and substrate pathways. I. Model and strategy to test symmorphosis in a network structure. J Exp Biol 1996; 199: 1643-1649.

172. Vock R, Hoppeler H, Claassen H, Wu DX, Billeter R, Weber JM, Taylor CR, and Weibel ER. Design of the oxygen and substrate pathways. VI. structural basis of intracellular substrate supply to mitochondria in muscle cells. J Exp Biol 1996; 199: 1689-1697. 


\section{CHAPTER 3}

Increased intramyocellular lipid storage capacity is associated with lower fasting-induced insulin resistance

Madeleen Bosma, Joris Hoeks, Noud A. van Herpen, Johanna Jorgensen, Gert Schaart, Esther Kornips, Matthijs K.C. Hesselink, Patrick Schrauwen

Submitted 


\section{ABSTRACT}

Obesity is associated with skeletal muscle insulin resistance, attributed to increased lipid supply to the muscle. However, high intramyocellular lipid (IMCL) levels do not necessarily result in impaired insulin signaling. Lipid droplet coat proteins modulate IMCL metabolism. Here we aimed to investigate the relation between intramyocellular lipid droplet storage capacity and lipid-induced insulin resistance, and the role of skeletal muscle PLIN2, PLIN3, PLIN5, ATGL and CGI-58 herein. Two human models of increased lipid supply were utilized; a prolonged $(60 \mathrm{~h})$ fast and consumption of a high fat diet for three weeks. Intramyocellular lipid (IMCL) storage was assessed using Oil-red-O-stainings. Insulin sensitivity was determined with hyperinsulinemic-euglycemic clamps. PLIN2, PLIN3, PLIN5, ATGL and CGI-58 expression was investigated by qPCR and Western blotting.

PLIN3 gene expression was downregulated after fasting ( $28 \%$ decrease, $P=0.003$ ), but this did not result in decreased PLIN3 protein content. Gene and protein expression of PLIN2, PLIN5, ATGL and CGI-58 were not significantly different in the fasted versus the fed condition. Interestingly, a larger increase in IMCL storage upon fasting was associated with a lower reduction in insulin sensitivity $(r=0.657, \mathrm{P}=0.039)$. Moreover, PLIN2 expression correlated positively with changes in IMCL storage $(r=0.732, \mathrm{P}=0.01)$. In the second study, a high fat diet resulted in increased IMCL but did not affect insulin sensitivity. PLIN5 protein levels showed a tendency for upregulation after the HFD intervention and correlated negatively with insulin sensitivity.

In conclusion, in contrast to mouse studies, PLIN expression is not induced upon prolonged fasting in human skeletal muscle. Subjects with a larger capacity to store intramyocellular lipids in lipid droplets become less insulin resistant after a prolonged fast. Contrastingly, this phenomenon was not apparent in the HFD intervention, indicating differential effects of IMCL storage capacity upon short and long-term increases in lipid availability. The data suggest that under acute conditions of high lipid availability an increased capacity to store IMCL protects against insulin resistance, and that PLIN2 may be an important determinant herein. 


\section{INTRODUCTION}

Obesity is associated with increased lipid supply to skeletal muscle [1]. Intramyocellular lipids (IMCL) are stored in lipid droplets (LDs), which are highly dynamic and consist of a neutral lipid core enclosed by a phospholipid monolayer [2]. This phospholipid monolayer is decorated with a variety of different LD coat proteins, which modulate LD dynamics and lipid metabolism (reviewed in [3-5]). Two major proteins involved in regulating LD lipolysis shuttle between the cytosol and the LD, namely ATGL (PNPLA2) and CGI-58 (ABHD5). ATGL catalyzes the initial step in TAG hydrolysis and is a rate-limiting enzyme in lipolysis [6]. Besides coactivation by CGI58 [7] and repression by G0S2 [8], ATGL activity is modulated by various LD coat proteins, including those of the perilipin (PLIN) protein family [9-14]. PLIN2 (ADRP, adipophilin), PLIN3 (TIP47), and PLIN5 (OXPAT, MLDP, LSDP5) appear to be the most prominent perilipins in skeletal muscle [15-18]. PLIN2 is involved in both LD synthesis and inhibition of LD lipolysis $[13,19]$, PLIN3 functions in the biogenesis of LDs [20]. PLIN5 localizes to both LDs and mitochondria, modulates lipolysis by interacting with ATGL and CGI-58 $[10,11,14]$, and is considered to be involved in interactions of LDs with mitochondria $[15,21]$.

Increased IMCL content is associated with the development of insulin resistance [22, 23]. However, increased IMCL levels do not necessarily result in impaired insulin signaling (reviewed in [24]), indicating that not $I M C L$ per se, but its characteristics and dynamics determine lipid-induced insulin resistance. In this context, one exercise session was shown to prevent lipid-induced insulin resistance by partitioning more fatty acids (FAs) into LD as triacylglycerol (TAG) in human skeletal muscle [25]. Furthermore, animal studies have demonstrated that increased partitioning of lipids towards TAG storage by overexpression of diacylglycerol acyltransferase (DGAT) protected against lipid-induced insulin resistance $[26,27]$. Therefore we propose that interindividual variation in intramyocellular TAG storage capacity - and the above-mentioned proteins involved in this process - are determinants of susceptibility to lipid-induced insulin resistance. In line with our hypothesis, animal models showed that feeding status and high fat intake affected the expression levels of LD coat proteins in skeletal muscle. Skeletal muscle ATGL protein content was increased upon fasting $[28,29]$. Furthermore, both PLIN2 and PLIN5 are upregulated upon fasting and high fat feeding in animal models [30-34]. In humans, skeletal muscle ATGL protein expression was similar in obese compared to lean subjects, but higher in type 2 diabetic subjects [35-37]. However, so far little is known about the expression of lipolytic enzymes and perilipins in human skeletal muscle under conditions with elevated skeletal muscle lipid supply and their role in human skeletal muscle lipid metabolism.

Here we investigated the expression of ATGL, CGI-58 and PLINs 2, 3 and 5 in human skeletal muscle under conditions of acute and chronic elevation of fatty acid supply to the muscle; fasting for $60 \mathrm{~h}$ and consumption of a high fat diet for three weeks. We hypothesized that IMCL storage capacity and LD coat protein expression are determinants of susceptibility to lipid-induced insulin resistance. 


\section{Lipid content and PLIN expression upon fasting and high fat diet consumption}

\section{METHODS}

\section{Fasting study}

Twelve young, healthy lean subjects without a family history of diabetes mellitus or any other endocrine disorder were fasted or fed in energy balance for $60 \mathrm{~h}$ in a randomized crossover design with a 2-week washout period in between. In the fasted condition, subjects were fasted for $60 \mathrm{~h}$ (calorie-free drinks only), whereas in the second condition, subjects were fed in energy balance (50-35-15\% of energy as carbohydrates, fat, and protein, respectively). Before the start of each experimental period, a standardized evening meal was provided. Subject stayed in a respiration chamber during the entire $60 \mathrm{~h}$ to ensure compliance to the dietary regime and to allow the measurement of $24 \mathrm{~h}$ substrate oxidation and energy expenditure [38]. In the respiration chamber, subjects followed an activity protocol as previously described [39]. After leaving the respiration chamber on the morning of the third day, a muscle biopsy was taken and a hyperinsulinemic-euglycemic clamp procedure was performed as described [38]. A detailed protocol was described previously [38]. Subject characteristics can be found in Supplemental Table 1. None of the subjects was engaged in sports activities for more than $2 \mathrm{~h}$ per week. The insulin sensitivity $\left(\mathrm{S}_{\mathrm{i}}\right.$ index) was calculated by correcting the glucose rate of disappearance $\left(R_{d}\right)$ for the glucose and insulin values during the clamp.

\section{High fat diet intervention study}

Ten sedentary, healthy overweight men participated (Supplemental Table 2). Subjects with a body weight gain or loss of more than $3 \mathrm{~kg}$ in past 3 months or more than 20 gram alcohol intake per day were excluded. The subjects consumed a low-fat run-in diet for 3 wk, after which baseline measurements were made (day 21). Subsequently, to investigate the effects of switching from a low- to a high-fat diet, subjects consumed a high-fat for three weeks, after which measurements were repeated (day 42). A detailed protocol has been described previously [40]. Before and after the diet-intervention, a muscle biopsy was taken and subjects underwent a hyperinsulinemic-euglycemic clamp as described [40]. The $S_{i}$ index was calculated by correcting the glucose rate of disappearance $\left(R_{d}\right)$ for the glucose and insulin values during the clamp.

Both study protocols were reviewed and approved by the Medical Ethical Committee of Maastricht University Medical Centre and all subjects gave written informed consent before participating in the study. Both studies have been registered at www.trialregister.nl; registration numbers NTR 2042 (fasting study) and NTR 2136 (high fat/low fat diet intervention study). Detailed study protocols and primary clinical outcomes were published previously $[38,40]$.

\section{Muscle biopsy}

A percutaneous needle muscle biopsy was taken from the $\mathrm{m}$. vastus lateralis in both studies, directly frozen in melting isopentane, and stored at $-80 \mathrm{C}$. Muscle biopsies were 
available in eight and nine subjects from the low- and high-fat groups, respectively. Fresh cryosections $(5 \mu \mathrm{m})$ were stained for IMCL by Oil-Red-O as described before [41].

\section{Quantitative Real-Time PCRs}

Total RNA was isolated from $\sim 30 \mathrm{mg}$ of skeletal muscle tissue using Trizol reagent (Invitrogen, Breda, The Netherlands). The quantity and integrity of the RNA was confirmed with the Nanodrop Spectrophotometer (NanoDrop Technologies, Inc, Wilmington, DE, USA). cDNA was synthesized using the high capacity RNA-to-cDNA kit (Life Technologies, Bleiswijk, the Netherlands). Real Time qRT-PCR reactions were performed using the Taqman universal PCR master mix on a ABI PRISM 7900 (Applied Biosystems, Nieuwerkerk aan den IJssel, Netherlands) using the following protocol: $2 \mathrm{~min}$ at $50^{\circ} \mathrm{C}, 10 \mathrm{~min}$ at $95^{\circ} \mathrm{C}$, followed by $40 \mathrm{cycli}$ at $95^{\circ} \mathrm{C}$ of $15 \mathrm{sec}$ and $60^{\circ} \mathrm{C}$ for $1 \mathrm{~min}$. For all genes except for RPLPO, Taqman probes were included to ensure specificity. RPLPO mRNA expression was detected using SYBR green (Bio-Rad, Veenendaal, The Netherlands). RPLPO, which was tested for intra-individual variability, was used as internal control. All expression data were normalized by using the delta-Ct method to normalize the relative abundance of the target transcript against the internal reference. Primer- and probesequences are given in Supplemental Table 3.

\section{Western blots}

Western blots were performed in protein lysates from whole muscle homogenates. Muscle samples were homogenized in RIPA lysis buffer containing 1\% NP40, 0.5\% SDS, and phosphatase- and protease inhibitors, lysates were mixed 1:1 with Laemmli sample buffer and were further processed for standard SDS-PAGE and Western blotting. Protein concentration was determined and equal amounts of protein were loaded per lane. The nitrocellulose membranes were incubated with antibodies against PLIN2 (GP40; Progen Biotechnik, Heidelberg, Germany), PLIN3 (10694-1-AP; Acris Antibodies, Herford, Germany), PLIN5 (GP31; Progen Biotechnik, Heidelberg, Germany), ATGL (Cell Signalling Technology, Bioké, Leiden, The Netherlands), CGI-58 (Novus Biologicals, Littleton, Colorado, USA), and SR-actin as the loading control (A-2172; Sigma, St. Louis, USA). Secondary antibodies for PLIN2, PLIN5, ATGL and SR-actin contained a fluorescent tag (IRDye800- or IRDye700-conjugated secondary antibodies (Rockland, Tebu-bio, Heerhugowaard, The Netherlands, and LICOR Biosciences, Westburg, Leusden, The Netherlands)), Protein quantification was performed by scanning on an Odyssey Infrared Imaging system (LI-COR Biotechnology, Lincoln, Nebraska, USA). CGI-58 was detected using an HRP-conjugated antibody and ECL detection. Protein content was expressed as arbitrary units (AU).

\section{Statistical analyses}

Results are presented as mean \pm SEM. Statistical analyses were performed using SPSS version 16.0 for MacOS 16.0 (SPSS, Chicago, IL). Statistical comparisons between 


\section{Lipid content and PLIN expression upon fasting and high fat diet consumption}

conditions and changes upon experimental interventions were performed using paired Ttests. Pearson's correlation coefficients were used to describe the linear association between variables. $\mathrm{P}<0.05$ was considered statistically significant.

\section{RESULTS}

\section{Effects of prolonged fasting on the expression of perilipins and lipolytic enzymes} We have published before that the prolonged fasting resulted in a 2.7 -fold increase in $I M C L$ content and a $45 \%$ reduction in the insulin sensitivity $\left(S_{i}\right)$ index [38]. We here measured gene and protein expression of PLIN2, PLIN3, PLIN5, ATGL and CGI-58 in human skeletal muscle after the 60 hours fasting regimen. PLIN3 gene expression was significantly downregulated after fasting ( $P=0.003,28 \%$ decrease) (Fig. 1B). Gene expression levels of PLIN2 ( $\mathrm{P}=0.69)$, PLIN5 ( $\mathrm{P}=0.72)$, ATGL $(\mathrm{P}=0.15)$ and CGI-58 $(\mathrm{P}=0.73)$ did not significantly change (Fig. 1). Protein contents of PLIN2 ( $P=0.92)$, PLIN3 ( $P=0.95)$, PLIN5 ( $P=0.99), A T G L$ $(=0.84)$ and $\mathrm{CGI}-58(P=0.20)$ were unaltered after fasting (Fig. 2).

A

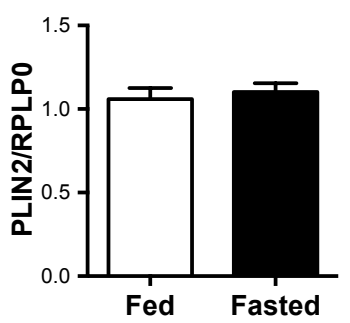

D

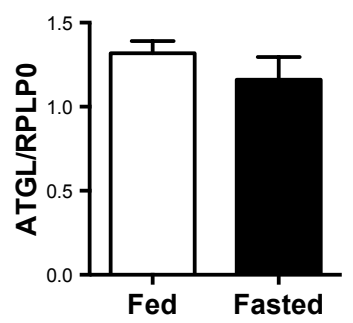

B

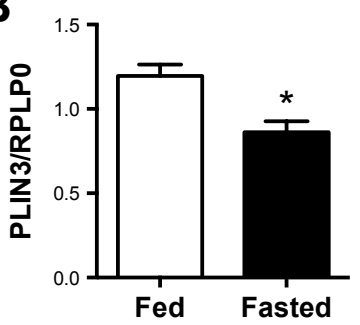

E

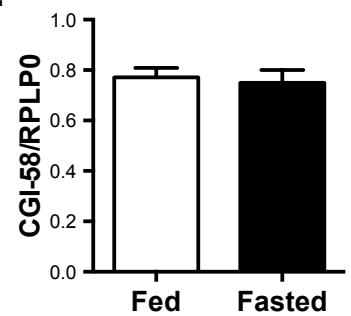

Figure 1. Gene expression levels of PLIN2 (A), PLIN3 (B), PLIN5 (C), ATGL (D) and CGI-58 (E) in the fed and the fasted state. Mean \pm SEM, $* P<0.05$.

We next investigated whether interindividual variation in the increase in IMCL upon fasting was associated with insulin resistance. Very interestingly, the change in IMCL upon fasting correlated positively with the change in insulin sensitivity (IS) ( $r=0.657, \mathrm{P}=0.039$ ) (Fig. 3A), indicating that increased intramyocellular lipid storage capacity is associated with lower fasting-induced insulin resistance. Upon fasting, the development of insulin 
resistance may function to spare glucose for utilization by the brain. Interestingly, both the change in IMCL and the change in IS upon fasting correlated negatively with plasma glucose levels after the fasting period ( $r=-0.720, \mathrm{P}=0.012$ and $r=-0.654, \mathrm{P}=0.029$, respectively) (Fig. 3B-C), implicating that a higher capacity for $\mathrm{IMCL}$ storage and the associated lower fasting-induced insulin resistance may in fact lead to a marked drop in plasma glucose levels upon fasting.

A

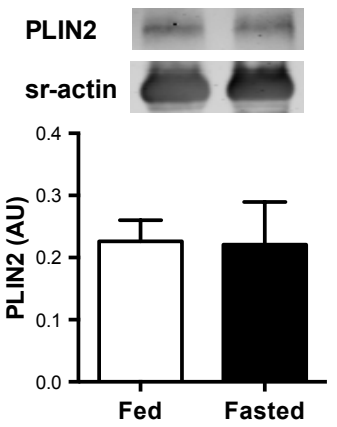

C

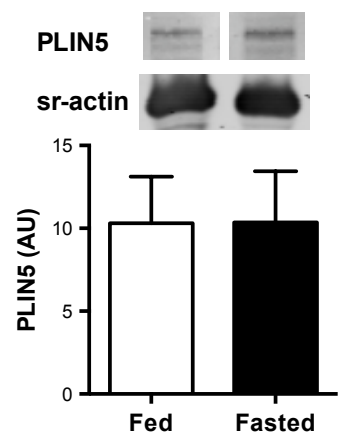

B PLIN3

sr-actin

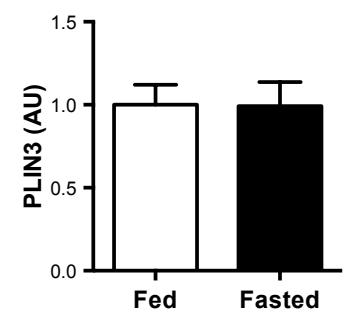

D

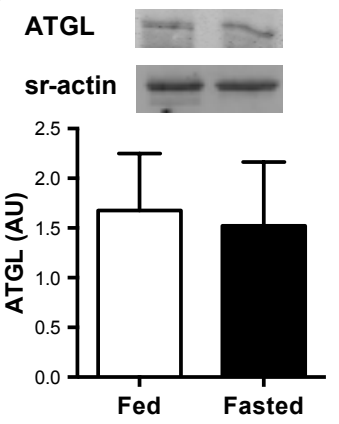

Figure 2. Protein content of PLIN2 (A), PLIN3 (B), PLIN5 (C), ATGL (D) and CGI-58 (E) in the fed and the fasted state. Error bars represent SEM.

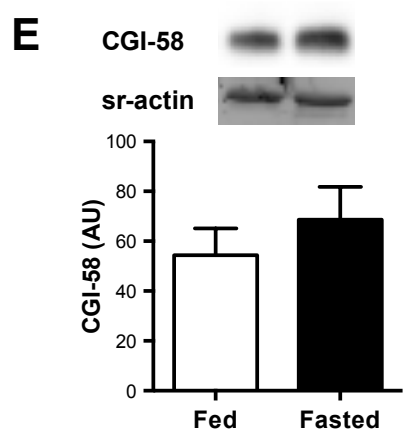

To explore potential explanations for interindividual variation in IMCL storage capacity and the protection against fasting-induced insulin resistance, we investigated correlations of the protein content of PLIN2, PLIN5, ATGL and CGI-58 with IMCL content and IS. Interestingly, PLIN2 protein content in the fed state showed a trend $(r=0.545, \mathrm{P}=0.10)$ for 


\section{Lipid content and PLIN expression upon fasting and high fat diet consumption}

positive correlation with the change in IMCL $(\triangle \mathrm{IMCL})$ upon fasting (Table 1$)$ and the postfasting IMCL level $(r=0.564, \mathrm{P}=0.071)$ (Table 1 and Fig. $4 \mathrm{~A}$ ). Moreover, the PLIN2 protein content after fasting correlated positively with both the post-fasting IMCL content $(r=0.732, \mathrm{P}=0.01)$ (Table 1$)$ and the change in IMCL content upon fasting $(r=0.628$, $\mathrm{P}=0.038)$ (Table 1). There was a tendency $(r=0.557, \mathrm{P}=0.094)$ for a positive correlation of the change in PLIN2 protein content with the increase in IMCL upon fasting (Table 1 and Fig. 4B). Furthermore, the change in PLIN2 protein content correlated positively with the IMCL level after fasting $(r=0.635, \mathrm{P}=0.036)$ (Table 1$)$.

A

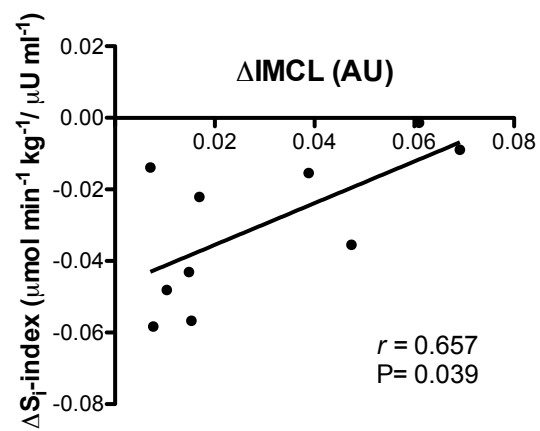

B

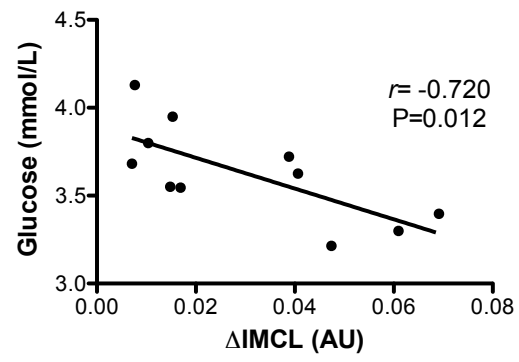

C

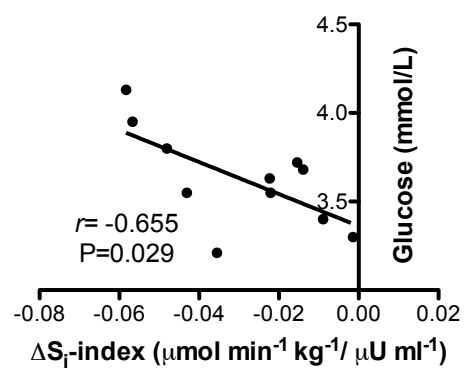

Figure 3. Correlations fasting study. (A) Correlation of the change in IMCL (fastingfed) with the change in $\mathrm{S}_{\mathrm{i}}$-index upon fasting $\quad\left(\Delta \mathrm{S}_{\mathrm{i}}\right.$-index=fasted-fed $)$. Correlation of the change in IMCL with the plasma glucose level after fasting. (C) Correlation of the change in the $\mathrm{S}_{\mathrm{i}}$-index with the plasma glucose level after fasting.

PLIN5 protein content after fasting correlated positively with post-fasting IMCL levels $(r=0.710, \mathrm{P}=0.022$ ) (Table 1 and Fig. $4 \mathrm{C}$ ) and the change in IMCL upon fasting ( $r=0.798$, $\mathrm{P}=0.010)$. PLIN5 ( $r=-0.679, \mathrm{P}=0.031)$ (Table 1$)$ and ATGL $(r=-0.689, \mathrm{P}=0.019)$ (Table 1 and 
Fig. 4D) protein content correlated negatively with IS in the fed state, whereas CGI-58 protein content showed a tendency for a positive correlation with IS ( $r=0.595, \mathrm{P}=0.054)$ (Table 1 and Fig. 4E).

Table 1. Correlations of the pre-, post- and delta protein expression of PLIN2, PLIN3, PLIN5, ATGL and CGI-58 with the pre-, post- and delta $\mathrm{S}_{\mathrm{i}}$-index and IMCL upon fasting. $r=$ Pearson correlation coefficient, $\mathrm{P}=\mathrm{P}$-value. The $\mathrm{S}_{\mathrm{i}}$-index is given in $\mu \mathrm{mol} \mathrm{min}^{-1} \mathrm{~kg}^{-1} / \mu \mathrm{U} \mathrm{ml}{ }^{-1}$. Correlations with $\mathrm{P}<0.10$ are highlighted in bold.

\begin{tabular}{|c|c|c|c|c|c|c|c|c|}
\hline & & & $\begin{array}{r}\text { Fed } \\
\text { IMCL (AU) }\end{array}$ & $\begin{array}{r}\text { Fed } \\
S_{\mathrm{i}} \text {-index }\end{array}$ & $\begin{array}{r}\text { Fasted } \\
\text { IMCL (AU) }\end{array}$ & $\begin{array}{r}\text { Fasted } \\
\mathrm{S}_{\mathrm{i}} \text {-index }\end{array}$ & $\begin{array}{r}\text { Delta } \\
\text { IMCL (AU) }\end{array}$ & $\begin{array}{r}\text { Delta } \\
\mathrm{S}_{\mathrm{i}} \text {-index }\end{array}$ \\
\hline \multirow[t]{10}{*}{ Fed } & PLIN2 & $r$ & 0.126 & -0.455 & 0.564 & -0.277 & 0.545 & 0.439 \\
\hline & & $P$ & 0.713 & 0.160 & 0.071 & 0.410 & 0.100 & 0.177 \\
\hline & PLIN3 & $r$ & -0.278 & -0.181 & -0.172 & -0.395 & -0.399 & -0.004 \\
\hline & & $P$ & 0.409 & 0.573 & 0.594 & 0.204 & 0.199 & 0.990 \\
\hline & PLIN5 & $r$ & 0.237 & -0.679 & 0.294 & -0.632 & 0.206 & 0.518 \\
\hline & & $\mathrm{P}$ & 0.511 & 0.031 & 0.410 & 0.050 & 0.568 & 0.125 \\
\hline & ATGL & $r$ & -0.059 & -0.689 & 0.105 & -0.764 & 0.17 & 0.449 \\
\hline & & $\mathrm{P}$ & 0.863 & 0.019 & 0.758 & 0.006 & 0.64 & 0.166 \\
\hline & CGI-58 & $r$ & -0.021 & 0.595 & -0.105 & 0.576 & -0.102 & -0.440 \\
\hline & & $\mathrm{P}$ & 0.951 & 0.054 & 0.759 & 0.064 & 0.778 & 0.176 \\
\hline \multirow[t]{10}{*}{ Fasted } & PLIN2 & $r$ & & & 0.732 & -0.157 & 0.628 & 0.376 \\
\hline & & $\mathrm{P}$ & & & 0.010 & 0.645 & 0.038 & 0.255 \\
\hline & PLIN3 & $r$ & & & -0.447 & -0.278 & -0.248 & 0.106 \\
\hline & & $\mathrm{P}$ & & & 0.168 & 0.382 & 0.489 & 0.743 \\
\hline & PLIN5 & $r$ & & & 0.710 & -0.373 & 0.798 & 0.557 \\
\hline & & $\mathrm{P}$ & & & 0.022 & 0.289 & 0.010 & 0.094 \\
\hline & ATGL & $r$ & & & 0.580 & 0.000 & 0.440 & 0.267 \\
\hline & & $\mathrm{P}$ & & & 0.061 & 0.999 & 0.203 & 0.427 \\
\hline & CGI-58 & $r$ & & & -0.211 & 0.333 & -0.145 & -0.287 \\
\hline & & $P$ & & & 0.534 & 0.317 & 0.690 & 0.392 \\
\hline \multirow[t]{10}{*}{ Delta } & PLIN2 & $r$ & & & 0.635 & -0.024 & 0.557 & 0.226 \\
\hline & & $\mathrm{P}$ & & & 0.036 & 0.944 & 0.094 & 0.504 \\
\hline & PLIN3 & $r$ & & & -0.154 & 0.082 & -0.014 & 0.128 \\
\hline & & $P$ & & & 0.650 & 0.799 & 0.969 & 0.692 \\
\hline & PLIN5 & $r$ & & & -0.143 & 0.332 & -0.013 & -0.125 \\
\hline & & $\mathrm{P}$ & & & 0.714 & 0.383 & 0.973 & 0.748 \\
\hline & ATGL & $r$ & & & 0.357 & 0.498 & 0.294 & -0.096 \\
\hline & & $P$ & & & 0.282 & 0.119 & 0.410 & 0.778 \\
\hline & CGI-58 & $r$ & & & -0.164 & -0.131 & -0.098 & 0.059 \\
\hline & & $P$ & & & 0.629 & 0.700 & 0.787 & 0.864 \\
\hline
\end{tabular}




\section{Lipid content and PLIN expression upon fasting and high fat diet consumption}

\section{High fat diet-induced changes in the expression of perilipins and proteins involved in lipolysis}

We next investigated the effect of another, more prolonged intervention characterized by lipid oversupply on the expression of the PLINs, ATGL and CGI-58. We previously published that consumption of a high fat diet (HFD) for 3 weeks resulted in a 1.55-fold increase in IMCL ( $P=0.043)$ without a significant effect on insulin sensitivity [40]. Here we evaluated the expression of several perilipins and lipolytic enzymes in the muscle biopsies from those subjects. CGI-58 gene expression was significantly downregulated ( $P=0.03$ ) (Fig. 5E). Gene expression levels of PLIN2 ( $\mathrm{P}=0.59)$, PLIN3 $(\mathrm{P}=0.14)$, PLIN5 $(\mathrm{P}=0.58)$ and ATGL $(P=0.34)$ were not significantly different after the diet intervention (Fig. 5). PLIN5 protein levels showed a tendency for upregulation after the HFD diet $(P=0.06)$. PLIN2, ATGL and CGI-58 protein contents did not show any significant differences $(P=0.74, P=0.48$, and $\mathrm{P}=0.21$, respectively) (Supplemental Fig. 1).

A

B

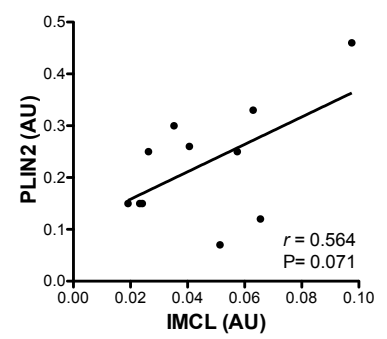

C

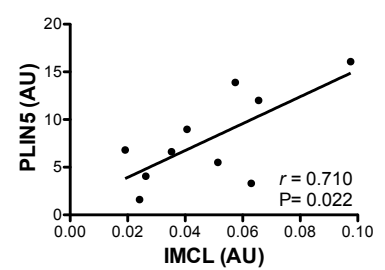

$\mathbf{E}$

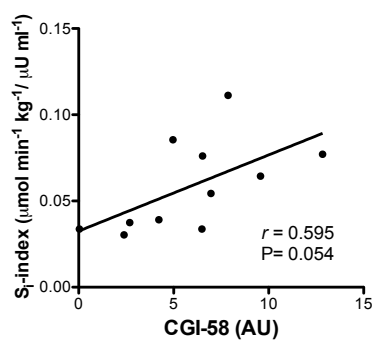

Figure 4. Correlations PLINs, ATGL and CGI-58 with IMCL and insulin sensitivity in the fasting study. (A) Correlation of PLIN2 in the fed state with IMCL in the fasted state. (B) Correlation of the change in PLIN2 with the change in IMCL (fasting-fed) upon fasting. (C) Correlation of PLIN5 with IMCL in the fasted state. (D) Correlation of ATGL with insulin sensitivity $\left(S_{i}{ }^{-}\right.$ index) in the fed state. (E) Correlation of CGI-58 with insulin sensitivity in the fed state. 
Correlations were computed to investigate whether changes in IMCL content and IS upon consumption of a HFD were associated with changes in protein expression of the abovementioned proteins (Table 2). PLIN2 protein content upon consumption of the HFD tended to correlate positively with the change in IMCL $(r=0.629, \mathrm{P}=0.069)$ (Table 2 and Supplemental Fig. 2). The change in PLIN5 protein content correlated negatively with the change in $\mathrm{S}_{\mathrm{i}}$-index $(r=-0.681, \mathrm{P}=0.043)$ (Table 2 and Supplemental Fig. 2). Moreover, in contrast with the effects of $60 \mathrm{~h}$ fasting, the change in IMCL levels upon 3 weeks consumption of a high fat did not correlate with changes in IS $(r=-0.229, \mathrm{P}=0.554)$.

A

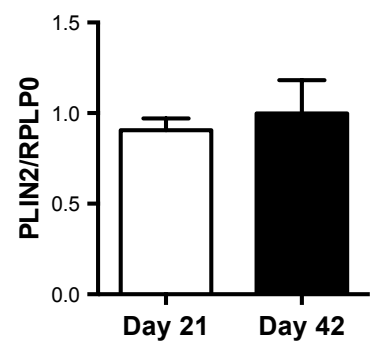

C

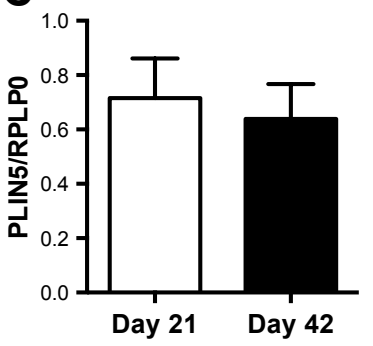

E

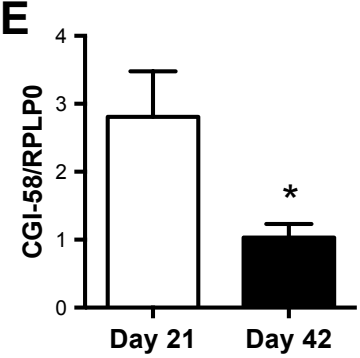

B

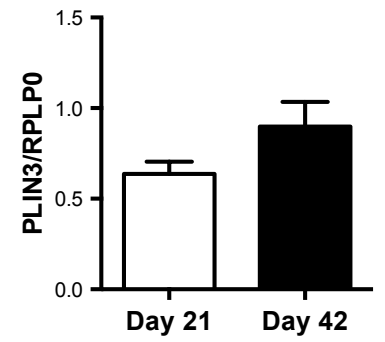

D

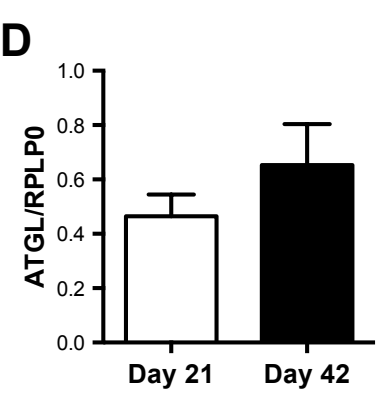

Figure 5. Gene expression levels of PLIN2 (A), PLIN3 (B), PLIN5 (C), ATGL (D) and CGI-58 (E) before and after consumption of a HFD for three weeks (day 21=after the run-in diet, day 42 is after 3 weeks HFD). Mean \pm SEM.

Table 2. Correlations of the change in protein expression (delta) of PLIN2, PLIN5, ATGL and CGI-58 with the delta $\mathrm{S}_{\mathrm{i}}$-index and $\mathrm{IMCL}$ upon consumption of a high fat diet for 3 weeks. $r=$ Pearson correlation coefficient, $\mathrm{P}=\mathrm{P}$-value. 


\begin{tabular}{|c|c|c|c|}
\hline & & $\begin{array}{r}\Delta \mathrm{IMCL} \\
(\mathrm{AU})\end{array}$ & $\begin{array}{r}\Delta S_{\mathrm{i}} \text {-index } \\
\left(\mu \mathrm{mol} \mathrm{min}{ }^{-1} \mathrm{~kg}^{-1} / \mu \mathrm{U} \mathrm{\textrm {ml } ^ { - 1 }}\right)\end{array}$ \\
\hline \multirow[t]{2}{*}{$\triangle$ PLIN2 } & $r$ & 0.629 & -0.028 \\
\hline & $\mathrm{P}$ & 0.069 & 0.943 \\
\hline \multirow[t]{2}{*}{$\Delta$ PLIN5 } & $r$ & 0.300 & -0.681 \\
\hline & $P$ & 0.433 & 0.043 \\
\hline \multirow[t]{2}{*}{$\Delta$ ATGL } & $r$ & 0.345 & -0.179 \\
\hline & $\mathrm{P}$ & 0.363 & 0.644 \\
\hline \multirow[t]{2}{*}{$\Delta \mathrm{CGI}-58$} & $r$ & 0.348 & -0.064 \\
\hline & $P$ & 0.359 & 0.870 \\
\hline
\end{tabular}

\section{DISCUSSION}

Prolonged fasting is associated with increased plasma FFA levels and augmented IMCL storage [38], and rapidly results in the development of insulin resistance [42]. We here show that subjects with a larger capacity to store lipids in intramyocellular LDs are less insulin resistant after fasting. Such a relation was not observed after a more chronic highfat diet intervention. Furthermore, we show that PLIN2 is a determinant of IMCL storage capacity. Our findings may indicate that especially under acute conditions, a high capacity to store IMCL may be protective against lipid-induced insulin resistance.

It has previously been shown that one bout of acute exercise protects against lipidinduced insulin resistance via an increased intramyocellular TAG storage capacity [25]. Our data are in harmony with those results. Jointly, these studies indicate that a high capacity to store IMCL blunts the acute development of lipid-induced insulin resistance upon acute exposure to high circulatory FAs. While maintaining insulin sensitivity in the face of high levels of fatty acids can be beneficial for post-exercise glycogen sensitivity, the physiological benefit upon fasting is less clear. During fasting, muscle insulin resistance serves to direct glucose to the brain. Hence, a blunted induction of insulin resistance may compromise glucose availability to the brain and is not necessarily considered beneficial. Likewise, both the IMCL storage capacity and the change in IS upon fasting correlated negatively with plasma glucose levels after fasting. Therefore, our results suggest that subjects with a larger capacity for IMCL storage remain relatively more insulin sensitive upon fasting and hence less effective in glucose sparing during fasting.

We next investigated whether the association of IMCL storage capacity and insulin sensitivity also exists in a model of prolonged lipid oversupply; consumption of a high fat diet for three weeks. However, in contrast to the fasting intervention, no correlation was found between IMCL storage and insulin sensitivity after the diet intervention. A main difference between the fasting intervention and the HFD intervention is the period of investigation: $60 \mathrm{~h}$ versus 3 weeks. In that context, the protective effect of TAG storage capacity on insulin sensitivity that was previously published was also found after a shortterm intervention (90 minutes of exercise) [25]. It is well possible that on the longer term increased lipid supply also leads to other adaptations, such as changes in fat oxidative 
capacity, that may mask the relation between TAG storage capacity and IS. Further mechanistic studies are needed to understand what determines IMCL storage capacity of skeletal muscle and how this is influenced by environmental conditions.

With respect to the determinants of IMCL storage capacity, LD coat proteins are increasingly recognized as important modulators of intracellular lipid metabolism. Interestingly, fasting downregulated gene expression of PLIN3, although this did not result in lower PLIN3 protein levels. In animal studies, PLIN3 gene expression remained unaltered upon fasting [31-33]. Furthermore, in contrast to the reported induction of ATGL, PLIN2 and PLIN5 upon fasting in animal studies [28, 29, 31-34], fasting for 60h did not induce expression of these lipid droplet coat proteins in human skeletal muscle, indicating that increasing circulatory FAs when energy balance is negative is not necessarily accompanied with induction of these genes/proteins. Our results demonstrate that species differences exist regarding skeletal muscle responses to fasting. In addition, our data indicate that even a substantial increase in muscle fat of 2.7-fold in the human skeletal muscle can occur without the necessity of increasing PLIN content. Consistently, also high-fat feeding resulted in an increase in IMCL without induction of PLIN2. Nevertheless, PLIN2 did correlate with IMCL upon fasting and tended to correlate with IMCL upon high fat feeding, indicating that a high PLIN2 availability is associated with increased IMCL content and that interindividual variation in PLIN2 might be one of the modulators of IMCL storage capacity. In accordance, we recently demonstrated that knockdown of PLIN2 prevented FA-induced intramyocellular TAG storage, indicating that the presence of PLIN2 is essential for intramyocellular TAG storage [30]. Interestingly, PLIN2 overexpression increased intramyocellular lipid accumulation while improving insulin sensitivity, indicating that PLIN2 facilitates neutral lipid storage which does not impair skeletal muscle insulin sensitivity [30].

ATGL protein levels in the fed state negatively correlated with IS, consistent with the paper of Badin et al. [36], in which a negative correlation of ATGL protein expression with the glucose disposal rate was reported in a mixed population of lean, obese and T2D subjects. This provides further support for the suggested importance of the lipolytic balance for skeletal muscle IS [43, 44]. In contrast, CGI-58 in the fed state tended to positively correlate with IS. PLIN5 is also involved in the regulation of lipolysis and modulates interactions of lipid droplets with mitochondria [11, 12, 14, 15, 21]. While PLIN5 was demonstrated to be upregulated upon fasting in mouse models [31, 33], Kuramoto et al. recently showed that PLIN5 is not required for fasting-induced IMCL storage in mice [45]. However, translating this mechanistic insight to the human situation should be done with care since species differences may exist regarding upregulation of PLIN5 upon fasting, as we show here. PLIN5 did not correlate with IS in either the fed or the fasted state. Moreover, PLIN5 correlated negatively with IS upon the HFD intervention in our group of obese sedentary subjects. In contrast, Amati et al., previously reported a positive correlation of PLIN5 with IS in a population with a wide range in BMI and physical fitness [35]. Clearly, further research is necessary to investigate the importance of skeletal muscle ATGL, CGI58 and PLIN5 expression levels for lipotoxicity and insulin sensitivity. 


\section{Lipid content and PLIN expression upon fasting and high fat diet consumption}

In summary, we here show that in contrast to mouse studies, PLIN expression is not induced upon prolonged fasting in human skeletal muscle. Furthermore, we show that subjects with a larger capacity to store lipids in intramyocellular LDs are less insulin resistant after fasting. This phenomenon was not apparent upon high lipid availability on the longer term. Furthermore, PLIN2 expression was associated with IMCL content. These data suggest that under acute conditions of high lipid availability an increased capacity to store fat in muscle protects against insulin resistance, and that PLIN2 may be an important determinant herein.

\section{REFERENCES}

1. Goodpaster BH, Theriault R, Watkins SC, and Kelley DE. Intramuscular lipid content is increased in obesity and decreased by weight loss. Metabolism 2000; 49: 467-472.

2. Tauchi-Sato K, Ozeki S, Houjou T, Taguchi R, and Fujimoto T. The surface of lipid droplets is a phospholipid monolayer with a unique fatty acid composition. J Biol Chem 2002; 277: 44507-44512.

3. Beller M, Thiel K, Thul PJ, and Jäckle H. Lipid droplets: A dynamic organelle moves into focus. FEBS Lett. 2010; 584: 2176-82.

4. Walther TC and Farese Jr RV. The life of lipid droplets. Biochim Biophys Acta 2009; 1791: 459-66.

5. Wolins NE, Brasaemle DL, and Bickel PE. A proposed model of fat packaging by exchangeable lipid droplet proteins. FEBS Lett 2006; 580: 5484-91.

6. Zimmermann R, Strauss JG, Haemmerle G, Schoiswohl G, Birner-Gruenberger R, Riederer M, Lass A, Neuberger G, Eisenhaber F, Hermetter A, and Zechner R. Fat mobilization in adipose tissue is promoted by adipose triglyceride lipase. Science 2004; 306: 1383-1386.

7. Lass A, Zimmermann R, Haemmerle G, Riederer M, Schoiswohl G, Schweiger M, Kienesberger P, Strauss JG, Gorkiewicz G, and Zechner R. Adipose triglyceride lipase-mediated lipolysis of cellular fat stores is activated by CGI-58 and defective in Chanarin-Dorfman Syndrome. Cell Metab 2006; 3: 309-319.

8. Yang X, Lu X, Lombès M, Rha GB, Chi Y-I, Guerin TM, Smart EJ, and Liu J. The G0/G1 switch gene 2 regulates adipose lipolysis through association with adipose triglyceride lipase. Cell Metab 2010; 11: 194-205.

9. Gandotra S, Lim K, Girousse A, Saudek V, O'Rahilly S, and Savage DB. Human frame shift mutations affecting the carboxyl terminus of perilipin increase lipolysis by failing to sequester the adipose triglyceride lipase (ATGL) coactivator AB-hydrolase-containing 5 (ABHD5). J Biol Chem 2011; 286: 34998-35006.

10. Granneman JG, Moore HPH, Krishnamoorthy R, and Rathod M. Perilipin controls lipolysis by regulating the interactions of AB-hydrolase containing 5 (Abhd5) and adipose triglyceride lipase (Atgl). J Biol Chem 2009; 284: 34538-34544.

11. Granneman JG, Moore HPH, Mottillo EP, Zhu Z, and Zhou L. Interactions of perilipin-5 (PLIN5) with adipose trigylceride lipase (ATGL). J Biol Chem 2011; 286: 5126-5135.

12. Granneman JG, Moore HP, Mottillo EP, and Zhu Z. Functional interactions between MLDP (LSDP5) and ABHD5 in the control of intracellular lipid accumulation. J Biol Chem 2009; 284: 3049-57.

13. Listenberger LL, Ostermeyer-Fay AG, Goldberg EB, Brown WJ, and Brown DA. Adipocyte differentiationrelated protein reduces the lipid droplet association of adipose triglyceride lipase and slows triacylglycerol turnover. J Lipid Res 2007; 48: 2751-2761.

14. Wang H, Bell M, Sreenevasan U, Hu H, Liu J, Dalen K, Londos C, Yamaguchi T, Rizzo MA, Coleman R, Gong D, Brasaemle D, and Sztalryd C. Unique regulation of adipose triglyceride lipase (ATGL) by perilipin 5, a lipid droplet-associated protein. J Biol Chem 2011; 286: 15707-15.

15. Bosma M, Minnaard R, Sparks LM, Schaart G, Losen M, De Baets MH, Duimel H, Kersten S, Bickel PE, Schrauwen $P$, and Hesselink MKC. The lipid droplet coat protein perilipin 5 also localizes to muscle mitochondria. Histochem. Cell Biol. 2012; 137: 205-216. 
16. Minnaard R, Schrauwen P, Schaart G, Jorgensen JA, Lenaers E, Mensink M, and Hesselink MKC. Adipocyte differentiation-related protein and OXPAT in rat and human skeletal muscle: involvement in lipid accumulation and type 2 diabetes mellitus. J Clin Endocrinol Metab 2009; 94: 4077-85.

17. Phillips SA, Choe CC, Ciaraldi TP, Greenberg AS, Kong AP, Baxi SC, Christiansen L, Mudaliar SR, and Henry RR. Adipocyte differentiation-related protein in human skeletal muscle: relationship to insulin sensitivity. Obes Res 2005; 13: 1321-9.

18. Shaw C, Sherlock M, Stewart P, and Wagenmakers A. Adipophilin distribution and colocalisation with lipid droplets in skeletal muscle. Histochem Cell Biol 2009; 131: 575-581.

19. Sapiro JM, Mashek MT, Greenberg AS, and Mashek DG. Hepatic triacylglycerol hydrolysis regulates PPAR- $\alpha$ activity. J Lipid Res 2009; 50: 1621-9.

20. Bulankina AV, Deggerich A, Wenzel D, Mutenda K, Wittmann JG, Rudolph MG, Burger KNJ, and Honing S. TIP47 functions in the biogenesis of lipid droplets. J Cell Biol 2009; 185: 641-655.

21. Wang H, Sreenevasan U, Hu H, Saladino A, Polster BM, Lund LM, Gong D-W, Stanley WC, and Sztalryd C. Perilipin 5, a lipid droplet associated protein, provides physical and metabolic linkage to mitochondria. J Lipid Res 2011; 52: 2159-2168.

22. Aguer C, Mercier J, Yong Wai Man C, Metz L, Bordenave S, Lambert K, Jean E, Lantier L, Bounoua L, Brun J, Raynaud de Mauverger E, Andreelli F, Foretz M, and Kitzmann M. Intramyocellular lipid accumulation is associated with permanent relocation ex vivo and in vitro of fatty acid translocase (FAT)/CD36 in obese patients. Diabetologia 2010; 53: 1151-1163.

23. Pan DA, Lillioja S, Kriketos AD, Milner MR, Baur LA, Bogardus C, Jenkins AB, and Storlien LH. Skeletal muscle triglyceride levels are inversely related to insulin action. Diabetes 1997; 46: 983-8.

24. Bosma M, Kersten S, Hesselink MKC, and Schrauwen P. Re-evaluating lipotoxic triggers in skeletal muscle: Relating intramyocellular lipid metabolism to insulin sensitivity. Prog Lipid Res 2012; 51: 36-49.

25. Schenk S and Horowitz JF. Acute exercise increases triglyceride synthesis in skeletal muscle and prevents fatty acid- induced insulin resistance. J Clin Invest 2007; 117: 1690-1698.

26. Liu L, Shi X, Choi CS, Shulman GI, Klaus K, Nair KS, Schwartz GJ, Zhang Y, Goldberg IJ, and Yu YH. Paradoxical coupling of triglyceride synthesis and fatty acid oxidation in skeletal muscle overexpressing DGAT1. Diabetes 2009; 58: 2516-2524.

27. Timmers S, de Vogel-van den Bosch J, Hesselink MKC, van Beurden D, Schaart G, Ferraz MJ, Losen M, Martinez-Martinez P, De Baets MH, Aerts JMFG, and Schrauwen P. Paradoxical increase in TAG and DAG content parallel the insulin sensitizing effect of unilateral DGAT1 overexpression in rat skeletal muscle. PLoS ONE 2011; 6: e14503.

28. Bertile F and Raclot T. ATGL and HSL are not coordinately regulated in response to fuel partitioning in fasted rats. J Nutr Biochem 2011; 22: 372-379.

29. Sanchez J, Palou A, and Pic $\tilde{A}^{3}$ C. Response to carbohydrate and fat refeeding in the expression of genes involved in nutrient partitioning and metabolism: striking effects on fibroblast growth factor-21 induction. Endocrinology 2009; 150: 5341-5350.

30. Bosma M, Hesselink MKC, Sparks LM, Timmers S, Ferraz MJ, Mattijssen F, van Beurden D, Schaart G, de Baets $\mathrm{MH}$, Verheyen FK, Kersten S, and Schrauwen P. Perilipin 2 improves insulin sensitivity in skeletal muscle despite elevated intramuscular lipid levels. Diabetes 2012; 61: 2679-2690.

31. Dalen KT, Dahl T, Holter E, Arntsen B, Londos C, Sztalryd C, and Nebb HI. LSDP5 is a PAT protein specifically expressed in fatty acid oxidizing tissues. Biochim Biophys Acta 2007; 1771: 210-27.

32. Dalen KT, Ulven SM, Arntsen BM, Solaas K, and Nebb HI. PPARalpha activators and fasting induce the expression of adipose differentiation-related protein in liver. J Lipid Res 2006; 47: 931-43.

33. Wolins NE, Quaynor BK, Skinner JR, Tzekov A, Croce MA, Gropler MC, Varma V, Yao-Borengasser A, Rasouli $\mathrm{N}$, Kern PA, Finck BN, and Bickel PE. OXPAT/PAT-1 is a PPAR-induced lipid droplet protein that promotes fatty acid utilization. Diabetes 2006; 55: 3418-28.

34. Yamaguchi T, Matsushita S, Motojima K, Hirose F, and Osumi T. MLDP, a novel PAT family protein localized to lipid droplets and enriched in the heart, is regulated by peroxisome proliferator-activated receptor $\alpha$. J Biol Chem 2006; 281: 14232-40.

35. Amati F, Dube JJ, Alvarez-Carnero E, Edreira MM, Chomentowski P, Coen PM, Switzer GE, Bickel PE, Stefanovic-Racic M, Toledo FGS, and Goodpaster BH. Skeletal muscle triglycerides, diacylglycerols, and 


\section{Lipid content and PLIN expression upon fasting and high fat diet consumption}

ceramides in insulin resistance: another paradox in endurance-trained athletes? Diabetes 2011; 60: 25882597.

36. Badin P-M, Louche K, Mairal A, Liebisch G, Schmitz G, Rustan AC, Smith SR, Langin D, and Moro C. Altered skeletal muscle lipase expression and activity contribute to insulin resistance in humans. Diabetes 2011; 60: 1734-42.

37. Li M, Paran C, Wolins NE, and Horowitz JF. High muscle lipid content in obesity is not due to enhanced activation of key triglyceride esterification enzymes or to the suppression of lipolytic proteins. Am J Physiol Endocrinol Metab 2011; 300: E699-707.

38. Hoeks J, van Herpen NA, Mensink M, Moonen-Kornips E, van Beurden D, Hesselink MKC, and Schrauwen P. Prolonged fasting identifies skeletal muscle mitochondrial dysfunction as consequence rather than cause of human insulin resistance. Diabetes 2010; 59: 2117-2125.

39. Schrauwen $P$, van Marken Lichtenbelt W, Saris W, and Westerterp K. Changes in fat oxidation in response to a high-fat diet. Am J Clin Nutr 1997; 66: 276-282.

40. Van Herpen NA, Schrauwen-Hinderling VB, Schaart G, Mensink RP, and Schrauwen P. Three weeks on a high-fat diet increases intrahepatic lipid accumulation and decreases metabolic flexibility in healthy overweight men. J Clin Endocrinol Metab 2011; 96: E691-E695.

41. Koopman R, Schaart G, and Hesselink M. Optimisation of oil red O staining permits combination with immunofluorescence and automated quantification of lipids. Histochem Cell Biol 2001; 116: 63-68.

42. Roden M. How free fatty acids inhibit glucose utilization in human skeletal muscle. News Physiol Sci 2004; 19: 92-96.

43. Badin P-M, Loubiere C, Coonen M, Louche K, Tavernier G, Bourlier V, Mairal A, Rustan AC, Smith SR, Langin D, and Moro C. Regulation of skeletal muscle lipolysis and oxidative metabolism by the co-lipase CGI-58. J Lipid Res 2012; 53: 839-848.

44. Meex RCR, Schrauwen P, and Hesselink MKC. The modulation of myocellular fat stores; lipid droplet dynamics in health and disease. Am J Physiol Regul Integr Comp Physiol 2009; 91053.2008.

45. Kuramoto K, Okamura T, Yamaguchi T, Nakamura TY, Wakabayashi S, Morinaga H, Nomura M, Yanase T, Otsu K, Usuda N, Matsumura S, Inoue K, Fushiki T, Kojima Y, Hashimoto T, Sakai F, Hirose F, and Osumi T. Perilipin 5, a lipid droplet-binding protein, protects the heart from oxidative burden by sequestering fatty acid from excessive oxidation. J Biol Chem 2012; 287: 23852-63. 


\section{SUPPLEMENTAL INFORMATION}

Supplemental Table 1. Subject characteristics fasting study.

\begin{tabular}{lc}
\hline Parameter & Mean \pm SEM \\
\hline Age (years) & $23.6 \pm 1.0$ \\
Body weight $(\mathrm{kg})$ & $78.5 \pm 2.5$ \\
Fat-free mass $(\mathrm{kg})$ & $65.9 \pm 1.8$ \\
Height $(\mathrm{m})$ & $1.86 \pm 0.02$ \\
$\mathrm{BMI}\left(\mathrm{kg} / \mathrm{m}^{2}\right)$ & $22.6 \pm 0.5$ \\
$\mathrm{VO}_{2} \mathrm{max}(\mathrm{ml} \mathrm{O} / \mathrm{kg} \mathrm{FFM} / \mathrm{min})$ & $57.5 \pm 1.5$ \\
\hline
\end{tabular}

Supplemental Table 2. Subject characteristics high fat diet intervention.

\begin{tabular}{lc}
\hline Parameter & Mean \pm SEM \\
\hline Age (years) & $56.4 \pm 2.5$ \\
Body weight $(\mathrm{kg})$ & $91.3 \pm 1.8$ \\
Fat-free mass $(\mathrm{kg})$ & $65.9 \pm 1.9$ \\
$\mathrm{Height}(\mathrm{m})$ & $1.80 \pm 0.02$ \\
$\mathrm{BMI}\left(\mathrm{kg} / \mathrm{m}^{2}\right)$ & $28.3 \pm 0.5$ \\
$\mathrm{VO}_{2} \mathrm{max}(\mathrm{ml} \mathrm{O} / \mathrm{kg} \mathrm{FFM} / \mathrm{min})$ & $46.6 \pm 2.4$ \\
\hline
\end{tabular}

Supplemental Table 3. Primersequences.

\begin{tabular}{llll}
\hline Gene & Forward & Reverse & Probe \\
\hline PLIN2 & GCATTGGATATGATGATACTGATGAGTC & GCGGGCAATtGCAAGAGT & CCACTGTGCTGAGCACATTGAGTCACGT \\
(ADRP) & & & \\
PLIN3 & AGCACCCAGGTGACAGTGG & CATGCTGGCCACACGGT & CACACTGGGCTGCTGTACCGGTTCTT \\
(TIP47) & & & \\
PLIN5 & GAGCCATGCTGTGGATGTTGTA & CAGTGCCGCGAGCTCTTC & TGGATCACTTCCTGCCCATGACGG \\
(OXPAT) & & & \\
ABHD5 & GGAGAGAGGTCAGGATGGCTAA & AACATCTTCTCTTCAGCTTCTTTAAGG & CTCCCCACATGGTGCCCTACGTCTATATC \\
(CGI-58) & & & \\
PNPLA2 & CCACGGCGCTGGTCA & GGGCCTCTTTAGATACCTCAATGA & TTGGCACCAGCCTCACCCAGG \\
(ATGL) & & & \\
RPLP0 & CCATTCTATCATCAACGGGTACAA & AGCAAGTGGGAAGGTGTAATCC & \\
\hline
\end{tabular}


Lipid content and PLIN expression upon fasting and high fat diet consumption

A

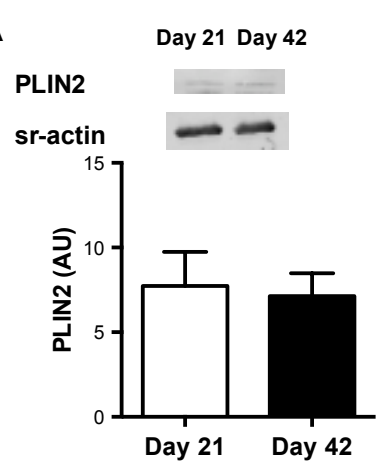

C

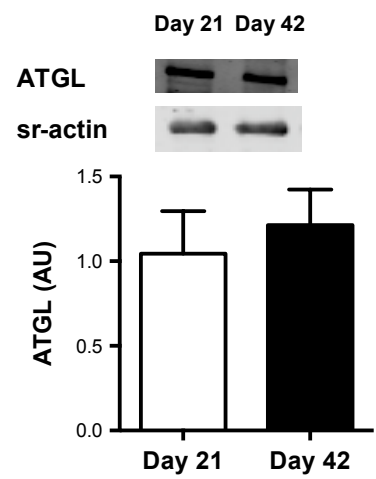

B

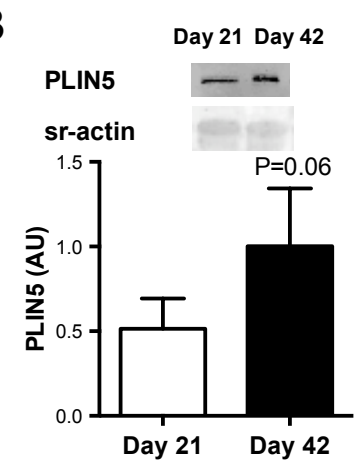

D
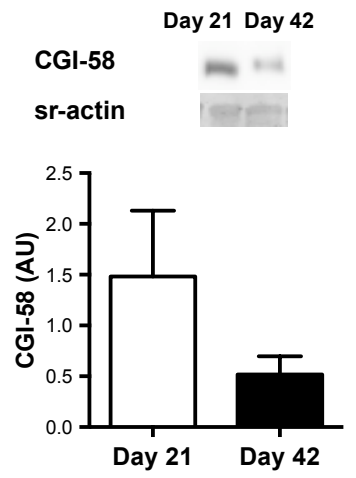

Supplemental Figure 1 . Protein content of PLIN2 (A), PLIN5 (B), ATGL (C), CGI-58 (D) before and after 3 weeks HFD (day 21=after the run-in diet, day 42 is after 3 weeks HFD). Error bars represent SEM. 
A

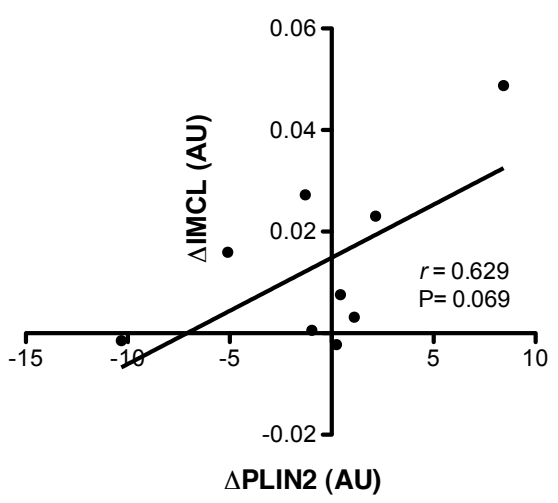

B

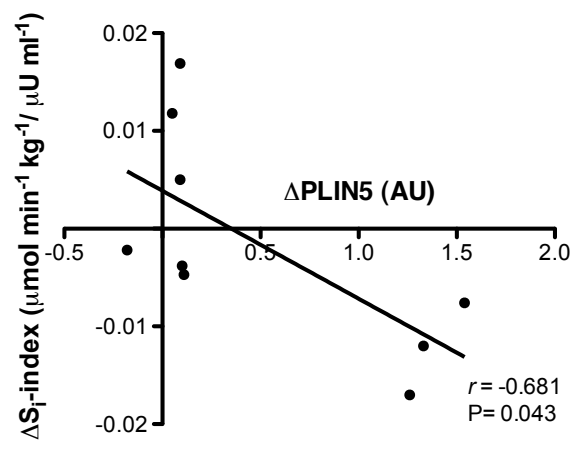

Supplemental Figure 2. Correlations HFD intervention. (A) Correlation of the change in PLIN2 protein content after the HFD intervention with the change in IMCL. (B) Correlation of the change in PLIN5 protein content upon consumption of the HFD with the change in the $\mathrm{S}_{\mathrm{i}}$-index. 


\section{CHAPTER 4}

\section{Reduced incorporation of fatty acids into triacylglycerol in myotubes established from obese individuals with type 2 diabetes}

Madeleen Bosma, Lauren M. Sparks, Lena Bilet, Bram Brouwers, Tineke van de Weijer, Gert Schaart, Esther Kornips, Matthijs K.C. Hesselink, Patrick Schrauwen

In preparation 


\section{ABSTRACT}

Type 2 diabetes (T2D) is characterized by increased intramuscular lipid (IMCL) content and disordered skeletal muscle lipid metabolism. Here we investigated skeletal muscle lipid turnover in T2D versus BMI-matched controls and examined if putative differences would be preserved in myotubes of individuals with T2D.

Male obese T2D individuals (T2D) $(n=6)$ and their age- and BMI-matched controls (C) $(n=6)$ underwent a hyperinsulinemic-euglycemic clamp, $\mathrm{VO}_{2} \mathrm{max}$ test, DXA scan and muscle biopsy of $v$. lateralis. Satellite cells were isolated. Myocytes were established and differentiated towards myotubes. IMCL content, ex vivo and in vitro ${ }^{14} \mathrm{C}$-palmitate oxidation ( ${ }^{14} \mathrm{CO}_{2}$ production) and incorporation of ${ }^{14} \mathrm{C}$-palmitate into lipids were measured in muscle biopsies and primary myotubes.

Intramuscular lipid content was similar between the two groups $(4.0 \pm 0.7 \%$ vs. $3.9 \pm 1.1 \%$ for $C$ vs. T2D, $P=0.97$ ). Palmitate oxidation (C: $0.99 \pm 0.17, T 2 D: 0.53 \pm 0.07 \mathrm{nmol} / \mathrm{mg}$ protein, $\mathrm{P}=0.03$ ) and incorporation into triacylglycerol (TAG) (C: $0.45 \pm 0.13, T 2 \mathrm{D}: 0.11 \pm$ $0.02 \mathrm{nmol} / \mathrm{mg}$ protein, $\mathrm{P}=0.047$ ) in muscle homogenates were significantly reduced in T2Ds vs. obese controls. Basal IMCL content $(0.007 \pm 0.001 \mu \mathrm{g} / \mathrm{mg}$ protein for $\mathrm{C}, 0.012 \pm$ $0.002 \mu \mathrm{g} / \mathrm{mg}$ protein for T2Ds, $\mathrm{P}=0.076$ ) tended to be higher in $\mathrm{T} 2 \mathrm{D}$ myotubes and was significantly associated with lower insulin sensitivity and higher fasting glucose; however, there was no difference in ${ }^{14} \mathrm{C}$-palmitate uptake in the myotubes $(3.15 \pm 0.41$ vs. $3.30 \pm$ 0.64 , for $C$ and $T 2 D$, respectively, $P=0.85$ ). Fatty acid oxidation in primary myotubes was not different between the groups, but incorporation of palmitate into TAG tended to be lower in the T2Ds and significantly corresponded with the ex vivo TAG incorporation $(r=0.848, \mathrm{P}=0.008)$. Furthermore, incorporation of ${ }^{14} \mathrm{C}$-oleate into TAG after 24 hours was significantly lower in myotubes from T2D patients compared with obese controls $(2.24 \pm$ 0.47 and $0.94 \pm 0.25 \mathrm{nmol} / \mathrm{mg}$ protein for $\mathrm{C}$ and $T 2 \mathrm{D}$, respectively, $\mathrm{P}=0.03)$. Our data indicate that the ability to incorporate fatty acids into TAGs might be an inherent feature of these muscle cells. Future studies should investigate the inherent pathways in muscle lipid turnover in order to identify the critical regulation sites. 


\section{INTRODUCTION}

Perturbations in lipid metabolism are associated with insulin resistance and type 2 diabetes (T2D) [1]. It has been proposed that an increased lipid supply, increased fatty acid uptake, altered lipid partitioning and a reduced capacity for skeletal muscle fat oxidation could contribute to intramyocellular lipid (IMCL) accumulation, lipotoxicity and insulin resistance (reviewed in [2-4]). However, whether these are inherited characteristics of T2D, or simply the consequence of altered lifestyle and obesity, remains an ongoing debate. In that context, studies in human primary myotubes are of interest, as cell autonomous models are devoid of direct environmental influences. Hulver et al. [5] demonstrated that myotubes of severely obese individuals retained an abnormal lipid partitioning (i.e. elevated triacylglycerol to blunted fatty acid oxidation ratio; TAG/FAO) [5]. Furthermore, Aguer et al. [6] showed increased IMCL content in muscle tissue, as well as in myotubes established from obese T2D subjects compared to obese nondiabetic controls, indicating that increased IMCL content is preserved in vitro. Alternatively, elevated fatty acid (FA) uptake could also contribute to the increased IMCL observed in obesity and T2D. Some studies show no difference in uptake of FA $[7,8]$, while others show increased FA uptake in skeletal muscle of obese and T2D individuals [9]. Likewise, studies in primary human myotubes also showed inconsistent results $[6,10,11]$. Taken together, it is still unclear whether disturbances that exist in skeletal muscle tissue lipid metabolism of T2D subjects are preserved in the myotubes.

As aberrant lipid metabolism is a central feature of obesity and T2D, the goal of the present study was to investigate whether disturbances exist in intramyocellular FA metabolism in skeletal muscle of obese T2D individuals compared to BMI- and agematched normoglycemic controls and to examine whether disturbances in lipid metabolism are retained in vitro in the myotubes established from these donors. Our study is a unique combination of ex vivo and in vitro analyses of lipid metabolism in human skeletal muscle, coupled with detailed in vivo clinical phenotyping to assess insulin sensitivity, aerobic capacity and substrate oxidation. We measured ex vivo FA metabolism in skeletal muscle tissue and established primary myotubes from these donors for in vitro studies. The myotubes were used to investigate lipid turnover (FA uptake, oxidation and storage) using two different long chain FAs. The in vitro characteristics were correlated with characteristics measured in vivo and ex vivo in the tissue. We show that FA incorporation into triacylglycerol (TAG) is impaired in T2D muscle and in myotubes established from these T2D donors, indicating that this perturbation is inherent to the T2D muscle cell. 


\section{METHODS}

\section{Subjects}

Six obese type 2 diabetic male subjects and six BMI- and age-matched male control subjects participated. Clinical characteristics are presented in Table 1. Subjects with cardiovascular disease, (genetic) diseases that are associated with altered lipid profiles, or subjects that lost $>3 \mathrm{~kg}$ body weight during the preceding 6 months were excluded from participation. Subjects with type 2 diabetes were diagnosed at least 1 year prior to beginning the study, were non-insulin dependent, had well-controlled diabetes $(\mathrm{HbA} 1 \mathrm{c}<7.8 \%)$ and no diabetes-related co-morbidities. Medication use was stable for at least 6 months. All type 2 diabetic patients were on metformin, two diabetics were also taking sulfonylurea. In addition, three diabetics were on statins and blood pressurelowering medication. Obese control subjects had no family history of diabetes and did not take any medication. The study was approved by the Medical Ethical Committee of Maastricht University Medical Centre, and all subjects gave written informed consent before participating in the study. All subjects performed a maximal aerobic capacity test $\left(\mathrm{VO}_{2} \mathrm{max}\right)$ as described previously [12]. Body composition was determined using hydrostatic weighing [13].

\section{Hyperinsulinemic-euglycemic clamp}

To measure peripheral insulin sensitivity, a two-step hyperinsulinemic-euglycemic clamp was performed. Patients were provided with a standardized meal, the day prior to the clamp and muscle biopsy. Also patients were refrained from their oral anti-diabetic medication for at least 1 week. After an overnight fast, a blood sample was drawn to measure glucose, insulin and free fatty acids (FFAs). Subsequently, step 1 was started; insulin was infused at a rate of $10 \mathrm{mU} / \mathrm{m}^{2} / \mathrm{min}$ for $4 \mathrm{~h}$ with variable co-infusion of $20 \%$ glucose (as a measure for liver insulin sensitivity). Subsequently, step 2 consisted of a $2 \mathrm{~h}$ insulin infusion at a rate of $40 \mathrm{mU} / \mathrm{m}^{2} / \mathrm{min}$ (and $20 \%$ variable glucose), this served as the measure for skeletal muscle insulin sensitivity because hepatic glucose production is almost totally inhibited. The M-value was calculated as the glucose infusion rate and corrected for lean body mass ( $\mu \mathrm{mol} / \mathrm{kg} / \mathrm{min}$ ).

\section{Muscle biopsy}

Muscle biopsies were taken from the vastus lateralis under local anesthesia ( $2 \%$ lidocaine) according to the Bergström technique [14] and processed for ex vivo assays performed the same day. The remainder was snap-frozen and stored at $-80^{\circ} \mathrm{C}$ for future analyses.

\section{Primary muscle cell cultures}

Primary skeletal muscle cell cultures were established as previously described [15]. Briefly, satellite cells (quiescent mononuclear muscle cells) were isolated by trypsin-collagenase digestion, pre-plated to remove fibroblasts and transferred to T-25 collagen-coated flasks in Dulbecco's Minimum Essential Medium (DMEM) (Invitrogen, Breda, The Netherlands) 
supplemented with $16 \%$ Fetal Bovine Serum (FBS) and human growth factors. Cells were grown at $37^{\circ} \mathrm{C}$ in a humidified atmosphere of $5 \% \mathrm{CO}_{2}$. Differentiation was initiated at approximately $90 \%$ confluence by switching to $\alpha$-MEM with $2 \%$ FBS and antibiotics and continued for 7 days. Media was changed every other day.

\section{Oil-red-O staining}

Fresh muscle cryosections $(5 \mu \mathrm{m})$ were stained for IMCL by Oil-Red-O as described previously [16] and expressed per cell surface area. Fully differentiated myotubes were fixed with $3.7 \%$ (vol/vol) formaldehyde in PBS for $20 \mathrm{~min}$. Thereafter, slides were incubated in $0.3 \%$ (wt/vol) Oil Red $\mathrm{O}$ in $60 \%$ (vol/vol) triethylphosphate for $30 \mathrm{~min}$. Subsequently, slides were mounted using mowiol. DAPI was included with the mowiol to allow visualization of nuclei. Slides were examined using a Nikon E800 fluorescence microscope (Uvikon). Digital images were captured and processed using Lucia G/F 5.49 image analysis software (Nikon).

\section{${ }^{14} \mathrm{C}$-labeled ex vivo palmitate oxidation and lipid incorporation}

Palmitate oxidation was determined by measuring production of ${ }^{14} \mathrm{CO}_{2}$ (complete oxidation) in skeletal muscle homogenates as previously described [17]. Briefly, v. lateralis muscle samples ( $70 \mathrm{mg}$ ) were placed in $1.5 \mathrm{~mL}$ of fresh ice-cold homogenization buffer containing (in mM) 250 sucrose, 10 Tris-HCl, 1 EDTA and 2 ATP, pH 7.4. Samples were thoroughly minced with surgical scissors and transferred to a $2 \mathrm{~mL}$ glass homogenization vessel. Muscle suspensions were homogenized on ice with a Teflon pestle at 10 passes across 30 seconds at $1200 \mathrm{rpm}$. This method does not affect mitochondrial morphology and function [18]. Subsequently, the muscle homogenates were plated in triplicate into a modified 48-well trapping device [19]. A small groove was engineered between adjacent wells so that $\mathrm{CO}_{2}$ could freely diffuse between the incubation and trap wells. Reactions were started with the addition of reaction media yielding final concentrations (in $\mathrm{mM}$ ) of 0.2 palmitate and $0.0175\left[1-{ }^{14} \mathrm{C}\right]$-palmitate and 125 sucrose, 20 Tris- $\mathrm{HCL}, 25 \mathrm{KH}_{2} \mathrm{PO}_{4}, 200$ $\mathrm{KCL}, 2.5 \mathrm{MgCl}, 0.25$ malate, $4 \mathrm{ATP}, 2.5 \mathrm{DTT}, 2.5$ carnitine, 0.125 coenzyme A, $0.25 \mathrm{NAD}+$ Trapping devices were sealed with a siliconized rubber gasket and incubated at $37^{\circ} \mathrm{C}$. After two hours, reactions were terminated in the sealed reaction plates by the addition of $70 \%$ perchloric acid to the incubation wells. Perchloric acid also results in precipitation of remaining FAs in the media. The trapping device was transferred to an orbital shaker, and ${ }^{14} \mathrm{CO}_{2}$ was trapped in the adjoining well in $1 \mathrm{~N} \mathrm{NaOH}$ for 1 hour. Following trapping, the muscle homogenates were spun for 15 minutes at $15,000 \times$ g and measurement of ${ }^{14} \mathrm{C}$ ASMs (acid-soluble metabolites) were performed in the supernatants. The remaining tissue homogenate was used for total lipid extraction with $1 \mathrm{ml}$ of chloroform/methanol $(2 \mathrm{v} / 1 \mathrm{v})$. Lipids were dried under nitrogen gas, re-dissolved in $100 \mathrm{ul}$ of chloroform/methanol (2v/1v) for thin layer chromatography (TLC) (Anal Tech TLC plates, Whatman Ltd., Kent, ME) and run in a mobile phase containing hexane/diethyl ether/acetic acid, $v / v / v, 30: 20: 2$ ). Bands corresponding to diacylglycerol (DAG) and triacylglycerol (TAG) were scraped and quantified on a multipurpose scintillation counter 


\section{Intramyocellular lipid incorporation capacity is retained in vitro}

(Wallac Winspectral 1414 liquid scintillation counter, Perkin Elmer, Boston, MA, USA) in $5 \mathrm{~mL}$ of OptiFluor (Perkin Elmer, Boston, MA, USA). Data were normalized to protein content of the muscle homogenate.

\section{In vitro ${ }^{14} \mathrm{C}$-palmitate oxidation and lipid incorporation}

Cells were pre-incubated for three hours with $\left[1-{ }^{14} \mathrm{C}\right]$-palmitate $(1 \mu \mathrm{Ci} / \mathrm{ml}$; PerkinElmer, Groningen, $\mathrm{NL})$ and non-labeled palmitate $(100 \mu \mathrm{M})$, L-carnitine $(1 \mathrm{mM})$ and HEPES (12.5 $\mathrm{mM}$ ) in $\alpha$-MEM (Invitrogen, Breda, The Netherlands). Palmitate was coupled to FA-free BSA in a molar ratio of 5:1. Following incubation, ${ }^{14} \mathrm{CO}_{2}$ and ${ }^{14} \mathrm{C}-\mathrm{ASM}$ (acid soluble metabolites) were measured as previously described [15]. All assays were performed in triplicate, and data were normalized to protein content. The ratio of $\mathrm{CO}_{2}$ :ASMs represents the ratio of lipid completely oxidized to $\mathrm{CO}_{2}$ relative to those metabolites of the lipid that are not completely oxidized to $\mathrm{CO}_{2}$, in this case ASMs and which most likely represent TCA cycle intermediates [20]. At the end of the lipid oxidation assay, cells were washed twice with PBS and harvested in $0.05 \%$ SDS for subsequent protein measurement and total lipid extraction with chloroform/methanol $(2 \mathrm{v} / 1 \mathrm{v})$. Lipids were dried under liquid nitrogen, redissolved for thin layer chromatography (TLC) (Anal Tech TLC plates, Whatman Ltd., Kent, $\mathrm{ME}$ ) and run in a mobile phase containing hexane/diethyl ether/acetic acid, $\mathrm{v} / \mathrm{v} / \mathrm{v}$, $30: 20: 2$ ). Bands corresponding to diacylglycerol (DAG), and triacylglycerol (TAG) were scraped and quantified using a multi-purpose scintillation counter (Wallac Winspectral 1414 liquid scintillation counter, Perkin Elmer, Boston, MA, USA).

\section{In vitro pulse-chase ${ }^{14} \mathrm{C}$-oleate experiments}

Pulse chase experiments were adapted from Koves et al. [21]. Muscle cells were grown and differentiated in 24-well plates. $\alpha$ MEM supplemented with $500 \mu \mathrm{M}$ oleate $(2 \mu \mathrm{Ci}$ per $\mathrm{ml}\left[1-{ }^{14} \mathrm{C}\right]$-oleic acid, PerkinElmer, Boston, MA, USA) complexed to BSA (1.25\%) was added for $24 \mathrm{~h}$ on day 6 of differentiation (pulse). The chase media consisted of $\alpha \mathrm{MEM}$ supplemented with $1 \mathrm{mM}$ carnitine and $12.5 \mathrm{mM}$ HEPES. Cell samples were collected in $0.05 \%$ SDS at 0 and $3 \mathrm{~h}$ after the chase. Media was collected $3 \mathrm{~h}$ after the chase to measure oxidation $\left({ }^{14} \mathrm{CO}_{2}\right.$ and ${ }^{14} \mathrm{C}$-ASMs) using a $\mathrm{CO}_{2}$ trapping device followed by scintillation counting as described previously [15]. Lipids were extracted using chloroform:methanol $(2: 1)$, and lipid species were separated of lipid species using thin layer chromatography as described previously [15]. Experiments were performed in triplicates per subject. Data were normalized to protein content.

\section{In vitro fatty acid uptake}

FA uptake was measured by incubating myotubes with FBS-free DMEM containing 0.2 $\mu \mathrm{Ci} / \mathrm{mL}\left[1-{ }^{14} \mathrm{C}\right]$-palmitate and $20 \mu \mathrm{M}$ non-labeled palmitate conjugated to FA-free BSA (ratio BSA to palmitate $1: 2.5$ ). Cells were incubated at $37^{\circ} \mathrm{C}$ for $4 \mathrm{~min}$, washed three times with PBS, and then lysed in $0.1 \mathrm{M} \mathrm{NaOH}$. Cell lysates were added to $5 \mathrm{~mL}$ OptiFluor (Perkin Elmer, Boston, MA, USA) and counted on a Wallac Winspectral 1414 liquid scintillation 
counter (Perkin Elmer, Boston, MA, USA). Experiments were performed in triplicates per subject. Data were normalized to protein content.

\section{In vitro triacylglycerol levels}

Intracellular TAG levels in differentiated myotubes were measured using the method of Schwartz and Wolins [22].

\section{Statistics}

Results are presented as mean \pm SEM. Statistical analyses were performed using SPSS version 16.0 for MacOS 16.0 (SPSS, Chicago, IL). Statistical comparisons between conditions were performed using unpaired T-tests. Pearson's correlation coefficients were used to describe the linear association between variables. $\mathrm{P}<0.05$ was considered statistically significant.

\section{RESULTS}

\section{In vivo}

\section{Clinical characteristics of type $\mathbf{2}$ diabetic subjects and obese controls}

By design, fasting plasma glucose levels were significantly higher in patients with type 2 diabetes (T2D) compared with obese controls (C) (Table 1). Circulating free fatty acids (FFAs) were not different between the two groups. Skeletal muscle insulin sensitivity (the $M$-value at the insulin infusion rate of $40 \mathrm{mU} / \mathrm{m}^{2} / \mathrm{min}$ ) tended to be lower in T2Ds compared to obese controls (Table 1 ). Aerobic capacity, as measured by $\mathrm{VO}_{2} \mathrm{max}$, was significantly lower in the T2D subjects compared with the controls (Table 1 ).

Table 1. Subject characteristics.

\begin{tabular}{llll}
\hline & C & T2D & P-value \\
\hline Age $(\mathrm{y})$ & $54.7 \pm 4.1$ & $58.3 \pm 2.1$ & 0.44 \\
BMI $\left(\mathrm{kg} / \mathrm{m}^{2}\right)$ & $31.2 \pm 0.26$ & $30.8 \pm 0.32$ & 0.33 \\
\%Fat & $32.8 \pm 3.0$ & $33.0 \pm 2.0$ & 0.96 \\
VO2max $(\mathrm{ml} / \mathrm{min} / \mathrm{kg})$ & $31.5 \pm 0.8$ & $25.5 \pm 1.83$ & $\mathbf{0 . 0 1}$ \\
Glucose $(\mathrm{mmol} / \mathrm{L})$ & $5.22 \pm 0.15$ & $7.13 \pm 0.39$ & $<0.01$ \\
FFA $(\mathrm{mmol} / \mathrm{L})$ & $0.78 \pm 0.39$ & $0.62 \pm 0.17$ & 0.76 \\
M-value $(\mu \mathrm{mol} / \mathrm{kg} / \mathrm{min})$ & $35.2 \pm 5.6$ & $23.4 \pm 3.6$ & 0.10 \\
\hline
\end{tabular}

\section{Ex vivo}

\section{Intramuscular lipid content, fiber type and fatty acid metabolism}

Intramuscular lipid content (IMCL) was similar between the two groups (5.2 $\pm 0.9 \%$ vs. 5.3 $\pm 1.7 \%$ in type 1 fibers for $C$ vs. T2D, $P=0.97 ; 2.7 \pm 0.4 \%$ vs. $2.5 \pm 0.6 \%$ in type 2 fibers, $\mathrm{P}=0.73$; and $4.0 \pm 0.7 \%$ vs. $3.9 \pm 1.1 \%$ for total lipid content, $\mathrm{P}=0.96$; Figure 1 ). 


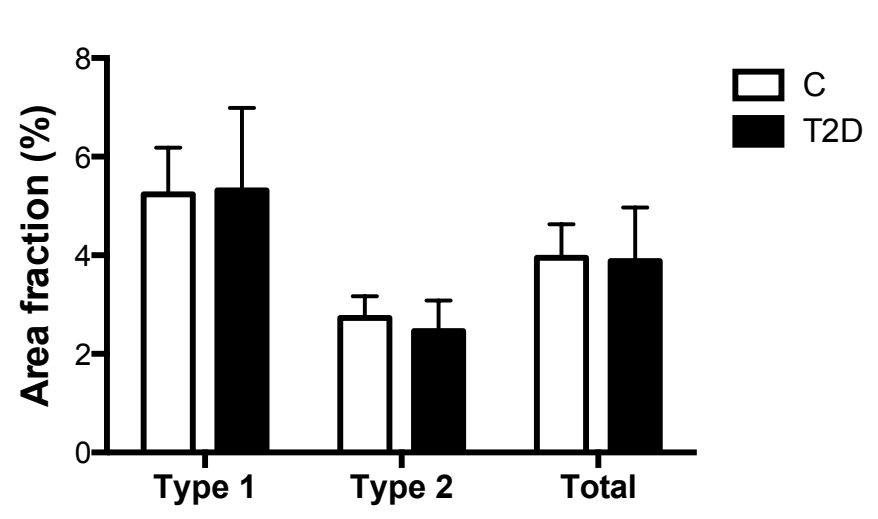

Figure 1. Intramyocellular neutral lipid content measured by Oil-red-O staining in combination with an immunofluorescence staining against slow myosin heavy chain to determine fiber type. Mean \pm SEM.

We then investigated fat oxidative capacity in skeletal muscle homogenates using an exogenously supplied long chain fatty acid (LCFA; palmitate). Palmitate oxidation to $\mathrm{CO}_{2}$ ("complete oxidation") was significantly reduced in subjects with T2D ( $0.99 \pm 0.17$ vs. 0.53 $\pm 0.07 \mathrm{nmol} / \mathrm{mg}$ protein for $\mathrm{C}$ vs. T2D, $\mathrm{P}=0.03$; Figure $2 \mathrm{~A}$ ). Acid-soluble metabolites (ASMs; "incomplete oxidation") were not different between the two groups ( $P=0.86$; Figure $2 B$ ). Thus, the ratio of complete to incomplete oxidation, which is indicative of a more efficient FA metabolism, was also reduced in the T2Ds $(0.12 \pm 0.01$ vs. $0.07 \pm 0.01$ for $C$ and T2D, respectively, $\mathrm{P}<0.01$; Figure $2 \mathrm{C}$ ).

Next, we measured the incorporation of ${ }^{14} \mathrm{C}$-palmitate into lipids in skeletal muscle homogenates. While incorporation of ${ }^{14} \mathrm{C}$-palmitate into the total lipid pool was similar between the two groups (Figure 2D), we did observe decreased incorporation of ${ }^{14} \mathrm{C}$ palmitate into triacylglycerols (TAGs) in T2D patients compared with obese controls $(0.45$ \pm 0.13 vs. $0.11 \pm 0.02 \mathrm{nmol} / \mathrm{mg}$ protein, for $\mathrm{C}$ and T2D respectively, $\mathrm{P}=0.047$; Figure $2 \mathrm{E}$ ), with similar incorporation into diacylglycerols (DAGs) (Figure 2F). This may indicate a blunted ability of the skeletal muscle of T2Ds to efficiently store and retain the lipids in the TAG pool.

\section{Relationships among in vivo and ex vivo characteristics}

Correlations are shown in Supplemental Figure 1. The ratio of palmitate $\mathrm{CO}_{2}: \mathrm{ASM}$ tended to correlate positively with $\mathrm{VO}_{2} \max (r=0.537, \mathrm{P}=0.072)$ and negatively with fasting plasma glucose levels $(r=-0.566, \mathrm{P}=0.055)$. 
A

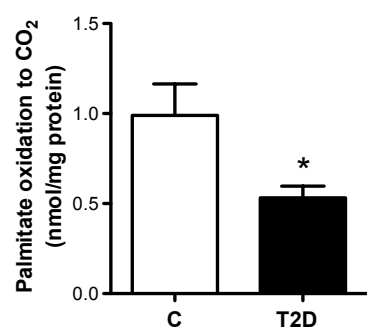

C

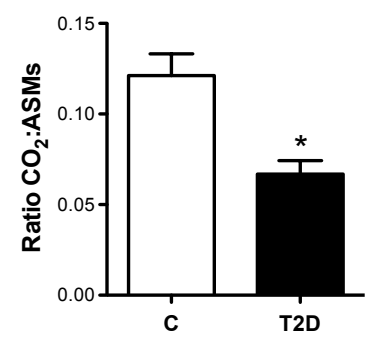

E

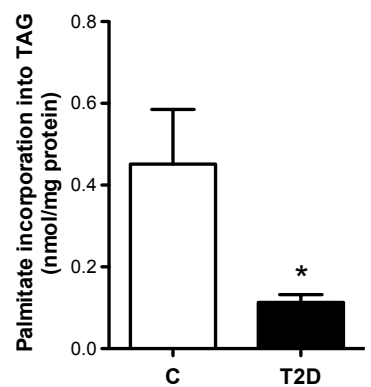

B

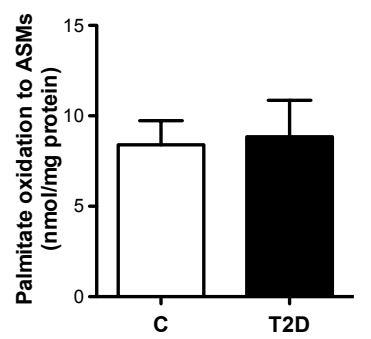

D

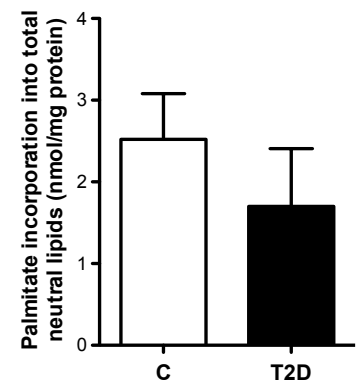

$\mathbf{F}$

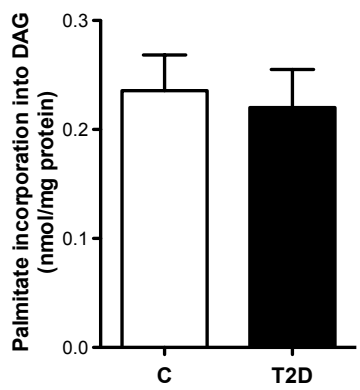

Figure 2. Ex vivo ${ }^{14} \mathrm{C}-$ palmitate metabolism. (A) ${ }^{14} \mathrm{C}$-palmitate oxidation to $\mathrm{CO}_{2}$. (B) ${ }^{14} \mathrm{C}$-palmitate oxidation to ASMs. (C) Ratio $\mathrm{CO}_{2}$ :ASMs. (D) Total ${ }^{14} \mathrm{C}$-palmitate incorporation into lipids. (E) ${ }^{14} \mathrm{C}$-palmitate incorporation into TAG. (F) ${ }^{14} \mathrm{C}$-palmitate incorporation into DAG. ${ }^{*} P<0.05$, error bars represent SEM.

\section{In vitro}

\section{Intramyocellular lipid content and metabolism}

Intramyocellular lipid (IMCL) content, under standard culturing conditions (i.e. without FA incubation) tended to be higher in the myotubes established from T2D patients compared with obese controls $(0.007 \pm 0.001 \mu \mathrm{g} / \mathrm{mg}$ protein for obese controls, $0.012 \pm 0.002 \mu \mathrm{g} / \mathrm{mg}$ protein for T2Ds, $\mathrm{P}=0.076$; Figure $3 \mathrm{~A}$ and $\mathrm{B})$. $\mathrm{IMCL}$ levels in primary myotubes were positively related with fasting blood glucose $(r=0.746, P=0.008$, Figure $3 C)$ and inversely related to $M$-value ( $r=-0.617, P=0.043$, Figure $3 D$ ), which may indicate that higher lipid content in these myotubes is associated with a reduced glucose control/homeostasis in vivo. 


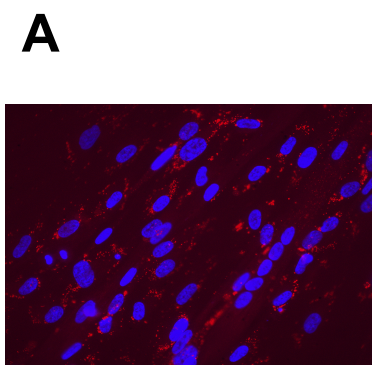

Control

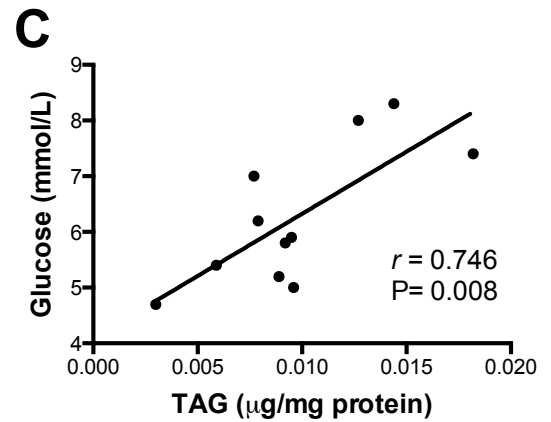

B

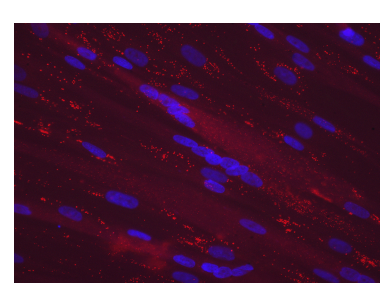

T2D

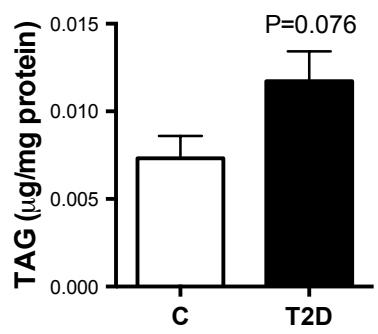

D

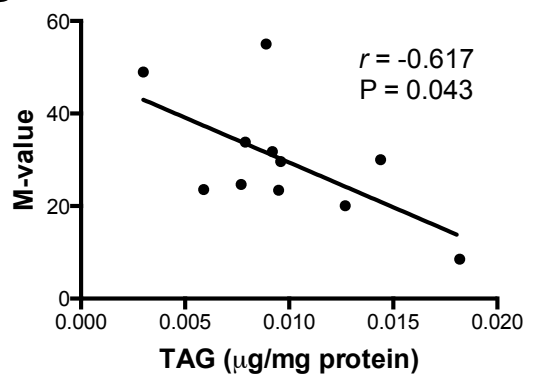

Figure 3. Intramyocellular lipid accumulation in primary human myotubes. (A) Oil-red-O staining. Representative pictures are shown. (B) TAG content in the myotubes (in the absence of FA treatment). (C-D) Correlation of the TAG content of the myotubes with the fasting plasma glucose level (C) and the M-value (D).

\section{Exogenous fatty acid metabolism}

In contrast to palmitate oxidation in muscle homogenates, in vitro ${ }^{14} \mathrm{C}$-palmitate oxidation to $\mathrm{CO}_{2}$ was not significantly lower in T2D patients compared with obese controls $(0.039 \pm$ 0.021 vs. $0.020 \pm 0.004 \mathrm{nmol} / \mathrm{mg}$ protein, respectively, $\mathrm{P}=0.38$; Figure $4 \mathrm{~A}$ ). Furthermore, oxidation to $A S M s$ was not significantly different $(P=0.59$; Figure $4 B$ ), and consequently neither was the ratio of $\mathrm{CO}_{2}$ to $\mathrm{ASMs}(\mathrm{P}=0.38$; Figure $4 \mathrm{C})$. Moreover, in vitro ${ }^{14} \mathrm{C}$-palmitate oxidation to $\mathrm{CO}_{2}$ did not correlate with the ex vivo palmitate oxidation ( $\left.r=-0.115, \mathrm{P}=0.721\right)$, suggesting that the capacity to oxidize palmitate to $\mathrm{CO}_{2}$ is not an inherent property of the myotubes established from these $\mathrm{T} 2 \mathrm{D}$ and obese individuals.

${ }^{14} \mathrm{C}$-palmitate incorporation into total lipid pool was lower in myotubes established from T2D patients compared with obese controls, but this difference did not reach significance due to the high variation $(5.84 \pm 1.46$ vs. $3.28 \pm 0.27 \mathrm{nmol} / \mathrm{mg}$ protein, respectively, $P=0.116$; Figure $4 \mathrm{D})$. Similarly, palmitate incorporation into TAGs $(0.39 \pm 0.16$ vs. $0.15 \pm 0.02$ vs. $\mathrm{nmol} / \mathrm{mg}$ protein, for $\mathrm{OB}$ and $\mathrm{T} 2 \mathrm{D}$ respectively, $\mathrm{P}=0.168$, Figure $4 \mathrm{E}$ ) and DAGs $(0.063 \pm 0.013$ vs. $0.047 \pm 0.007 \mathrm{nmol} / \mathrm{mg}$ protein, $\mathrm{P}=0.290$, for $\mathrm{C}$ and T2D, respectively; Figure $4 \mathrm{~F}$ ) were not statistically significant different between groups. However, in vitro ${ }^{14} \mathrm{C}$-palmitate incorporation into TAGs strongly correlated with ex vivo ${ }^{14} \mathrm{C}$-palmitate incorporation into TAGs $(r=0.848, \mathrm{P}=0.008)$. Similarly, in vitro ${ }^{14} \mathrm{C}$-palmitate 
incorporation into total neutral lipids also positively correlated with ex vivo ${ }^{14} \mathrm{C}$-palmitate incorporation into TAGs $(r=0.837, \mathrm{P}=0.01)$. Thus, while we did not see the observed ex vivo differences in TAG incorporation retained in vitro when comparing the T2Ds with obese controls (Figure $4 \mathrm{E}$ ), we did find strong relationships between these two measures. Finally, palmitate uptake was similar between the groups ( $3.15 \pm 0.41$ vs. $3.30 \pm 0.64$, for $C$ and T2D, respectively, $P=0.85$; Figure $4 G$ ).

A

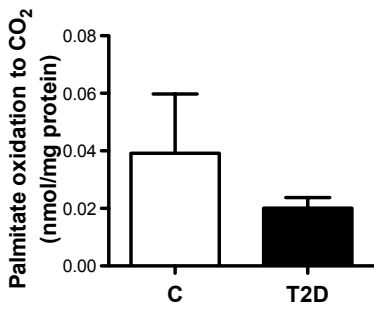

C

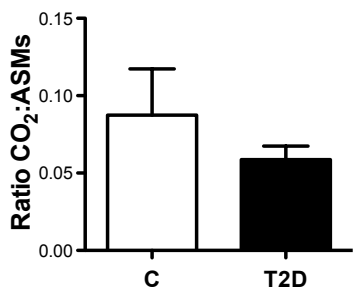

$\mathbf{E}$

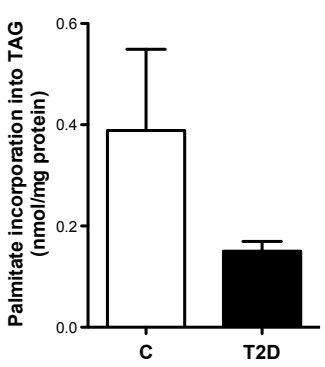

G

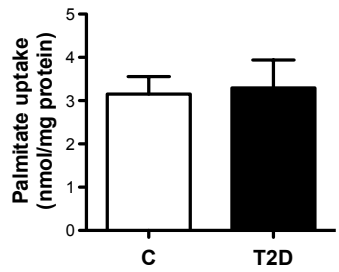

B

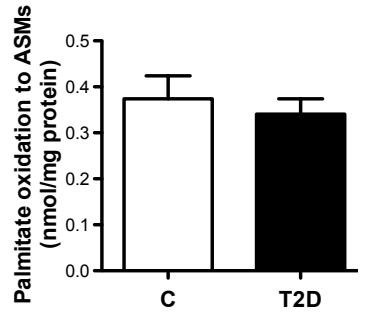

D

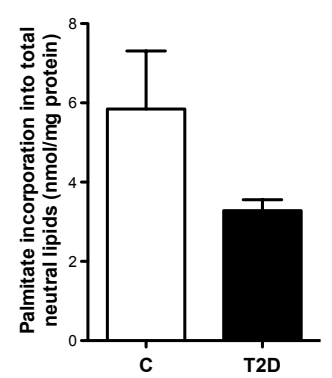

F

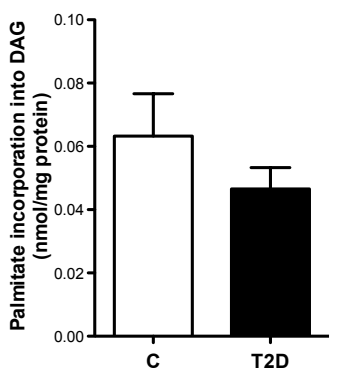

Figure 4. In vitro exogenous ${ }^{14} \mathrm{C}$-palmitate metabolism. (A) ${ }^{14} \mathrm{C}$-palmitate oxidation to $\mathrm{CO}_{2}$. (B) ${ }^{14} \mathrm{C}$-palmitate oxidation to ASMs. (C) Ratio $\mathrm{CO}_{2}$ :ASMs. (D) Total ${ }^{14} \mathrm{C}$ palmitate incorporation into lipids. (E) ${ }^{14} \mathrm{C}$-palmitate incorporation into TAG. (F) ${ }^{14} \mathrm{C}$-palmitate incorporation into DAG. (G) ${ }^{14} \mathrm{C}$-palmitate uptake. Error bars represent SEM. 


\section{Endogenous fatty acid metabolism}

The lack of difference in ${ }^{14} \mathrm{C}$-palmitate oxidation in primary myotubes from T2Ds versus obese controls is consistent with work by Gaster et al. [23], who reported no reduction in oxidation of exogenous lipid in myotubes from obese or obese T2D subjects compared with lean subjects. However, they showed that complete oxidation of endogenous lipid (IMCL oxidation) was reduced in obese and T2D myotubes compared with lean controls [23]. Therefore, we examined ${ }^{14} \mathrm{C}$-oleate oxidation after a $24 \mathrm{~h}$ pulse with $500 \mu \mathrm{M}$ oleate in the absence of carnitine to label the endogenous lipid pool. Oleate was chosen instead of palmitate because of the lipotoxic effects of palmitate loading of myotubes [24, 25]. Interestingly, incorporation of ${ }^{14} \mathrm{C}$-oleate into the total lipid pool after 24 hours was significantly lower (1.7-fold) in myotubes from T2D patients compared with obese controls (16.3 \pm 2.40 vs. $9.5 \pm 0.78 \mathrm{nmol} / \mathrm{mg}$ protein for $C$ and T2D, respectively, $P=0.02$, Figure $5 \mathrm{~A}$ ). Furthermore, ${ }^{14} \mathrm{C}$-oleate incorporation into TAGs was significantly lower in T2D patients $(2.24 \pm 0.47$ and $0.94 \pm 0.25 \mathrm{nmol} / \mathrm{mg}$ protein for $\mathrm{C}$ and $\mathrm{T} 2 \mathrm{D}$, respectively, $\mathrm{P}=0.03$, Figure $5 B)$. DAG synthesis was not significantly different between the two groups $(0.17 \pm 0.05$ and $0.10 \pm 0.02 \mathrm{nmol} / \mathrm{mg}$ protein, respectively, $\mathrm{P}=0.31$, Figure $5 \mathrm{C}$ ).

A

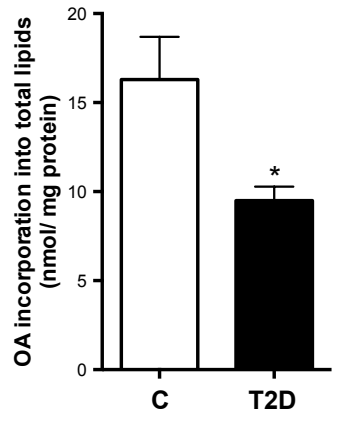

B

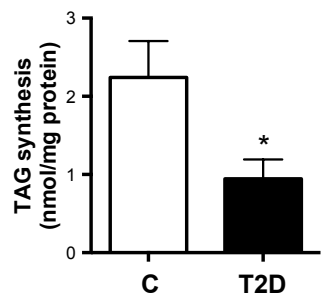

C

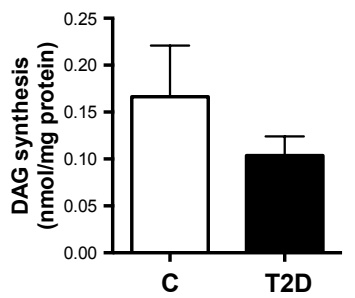

Figure 5. Lipid synthesis in primary myotubes. Incorporation of ${ }^{14} \mathrm{C}$-oleate was measured after $24 \mathrm{~h}$ incubation with $400 \mu \mathrm{M}$ oleate in the absence of carnitine. (A) Total lipid synthesis. (B) TAG synthesis. (C) DAG synthesis. ${ }^{*} \mathrm{P}<0.05$. Error bars represent SEM.

After $24 \mathrm{~h}$ incubation with oleate, oxidation was initiated by addition of carnitine and measured after 3 hours. Interestingly, even despite reduced ${ }^{14} \mathrm{C}$-oleate incorporation in TAG in T2D patients, the oxidation of endogenous ${ }^{14} \mathrm{C}$-oleate to $\mathrm{CO}_{2}$ was not different in obese controls versus T2D myotubes $(0.009 \pm 0.002$ vs. $0.006 \pm 0.002 \mathrm{nmol} / \mathrm{mg}$ protein, respectively, $\mathrm{P}=0.384$; Figure $6 \mathrm{~A})$. Likewise, oxidation to $\mathrm{ASMs}$ was similar between the two groups $(0.070 \pm 0.012$ vs. $0.058 \pm 0.015 \mathrm{nmol} / \mathrm{mg}$ protein, $\mathrm{P}=0.543$; for $\mathrm{C}$ and T2D respectively; Figure 6B). Consequently, no differences were observed in the ratio of $\mathrm{CO}_{2}$ to ASMs ( $0.126 \pm 0.032$ vs. $0.093 \pm 0.033, P=0.49$; for $C$ and $T 2 D$ respectively; Figure $6 C$ ) Thus, in concert with the oxidation rates of exogenous ${ }^{14} \mathrm{C}$-palmitate, oxidation of the endogenous labeled oleate pool was similar in both groups of primary myotubes. 
A

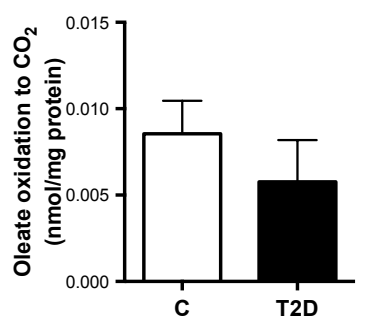

B

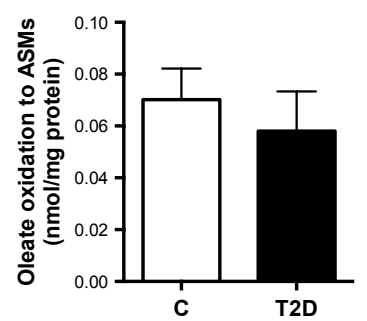

C

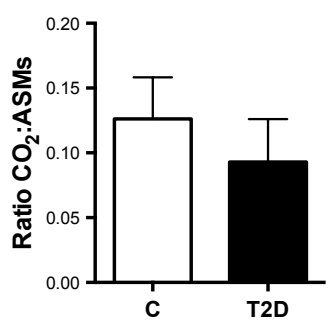

Figure 6. In vitro endogenous ${ }^{14} \mathrm{C}$-oleate oxidation. Primary myotubes were loaded with $400 \mu \mathrm{M}$ oleate for $24 \mathrm{~h}$ and then pulsed in the presence of $1 \mathrm{mM}$ carnitine for $3 \mathrm{~h}$. Oxidation rates were measured during this $3 \mathrm{~h}$ pulse period. (A) ${ }^{14} \mathrm{C}$-oleate oxidation to $\mathrm{CO}_{2}$. (B) ${ }^{14} \mathrm{C}$-oleate oxidation to ASMs. (C) Ratio $\mathrm{CO}_{2}$ :ASMs. Error bars represent SEM.

\section{DISCUSSION}

Obesity and type 2 diabetes (T2D) are associated with ectopic lipid accumulation in tissues such as skeletal muscle [1, 26-29]. IMCL content inversely correlates with peripheral insulin sensitivity [30-33], suggesting that fat accumulation leads to insulin resistance. However, recent studies suggest that increasing the TAG storage capacity may be beneficial [34-36]. Here, we investigated the oxidative and storage capacities of both skeletal muscle tissue and myotubes established from satellite cells of obese individuals with T2D and their BMI-matched non-diabetic controls. We show that oxidation and incorporation of an exogenously supplied long-chain FA (LCFA, palmitate) into TAGs are significantly blunted in muscle tissue from T2D individuals. Importantly, we demonstrate that this blunted FA oxidative capacity is not retained in the myotubes. However, the myotubes of the T2D individuals did show reduced incorporation of exogenous palmitate into TAG, and this was significantly related to the impaired palmitate incorporation into TAG observed ex vivo. Moreover, incorporation of oleate into the total neutral lipid pool, specifically the TAG pool, after prolonged FA incubation in the absence of carnitine supplementation was significantly reduced in the myotubes from the T2D subjects. Since the absence of carnitine prevents FA oxidation, this measurement mainly reflects unidirectional TAG synthesis. Therefore, we conclude that lower lipid incorporation is an inherent metabolic characteristic of myotubes of T2D individuals compared with BMImatched obese controls.

We show a blunted complete oxidation of palmitate in the skeletal muscle tissue of obese individuals with T2D compared with their BMI-matched controls. As there were no differences in the acid-soluble metabolites (ASMs), the ratio of complete to incomplete oxidation was also reduced in T2Ds. These findings extend those of Hulver et al. [37], who demonstrated aberrant exogenous FA oxidation in the skeletal muscle of obese and severely obese (BMI $53.8 \pm 3.5 \mathrm{~kg} / \mathrm{m}^{2}$ ) individuals compared with lean controls [37]. In this context, our data imply that $\mathrm{T} 2 \mathrm{D}$ is associated with reduced tissue FA oxidation 


\section{Intramyocellular lipid incorporation capacity is retained in vitro}

independent of BMI. Interestingly though, we did not observe significant differences in oxidation of exogenous palmitate to $\mathrm{CO}_{2}$ and ASMs between myotubes of T2Ds and obese controls. Additionally, we examined if FA oxidation from endogenous lipid pools was compromised in T2D myotubes. After an overnight loading of the myocyte lipid pool with oleate, no differences in endogenous FA oxidation rates between obese and T2D myotubes were observed. This contrasts with the findings of Gaster et al. [23] who demonstrated that complete oxidation of endogenous, but not exogenous, FAs was reduced in T2D myotubes compared with obese controls. However, Gaster et al. show reduced oxidation of palmitate in T2D myotubes after chronic incubation (four days) with $600 \mu \mathrm{M}$ palmitate [23], which presumably represents a combination of inherent oxidative capacity and susceptibility to palmitate-associated lipotoxicity. Our data suggest that a reduced myocellular fat oxidative capacity in T2D patients may not be an inherent quality, but rather a consequence of their environment.

It was recently shown that one bout of exercise improves the capacity to store TAG in muscle and thereby prevents lipid-induced insulin resistance [36]. Moreover, by use of in vivo infusion of ${ }^{13} \mathrm{C}$-palmitate, Bergman et al. [38] showed that palmitate incorporation into skeletal muscle TAG was increased in endurance trained athletes compared with sedentary controls. Here we found that incorporation of palmitate into TAGs, but not into DAGs, was blunted in skeletal muscle of T2D patients. Collectively, these reports indicate that increased channeling of FAs towards storage in the form of TAGs in skeletal muscle is associated with an improved metabolic profile. In contrast to reduced oxidative capacity in T2D, which was not retained in the myotubes, reduced incorporation of FAs into TAG in T2D was retained in the myotubes. By reducing lipid intermediate accumulation, a high capacity to channel FAs towards intramyocellular neutral lipid-TAGs- storage may protect against lipid-induced insulin resistance. Thus, a reduced rate of TAG storage in T2D may be an important factor in the development of lipid-induced insulin resistance in these patients.

A possible explanation for the retained aberrant lipid incorporation capacity might be that the relative abundance and capacities of enzymes involved in neutral lipid synthesis, lipid droplet synthesis and stability are compromised. For example, we and others have previously demonstrated that increasing the abundance of diacylglycerol acyltransferase (DGAT) - the rate-limiting enzyme for the final step in TAG synthesis - or perilipin 2 (PLIN2) or PLIN5 - lipid droplet coat proteins - increases the intramyocellular TAG content [34, 35, $39,40]$. Future studies should investigate the inherent pathways in muscle lipid turnover in order to identify the critical regulation sites.

The finding that the capacity to incorporate FAs into TAGs is reduced in T2D patients, combined with a similar fat oxidative capacity, seems incompatible with similar or higher IMCL content in T2D muscle [6, 41-43]. One explanation for this discrepancy could be an altered FA uptake into muscle. Skeletal muscle FA uptake is a controversial topic, with some investigators finding no difference in uptake of FAs $[7,8]$, while others show increased FA uptake in skeletal muscle of obese and T2D individuals [9]. Here we could not detect differences in FA uptake rates in cultured myotubes of T2D patients compared with 
obese controls. However, it should be noted that the measurement of FA incorporation into TAG is a capacity measurement and illustrates the capacity to redirect FAs into TAG in a given period of time. Alterations in lipolysis or increased 24h FA flux into muscle in T2D patients could explain why IMCL content may be higher in the long term situation.

It should be noticed that a potential limitation of this study is the lower $\mathrm{VO}_{2}$ max in the diabetics, which may affect the ex vivo findings. Hence, the lower palmitate oxidation to $\mathrm{CO}_{2}$ observed in the diabetics ex vivo may partly be explained by lower physical fitness. Nevertheless, the strength of the present study is the incorporation of the in vitro experiments, in which we show that - in contrast to oxidative capacity - FA incorporation into TAG is inherently perturbed in obese individuals with type 2 diabetes compared with their BMI-matched controls. Our results are consistent with the view that IMCL content and lipid turnover have a significant impact on insulin sensitivity and glucose homeostasis since the ex vivo and in vitro findings corresponded with these markers of in vivo metabolic health. Future studies using primary human muscle cell models with musclespecific modulations of the lipid turnover pathways may help to unravel the specific regulation sites of skeletal muscle and whole-body energy metabolism in vivo. These findings could have profound implications for how we utilize precision medicine to treat, manage and prevent type 2 diabetes moving forward.

\section{REFERENCES}

1. McGarry JD. What if Minkowski had been ageusic? An alternative angle on diabetes. Science 1992; 258: 766-770.

2. Glatz JFC, Luiken JJFP, and Bonen A. Membrane fatty acid transporters as regulators of lipid metabolism: implications for metabolic disease. Physiol Rev 2010; 90: 367-417.

3. Morino K, Petersen KF, and Shulman GI. Molecular mechanisms of insulin resistance in humans and their potential links with mitochondrial dysfunction. Diabetes 2006; 55: S9-S15.

4. Bosma M, Kersten S, Hesselink MKC, and Schrauwen P. Re-evaluating lipotoxic triggers in skeletal muscle: Relating intramyocellular lipid metabolism to insulin sensitivity. Prog Lipid Res 2012; 51: 36-49.

5. Hulver MW, Berggren JR, Carper MJ, Miyazaki M, Ntambi JM, Hoffman EP, Thyfault JP, Stevens R, Dohm GL, Houmard JA, and Muoio DM. Elevated stearoyl-CoA desaturase-1 expression in skeletal muscle contributes to abnormal fatty acid partitioning in obese humans. Cell Metab 2005; 2: 251-261.

6. Aguer C, Mercier J, Yong Wai Man C, Metz L, Bordenave S, Lambert K, Jean E, Lantier L, Bounoua L, Brun J, Raynaud de Mauverger E, Andreelli F, Foretz M, and Kitzmann M. Intramyocellular lipid accumulation is associated with permanent relocation ex vivo and in vitro of fatty acid translocase (FAT)/CD36 in obese patients. Diabetologia 2010; 53: 1151-1163.

7. Bruce CR, Anderson MJ, Carey AL, Newman DG, Bonen A, Kriketos AD, Cooney GJ, and Hawley JA. Muscle oxidative capacity is a better predictor of insulin sensitivity than lipid status. J Clin Endocrinol Metab 2003; 88: 5444-5451.

8. Pelsers MMAL, Tsintzas K, Boon H, Jewell K, Norton L, Luiken JJFP, Glatz JFC, and Van Loon LJC. Skeletal muscle fatty acid transporter protein expression in type 2 diabetes patients compared with overweight, sedentary men and age-matched, endurance-trained cyclists. Acta Physiologica 2007; 190: 209-219.

9. Bonen A, Parolin ML, Steinberg GR, Calles-Escandon J, Tandon NN, Glatz JFC, Luiken JJFP, Heigenhauser GJF, and Dyck DJ. Triacylglycerol accumulation in human obesity and type 2 diabetes is associated with increased rates of skeletal muscle fatty acid transport and increased sarcolemmal FAT/CD36. FASEB J 2004; 


\section{Intramyocellular lipid incorporation capacity is retained in vitro}

10. Aguer C, Foretz M, Lantier L, Hebrard S, Viollet B, Mercier J, and Kitzmann M. Increased FAT/CD36 cycling and lipid accumulation in myotubes derived from obese type 2 diabetic patients. PLoS ONE 2011; 6: e28981.

11. Gaster M, Rustan AC, Aas V, and Beck-Nielsen H. Reduced lipid oxidation in skeletal muscle from type 2 diabetic subjects may be of genetic origin: evidence from cultured myotubes. Diabetes 2004; 53: 542-548.

12. Kuipers H, Verstappen FTJ, Keizer HA, Geurten P, and van Kranenburg G. Variability of aerobic performance in the laboratory and its physiologic correlates. Int J Sports Med 1985; 06: 197,201.

13. Siri WE. The gross composition of the body. Adv Biol Med Phys 1956; 4: 239-80.

14. Bergstrom J. Percutaneous needle biopsy of skeletal muscle in physiological and clinical research. Scand J Clin Lab Invest 1975; 35: 609-16.

15. Sparks LM, Moro C, Ukropcova B, Bajpeyi S, Civitarese AE, Hulver MW, Thoresen GH, Rustan AC, and Smith SR. Remodeling lipid metabolism and improving insulin responsiveness in human primary myotubes. PLoS ONE 2011; 6: e21068.

16. Koopman R, Schaart G, and Hesselink M. Optimisation of oil red O staining permits combination with immunofluorescence and automated quantification of lipids. Histochem Cell Biol 2001; 116: 63-68.

17. Kim JY, Koves TR, Yu GS, Gulick T, Cortright RN, Dohm GL, and Muoio DM. Evidence of a malonyl-CoAinsensitive carnitine palmitoyltransferase I activity in red skeletal muscle. Am J Physiol Endocrinol Metab 2002; 282: E1014-E1022.

18. Scholte HR, Yu Y, Ross JD, Oosterkamp II, Boonman AMC, and Busch HFM. Rapid isolation of muscle and heart mitochondria, the lability of oxidative phosphorylation and attempts to stabilize the process in vitro by taurine, carnitine and other compounds. Mol Cell Biochem 1997; 174: 61-66.

19. Ukropcova B, McNeil M, Sereda O, de Jonge L, Xie H, Bray GA, and Smith SR. Dynamic changes in fat oxidation in human primary myocytes mirror metabolic characteristics of the donor. J Clin Invest 2005; 115: 1934-1941.

20. Koves TR, Ussher JR, Noland RC, Slentz D, Mosedale M, Ilkayeva O, Bain J, Stevens R, Dyck JRB, Newgard $\mathrm{CB}$, Lopaschuk GD, and Muoio DM. Mitochondrial overload and incomplete fatty acid oxidation contribute to skeletal muscle insulin resistance. Cell Metab 2008; 7: 45-56.

21. Koves TR, Sparks LM, Kovalik JP, Mosedale M, Arumugam R, DeBalsi KL, Everingham K, Thorne L, Phielix E, Meex RC, Kien CL, Hesselink MKC, Schrauwen P, and Muoio DM. PPARy coactivator-1 $\alpha$ contributes to exercise-induced regulation of intramuscular lipid droplet programming in mice and humans. J Lipid Res 2012;

22. Schwartz DM and Wolins NE. A simple and rapid method to assay triacylglycerol in cells and tissues. J Lipid Res 2007; 48: 2514-2520.

23. Gaster M. Reduced lipid oxidation in myotubes established from obese and type 2 diabetic subjects. Biochem Biophys Res Commun 2009; 382: 766-770.

24. Watt MJ, Hoy AJ, Muoio DM, and Coleman RA. Distinct roles of specific fatty acids in cellular processes: implications for interpreting and reporting experiments. Am J Physiol Endocrinol Metab 2012; 302: E1-E3.

25. Aas V, Rokling-Andersen M, Wensaas AJ, Thoresen GH, Kase ET, and Rustan AC. Lipid metabolism in human skeletal muscle cells: effects of palmitate and chronic hyperglycaemia. Acta Physiol Scand 2005; 183: 31-41.

26. Chen YDI, Golay A, Swislocki ALM, and Reaven GM. Resistance to insulin suppression of plasma free fatty acid concentrations and insulin stimulation of glucose uptake in noninsulin-dependent diabetes mellitus. J Clin Endocrinol Metab 1987; 64: 17-21.

27. Falholt K, Jensen I, Lindkaer Jensen S, Mortensen H, Volund A, Heding LG, Noerskov Petersen P, and Falholt W. Carbohydrate and lipid metabolism of skeletal muscle in type 2 diabetic patients. Diabet Med 1988; 5: 27-31.

28. Reaven GM. Banting lecture 1988. Role of insulin resistance in human disease. Diabetes 1988; 37: 1595607.

29. Reaven GM, Hollenbeck C, Jeng CY, Wu MS, and Chen YD. Measurement of plasma glucose, free fatty acid, lactate, and insulin for $24 \mathrm{~h}$ in patients with NIDDM. Diabetes 1988; 37: 1020-4. 
30. Krssak M, Falk Petersen K, Dresner A, DiPietro L, Vogel SM, Rothman DL, Roden M, and Shulman GI. Intramyocellular lipid concentrations are correlated with insulin sensitivity in humans: a $1 \mathrm{H} N \mathrm{NM}$ spectroscopy study. Diabetologia 1999; 42: 113-6.

31. Moro C, Galgani JE, Luu L, Pasarica M, Mairal A, Bajpeyi S, Schmitz G, Langin D, Liebisch G, and Smith SR. Influence of gender, obesity, and muscle lipase activity on intramyocellular lipids in sedentary individuals. J Clin Endocrinol Metab 2009; 94: 3440-3447.

32. Pan DA, Lillioja S, Kriketos AD, Milner MR, Baur LA, Bogardus C, Jenkins AB, and Storlien LH. Skeletal muscle triglyceride levels are inversely related to insulin action. Diabetes 1997; 46: 983-8.

33. Perseghin G, Scifo P, De Cobelli F, Pagliato E, Battezzati A, Arcelloni C, Vanzulli A, Testolin G, Pozza G, Del Maschio A, and Luzi L. Intramyocellular triglyceride content is a determinant of in vivo insulin resistance in humans: a $1 \mathrm{H}-13 \mathrm{C}$ nuclear magnetic resonance spectroscopy assessment in offspring of type 2 diabetic parents. Diabetes 1999; 48: 1600-1606.

34. Bosma M, Hesselink MKC, Sparks LM, Timmers S, Ferraz MJ, Mattijssen F, van Beurden D, Schaart G, de Baets $\mathrm{MH}$, Verheyen FK, Kersten S, and Schrauwen P. Perilipin 2 improves insulin sensitivity in skeletal muscle despite elevated intramuscular lipid levels. Diabetes 2012; 61: 2679-2690.

35. Liu L, Shi X, Choi CS, Shulman GI, Klaus K, Nair KS, Schwartz GJ, Zhang Y, Goldberg IJ, and Yu YH. Paradoxical coupling of triglyceride synthesis and fatty acid oxidation in skeletal muscle overexpressing DGAT1. Diabetes 2009; 58: 2516-2524.

36. Schenk $\mathrm{S}$ and Horowitz JF. Acute exercise increases triglyceride synthesis in skeletal muscle and prevents fatty acid-induced insulin resistance. J Clin Invest 2007; 117: 1690-1698.

37. Hulver MW, Berggren JR, Cortright RN, Dudek RW, Thompson RP, Pories WJ, MacDonald KG, Cline GW, Shulman GI, Dohm GL, and Houmard JA. Skeletal muscle lipid metabolism with obesity. Am J Physiol Endocrinol Metab 2003; 284: E741-E747.

38. Bergman BC, Perreault L, Hunerdosse DM, Koehler MC, Samek AM, and Eckel RH. Increased intramuscular lipid synthesis and low saturation relate to insulin sensitivity in endurance-trained athletes. J Appl Physiol 2010; 108: 1134-1141.

39. Bosma M, Sparks LM, Hooiveld G, Jorgensen J, Houten SM, Schrauwen P, Kersten S, and Hesselink MKC. Overexpression of PLIN5 in skeletal muscle promotes oxidative gene expression and intramyocellular lipid content without compromising insulin sensitivity. Biochim Biophys Acta 2012; In press.

40. Timmers S, de Vogel-van den Bosch J, Hesselink MKC, van Beurden D, Schaart G, Ferraz MJ, Losen M, Martinez-Martinez P, De Baets MH, Aerts JMFG, and Schrauwen P. Paradoxical increase in TAG and DAG content parallel the insulin sensitizing effect of unilateral DGAT1 overexpression in rat skeletal muscle. PLoS ONE 2011; 6: e14503.

41. Goodpaster BH, Theriault R, Watkins SC, and Kelley DE. Intramuscular lipid content is increased in obesity and decreased by weight loss. Metabolism 2000; 49: 467-472.

42. Schrauwen-Hinderling V, Kooi M, Hesselink M, Jeneson J, Backes W, van Echteld C, van Engelshoven J, Mensink M, and Schrauwen P. Impaired in vivo mitochondrial function but similar intramyocellular lipid content in patients with type 2 diabetes mellitus and BMI-matched control subjects. Diabetologia 2007; 50: 113-120.

43. Van Loon LJC, Koopman R, Manders R, van der Weegen W, van Kranenburg GP, and Keizer HA. Intramyocellular lipid content in type 2 diabetes patients compared with overweight sedentary men and highly trained endurance athletes. Am J Physiol Endocrinol Metab 2004; 287: E558-E565. 


\section{SUPPLEMENTAL INFORMATION}

A

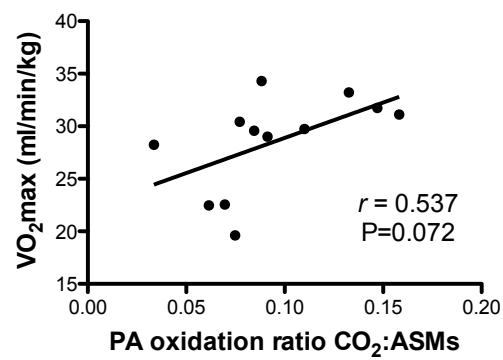

B

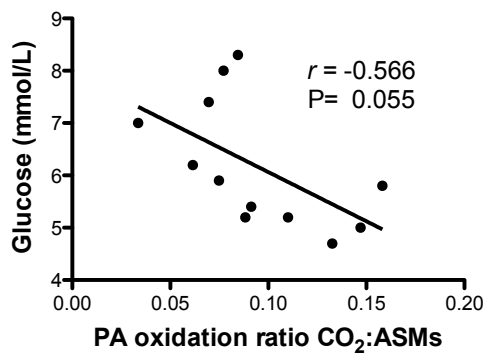

Supplemental Figure 1. Correlation of the ratio ${ }^{14} \mathrm{C}$-palmitate oxidation to $\mathrm{CO}_{2}: \mathrm{ASMs}$ with $(\mathbf{A})$ the $\mathrm{VO}_{2} \mathrm{max}$ and $(\mathbf{B})$ the fasting plasma glucose level. 


\section{CHAPTER 5}

\section{Perilipin 2 improves insulin sensitivity in skeletal muscle despite elevated intramuscular lipid levels}

Madeleen Bosma, Matthijs K.C. Hesselink, Lauren M. Sparks, Silvie Timmers, Maria João Ferraz, Frits Mattijssen, Denis van Beurden, Gert Schaart, Marc. H. de Baets, Fons K. Verheyen, Sander Kersten,

Patrick Schrauwen

Diabetes 2012; 61: 2679-2690 


\section{ABSTRACT}

Type 2 diabetes is characterized by excessive lipid storage in skeletal muscle. Excessive intramyocellular lipid storage exceeds intracellular needs and induces lipotoxic events ultimately contributing to the development of insulin resistance. Lipid droplet (LD)-coating proteins may control proper lipid storage in skeletal muscle. Perilipin 2 (PLIN2/ADRP) is one of the most abundantly expressed LD-coating proteins in skeletal muscle. Here we examined the role of PLIN2 in myocellular lipid handling and insulin sensitivity by investigating the effects of in vitro PLIN2 knockdown and in vitro and in vivo overexpression. PLIN2 knockdown decreased LD formation and triacylglycerol storage, marginally increased FA oxidation, and increased incorporation of palmitate into diacylglycerols and phospholipids. PLIN2 overexpression in vitro increased intramyocellular TAG storage paralleled with improved insulin sensitivity. In vivo musclespecific PLIN2 overexpression resulted in increased LD accumulation and blunted the highfat diet-induced increase of OXPHOS protein content. Diacylglycerol levels were unchanged, while ceramide levels were increased. Despite the increased intramyocellular lipid accumulation, PLIN2 overexpression improved skeletal muscle insulin sensitivity. We conclude that PLIN2 is essential for lipid storage in skeletal muscle by enhancing the partitioning of excess FAs towards TAG storage in LDs thereby blunting lipotoxicityassociated insulin resistance. 


\section{INTRODUCTION}

Lipid droplets serve an essential function in eukaryotic cells. Accordingly intracellular lipid levels need to be tightly controlled. Indeed, inappropriate intracellular lipid storage leads to impaired cellular function. In obesity, lipids will overflow into the circulation as a result of lack of storage capacity in adipose tissue and as a consequence lipids may accumulate ectopically in tissues including skeletal muscle (intramyocellular lipids, IMCL). This ectopic fat storage exceeds intracellular demand and may result in lipotoxic events including the development of insulin resistance (reviewed in [1, 2]). Paradoxically, IMCL is increased in both endurance-trained athletes and type 2 diabetic patients [3, 4], indicating that ectopic lipid accumulation per se does not induce insulin resistance.

Thus far, explanations for this athlete's paradox have focused on lipid turnover, oxidative capacity, and levels of lipid intermediates [5-8]. Interestingly, one exercise session was shown to prevent lipid-induced insulin resistance by partitioning more fatty acids towards triacylglycerol (TAG) synthesis in skeletal muscle [9]. Therefore, increasing the depot for TAG storage might improve insulin sensitivity. Intracellular TAG is stored in lipid droplets, which are increasingly recognized as dynamic organelles. They are composed of a neutral lipid core containing TAG, diacylglycerol (DAG), cholesterolesters, retinol esters, and free cholesterol [10] surrounded by a phospholipid monolayer [11] and a protein coat, composed of a variety of LD-coating proteins (reviewed in [12]). Accumulating evidence suggests that LD-coating proteins mediate LD dynamics including LD synthesis, growth and fusion, intracellular transport, organelle interactions, and LD breakdown and lipolysis (reviewed in [13, 14].

The best characterized family of LD-coating proteins is the PLIN protein family, including perilipin (PLIN1), perilipin 2 (PLIN2, adipophilipin, ADRP), perilipin 3 (PLIN3, TIP47), perilipin 4 (PLIN4, S3-12), and perilipin 5 (PLIN5, OXPAT). Whereas PLIN1 expression is restricted to adipose tissue, where it plays a crucial role in the control of storage and degradation of lipid droplets $[15,16]$, PLIN2 is expressed in several tissues including liver, small intestine and skeletal muscle $[17,18]$. PLIN2 in skeletal muscle was previously shown to colocalize with IMCL [19]. Interestingly, skeletal muscle PLIN2 gene expression was shown to be lower in type 2 diabetics versus obese controls [20]. Furthermore, weight loss as well as metformin treatment, both resulting in lower IMCL levels [21, 22], were demonstrated to increase skeletal muscle PLIN2 levels in parallel with improved insulin sensitivity [23]. PLIN2 may be involved in the protection against lipotoxicity by facilitating efficient IMCL storage in the form of TAG. However, loss- and gain of function studies to characterize PLIN2 function in skeletal muscle, required to obtain more functional insight into the role of PLIN2 in muscle, have not been performed to date. Here we aimed to examine the role of PLIN2 in myocellular fat accumulation, lipotoxicity and insulin sensitivity. 


\section{MATERIALS AND METHODS}

\section{Cell culture experiments}

C2C12 cells (LGC standards, Teddington, USA) were maintained in DMEM (Invitrogen, Breda, The Netherlands) containing antibiotics supplemented with $10 \%$ FCS, grown on ECM matrigel (Sigma, St. Louis, USA) coated cell culture plates (Greiner Bio-One, Alphen aan de Rijn, The Netherlands), and differentiated over the course of a week in DMEM supplemented with $2 \%$ FCS (differentiation media). Cells were treated with $200-800 \mu \mathrm{M}$ fatty acids (6-24h) (octanoic acid, oleic acid or palmitic acid conjugated to BSA, ratio BSA to FA 1:2.5), or solely BSA as a control. For RNAi experiments, cells were transfected with 10 nM Stealth RNAi oligos using Lipofectamine RNAiMAX (Invitrogen, Breda, The Netherlands) as transfection reagent. PLIN2 overexpression was achieved by transfections with pENTR1A-pUC Plin2-construct with Lipofectamine-2000 (Invitrogen, Breda, The Netherlands).

\section{Lipid metabolism}

In vitro ${ }^{14} \mathrm{C}$-palmitate metabolism was measured as described [24]. Intracellular triglyceride levels were measured using the method of Schwartz and Wolins [25].

\section{Glucose uptake assay}

Glucose uptake was measured as described [26].

\section{Animal studies}

C5BI6 mice were fed a low fat (10E\% fat) or a high fat (45E\% fat) diet (Research Diet Services, Wijk bij Duurstede, The Netherlands) for 8 weeks. Tibialis anterior was dissected. 7-week old male Wistar rats were purchased from Charles River (Wilmington, Massachusetts, USA). Rats were fed either a chow diet $(n=4)$ (SSNIFF', Bio Services, Uden, The Netherlands) or a high fat diet $(n=12)$ (45\% energy from fat, D01060502, Research Diets, New Brunswick, NJ, USA). The Institutional Animal Care and Use Committee of Maastricht University approved the experiments. The total intervention lasted 3 weeks. One week after the start of the diets, rats were cannulated, followed by gene electroporation and the hyperinsulinemic euglycemic clamp, with one-week recovery periods in-between.

\section{Electroporation}

Overexpression of mouse PLIN2 in the left tibialis anterior (TA) muscle of the rat was accomplished by an in vivo DNA electroporation technique under isoflurane anesthesia. Left TA muscles were transcutaneously injected with $75 \mu \mathrm{g}$ pENTR1A-pUC Plin2-construct, right TA muscles were injected with empty vector as a control. Within $15 \mathrm{~s}$ after the last injection one high voltage pulse of $800 \mathrm{~V} / \mathrm{cm}$ and four low voltage pulses of $80 \mathrm{~V} / \mathrm{cm}$ at 
$1 \mathrm{~Hz}$ were generated by an ECM 830 electroporator (BTX, San Diego, CA, USA) as described before [27].

\section{Hyperinsulinemic euglycemic clamp}

Clamps were performed as previously described [28]. Briefly, after a $6 \mathrm{~h}$ fast, a continuous infusion of insulin was administered at a rate of $13 \mathrm{mU} / \mathrm{kg} / \mathrm{min}$ for $120 \mathrm{~min}$. The glucose infusion rate was adjusted to maintain blood glucose concentration within the range of 4.5-5.5 mM. Rats were conscious during the full procedure. $45 \mathrm{~min}$ before completion of the clamp, a bolus of $140 \mu \mathrm{Ci} / \mathrm{kg}$ of $2-\left[{ }^{3} \mathrm{H}(\mathrm{N})\right]$-deoxy-D-glucose was administered.

\section{Lipid species}

Skeletal muscle DAG, TAG and ceramide levels were measured as described [28].

\section{Western blots}

Western blotting studies were performed using antibodies directed against PLIN2 (Progen, Heidelberg, Germany), PLIN3 (Santa Cruz, Heidelberg, Germany), PLIN5 (Progen, Heidelberg, Germany), pAkt and Akt, ATGL (Cell Signalling Technology, Leiden, the Netherlands), CGI-58 (Novus Biologicals, Littleton, USA), PGC1 $\alpha$ (Calbiochem, Amsterdam, The Netherlands), UCP3 (kindly provided by L.J. Slieker, Eli Lilly), and OXPHOS (Mitosciences, Eugene, Oregon, USA). Protein expression values were standardized against actin protein expression (Sigma, St. Louis, USA). Secondary antibodies contained an infrared dye (IRdye). Protein quantification was performed by scanning on an Odyssey Infrared Imaging system (LI-COR Biotechnology, Lincoln, Nebraska, USA).

\section{Statistical analysis}

Differences between groups were evaluated with Univariate ANOVA followed by Tukey's honestly significant difference post-hoc tests (cell studies), unpaired (cell studies) or paired T-tests (animal experiments). $\mathrm{P}<0.05$ was considered statistically significant.

\section{RESULTS}

\section{PLIN2 protein expression is induced upon lipid loading}

We first examined if TAG accumulation in myotubes is indeed associated with altered expression of PLIN2. To this end, C2C12 mouse myotubes were incubated with different types of fatty acids (FAs) $(200 \mu \mathrm{M})$ (Fig. 1A). Octanoate, a short-chain fatty acid that is preferentially oxidized, did not increase TAG levels, whereas incubation with either oleate or palmitate led to marked accumulation of myocellular TG as well as an increase in PLIN2 protein expression. The induction of PLIN2 protein levels was dependent on FA concentration, but reached the maximal induction at a FA concentration of $200 \mu \mathrm{M}$ (Supplementary Fig. 1A), and on FA incubation time, when the FA concentration was held constant at $200 \mu \mathrm{M}$ (Supplementary Fig. 1B). Next we determined the in vivo effects of 


\section{PLIN2 improves insulin sensitivity}

lipid overload on PLIN2 protein content. We found that both an 8-week HFD (Figure 1B) and 6 or 24 h hours of fasting (Supplementary Fig. 1C) significantly increased PLIN2 protein levels in mouse skeletal muscle.

\section{Knockdown of PLIN2 increases the cellular oxidative capacity}

The lack of LD storage capacity in PLIN2 knockdown cells may be compensated by enhanced fat oxidative capacity or reduced fatty acid uptake. To investigate these possibilities, we used an unbiased approach by implementing a whole genome expression analysis in the PLIN2 knockdown cells (Fig. 2 and Table 1). Specifically, overrepresentation analysis of functional Gene Ontology classes showed suppression of numerous pathways related to fatty acid transport and lipid storage (Fig. 2). Examples of genes that were downregulated upon PLIN2 knockdown include Fads2 and Agpat9 (Table 1). Furthermore, Gene Ontology classes corresponding to respiratory electron transport chain and glucose/ carbohydrate metabolism were increased upon PLIN2 knockdown (Fig. 2), indicating a compensatory increase in expression of genes involved in mitochondrial function (average PLIN2 knockdown effect across treatment conditions: Pgc1 $\alpha \mathrm{FC}=3.2$, Mterf FC=2.2, Mrps33 FC=1.5, Mfn1 FC=1.3, Mtrf1/ FC=1.8) (Table 1).

Consistent with the gene expression levels, knockdown of PLIN2 increased protein expression of OXPHOS complexes (Fig. $3 \mathrm{~A}$ and Fig S3) (total OXPHOS Univariate ANOVA PLIN2 knockdown effect $\mathrm{P}<0.05$, Complex I: $\mathrm{P}=0.095$, II: $\mathrm{P}=0.052, \mathrm{III}: \mathrm{P}<0.05$, and $\mathrm{V}$ : $\mathrm{P}<0.01)$. Therefore, we next investigated whether PLIN2 knockdown resulted in a compensatory increased capacity to oxidize fat in order to deal with the lower capacity for lipid storage by measuring ${ }^{14} \mathrm{C}$-palmitate oxidation. Knockdown of PLIN2 tended to increase total ${ }^{14} \mathrm{C}$-palmitate oxidation ( $\left.\mathrm{P}=0.055\right)$ (Fig. 3B). However, complete ${ }^{14} \mathrm{C}$ palmitate oxidation to $\mathrm{CO}_{2}$ was not affected (Fig. $3 \mathrm{C}$ ). Instead, the tendency to increased ${ }^{14} \mathrm{C}$-palmitate oxidation can probably be ascribed to an increase in incomplete oxidation (acid soluble metabolites-ASMs) ( $P=0.108$, Fig. 3D). Thus, PLIN2-knockdown effects on palmitate oxidation were modest, indicating that the increased mitochondrial density only partly compensated for the reduction in TAG storage capacity. 

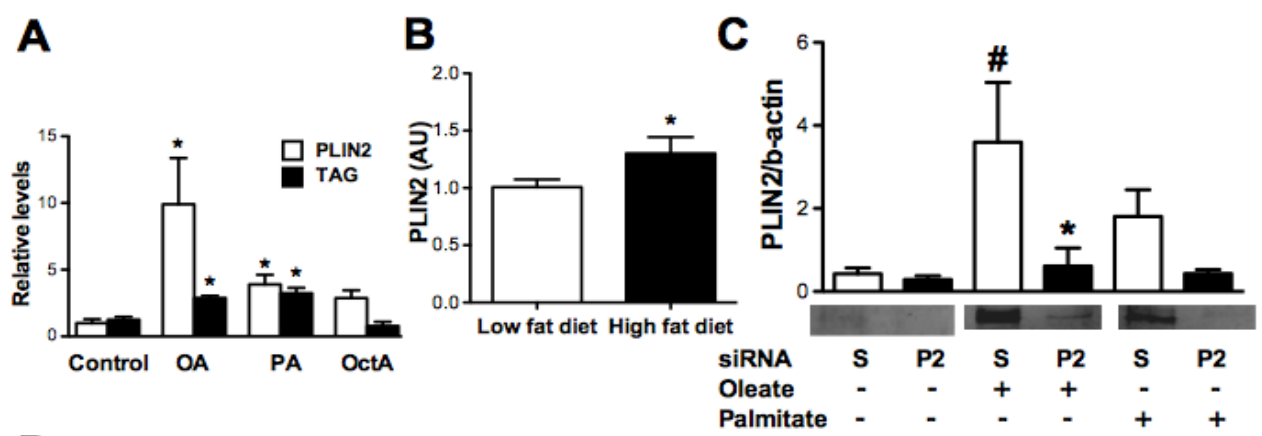

D
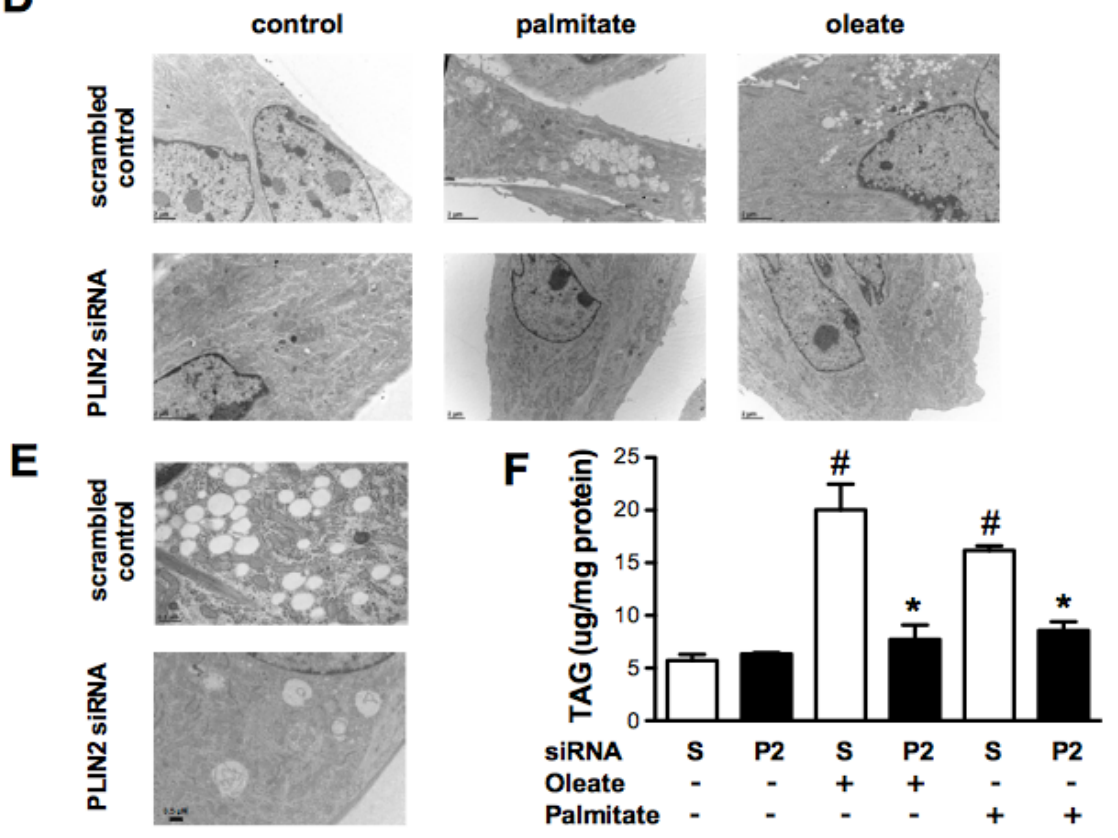

Figure 1. PLIN2 knockdown lowers intracellular neutral lipid accumulation. (A) C2C12 myotubes were incubated overnight with $80 \mu \mathrm{M}$ BSA complexed to $200 \mu \mathrm{M}$ oleate (OA), palmitate (PA), octanoate (OctA), or solely BSA as a control. PLIN2 and TAG levels are expressed as fold change relative to the control treatment. ${ }^{*} \mathrm{P}<0.05$ compared with the control treatment. (B) PLIN2 protein expression in tibialis anterior muscle of C57BI6 mice fed a high fat or normal chow diet for 8 weeks. (C-F) C2C12 myotubes were transfected with PLIN2 siRNA (P2) or a scrambled control (S) and incubated overnight with $200 \mu \mathrm{M}$ BSA-coupled oleate, palmitate or solely $80 \mu \mathrm{M}$ BSA. Subsequently, cells were harvested to measure PLIN2 protein expression (C) and TAG levels (F). ${ }^{\#} \mathrm{P}<0.05$ versus control (FA effect), ${ }^{*} P<0.05$ versus scrambled control with the corresponding FA treatment. Data are expressed as mean \pm SEM, $n=3-4$. ( $D$ and $E$ ) Electron microscopy pictures; (E) highlights the oleatetreatment condition (increased LD size upon PLIN2 knockdown). 


\section{PLIN2 improves insulin sensitivity}

\section{PLIN2 is essential for intracellular LD storage}

To obtain further insight into the importance of PLIN2 for efficient TAG storage, we knocked-down PLIN2 in myotubes using siRNA. Compared to PLIN2 levels in cells transfected with a scrambled control oligo, PLIN2 mRNA levels were reduced by $90 \%$ (Supplementary Fig. 2A) and protein levels decreased with $85 \%$ on average (Fig. 1C). The knockdown of PLIN2 prevented FA-induced TAG accumulation and LD formation even upon oleate or palmitate incubation, demonstrating that PLIN2 is essential for TAG storage in LDs (Fig. 1D-F). Protein expression of the LD-coating protein PLIN3 was not affected by PLIN2 knockdown, excluding a compensatory increase of this protein (Supplementary Fig. 2B). Please note that the LD-coating proteins PLIN1, PLIN4 and PLIN5 are not expressed in $\mathrm{C} 2 \mathrm{C} 12$ cells. Electron microscopic imaging confirmed that oleate and palmitate led to massive lipid accumulation in control cells, whereas this lipid accumulation was largely absent after FA loading in the PLIN2 knockdown cells (Fig. 1D-E). The few LDs that were present in PLIN2 knockdown cells were markedly larger in size compared to control cells.

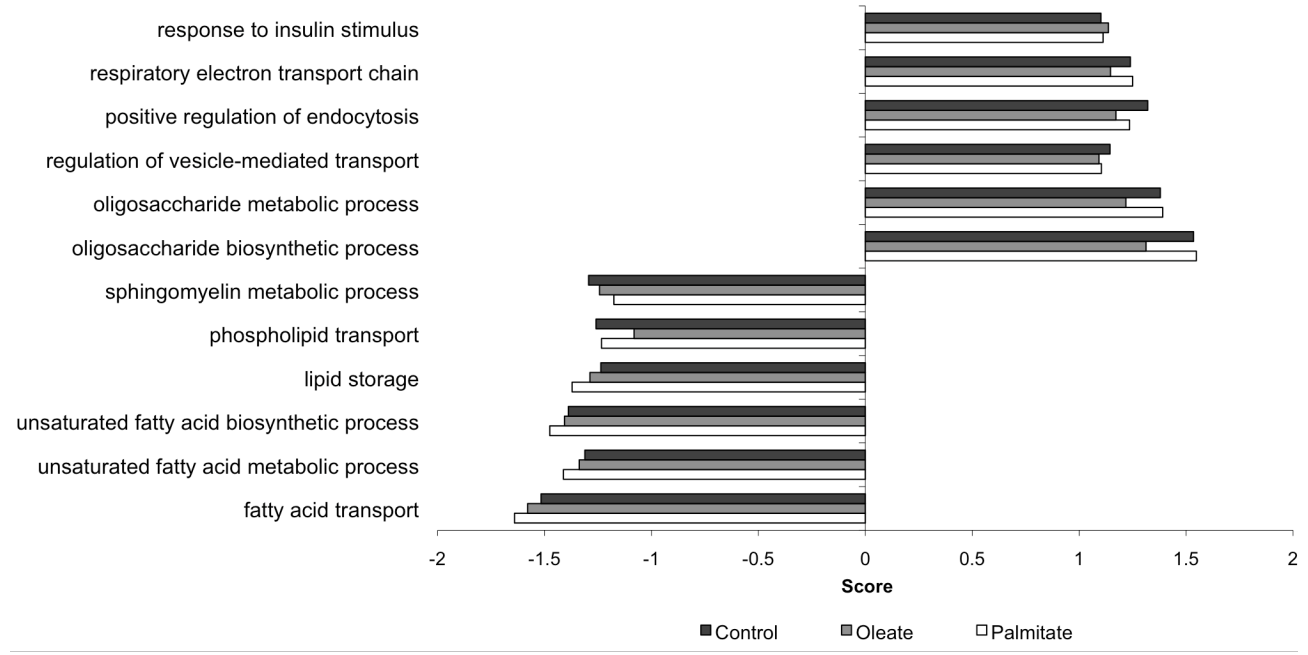

Figure 2. Gene-expression profiles. Selected pathways identified by Gene Score Resampling (GSR) in ErmineJ. Only pathways that were significantly up- or downregulated $(P<0.05)$ are shown. The enrichment score reflects the degree to which a gene set is overrepresented at the top (upregulated, positive score) or bottom (downregulated, negative score) of the ranked gene list and is corrected for gene set size. Black bars: control condition, grey bars: oleate, white bars: palmitate treatment. Microarray data have been submitted to Gene Expression Omnibus (GSE38590).

\section{Knockdown of PLIN2 increases palmitate incorporation into DAG and phospholipids}

In the PLIN2 knockdown situation, the lack of the capacity to store FAs as TAG in LDs resulted in a trend towards increased total FA oxidation, with the majority of ${ }^{14} \mathrm{C}$-palmitate being incompletely oxidized and accounted for in ${ }^{14} \mathrm{C}$-ASMs. Thus, another possibility to 
deal with FAs in the absence of cellular TAG storage capacity would be to store FAs in lipid species other than TAG. Therefore, ${ }^{14} \mathrm{C}$-palmitate incorporation into total neutral lipids, TAG, DAG, and phospholipids was determined. Compared with the scrambled control, a $3 \mathrm{~h}$ ${ }^{14} \mathrm{C}$-palmitate incubation of PLIN2 knockdown cells resulted in a lower incorporation of palmitate in the total neutral lipid pool $(P<0.01)$ (Fig. 3E). Besides decreased total intracellular lipid storage, FA incorporation into neutral lipids shifted from TAG towards DAG and phospholipids. ${ }^{14} \mathrm{C}$-palmitate incorporation into phospholipids and DAG was increased in the PLIN2 knockdown cells compared with the scrambled control cells $(P<0.01$ and $\mathrm{P}<0.05$, respectively), balancing the lower incorporation into TAG $(\mathrm{P}<0.01)$ (Fig. $3 \mathrm{~F}-\mathrm{H})$. PLIN2 knockdown did not compromise insulin signaling (Fig. $3 \mathrm{I}-\mathrm{J}, \mathrm{P}=0.0528$ for basal pAkt, $\mathrm{P}=0.82$ for insulin stimulated $\mathrm{pAkt}, \mathrm{P}=0.094$ for deoxyglucose uptake).

In summary, PLIN2 is essential for LD formation and stability and intracellular TAG storage. PLIN2 knockdown increases FA oxidation only marginally.

Table 1: Expression patterns of a selection of genes in the 6 treatment conditions, derived from pools of 4 samples per treatment condition.

\begin{tabular}{|c|c|c|c|c|c|c|c|c|}
\hline \multirow[b]{2}{*}{ Gene } & \multirow[b]{2}{*}{ GeneID } & \multirow[b]{2}{*}{ Gene name } & \multicolumn{3}{|c|}{$\begin{array}{c}\text { Negative } \\
\text { control }\end{array}$} & \multicolumn{3}{|c|}{$\begin{array}{c}\text { PLIN2 } \\
\text { knockdown }\end{array}$} \\
\hline & & & C & OA & PA & C & OA & PA \\
\hline Adfp & 11520 & Adipose differentiation related protein & 1 & 1.68 & 1.79 & 0.21 & 0.32 & 0.30 \\
\hline M6prbp1 & 66905 & $\begin{array}{l}\text { Mannose-6-phosphate receptor binding protein } \\
1 \text { (TIP47) }\end{array}$ & 1 & 1.06 & 0.97 & 1.07 & 0.98 & 1.07 \\
\hline Dgke & 56077 & Diacylglycerol kinase, $\varepsilon$ & 1 & 1.23 & 0.66 & 1.81 & 2.02 & 1.97 \\
\hline Fads2 & 56473 & Fatty acid desaturase 2 & 1 & 0.51 & 1.30 & 0.53 & 0.33 & 0.73 \\
\hline Pltp & 18830 & Phospholipid transfer protein & 1 & 1.31 & 0.83 & 0.41 & 0.44 & 0.37 \\
\hline Smpdl3b & 100340 & Sphingomyelin phosphodiesterase, acid-like 3B & 1 & 1.01 & 0.88 & 0.42 & 0.41 & 0.55 \\
\hline Elovi4 & 83603 & Elongation of very long chain fatty acids-like 4 & 1 & 0.99 & 0.85 & 0.65 & 0.70 & 0.53 \\
\hline Agpat4 & 68262 & 1-Acylglycerol-3-phosphate $O$-acyltransferase 4 & 1 & 1.01 & 0.91 & 0.51 & 0.57 & 0.57 \\
\hline Agpat9 & 231510 & 1-Acylglycerol-3-phosphate $O$-acyltransferase 9 & 1 & 1.33 & 1.42 & 0.50 & 0.61 & 0.59 \\
\hline Dgat2 & 67800 & Diacylglycerol O-acyltransferase 2 & 1 & 0.84 & 0.75 & 0.60 & 0.53 & 0.58 \\
\hline Dhrs3 & 20148 & Dehydrogenase/reductase member 3 & 1 & 1.30 & 1.95 & 0.58 & 0.74 & 0.66 \\
\hline Erlin2 & 244373 & ER lipid raft associated 2 & 1 & 1.12 & 1.07 & 1.70 & 1.53 & 1.70 \\
\hline Erlin1 & 226144 & ER lipid raft associated 1 & 1 & 1.25 & 1.13 & 1.47 & 1.68 & 1.70 \\
\hline Ppara & 19013 & Peroxisome proliferator activated receptor $\alpha$ & 1 & 1.28 & 1.00 & 1.75 & 1.59 & 1.50 \\
\hline Ppargc1a & 19017 & $\begin{array}{l}\text { Peroxisome proliferative activated receptor } \gamma \\
\text { coactivator } 1 \alpha\end{array}$ & 1 & 1.12 & 0.81 & 3.46 & 2.96 & 2.95 \\
\hline Mterf & 545725 & Mitochondrial transcription termination factor & 1 & 2.17 & 1.09 & 4.02 & 1.85 & 2.02 \\
\hline Mrps33 & 14548 & Mitochondrial ribosomal protein S33 & 1 & 1.33 & 1.38 & 2.00 & 2.18 & 1.30 \\
\hline Car3 & 12350 & Carbonic anhydrase 3 & 1 & 1.25 & 0.82 & 12.4 & 12.7 & 11.5 \\
\hline$M f n 1$ & 67414 & Mitofusin 1 & 1 & 1.01 & 0.95 & 1.29 & 1.37 & 1.31 \\
\hline Cpt1b & 12895 & Carnitine palmitoyltransferase $1 \mathrm{~b}$, muscle & 1 & 2.36 & 1.40 & 0.69 & 1.19 & 0.89 \\
\hline Mtrf1l & 108853 & Mitochondrial translational release factor 1-like & 1 & 1.40 & 1.26 & 2.32 & 2.07 & 1.93 \\
\hline Atp5g1 & 11951 & $\begin{array}{l}\text { ATP synthase, } \mathrm{H}+\text { transporting, mitochondrial F0 } \\
\text { complex, subunit c isoform } 1\end{array}$ & 1 & 1.92 & 0.91 & 1.04 & 2.73 & 0.97 \\
\hline Pdk2 & 18604 & Pyruvate dehydrogenase kinase, isoenzyme 2 & 1 & 0.98 & 0.84 & 1.74 & 1.94 & 1.68 \\
\hline
\end{tabular}




\begin{tabular}{|c|c|c|c|c|c|c|c|c|}
\hline Mlycd & 56690 & Malonyl-CoA decarboxylase & 1 & 1.82 & 1.01 & 1.19 & 1.67 & 1.57 \\
\hline Atp13a5 & 268878 & ATPase type $13 \mathrm{~A} 5$ & 1 & 1.05 & 0.72 & 2.85 & 2.68 & 2.31 \\
\hline Gk5 & 235533 & Glycerol kinase 5 & 1 & 1.00 & 0.79 & 1.35 & 1.55 & 1.60 \\
\hline Lctl & 235435 & Lactase-like & 1 & 0.64 & 0.95 & 0.31 & 0.25 & 0.29 \\
\hline Rrad & 56437 & Ras-related associated with diabetes & 1 & 0.76 & 1.30 & 0.29 & 0.26 & 0.45 \\
\hline Rassf2 & 215653 & $\begin{array}{l}\text { Ras association (RalGDS/AF-6) domain family } \\
\text { member } 2\end{array}$ & 1 & 1.09 & 0.78 & 0.23 & 0.20 & 0.27 \\
\hline Fgf21 & 56636 & Fibroblast growth factor 21 & 1 & 0.77 & 0.84 & 0.21 & 0.23 & 0.20 \\
\hline Pld1 & 18805 & Phospholipase D1 & 1 & 1.18 & 0.83 & 1.62 & 1.56 & 1.63 \\
\hline Atf3 & 11910 & Activating transcription factor 3 & 1 & 1.05 & 1.97 & 0.40 & 0.43 & 0.42 \\
\hline $\operatorname{lgfbp3}$ & 16009 & Insulin-like growth factor binding protein 3 & 1 & 0.70 & 0.78 & 4.71 & 4.22 & 4.00 \\
\hline Mapk1 & 26413 & Mitogen-activated protein kinase 1 & 1 & 1.08 & 0.92 & 1.31 & 1.28 & 1.35 \\
\hline Gga2 & 74105 & $\begin{array}{l}\text { Golgi associated, } \gamma \text { adaptin ear containing, ARF } \\
\text { binding protein } 2\end{array}$ & 1 & 0.92 & 0.82 & 1.81 & 1.89 & 1.95 \\
\hline Gpr56 & 14766 & G protein-coupled receptor 56 & 1 & 0.59 & 0.88 & 0.09 & 0.08 & 0.09 \\
\hline Purb & 19291 & Purine rich element binding protein B & 1 & 1.01 & 1.16 & 0.46 & 0.47 & 0.51 \\
\hline Tnfrsf12a & 27279 & $\begin{array}{l}\text { Tumor necrosis factor receptor superfamily, } \\
\text { member } 12 a\end{array}$ & 1 & 0.84 & 1.11 & 0.59 & 0.64 & 0.55 \\
\hline
\end{tabular}

Expression levels in scrambled control cells without FA treatment was set at 1 and expression levels in other groups were related to this reference condition. qPCRs were performed for a selection of genes to validate the microarray data (Supplementary Fig. 3). C: Control (BSA); OA: oleate; PA: palmitate condition.

\section{PLIN2 overexpression protects against palmitate-induced impairments in insulin-stimulated glucose uptake}

Lipid intermediate accumulation other than TAG storage is considered to negatively affect insulin signaling [29], while efficient TAG storage is considered harmless [28, 30]. Results from the PLIN2 knockdown studies illustrate that PLIN2 is necessary for efficient storage of FAs into inert TAG. Therefore, we next investigated whether overexpression of PLIN2 could facilitate efficient muscle TAG storage, and thereby prevent fat-induced impairments in insulin signaling. Hence, we overexpressed PLIN2 in vitro in order to investigate its potential beneficial effects on intramyocellular lipid handling. PLIN2 overexpression resulted in a two-fold increase in PLIN2 expression (Fig. 4A), a 6-fold increased intracellular TAG storage $(P=0.04)$ (Fig. $4 B$ ), and increased ${ }^{14} \mathrm{C}$-palmitate incorporation into total neutral lipids $(P=0.013), D A G$ and TAG $(P=0.003$ and $P=0.042$, respectively) while decreasing its incorporation into phospholipids ( $P=0.006)$ (Fig. 4C-F). We next tested if PLIN2-facilitated intramyocellular TAG storage could prevent palmitateinduced disruptions in insulin signaling. To this end, PLIN2- and empty vector transfected C2C12 myotubes were incubated overnight with $400 \mu \mathrm{M}$ palmitate, known to impair insulin signaling [31]. In line with the hypothesis, PLIN2 overexpression rescued palmitatemediated impairments in insulin-stimulated glucose uptake (Fig. 4G) $(P<0.05)$. 


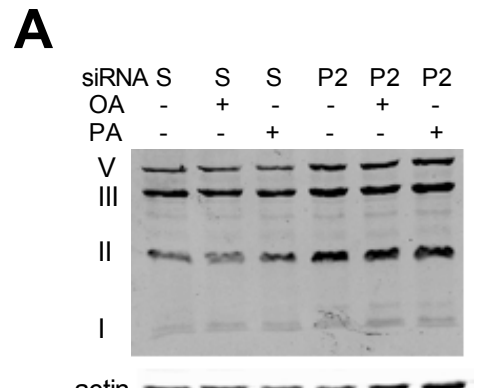

B
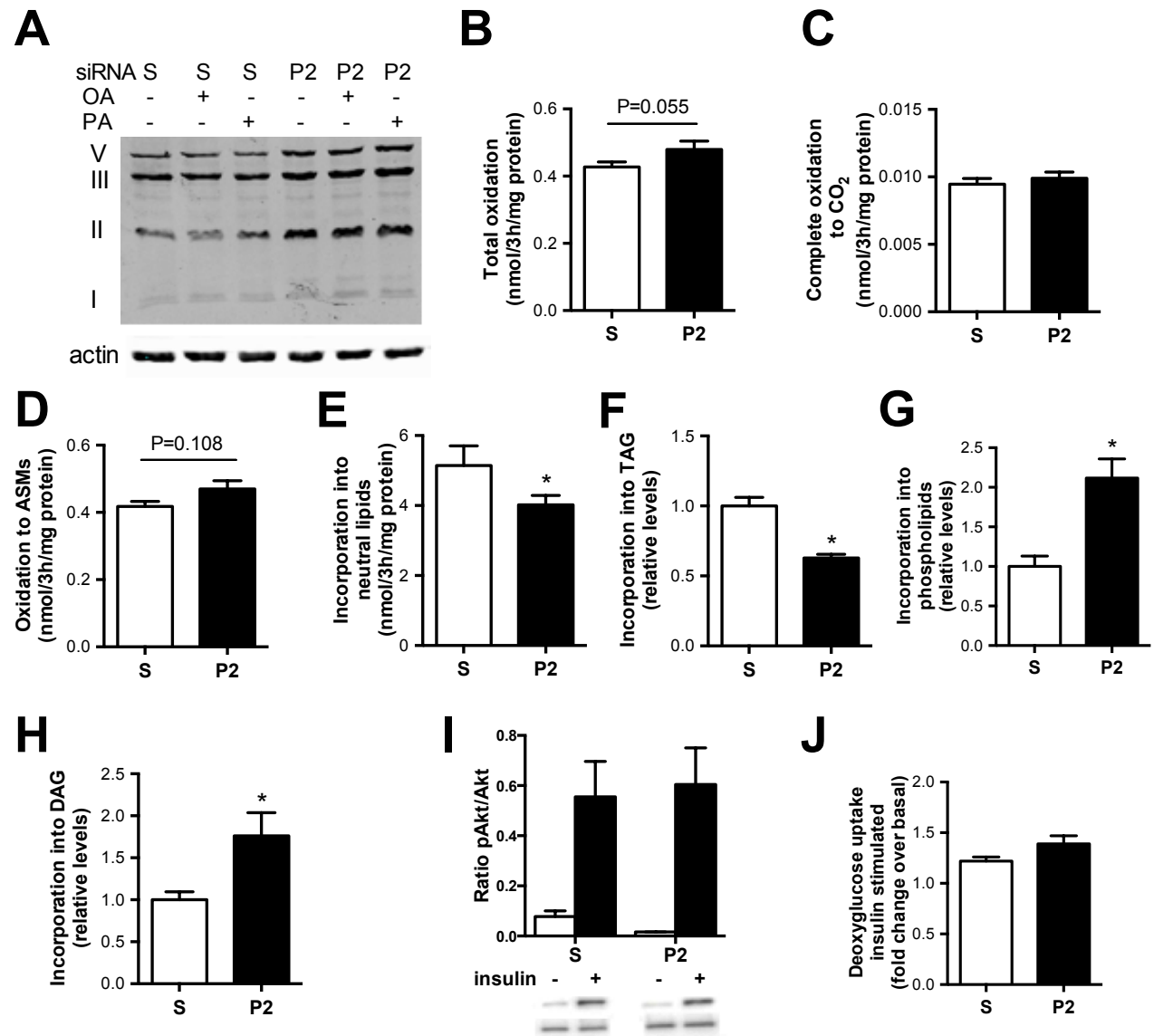

Figure 3. Altered lipid metabolism and oxidative capacity in PLIN2 knockdown cells. (A) Protein expression of the OXPHOS complexes I, II, III and V in cell cultures transfected with either PLIN2 siRNA [P2] or scrambled control siRNA [S], expressed as arbitrary units (AU), $n=4$ for each treatment condition. (B-E) Analysis of $3 \mathrm{~h}{ }^{14} \mathrm{C}$-palmitate oxidation rates in PLIN2 knockdown and negative control cells; total oxidation (sum of ${ }^{14} \mathrm{C}-\mathrm{CO}_{2}$ and ${ }^{14} \mathrm{C}-\mathrm{ASMs}$ ) (B), complete oxidation to $\mathrm{CO}_{2}$ (C), incomplete oxidation to acid soluble metabolites (ASMs) (D), $n=6$ per treatment condition. $(\mathrm{E}-\mathrm{H}){ }^{14} \mathrm{C}$ Palmitate incorporation into total neutral lipids (E), TAG (F), phospholipids (G), and DAG (H). Values were normalized to protein levels. Incorporation into TAG, DAG and phospholipids is expressed relative to the control condition. (I) Insulin-stimulated Akt phosphorylation (ratio pAkt/Akt). (J) Insulin-stimulated ${ }^{3} \mathrm{H}$-deoxyglucose uptake. ${ }^{*} \mathrm{P}<0.05$, error bars represent $\mathrm{SEM}$.

\section{In vivo, unilateral overexpression of PLIN2}

To investigate if PLIN2 overexpression also has beneficial effects on insulin sensitivity in vivo, we overexpressed PLIN2 unilaterally in muscle of rats fed chow or high fat diet (HFD). We used an in vivo gene electroporation method to achieve ectopic PLIN2 expression in rat tibialis anterior muscle in one leg, using the contralateral leg of the same animal as control. Marked overexpression of PLIN2 in rat tibialis anterior muscle was obtained, as demonstrated by Western blotting (2.5-fold on average in whole-muscle lysates) (Fig. 5A), 


\section{PLIN2 improves insulin sensitivity}

as well as immunofluorescence showing numerous LDs coated by PLIN2 (Figure 5B). Lipid droplets in PLIN2 overexpressing muscle were larger and more numerous (Fig. 5B-C), indicating increased IMCL levels upon PLIN2 overexpression.

A

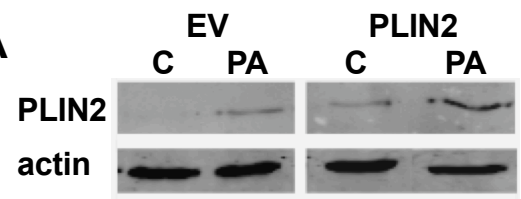

B

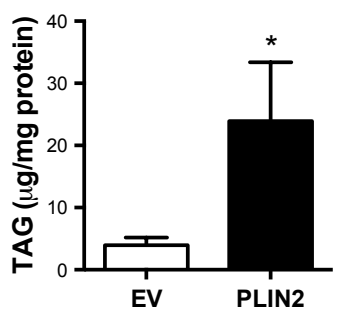

D

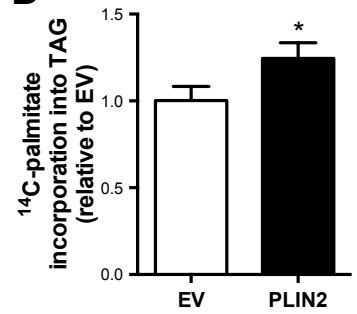

$\mathbf{F}$

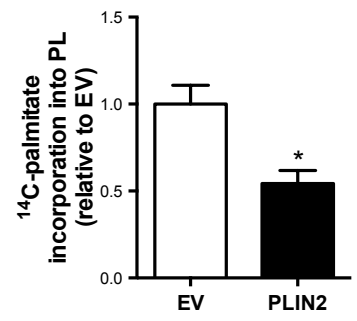

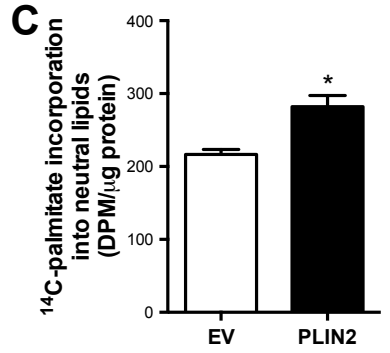

E

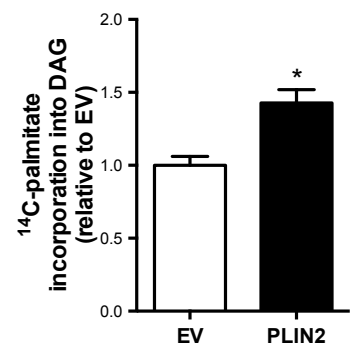

G

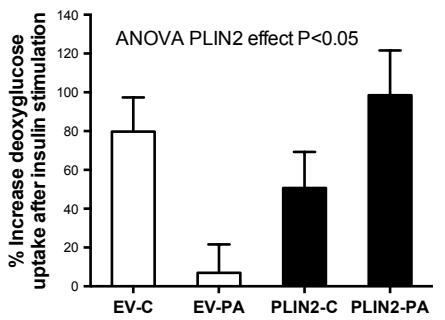

Figure 4. PLIN2 overexpression protects against palmitate-induced insulin resistance in $\mathrm{C} 2 \mathrm{C} 12$ myotubes. (A) Western blot demonstrating efficiency of PLIN2 overexpression. (B) TAG levels. (C-F) Incorpora-tion into (C) neutral lipids, (D) TAG, (E) DAG, and (F) phospholipids (PL). Incorporation into TAG, DAG and $P L$ is expressed relative to the control condition. (G) Insulin-stimulated deoxy-glucose uptake. EV: empty vector, PA: palmitate $(400 \mu \mathrm{M}), \mathrm{C}$ : control. ${ }^{*} \mathrm{P}<0.05$, error bars represent SEM.

An unbiased whole genome expression analysis revealed that genes related to lipid metabolism and mitochondrial fatty acid oxidation were differentially regulated in PLIN2electroporated versus control muscle in rats on the high fat diet (Table 2 and Supplementary Fig. 4). More specifically, examples of genes that were downregulated upon PLIN2 overexpression included PGC1 $\alpha$ (FC=-1.92), CPT2 (FC=-1.74) and the mitofusins (MFN1- FC=-1.53; MFN2- FC=-1.53) (Table 2). This group of downregulated genes was overrepresented in gene sets linked with oxidative phosphorylation, fatty acid oxidation, and mitochondrial function (Supplementary Fig. 4) and included PPAR $\alpha$ target 
genes (Supplementary Fig. S5). Upregulated genes included SCD1 (FC=1.62) and PPARY $(F C=1.57)$ and were associated with gene sets related to lipid storage and carbohydrate metabolism (Table 2). Thus, PLIN2 overexpression was associated with a metabolic profile consistent with a shift from FA oxidation towards lipid storage.

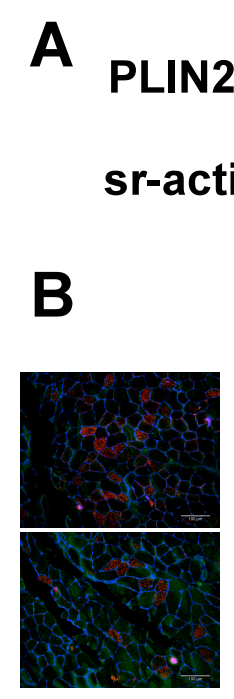

Empty vector
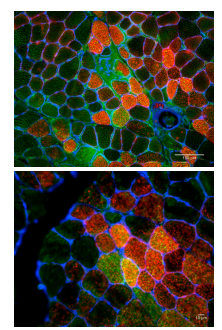

PLIN2
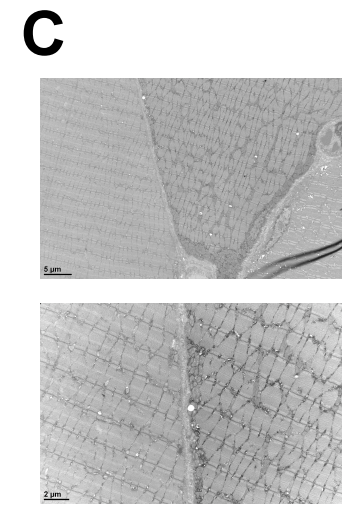

Empty vector
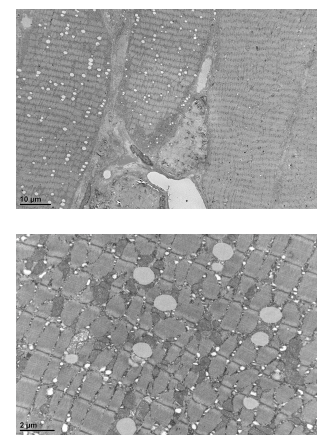

PLIN2

Figure 5. Gene-electrotransfer-mediated over-expression of PLIN2 in rat tibialis anterior muscle. (A) Representative Western blot demonstrating overexpression of PLIN2 in the left tibialis anterior muscle. EV: empty vector. (B) Lipid accumulation (red; Oilred-O) and PLIN2 expression (green) (overlap of PLIN2 and lipids appears yellow, but depends on the place of the cross-cut through the intracellular lipid droplets) in tibialis anterior muscle sections of the right (control; empty vector) and left (PLIN2-vector) leg of rats fed a high fat diet. Cell membranes are stained in blue. Representative pictures are shown. The image on the right lower panel is a magnification of a selection of the picture above. (C) Ultrastructure (TEM) of muscle samples from sham electroporated and PLIN2 electroporated muscle.

\section{PLIN2 overexpression induces changes in the expression of proteins involved in lipid metabolism}

Western blottings were performed to extend the PLIN2 overexpression-mediated changes in gene expression to proteins involved in mitochondrial function (OXPHOS, PGC1 $\alpha$, UCP3) and lipolysis (ATGL, CGI-58, PLIN5). In the chow-fed group of animals, no significant changes in protein expression were observed upon PLIN2 overexpression. However, in rats fed the HFD for four weeks, protein levels of OXPHOS complexes I, III and V tended to be decreased by PLIN2 overexpression ( $\mathrm{P}=0.075$ for complex II) (Supplementary Fig. 6A), 


\section{PLIN2 improves insulin sensitivity}

suggesting that the HFD-induced upregulation of OXPHOS protein expression was blunted by PLIN2 overexpression. These results corresponded with the observed lower gene expression levels of genes related with mitochondrial function and fatty acid oxidation (Table 2 and Supplementary Fig. 4). PGC1 $\alpha$ protein expression as well as PLIN5, another LD-coating protein, which is supposed to be involved in oxidative processes [32], tended to be decreased upon PLIN2 overexpression ( $\mathrm{P}=0.062$ and $\mathrm{P}=0.078$, respectively) (Supplementary Fig. 6B-C). Protein expression of ATGL, CGI-58, and UCP3 were not significantly changed (Supplementary Fig. 6D-F).

Table 2: Heat map. Fold changes in gene expression for a selection of genes are given for PLIN2 versus empty-vector electroporated muscles. qPCRs were performed for a selection of genes to validate the microarray data (Supplementary Fig. 4).

\begin{tabular}{|c|c|c|c|c|}
\hline ID & Fold change & Gene & Unigene & Description \\
\hline 308100 & 2.63 & Acat3 & Rn.203063 & Acetyl-Coenzyme $\mathrm{A}$ acetyltransferase 3 \\
\hline 100359680 & 2.43 & $\begin{array}{l}\text { LOC1003596 } \\
80\end{array}$ & Rn.81758 & Lysophosphatidylcholine acyltransferase 2-like \\
\hline 313220 & 2.39 & Acnat2 & Rn.162815 & Acyl-coenzyme $\mathrm{A}$ amino acid $\mathrm{N}$-acyltransferase 2 \\
\hline 29347 & 2.23 & Faah & Rn.89119 & Fatty acid amide hydrolase \\
\hline 499210 & 2.18 & Acer3 & Rn.19122 & Alkaline ceramidase 3 \\
\hline 500973 & 2.12 & Slc37a2 & Rn.224149 & $\begin{array}{l}\text { Solute carrier family } 37 \text { (glycerol-3-phosphate transporter), } \\
\text { member } 2\end{array}$ \\
\hline 64035 & 2.09 & Pygl & Rn.21399 & Phosphorylase, glycogen \\
\hline 360622 & 2.05 & $\operatorname{lgfbp} 4$ & Rn.160666 & Insulin-like growth factor binding protein 4 \\
\hline 361401 & 1.99 & Pla2g15 & Rn.93631 & Phospholipase $A 2$, group XV \\
\hline 83730 & 1.94 & Vamp8 & Rn.82672 & Vesicle-associated membrane protein 8 \\
\hline 296474 & 1.93 & Pric285 & Rn.47450 & $\begin{array}{l}\text { Peroxisomal proliferator-activated receptor A interacting } \\
\text { complex } 285\end{array}$ \\
\hline 24377 & 1.91 & G6pd & Rn.11040 & Glucose-6-phosphate dehydrogenase \\
\hline 29411 & 1.9 & Ppt1 & Rn.1574 & Palmitoyl-protein thioesterase 1 \\
\hline 361527 & 1.9 & Pld3 & Rn.128036 & Phospholipase D family, member 3 \\
\hline 286896 & 1.83 & Sgp/1 & Rn.26953 & Sphingosine-1-phosphate lyase 1 \\
\hline 298199 & 1.76 & Adfp & Rn.101967 & Adipose differentiation related protein \\
\hline 296371 & 1.7 & Pltp & Rn.117434 & Phospholipid transfer protein \\
\hline 288707 & 1.7 & Gltp & Rn.4111 & Glycolipid transfer protein \\
\hline 29560 & 1.7 & Hif1a & Rn.10852 & Hypoxia-inducible factor $1, \alpha$ subunit \\
\hline 314649 & 1.69 & S1pr4 & Rn.225785 & Sphingosine-1-phosphate receptor 4 \\
\hline 294422 & 1.68 & Smpdl3a & Rn.8142 & Sphingomyelin phosphodiesterase, acid-like $3 \mathrm{~A}$ \\
\hline 361076 & 1.65 & RGD1561955 & Rn.200706 & Similar to diacylglycerol kinase $\eta$ \\
\hline 246074 & 1.64 & Scd1 & Rn.1023 & Stearoyl-CoA desaturase 1 \\
\hline 25096 & 1.63 & Pld1 & Rn.11130 & Phospholipase D1 \\
\hline 314360 & 1.6 & Galc & Rn.30608 & Galactosylceramidase \\
\hline 54315 & 1.59 & Ucp2 & Rn.13333 & Uncoupling protein 2 (mitochondrial, proton carrier) \\
\hline 24334 & 1.58 & Eno2 & Rn.10828 & Enolase $2, \gamma$, neuronal \\
\hline 25664 & 1.57 & Pparg & Rn.23443 & Peroxisome proliferator-activated receptor $\gamma$ \\
\hline 24654 & 1.53 & Plcb1 & Rn.45523 & Phospholipase C, beta 1 (phosphoinositide-specific) \\
\hline
\end{tabular}




\begin{tabular}{|c|c|c|c|c|}
\hline 25595 & 1.5 & Map2 & Rn.10484 & Microtubule-associated protein 2 \\
\hline 301265 & -3.19 & Adhfe1 & Rn.90768 & Phospholipase A2, group VII \\
\hline 291437 & -2.61 & St3gal6 & Rn.199051 & Lipase, endothelial \\
\hline 81782 & -2.42 & Cxcl14 & Rn.59 & Sterol $O$-acyltransferase 1 \\
\hline 308100 & -2.38 & Serh/2 & Rn.203063 & Acetyl-CoA acetyltransferase 3 \\
\hline 117243 & -3.31 & Acsl6 & Rn.33697 & Acyl-CoA synthetase long-chain family member 6 \\
\hline 114508 & -3.17 & $F b p 2$ & Rn.15319 & Fructose-1,6-bisphosphatase 2 \\
\hline 25747 & -3.04 & Ppara & Rn.9753 & Peroxisome proliferator activated receptor $\alpha$ \\
\hline 291135 & -2.71 & $A \cot 13$ & Rn.1730 & Acyl-CoA thioesterase 13 \\
\hline 79131 & -2.28 & Fabp3 & Rn.32566 & Fatty acid binding protein 3 , muscle and heart \\
\hline 311617 & -2.26 & Fitm2 & Rn.107822 & Fat storage-inducing transmembrane protein 2 \\
\hline 361637 & -2.24 & Acsm5 & Rn.35367 & Acyl-CoA synthetase medium-chain family member 5 \\
\hline 117035 & -2.05 & Slc25a20 & Rn.3289 & $\begin{array}{l}\text { Solute carrier family } 25 \text { (carnitine/acylcarnitine } \\
\text { translocase), member } 20\end{array}$ \\
\hline 252898 & -1.95 & Acox 2 & Rn.10622 & Acyl-CoA oxidase 2 , branched chain \\
\hline 171142 & -1.93 & Ehhadh & Rn.3671 & $\begin{array}{l}\text { Enoyl-Coenzyme A, hydratase/3-hydroxyacyl CoA } \\
\text { dehydrogenase }\end{array}$ \\
\hline 83516 & -1.92 & Ppargc1a & Rn.19172 & $\begin{array}{l}\text { Peroxisome proliferator-activated receptor } \gamma \text {, coactivator } \\
1 \alpha\end{array}$ \\
\hline 64304 & -1.87 & Acads & Rn.1167 & Acyl-CoA dehydrogenase, $C-2$ to $C-3$ short chain \\
\hline 29470 & -1.84 & Mecr & Rn.15375 & Mitochondrial trans-2-enoyl-CoA reductase \\
\hline 25413 & -1.74 & Cpt2 & Rn.11389 & Carnitine palmitoyltransferase 2 \\
\hline 305166 & -1.72 & Agpat9 & Rn.214521 & 1-Acylglycerol-3-phosphate O-acyltransferase 9 \\
\hline 25062 & -1.7 & Gpd2 & Rn.89705 & Glycerol-3-phosphate dehydrogenase 2, mitochondrial \\
\hline 305606 & -1.69 & Mtif2 & Rn.160632 & Mitochondrial translational initiation factor 2 \\
\hline 25288 & -1.68 & Acs/1 & Rn.6215 & Acyl-CoA synthetase long-chain family member 1 \\
\hline 25624 & -1.68 & Vamp1 & Rn.31977 & Vesicle-associated membrane protein 1 \\
\hline 252900 & -1.66 & Dgat2 & Rn.9523 & Diacylglycerol $O$-acyltransferase homolog 2 (mouse) \\
\hline 171155 & -1.66 & Hadhb & Rn.11253 & $\begin{array}{l}\text { Hydroxyacyl-CoA dehydrogenase/3-ketoacyl-CoA } \\
\text { thiolase/enoyl-CoA hydratase, } \beta \text { subunit }\end{array}$ \\
\hline 29653 & -1.65 & Gpam & Rn.44456 & Glycerol-3-phosphate acyltransferase, mitochondrial \\
\hline 25708 & -1.57 & Ucp3 & Rn.9902 & Uncoupling protein 3 (mitochondrial, proton carrier) \\
\hline 64476 & -1.56 & Mfn2 & Rn.8570 & Mitofusin 2 \\
\hline 192647 & -1.53 & Mfn1 & Rn.160939 & Mitofusin 1 \\
\hline 313510 & -1.52 & Atpaf1 & Rn.18579 & ATP synthase mitochondrial F1 complex assembly factor 1 \\
\hline 353229 & -1.52 & Sgms1 & Rn.55975 & Sphingomyelin synthase 1 \\
\hline 291567 & -1.52 & Ppargc1b & Rn.163382 & $\begin{array}{l}\text { Peroxisome proliferator-activated receptor gamma, } \\
\text { coactivator } 1 \beta\end{array}$ \\
\hline
\end{tabular}

PLIN2 overexpression augments myocellular fat storage while blunting high fat diet induced insulin resistance

We next investigated if the enhanced TAG storage capacity was associated with a reduction in the lipotoxic FA intermediates DAG and ceramides. Interestingly, despite increased IMCL accumulation, PLIN2 overexpression did not increase DAG levels (Fig. 6A), nor was the FA-composition (saturation and fatty acid chain length) of the DAG fraction 


\section{PLIN2 improves insulin sensitivity}

affected by PLIN2 overexpression (Supplementary Fig. 7). Thus, increased total intramyocellular lipid levels in PLIN2-overexpressing muscle were not paralleled by increased DAG levels, indicating that FAs were stored as TAG. Intriguingly, ceramide levels were increased by $23 \%$ (Fig. 6B) upon PLIN2 overexpression.

A

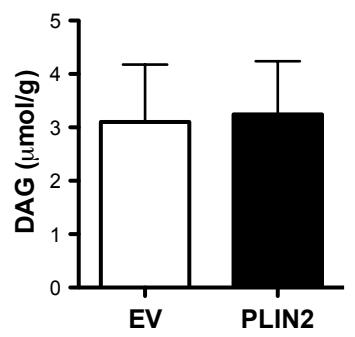

B

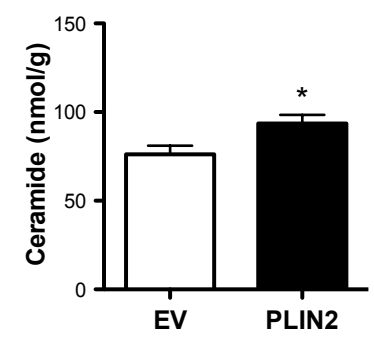

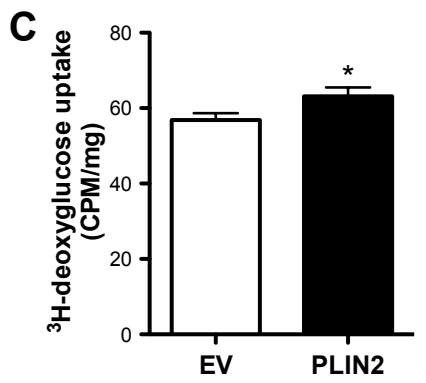

Figure 6. Overexpression of PLIN2 in tibialis anterior muscle of rats on a high fat diet improves insulin sensitivity of the muscle. (A) Skeletal muscle DAG and (B) ceramide levels in PLIN2- or empty vector (EV) electroporated muscle of rats on a high fat diet. (C) ${ }^{3} \mathrm{H}$-labeled deoxyglucose uptake in control and PLIN2-electroporated tibialis anterior muscle of rats on a high fat diet $(n=11)$. Error bars represent SEM.

PLIN2 overexpression thus increased IMCL levels concurrent with an altered gene expression profile favoring efficient fat storage rather than oxidation. Therefore, we investigated whether these consequences of PLIN2 overexpression would affect insulin sensitivity. To this end, a hyperinsulinemic euglycemic clamp was implemented. As anticipated, rats on the HFD gained significantly more weight compared with the rats on a control (chow) diet (chow $+1.91 \pm 0.41$ vs. HFD $+2.94 \pm 0.20 \mathrm{~g} / \mathrm{d}, \mathrm{P}=0.01$ ) and a HFD feeding period of 3 weeks sufficed to impede whole-body insulin sensitivity as indicated by a lower glucose infusion rate during the stable phase of the clamp (chow $31.8 \pm 1.0$ vs. HFD $26.6 \pm 1.6 \mathrm{mg} / \mathrm{min} / \mathrm{kg}, P=0.05)$. PLIN2-overexpression effects on insulin sensitivity were investigated in rats fed the HFD. During the stable phase of the clamp, ${ }^{3} \mathrm{H}$-labeled deoxyglucose was administered intravenously to investigate muscle-specific deoxyglucose uptake, comparing the PLIN2-overexpressing tibialis anterior muscle with the control sham-electroporated muscle of the same rat. Interestingly, despite the profoundly increased total intramyocellular lipid accumulation (Fig. 5B-C) and the increased ceramide levels (Fig. 6B), insulin sensitivity was not impaired in the PLIN2 overexpressing leg. Rather, deoxyglucose uptake significantly increased by $11.1 \%$ in the PLIN2 overexpressing leg compared with the control leg ( $P=0.045$ ) (Fig. 6C).

\section{DISCUSSION}

The protein coat of lipid droplets is an important interface for the regulation of intracellular lipid metabolism. PLIN2 is one of the main lipid droplet-coating proteins in 
non-adipose tissue. In the present study we demonstrate that PLIN2 plays an essential role in skeletal muscle IMCL storage. First of all we showed that PLIN2 is upregulated upon loading myotubes with long chain FAs and after prolonged consumption of a high fat diet or fasting in skeletal muscle of mice. These findings served as a first indication for a role for PLIN2 in skeletal muscle lipid metabolism. In subsequent loss of function experiments we demonstrate that PLIN2 plays an essential role in skeletal muscle lipid handling. siRNAmediated knockdown of PLIN2 prevented intramyocellular TAG storage. Moreover, palmitate incorporation into DAG and phospholipids was increased, indicating that PLIN2 is necessary for FA channeling to TAG in LDs and that in the absence of PLIN2, part of the FAs are channeled to storage in the form of lipid intermediates other than TAG. Moreover, LD accumulation was restricted to a few lipid droplets per myotube upon PLIN2 knockdown, indicating that PLIN2 is essential for the formation and/or stability of LDs. Studies towards subcellular localization of LDs indicated that PLIN2 might be involved in budding of LDs from ER or cell membrane structures [33,34]. Functional involvement of PLIN2 in LD synthesis has been shown in studies in fibroblasts and liver [35-37]. Our results support a role for PLIN2 in skeletal muscle LD synthesis, LD stability and TAG storage.

Next to a lowering in intramyocellular TAG content after PLIN2 knockdown, we observed less LDs, but the few existing LDs per cell had a larger size, indicating that the cell copes with the flux of FAs entering the cells by maximizing the volume-to-surface ratio in the few available lipid droplets. The latter is consistent with the study of Bell et al. in which PLIN2 knockdown was shown to decrease LD number while increasing LD size [38].

Enhancing the partitioning of excess FAs towards TAG storage is considered to be beneficial in preventing insulin resistance by limiting the accumulation of lipotoxic lipid species like ceramides, DAG and fatty acyl-CoA [28, 30]. As our knockdown studies demonstrated that PLIN2 is essential for intramyocellular TAG storage, we investigated whether PLIN2 overexpression would influence lipid metabolism and lipid-induced insulin resistance. Therefore, we determined the effects of in vitro PLIN2 overexpression in C2C12 myotubes and in vivo unilateral muscle-specific ectopic PLIN2 expression in rat tibialis anterior muscle. PLIN2 overexpression markedly augmented the accumulation of TAG in lipid droplets, which were both greater in number and larger in size, consistent with previous studies [36]. Short-term incorporation of palmitate into both TAG and DAG was increased upon PLIN2 overexpression in myotubes, indicating increased channeling of FAs towards storage. Increased total intramyocellular lipid levels upon prolonged PLIN2 overexpression in tibialis anterior muscle (7 days) were not paralleled by increased intramyocellular DAG levels, indicating that FAs were efficiently stored as neutral TAG. Moreover, the gene expression profiles show a shift towards increased gene expression of genes involved in lipid storage, further supporting the notion that PLIN2 facilitates intramyocellular TAG storage.

The increase in TAG accumulation was not paralleled with an increased oxidative capacity. In contrast, the HFD-induced increase in mitochondrial density was blunted upon PLIN2 overexpression and genes involved in FA oxidation and mitochondrial function were downregulated. One could hypothesize that an increased capacity to efficiently store TAG 


\section{PLIN2 improves insulin sensitivity}

in muscle would diminish the need for an increased fat oxidative capacity. Decreased expression of genes and proteins involved in fatty acid oxidation has been described previously in conditions of inhibited lipolysis [39, 40]. Recent studies show that the regulation of mitochondrial genes by their transcription factors PPAR $\alpha$ and PGC1 require fatty acids that are liberated by lipolysis from LD. Thus, ATGL deficient mice are characterized by a marked reduction in mitochondrial function, which can be rescued by administration of the PPAR agonist Wy14,643 [41]. Likewise, PLIN2 overexpression decreased gene expression of several PPAR $\alpha$ target genes. It could be hypothesized that PLIN2-facilitated LD storage reduces lipid turnover, leading to a reduced transcriptional activity of mitochondrial genes, consistent with the results of our micro-array analysis. In that respect, studies in hepatocytes and embryonic kidney cells reported an increased lipolysis after PLIN2 knockdown [37, 38, 40], indicating that PLIN2 shields the droplet from lipolysis. A proper balance between IMCL synthesis, lipolysis and oxidative metabolism ensures low local intracellular FA levels thereby preventing against lipotoxicity.

Our study is the first to examine the effects of overexpression of PLIN2 on insulin sensitivity. PLIN2 loss of function studies in tissues other than muscle showed inconsistent results on insulin sensitivity [38, 42-44]. Lowering of PLIN2 activity was demonstrated to improve liver insulin sensitivity in mice models of PLIN2 inhibition [43, 44], while siRNAmediated knockdown of PLIN2 plus PLIN3 in liver cells impaired insulin sensitivity [38]. In our study we hypothesized that overexpression of PLIN2 - by enhancing partitioning of excess fat towards TAG storage - would improve insulin sensitivity. Whereas in vitro PLIN2 knockdown in our hands did not affect insulin sensitivity, we did indeed find that PLIN2 overexpression completely rescued palmitate-induced impairments in insulin signaling, in parallel with increased intracellular TAG accumulation. We were able to extend this observation to the in vivo situation by showing improved insulin sensitivity in skeletal muscle of PLIN2-electroporated muscle of rats on a high fat diet, despite increased IMCL storage. While IMCL levels were increased, DAG levels were unaffected and unexpectedly, ceramide levels were increased upon PLIN2 overexpression. The latter is consistent with the study of Brown et al. [45], describing that increased ceramide levels associated with lowered lipase activity in liver did not impair insulin sensitivity [45], this leaves the option open that the subcellular localization of ceramide (rather than simply ceramide content) may be a determinant of the lipotoxic potential of ceramides.

One limitation of our in vivo study is that our results only apply to overexpression of PLIN2 in tibialis anterior muscle, which is mainly composed of type Ilb fibers. Glycolytic muscles are prone to lipid-induced insulin resistance [46]. Therefore, the observation that overexpression of PLIN2 resulted in excessive lipid storage in the predominantly glycolytic tibialis anterior muscle while at the same time improving insulin-stimulated glucose uptake indicates that PLIN2-mediated improved partitioning of FAs in LDs is a potent way to blunt lipid-induced insulin resistance.

We conclude that high levels of PLIN2 are beneficial for proper storage of TAG in skeletal muscle and thereby prevent the development of insulin resistance. In that respect, we recently observed increased PLIN2 levels in skeletal muscle after training as 
well as in trained compared with untrained subjects (unpublished data), providing additional evidence that high PLIN2 levels - even with high IMCL content - are associated with improved insulin sensitivity. Likewise, Coen et al. showed lower PLIN2 gene expression levels in skeletal muscle of insulin resistant obese subjects versus BMI-matched insulin sensitive controls [20] and both weight loss and pharmacological insulin sensitizing strategies (troglitazone or metformin) resulted in increased PLIN2 protein levels in skeletal muscle [23].

In summary, using in vitro and in vivo methods we establish that PLIN2 is an important facilitator of IMCL storage. PLIN2 is essential for myocellular TAG storage in lipid droplets. By improving IMCL storage, PLIN2 protects from lipotoxicity resulting in enhanced insulin sensitivity.

\section{REFERENCES}

1. Chow L, From A, and Seaquist E. Skeletal muscle insulin resistance: the interplay of local lipid excess and mitochondrial dysfunction. Metabolism 2010; 59: 70-85.

2. Goodpaster BH and Wolf D. Skeletal muscle lipid accumulation in obesity, insulin resistance, and type 2 diabetes. Pediatr Diabetes 2004; 5: 219-226.

3. Goodpaster BH, He J, Watkins S, and Kelley DE. Skeletal muscle lipid content and insulin resistance: evidence for a paradox in endurance-trained athletes. J Clin Endocrinol Metab 2001; 86: 5755-5761.

4. Van Loon LC and Goodpaster B. Increased intramuscular lipid storage in the insulin-resistant and endurance-trained state. Pflügers Arch 2006; 451: 606-616.

5. Bruce CR, Anderson MJ, Carey AL, Newman DG, Bonen A, Kriketos AD, Cooney GJ, and Hawley JA. Muscle oxidative capacity is a better predictor of insulin sensitivity than lipid status. J Clin Endocrinol Metab 2003; 88: 5444-5451.

6. Dubé JJ, Amati F, Stefanovic-Racic M, Toledo FGS, Sauers SE, and Goodpaster BH. Exercise-induced alterations in intramyocellular lipids and insulin resistance: the athlete's paradox revisited. Am J Physiol Endocrinol Metab 2008; 294: E882-888.

7. Meex RCR, Schrauwen-Hinderling VB, Moonen-Kornips E, Schaart G, Mensink M, Phielix E, van de Weijer T, Sels JP, Schrauwen P, and Hesselink MKC. Restoration of muscle mitochondrial function and metabolic flexibility in type 2 diabetes by exercise training is paralleled by increased myocellular fat storage and improved insulin sensitivity. Diabetes 2010; 59: 572-579.

8. Moro C, Bajpeyi S, and Smith SR. Determinants of intramyocellular triglyceride turnover: implications for insulin sensitivity. Am J Physiol Endocrinol Metab 2008; 294: E203-13.

9. Schenk $S$ and Horowitz JF. Acute exercise increases triglyceride synthesis in skeletal muscle and prevents fatty acid-(0)induced insulin resistance. J Clin Invest 2007; 117: 1690-1698.

10. DiAugustine RP, Schaefer JM, and Fouts JR. Hepatic lipid droplets. Isolation, morphology and composition. Biochem J 1973; 132: 323-7.

11. Tauchi-Sato K, Ozeki S, Houjou T, Taguchi R, and Fujimoto T. The surface of lipid droplets is a phospholipid monolayer with a unique fatty acid composition. J Biol Chem 2002; 277: 44507-44512.

12. Wolins NE, Brasaemle DL, and Bickel PE. A proposed model of fat packaging by exchangeable lipid droplet proteins. FEBS Lett 2006; 580: 5484-91.

13. Beller M, Thiel K, Thul PJ, and Jäckle H. Lipid droplets: A dynamic organelle moves into focus. FEBS Lett. 2010; 584: 2176-82.

14. Walther TC and Farese Jr RV. The life of lipid droplets. Biochim Biophys Acta 2009; 1791: 459-66.

15. Blanchette-Mackie EJ, Dwyer NK, Barber T, Coxey RA, Takeda T, Rondinone CM, Theodorakis JL, Greenberg AS, and Londos C. Perilipin is located on the surface layer of intracellular lipid droplets in adipocytes. J Lipid Res 1995; 36: 1211-1226. 


\section{PLIN2 improves insulin sensitivity}

16. Greenberg AS, Egan JJ, Wek SA, Garty NB, Blanchette-Mackie EJ, and Londos C. Perilipin, a major hormonally regulated adipocyte-specific phosphoprotein associated with the periphery of lipid storage droplets. J Biol Chem 1991; 266: 11341-11346.

17. Heid HW, Moll R, Schwetlick I, Rackwitz HR, and Keenan TW. Adipophilin is a specific marker of lipid accumulation in diverse cell types and diseases. Cell Tissue Res 1998; 294: 309-321.

18. Jiang HP and Serrero G. Isolation and characterization of a full-length cDNA coding for an adipose differentiation-related protein. Proc Natl Acad Sci 1992; 89: 7856-7860.

19. Minnaard R, Schrauwen P, Schaart G, Jorgensen JA, Lenaers E, Mensink M, and Hesselink MKC. Adipocyte differentiation-related protein and OXPAT in rat and human skeletal muscle: involvement in lipid accumulation and type 2 diabetes mellitus. J Clin Endocrinol Metab 2009; 94: 4077-85.

20. Coen PM, Dubé JJ, Amati F, Stefanovic-Racic M, Ferrell RE, Toledo FGS, and Goodpaster BH. Insulin resistance is associated with higher intramyocellular triglycerides in type I but not type II myocytes concomitant with higher ceramide content. Diabetes 2009; 59: 80-8.

21. Goodpaster BH, Theriault R, Watkins SC, and Kelley DE. Intramuscular lipid content is increased in obesity and decreased by weight loss. Metabolism 2000; 49: 467-472.

22. Teranishi T, Ohara T, Maeda K, Zenibayashi M, Kouyama K, Hirota Y, Kawamitsu H, Fujii M, Sugimura K, and Kasuga M. Effects of pioglitazone and metformin on intracellular lipid content in liver and skeletal muscle of individuals with type 2 diabetes mellitus. Metabolism 2007; 56: 1418-1424.

23. Phillips SA, Choe CC, Ciaraldi TP, Greenberg AS, Kong AP, Baxi SC, Christiansen L, Mudaliar SR, and Henry RR. Adipocyte differentiation-related protein in human skeletal muscle: relationship to insulin sensitivity. Obes Res 2005; 13: 1321-9.

24. Boschmann M, Engeli S, Moro C, Luedtke A, Adams F, Gorzelniak K, Rahn G, Mahler A, Dobberstein K, Kruger A, Schmidt S, Spuler S, Luft FC, Smith SR, Schmidt HHJ, and Jordan J. LMNA mutations, skeletal muscle lipid metabolism, and insulin resistance. J Clin Endocrinol Metab 2010; 1634-43.

25. Schwartz DM and Wolins NE. A simple and rapid method to assay triacylglycerol in cells and tissues. J Lipid Res 2007; 48: 2514-2520.

26. Hommelberg P, Plat J, Sparks L, Schols A, van Essen A, Kelders M, van Beurden D, Mensink R, and Langen R. Palmitate-induced skeletal muscle insulin resistance does not require NF-kB activation. Cell Mol Life Sci 2011; 68: 1215-1225.

27. Bruce CR, Hoy AJ, Turner N, Watt MJ, Allen TL, Carpenter K, Cooney GJ, Febbraio MA, and Kraegen EW. Overexpression of carnitine palmitoyltransferase- 1 in skeletal muscle is sufficient to enhance fatty acid oxidation and improve high fat diet-induced insulin resistance. Diabetes 2009; 58: 550-558.

28. Timmers S, de Vogel-van den Bosch J, Hesselink MKC, van Beurden D, Schaart G, Ferraz MJ, Losen M, Martinez-Martinez P, De Baets MH, Aerts JMFG, and Schrauwen P. Paradoxical increase in TAG and DAG content parallel the insulin sensitizing effect of unilateral DGAT1 overexpression in rat skeletal muscle. PLoS ONE 2011; 6: e14503.

29. Samuel VT, Petersen KF, and Shulman GI. Lipid-induced insulin resistance: unravelling the mechanism. The Lancet 2010; 375: 2267-2277.

30. Liu L, Shi X, Choi CS, Shulman GI, Klaus K, Nair KS, Schwartz GJ, Zhang Y, Goldberg IJ, and Yu YH. Paradoxical coupling of triglyceride synthesis and fatty acid oxidation in skeletal muscle overexpressing DGAT1. Diabetes 2009; 58: 2516-2524.

31. Gaster M, Rustan AC, and Beck-Nielsen H. Differential utilization of saturated palmitate and unsaturated oleate: evidence from cultured myotubes. Diabetes 2005; 54: 648-656.

32. Wolins NE, Quaynor BK, Skinner JR, Tzekov A, Croce MA, Gropler MC, Varma V, Yao-Borengasser A, Rasouli $\mathrm{N}$, Kern PA, Finck BN, and Bickel PE. OXPAT/PAT-1 is a PPAR-induced lipid droplet protein that promotes fatty acid utilization. Diabetes 2006; 55: 3418-28.

33. Gao J and Serrero G. Adipose differentiation related protein (ADRP) expressed in transfected COS-7 cells selectively stimulates long chain fatty acid uptake. J Biol Chem 1999; 274: 16825-16830.

34. Robenek H, Hofnagel O, Buers I, Robenek MJ, Troyer D, and Severs NJ. Adipophilin-enriched domains in the ER membrane are sites of lipid droplet biogenesis. J Cell Sci 2006; 119: 4215-4224. 
35. Chang BH, Li L, Paul A, Taniguchi S, Nannegari V, Heird WC, and Chan L. Protection against fatty liver but normal adipogenesis in mice lacking adipose differentiation-related protein. Mol Cell Biol 2006; 26: 106376.

36. Imamura M, Inoguchi T, Ikuyama S, Taniguchi S, Kobayashi K, Nakashima N, and Nawata H. ADRP stimulates lipid accumulation and lipid droplet formation in murine fibroblasts. Am J Physiol Endocrinol Metab 2002; 283: E775-783.

37. Listenberger LL, Ostermeyer-Fay AG, Goldberg EB, Brown WJ, and Brown DA. Adipocyte differentiationrelated protein reduces the lipid droplet association of adipose triglyceride lipase and slows triacylglycerol turnover. J Lipid Res 2007; 48: 2751-2761.

38. Bell M, Wang H, Chen H, McLenithan JC, Gong D-W, Yang R-Z, Yu D, Fried SK, Quon MJ, Londos C, and Sztalryd C. Consequences of lipid droplet coat protein downregulation in liver cells: abnormal lipid droplet metabolism and induction of insulin resistance. Diabetes 2008; 57: 2037-2045.

39. Pinent M, Hackl H, Burkard TR, Prokesch A, Papak C, Scheideler M, Hämmerle G, Zechner R, Trajanoski Z, and Strauss JG. Differential transcriptional modulation of biological processes in adipocyte triglyceride lipase and hormone-sensitive lipase-deficient mice. Genomics 2008; 92: 26-32.

40. Sapiro JM, Mashek MT, Greenberg AS, and Mashek DG. Hepatic triacylglycerol hydrolysis regulates PPAR- $\alpha$ activity. J Lipid Res 2009; 50: 1621-9.

41. Wölkart G, Schrammel A, Dörffel K, Haemmerle G, Zechner R, and Mayer B. Cardiac dysfunction in adipose triglyceride lipase deficiency: Treatment with a PPAR $\alpha$ agonist. Br J Pharmacol 2011; 380-389.

42. Chang BHJ, Li L, Saha P, and Chan L. Absence of adipose differentiation related protein upregulates hepatic VLDL secretion, relieves hepatosteatosis and improves whole body insulin resistance in leptin-deficient mice. J Lipid Res 2010; 51: 2132-42.

43. Imai Y, Varela GM, Jackson MB, Graham MJ, Crooke RM, and Ahima RS. Reduction of hepatosteatosis and lipid levels by an adipose differentiation-related protein antisense oligonucleotide. Gastroenterology 2007; 132: 1947-54.

44. Varela GM, Antwi DA, Dhir R, Yin X, Singhal NS, Graham MJ, Crooke RM, and Ahima RS. Inhibition of ADRP prevents diet-induced insulin resistance. Am J Physiol Gastrointest Liver Physiol 2008; 295: G621-8.

45. Brown JM, Betters JL, Lord C, Ma Y, Han X, Yang K, Alger HM, Melchior J, Sawyer J, Shah R, Wilson MD, Liu X, Graham MJ, Lee R, Crooke R, Shulman GI, Xue B, Shi H, and Yu L. CGI-58 knockdown in mice causes hepatic steatosis but prevents diet-induced obesity and glucose intolerance. J Lipid Res 2010; 51: 33063315.

46. Levin MC, Monetti M, Watt MJ, Sajan MP, Stevens RD, Bain JR, Newgard CB, Farese RV, and Farese RV. Increased lipid accumulation and insulin resistance in transgenic mice expressing DGAT2 in glycolytic (type II) muscle. Am J Physiol Endocrinol Metab 2007; 293: E1772-E1781. 


\section{SUPPLEMENTAL INFORMATION}

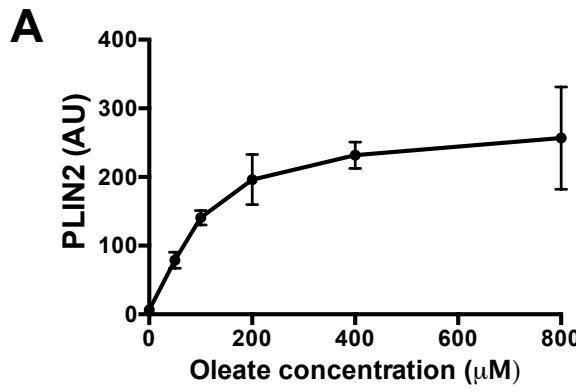

B
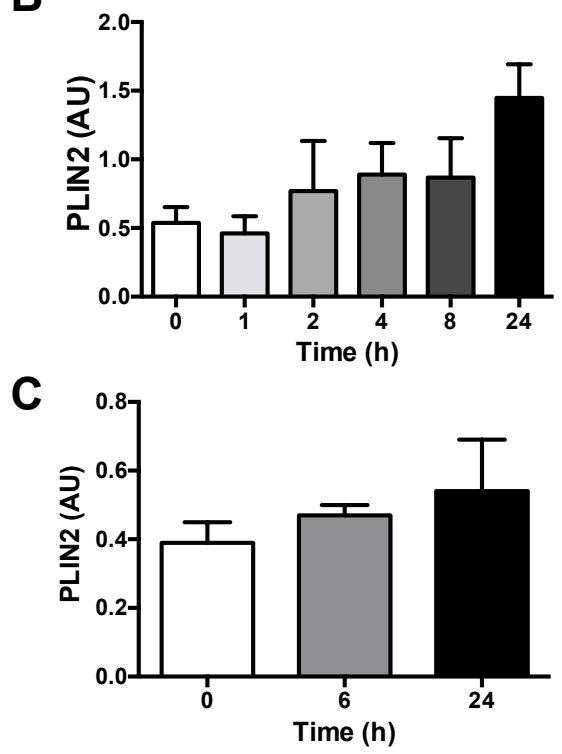

Figure S1. (A and B) C2C12 myotubes were incubated with BSA-complexed oleate. (A) Concentration range (oleate). (B) Time range ( 0 to $24 \mathrm{~h}$ following incubation with $200 \mu \mathrm{M}$ oleate). (C) PLIN2 protein expression was measured in gastrocnemius muscle of male Sv129 mice (2-3-monthold) after 0, 6 or $24 \mathrm{~h}$ of fasting (fasting was started at the onset of the light cycle) $(n=4$ 5 per group). ${ }^{*} \mathrm{P}<0.05$. 

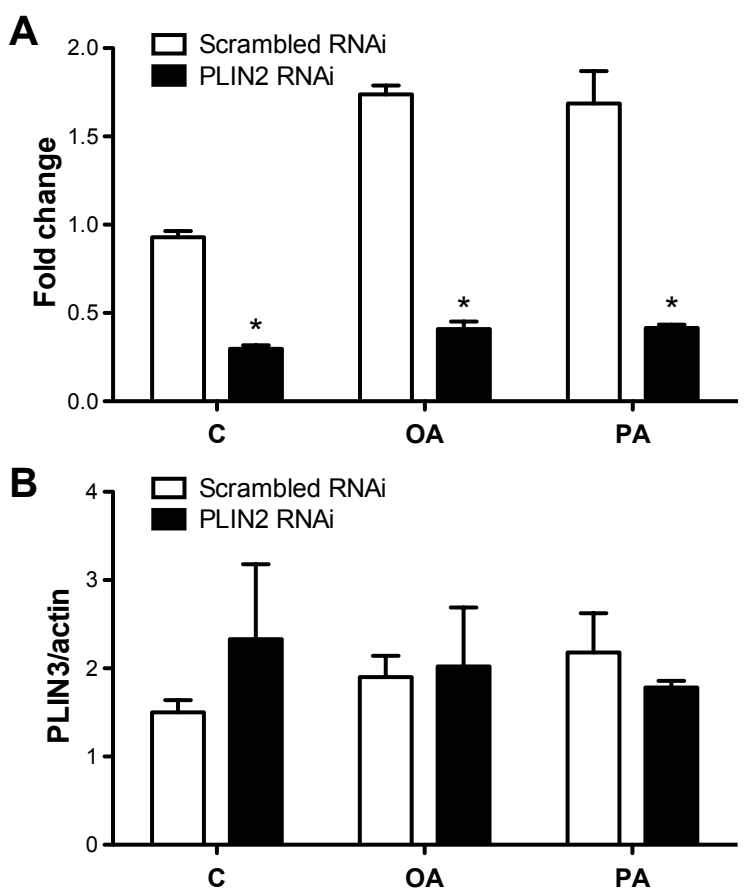

Figure S2. (A) Efficacy of siRNAmediated knockdown of PLIN2. C2C12 myotubes were transfected with PLIN2 siRNA or a scrambled control. RNA was isolated, reverse transcribed, and PLIN2 mRNA expression was measured by qPCR. (B) TIP47 protein expression was not affected by PLIN2 knockdown. C2C12 myotubes were transfected with PLIN2 siRNA or a scrambled control and incubated overnight with $200 \mu \mathrm{M}$ BSA-coupled oleate, palmitate or solely $80 \mu \mathrm{M}$ BSA. Subsequently, cells were harvested to measure TIP47/PLIN3 protein levels (total cell lysates). 


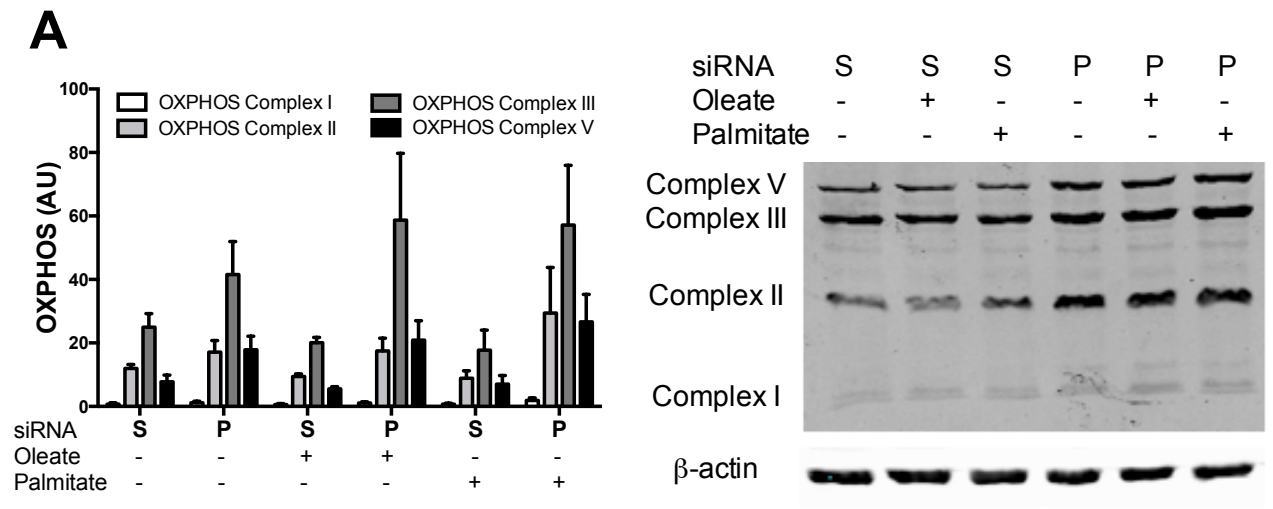

\section{B}
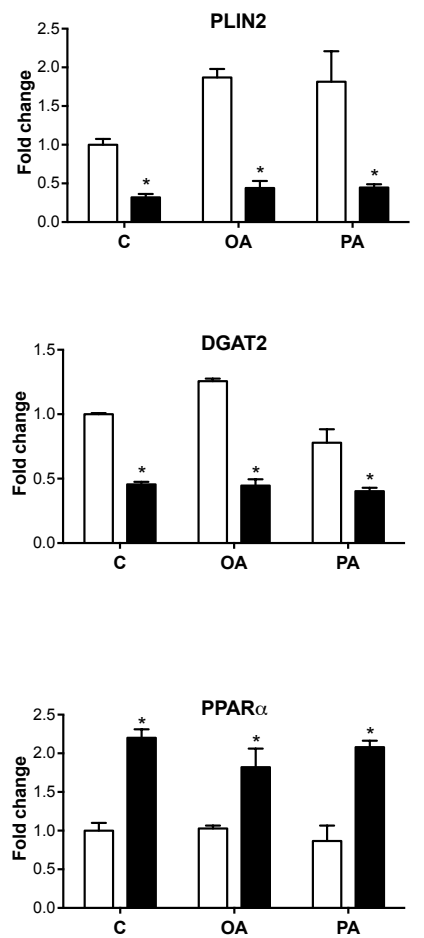
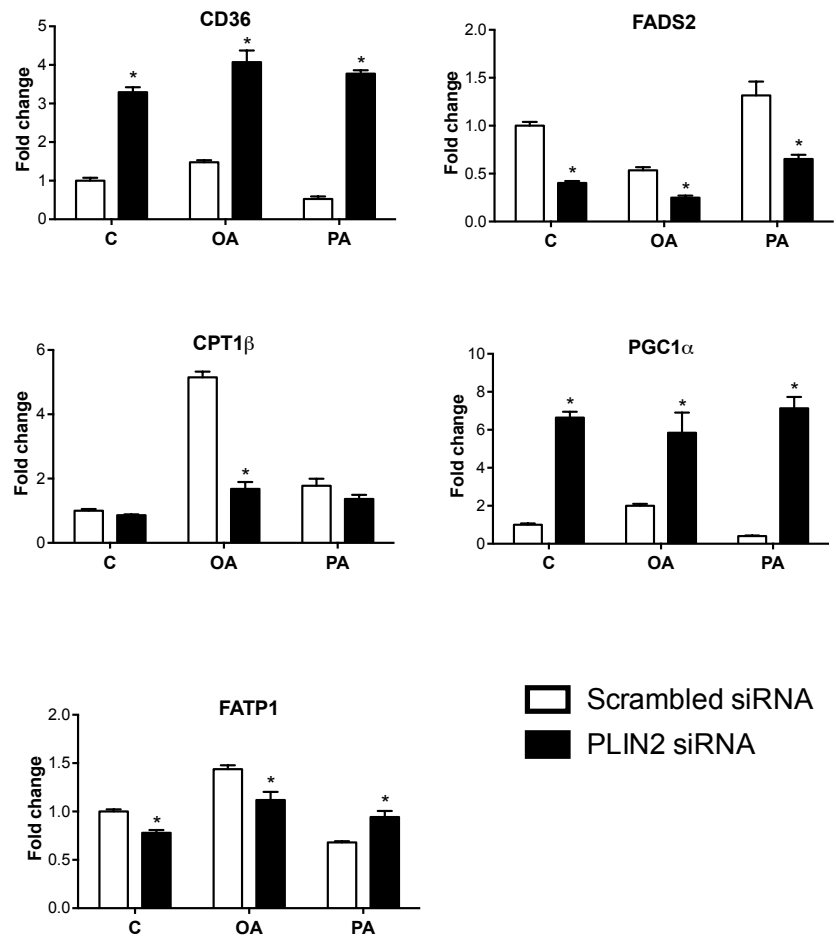

Figure S3. (A) Protein expression of the OXPHOS complexes I, II, III and V in cell cultures transfected with either PLIN2 siRNA [P2] or S-scrambled control siRNA [S], expressed as arbitrary units (AU), $n=4$ for each treatment condition. (B) Microarray validation: qPCRs were performed for a selection of genes. ${ }^{*} \mathrm{P}<0.05$. 
A

cellular lipid catabolic processcellular respirationacetyl-CoA catabolic process-

fatty acid catabolic processlipid oxidationregulation of fatty acid metabolic processfatty acid beta-oxidationlipid modificationmitochondrion organizationelectron transport chainrespiratory electron transport chainregulation of triglyceride metabolic processcarnitine transportmitochondrial respiratory chain complex assemblytriglyceride metabolic processshort-chain fatty acid metabolic processcarnitine shuttleoxidative phosphorylationtricarboxylic acid cycleATP synthesis coupled electron transportresponse to carbohydrate stimulusregulation of lipase activitypositive regulation of MAP kinase activityvesicle organizationcellular response to nutrient levelssphingolipid metabolic processresponse to lipidcellular response to nutrientsphingoid metabolic processceramide metabolic processcellular response to lipidlipid storagepositive regulation of lipid transportresponse to ATP-

B
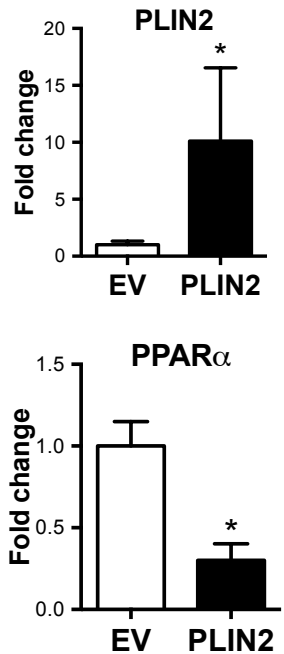

FABP3
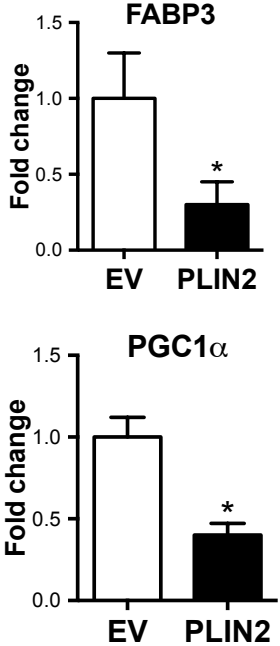
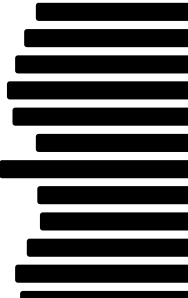

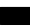
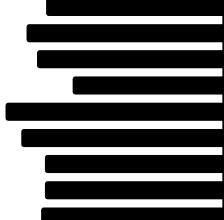

2

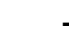

Score
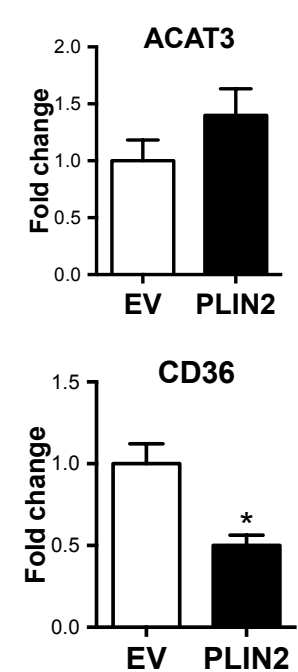

Figure S4. (A) Gene expression profile for PLIN2- or empty vector-electroporated muscles. Selected pathways identified by Gene Score Resampling (GSR) in ErmineJ. Only pathways that were significantly up- or downregulated $(\mathrm{P}<0.05)$ are shown. The enrichment score reflects the degree to which a gene set is overrepresented at the top (upregulated, positive score) or bottom (downregulated, negative score) of the ranked gene list and is corrected for gene set size. (B) qPCRs were performed for a selection of genes to confirm the microarray data. 
A

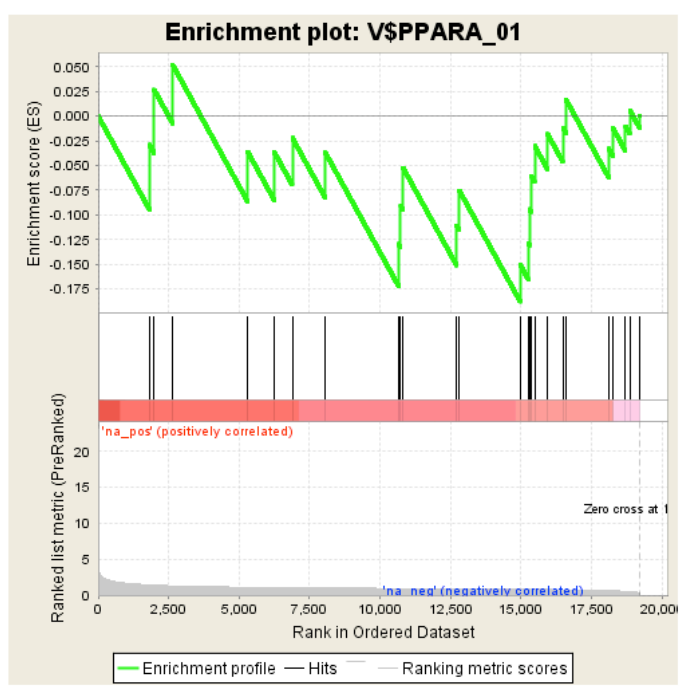

B

\begin{tabular}{|c|c|c|c|c|}
\hline PROBE & $\begin{array}{r}\text { RANK IN } \\
\text { GENE LIST } \\
\end{array}$ & $\begin{array}{r}\text { RANK METRIC } \\
\text { SCORE } \\
\end{array}$ & $\begin{array}{r}\text { RUNNING } \\
\text { ES } \\
\end{array}$ & $\begin{array}{r}\text { CORE } \\
\text { ENRICHMENT } \\
\end{array}$ \\
\hline MASP2 & 14972 & 0.832 & -0.15 & Yes \\
\hline NR2F6 & 15271 & 0.821 & -0.129 & Yes \\
\hline HOXD3 & 15306 & 0.82 & -0.094 & Yes \\
\hline MYH10 & 15362 & 0.818 & -0.06 & Yes \\
\hline ETFB & 18112 & 0.652 & -0.033 & Yes \\
\hline TOMM70A & 15486 & 0.814 & -0.03 & Yes \\
\hline DNAJA2 & 15940 & 0.796 & -0.018 & Yes \\
\hline PTPRG & 16483 & 0.77 & -0.012 & Yes \\
\hline ESRRA & 18254 & 0.635 & -0.012 & Yes \\
\hline PPARGC1A & 18709 & 0.564 & -0.01 & Yes \\
\hline FBP2 & 19210 & 0.286 & 0.001 & Yes \\
\hline CD36 & 18860 & 0.531 & 0.006 & Yes \\
\hline MLLT6 & 16597 & 0.764 & 0.017 & Yes \\
\hline PDZK1 & 10655 & 0.954 & -0.129 & No \\
\hline PEX16 & 12716 & 0.901 & -0.111 & No \\
\hline RTN4 & 10730 & 0.952 & -0.09 & No \\
\hline PAPLN & 12810 & 0.899 & -0.075 & No \\
\hline CACNB1 & 10818 & 0.949 & -0.052 & No \\
\hline HMGCS2 & 8056 & 1.025 & -0.037 & No \\
\hline PGF & 6247 & 1.086 & -0.036 & No \\
\hline SLC23A3 & 5297 & 1.127 & -0.036 & No \\
\hline SRC & 1817 & 1.467 & -0.029 & No \\
\hline KLF5 & 6885 & 1.063 & -0.022 & No \\
\hline SS18 & 1984 & 1.432 & 0.027 & No \\
\hline $\mathrm{BICC1}$ & 2642 & 1.322 & 0.052 & No \\
\hline
\end{tabular}

Figure S5. (A) Overrepresentation of PPAR $\alpha$ target genes in the group of genes that were downregulated upon PLIN2 electroporation. (A) Enrichment plot (GSEA gene set enrichment analysis). (B) Genes included in this gene set. These genes have the promoter regions [$2 \mathrm{~kb}, 2 \mathrm{~kb}$ ] around transcription start site that contain the motif CARAACTAGGNCAAAGGTCA which matches annotation for PPAR $\alpha$. 
A

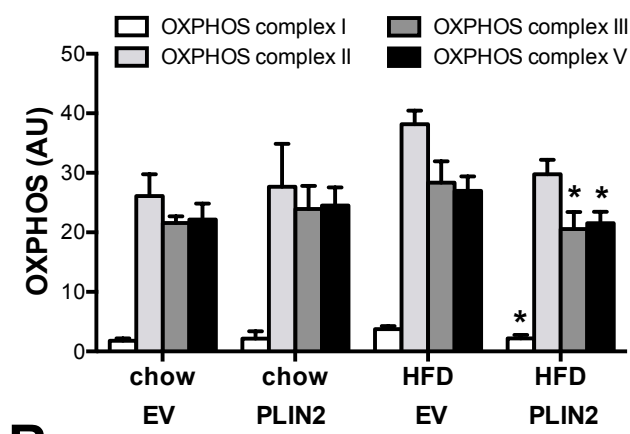

B

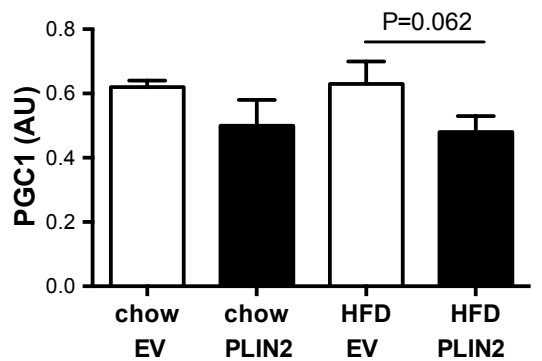

D

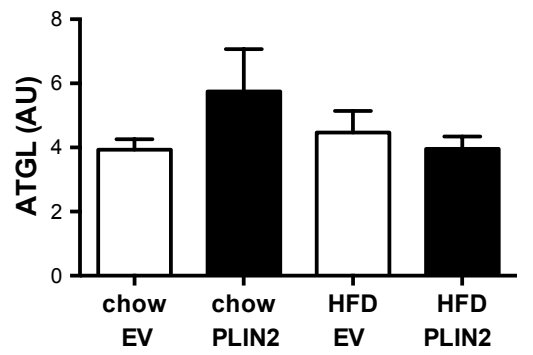

F

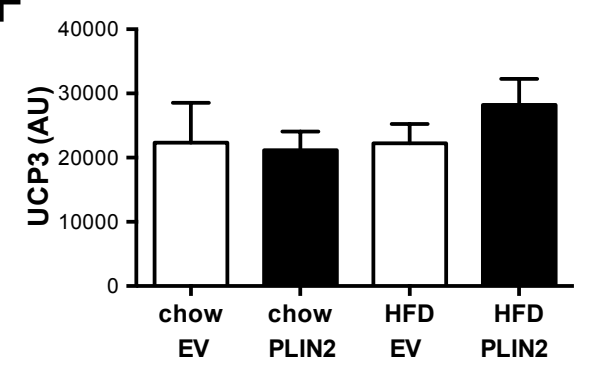

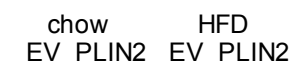

Complex V - -

Complex III

Complex II

Complex I

sr-actin
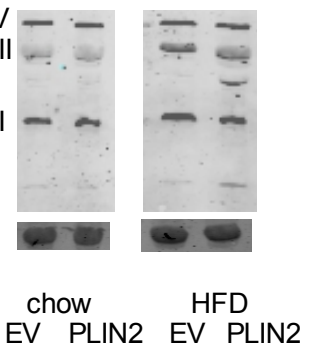

PGC1

PLIN5

C

sr-actin
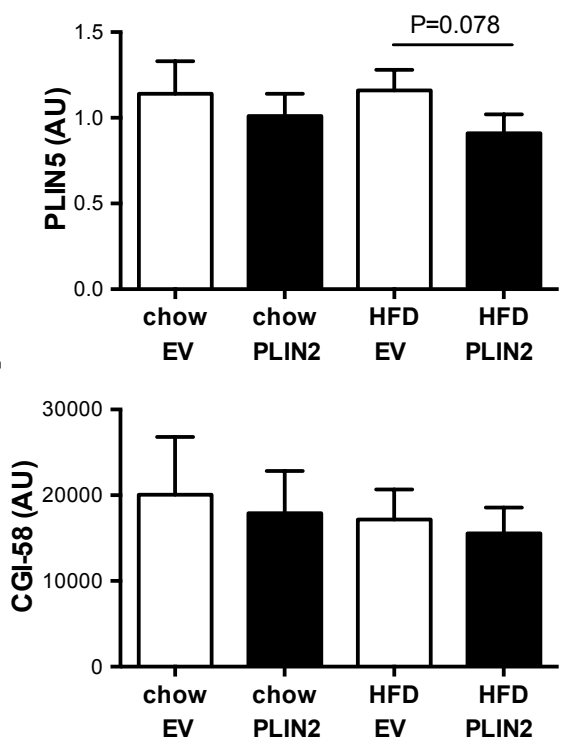

Figure S6. Protein expression of OXPHOS complexes, PGC1, PLIN5, ATGL, CGI-58 and UCP3 in PLIN2 or empty vector electroporated muscle. Muscle homogenates from tibialis anterior electroporated muscles from chow- and HFD-fed animals were blotted for protein expression of OXPHOS complexes (A), PGC1 (B), PLIN5/OXPAT (C), ATGL (D), CGI-58 (E), and UCP3 (F), *P<0.05 (ANOVA-Tukey's posthoc analyses). EV: empty vector. 


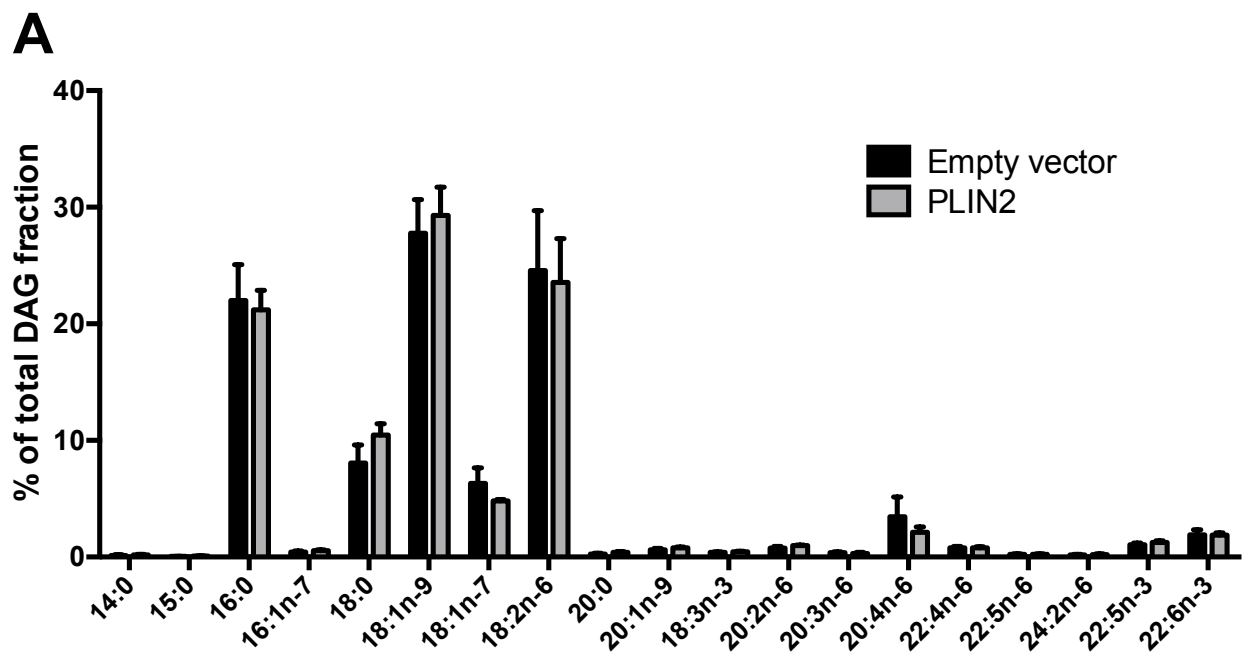

B

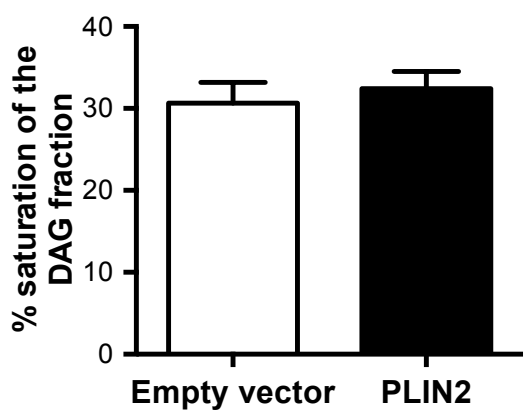

Figure S7. Fatty acid composition of the DAG fraction. (A) The FA composition of the DAG fraction depicted in percentage of the total DAG fraction for rats on high fat diet in the empty vector- or PLIN2 electroporated legs. (B) Saturation of the FAs in the DAG fraction in the empty vector- or PLIN2 electroporated legs of rats on a high fat diet (percentage of the total DAG fraction). 
A

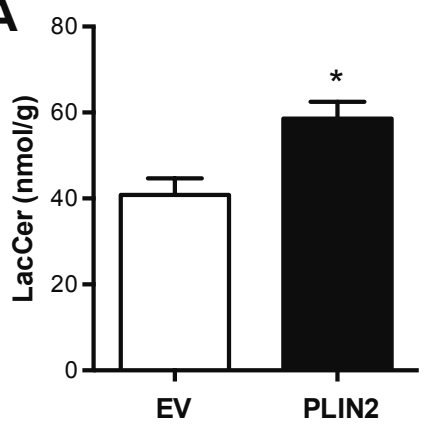

B

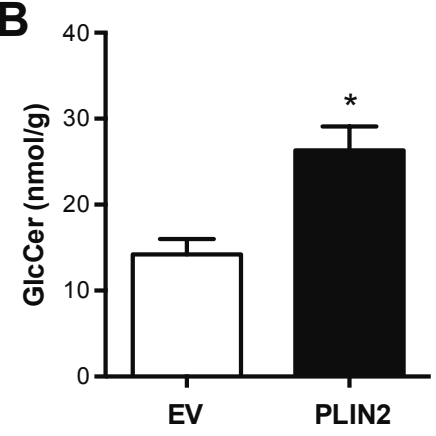

Figure S8. Lactosylceramide (A) and glycosylated ceramide (B) levels in PLIN2 or empty vector (EV) electroporated tibialis anterior muscle of rats fed a HFD. 


\section{CHAPTER 6}

\section{The lipid droplet coat protein perilipin 5 also localizes to muscle mitochondria}

Madeleen Bosma, Ronnie Minnaard, Lauren M. Sparks, Gert Schaart, Mario Losen, Marc H. de Baets, Hans Duimel, Sander Kersten, Perry E. Bickel, Patrick Schrauwen, Matthijs K.C. Hesselink

Histochemistry and Cell Biology 2012; 137: 205-216 


\section{ABSTRACT}

Perilipin 5 (PLIN5/OXPAT) is a lipid droplet (LD) coat protein mainly present in tissues with a high fat-oxidative capacity, suggesting a role for PLIN5 in facilitating fatty acid oxidation. Here, we investigated the role of PLIN5 in fat oxidation in skeletal muscle.

In human skeletal muscle we observed that PLIN5 (but not PLIN2) protein content correlated tightly with OXPHOS content and in rat muscle PLIN5 content correlated with mitochondrial respiration rates on a lipid-derived substrate. This prompted us to examine PLIN5 protein expression in skeletal muscle mitochondria by means of immunogold electron microscopy and Western blots in isolated mitochondria. These data show that PLIN5, in contrast to PLIN2, not only localizes to LD but also to mitochondria, possibly facilitating fatty acid oxidation. Unilateral overexpression of PLIN5 in rat tibialis anterior muscle augmented myocellular fat storage without increasing mitochondrial density as indicated by the lack of change in protein content of five components of the OXPHOS system. Mitochondria isolated from PLIN5 overexpressing muscles did not possess increased fatty-acid respiration. Interestingly though, ${ }^{14} \mathrm{C}$-palmitate oxidation assays in muscle homogenates from PLIN5 overexpressing muscles revealed a $44.8 \%(p=0.05)$ increase in complete fatty acid oxidation. Thus, in mitochondrial isolations devoid of LD, PLIN5 does not augment fat oxidation, while in homogenates containing PLIN5-coated LD, fat oxidation is higher upon PLIN5 overexpression.

The presence of PLIN5 in mitochondria helps to understand why PLIN5, in contrast to PLIN2, is of specific importance in fat oxidative tissues. Our data suggests involvement of PLIN5 in directing fatty acids from the LD to mitochondrial fatty acid oxidation. 


\section{INTRODUCTION}

Perilipin 5 (aliases include OXPAT, lipid storage droplet protein 5 , myocardial lipid droplet protein and PAT-1) is a lipid droplet (LD) coat protein that belongs to the perilipin family of proteins. Although the tissue distribution of this protein family differs considerably between members, all perilipin proteins are involved in accumulation and metabolism of lipids in LDs $[1,2]$. Perilipin 5 (PLIN5) expression is highest in tissues with a high fatoxidative capacity, such as heart, oxidative (type I) skeletal muscles and brown adipose tissue [3-5]. Recently, we showed that in rat and human skeletal muscle, PLIN5 protein content paralleled the LD content, with most abundant expression in muscle fibres that have highest fat content (type 1 fibres in humans, type $2 a$ in rodents) [6].

PLIN5 has been found covering the lipid droplet and to be present in the cytosol [3, 4]. PLIN5 overexpression in vitro in OP-9 and COS-7 cells increased cellular triglyceride storage in parallel with increases in fatty acid (FA) oxidation and induction of gene expression of mitochondrial enzymes involved in oxidative metabolism [4]. These results suggest involvement of PLIN5 in triglyceride storage as well as oxidative degradation of FAs released from the droplet, and suggest involvement of PLIN5 in lipid turnover. Recently, it has been shown that PLIN5 indeed has the potential to modulate the interaction of the major triacylglycerol lipase ATGL with the LD as well as with its co-factor CGI-58 [7] in a well orchestrated manner to modulate LD lipolysis [8-10].

To maintain cellular concentrations of cytotoxic FAs low, effective shuttling of FAs towards mitochondrial oxidation should be facilitated. In oxidative tissues this is in part facilitated by the close vicinity, and sometimes even physical interaction of LD with mitochondria. Functional interactions between LDs and mitochondria have long been reported [11-14], and evidence is emerging that mitochondria are not only actively controlling FA levels in their vicinity by directing FAs towards $\beta$-oxidation, but the presence of the enzymatic machinery to re-esterify FA in mitochondria indicates that mitochondria may also have the option to redirect the fatty acids towards triacylglycerol synthesis in LD. Likewise, isoforms of acyl CoA:diacylglycerol acyltransferase (DGAT) [15], glycerol 3-phosphate acyl transferases (GPAT) [16, 17] and long-chain acyl-CoA synthetases [18] have been identified in mitochondria. Orchestrated interaction of processes at the LD and the mitochondria is hence of pivotal importance in tissues like cardiac and skeletal muscle and brown adipose tissue where large fluctuations in fatty acid oxidation are prominent. These tissues also typically express PLIN5 as a LD coat protein.

Imaging the LDs and PLIN5 by immunofluorescence revealed that the majority of PLIN5 is localized to the lipid droplet but also that -mainly in fat oxidative type I muscle fibres- PLIN5 could be readily detected in a staining pattern similar to recognised mitochondrial proteins [6]. This staining pattern, along with the high expression of PLIN5 in tissues with high FA oxidation capacity [3-5] and the observation that overexpressing PLIN5 increased both palmitate oxidation and the expression of genes encoding mitochondrial proteins [4] hints towards involvement of PLIN5 in mitochondrial fat 


\section{PLIN5 localizes to muscle mitochondria}

oxidation. Likewise, it has recently been suggested that PLIN5 at the LD surface may recruit LD to the mitochondria [19].

We here show that PLIN5 is present within the mitochondria in cardiac and skeletal muscle. PLIN5 overexpression in skeletal muscle indicates that lipid droplets and mitochondria need interaction before PLIN5 possesses its facilitating role to augment mitochondrial fat oxidation.

\section{MATERIALS AND METHODS}

\section{PLIN5 antibody}

The PLIN5 antibody used in this study is directed against amino acids 451-463 of the Cterminus and was derived from Progen (\#GP31; guinea pig polyclonal; Progen, Heidelberg, Germany). This antibody, as well as other available antibodies against PLIN5, was tested in pilot experiments (Western blots and immunogold labelling for electron microscopy) in a variety of cells and tissues known to vary in endogenous PLIN5 protein expression (HEK and $\mathrm{C2C12}$ cells, white adipose tissue, cardiac muscle, glycolytic skeletal muscle (EDL), oxidative skeletal muscle (soleus), liver and testis). Thus, PLIN5 expression was highest in oxidative tissues (heart and oxidative skeletal muscle). The antibody used in this study showed the expected tissue distribution, a double band of the expected size, and a low background and specific PLIN5 labelling on the transmission electron microscopy pictures. Negative controls using non-immune serum did not show any bands in Westerns nor did it result in immunogold or immunofluorescence staining.

\section{Cell culture and treatments}

HEK293 cells (LGC standards, Teddington, Middlesex, United Kingdom) were maintained in DMEM (GlutaMAX low glucose DMEM, Invitrogen, Breda, The Netherlands) containing antibiotics $(50 \mathrm{U} / \mathrm{ml}$ penicillin and $50 \mathrm{\mu g} / \mathrm{ml}$ streptomycin; Gibco-Invitrogen, Rockville, USA) supplemented with $10 \%$ FCS. Cells were grown in 12-well plates (Greiner Bio-One, Alphen aan de Rijn, The Netherlands) and transfected with Plin5 plasmid construct (pcDNA3.1-CMV; $2 \mu \mathrm{g}$ per well) using $10 \mu \mathrm{L} / \mathrm{ml}$ Lipofectamine2000 as transfection reagent (Invitrogen, Breda, The Netherlands). Cells were harvested $24 \mathrm{~h}$ posttransfection.

\section{Human study}

Eleven healthy, lean, male volunteers without a family history of diabetes or any other endocrine disorder participated in this study. The mean age of the subjects was $23.6 \pm 1.0$ years; mean BMI was $22.6 \pm 0.5 \mathrm{~kg} / \mathrm{m}^{2}$. Subjects were fed in energy balance for $60 \mathrm{~h}(50-$ $35-15 \%$ of energy as carbohydrates, fat, and protein, respectively). After $60 \mathrm{~h}$, a muscle biopsy of the vastus lateralis was taken using the Bergstrom technique [20]. Muscle samples were immediately frozen in melting isopentane and stored at $80^{\circ} \mathrm{C}$ until assayed. The study protocol was reviewed and approved by the Medical Ethical Committee of 
Maastricht University Medical Centre and all subjects gave their written informed consent before participating in the study.

\section{ZDF rat study design}

Twenty-six male, ZDF rats (ZDF/Gmi, fa/fa) were purchased from Charles River (Chatillonsur-Chalaronne, France). The rats arrived at the age of 5 or 11 weeks and were housed in pairs with ad libitum access to tap water and chow. At 6,12 , and 19 weeks of age $(n=8$, $n=8$, and $n=10$, respectively), rats were killed by cervical dislocation, and hind leg muscles were rapidly dissected. The tibialis anterior muscle was processed for mitochondrial isolation [21] and soleus and EDL muscles were processed for electron microscopy or rapidly frozen in melting isopentane (Fluka, Zwijndrecht, The Netherlands), and stored at $80^{\circ} \mathrm{C}$. All experiments were approved by the The Animal Care and Use Committee of Maastricht University (approval number 2005-058) and the study complied with the principles of laboratory animal care.

\section{Electroporation study design}

A total of eighteen 8-week old male Wistar rats were purchased from Charles River (Wilmington, Massachusetts, USA). Rats were housed individually on a 12:12 h light-dark cycle (light from 7:00 am to 7:00 pm), at room temperature $\left(21-22{ }^{\circ} \mathrm{C}\right.$ ) with ad libitum access to tap water. Rats were fed a high fat diet (45\% energy from fat, D01060502, Research Diets, New Brunswick, NJ, USA) for the duration of the 3-week intervention. The Animal Care and Use Committee of Maastricht University approved the experiments (approval number 2010-036) and the study complied with the principles of laboratory animal care. During the experiments all efforts were made to minimize suffering of the animals.

\section{Electroporation}

Two weeks after the start of the diet, overexpression of Plin5 in either the right or left tibialis anterior (TA) muscle of the rat was accomplished by an in vivo DNA electrotransfer technique to obtain overexpression of mouse perilipin 5 in one leg; the contralateral TA served as a sham-electroporated internal control. Plin5 was electroporated randomly in the left or the right TA. DNA electroporation was performed under isoflurane anaesthesia. TA muscles were transcutaneously injected with either $150 \mu \mathrm{g}(2 \mu \mathrm{g} / \mu \mathrm{l})$ pcDNA3.1-CMVPlin5 or pcDNA3.1-empty vector in $0.9 \%$ sterile $\mathrm{NaCl}$. Within 15 seconds after the last injection 5 electric pulses were applied by two stainless steel plate electrodes placed at the ventral and dorsal side of the leg. One high voltage pulse of $800 \mathrm{~V} / \mathrm{cm}$ and four low voltage pulses of $80 \mathrm{~V} / \mathrm{cm}$ at $1 \mathrm{~Hz}$ were generated by an ECM 830 electroporator (BTX, San Diego, CA, USA) as described previously [22, 23]. Rats were sacrificed 8 days postelectroporation. TA muscles were excised and processed for mitochondrial isolations and electron microscopy. The remainder of the TA was rapidly frozen in melting isopentane for histology and protein isolations. 


\section{PLIN5 localizes to muscle mitochondria}

\section{Mitochondrial isolations}

After excision, the right and left TA muscles were placed into ice-cold medium containing $100 \mathrm{mM}$ sucrose, $100 \mathrm{mM} \mathrm{KCl}, 50 \mathrm{mM}$ Tris- $\mathrm{HCl}, 1 \mathrm{mM} \mathrm{KH}_{2} \mathrm{PO}_{4}, 0.1 \mathrm{mM} \mathrm{EGTA}$, and $0.2 \%$ (wt/vol) FA-free bovine serum albumin ( $\mathrm{pH}$ 7.4). The TA was immediately processed for mitochondrial isolation, essentially according to Tonkonogi and Sahlin [24]. The protein concentration in the mitochondrial pellet was measured using fluorescamine (Fluram; Fluka, Zwijndrecht, the Netherlands) with bovine serum albumin as a standard [25]. Freshly isolated mitochondria were used immediately for mitochondrial respirometry. Remaining mitochondria were stored at $-80^{\circ} \mathrm{C}$ for further analysis.

\section{High-resolution respirometry in isolated mitochondria}

Mitochondrial oxygen consumption was measured essentially according to Hoeks et al. [26] at $37^{\circ} \mathrm{C}$ using a two-chamber oxygraph (OROBOROS Instruments, Innsbruck, Austria) and expressed as pmol $\mathrm{O}_{2} / \mathrm{mg}$ mitochondrial protein per second. Mitochondria were characterized using a carbohydrate-derived substrate ( $5 \mathrm{mM}$ pyruvate) and a FA-derived substrate (50 $\mu \mathrm{M}$ palmitoyl-CoA plus $2 \mathrm{mM}$ carnitine). For this purpose, mitochondria (0.1 $\mathrm{mg}$ for pyruvate and $0.2 \mathrm{mg}$ for palmitoyl-CoA plus carnitine) were incubated in a medium consisting of $100 \mathrm{mM}$ sucrose, $20 \mathrm{mM} \mathrm{K}$-Tes (pH 7.2), $50 \mathrm{mM} \mathrm{KCl}, 2 \mathrm{mM} \mathrm{MgCl}, 1 \mathrm{mM}$

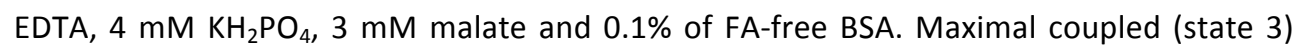
respiration was initiated by addition of $450 \mu \mathrm{M}$ of adenosine diphosphate (ADP). State 40 respiration, reflecting proton leak, was measured as the residual respiration following addition of $1 \mu \mathrm{g} / \mathrm{ml}$ oligomycin (an F1-F0 ATPase inhibitor). Maximal oxygen flux rates (state uncoupled, state $U$ ) were obtained by titration of the chemical uncoupler carbonyl cyanide $p$-trifluoromethoxyphenylhydrazone (FCCP). Addition of excess cytochrome $C$ to the chamber in the presence of pyruvate and ADP did not increase respiration (data not shown); indicating that during isolation outer mitochondrial membrane integrity was retained.

\section{${ }^{14} \mathrm{C}$-palmitate oxidation assay}

Ex vivo fat oxidation was measured as described [27]. Briefly, muscle was homogenized in a buffer (pH 7.4) containing $250 \mathrm{mM}$ sucrose, $10 \mathrm{mM}$ Tris-HCL, $2 \mathrm{mM}$ ATP and $1 \mathrm{mM}$ EDTA (Sigma, St. Louis, USA). Subsequently, muscle homogenates were incubated for $2 \mathrm{~h}$ with [1-

${ }^{14} \mathrm{C}$-labelled palmitate $(1 \mu \mathrm{Ci} / \mathrm{ml}$, Perkin Elmer, Boston, USA) and $200 \mu \mathrm{M}$ non-labelled (cold) palmitate in reaction media containing L-carnitine, ATP and coenzyme A (all from Sigma, St. Louis, USA) at $37^{\circ} \mathrm{C}$. Palmitate was coupled to FA-free BSA in a molar ratio of $5: 1$. After incubation, reactions were terminated by adding $40 \mu \mathrm{l}$ of $70 \%$ perchloric acid, and the $\mathrm{CO}_{2}$ produced during the incubation was trapped in $200 \mu \mathrm{l}$ of $1 \mathrm{~N}$ sodium hydroxide that had been added to adjacent wells [28]. The acidified medium was stored at $4^{\circ} \mathrm{C}$ overnight, and then acid soluble metabolites (ASMs) were assayed in supernatants of the acid precipitate. Radioactivity of $\mathrm{CO}_{2}$ and $\mathrm{ASMs}$ was determined by liquid scintillation 
counting by use of $5 \mathrm{ml}$ of Hionic Fluor (Perkin Elmer, Boston, USA). Data were normalized to protein content.

\section{Electron microscopy procedures}

Ultrastructural morphology and PLIN5 localization were examined using transmission electron microscopy. For determinations of ultrastructural morphology, muscle tissue sections were fixed in $2.5 \%$ glutaraldehyde in $0.1 \mathrm{M}$ phosphate buffer ( $\mathrm{pH}$ 7.4). Postfixation was performed in $1 \%$ osmium tetroxide in $0.1 \mathrm{M}$ cacodylate buffer $(\mathrm{pH} 7.4)$ supplemented with $1.5 \%$ potassium ferrocyanide. The samples were then dehydrated and embedded in epon. Ultrathin sections were examined using a Philips CM100 electron microscope.

For determinations of subcellular localization of PLIN5, soleus, extensor digitorum longus (EDL) and heart muscle tissues 14-wk old ZDF rats (ZDF/Gmi, fa/fa) and tibialis anterior muscle tissues from electroporated Wistar rats were cut into pieces with a maximum size of $1 \mathrm{~mm}^{3}$, fixed for $1 \mathrm{~h}$ at room temperature in a mixture of $2 \%$ formaldehyde and $0.2 \%$ glutaraldehyde in $0.1 \mathrm{M}$ phosphate buffer $(\mathrm{pH} 7.4)$, and stored in $1 \%$ formaldehyde in 0.1 $\mathrm{M}$ phosphate buffer ( $\mathrm{pH}$ 7.4). Tissue pieces were immersed in a $2.3 \mathrm{M}$ sucrose solution, frozen in liquid nitrogen and ultrathin cryo-sections were cut under liquid nitrogen, sections were transferred from the knife edge to a formvar and carbon-coated grid in 2.3 M sucrose/ 1.8\% methylcellulose (1:1), as described by Tokuyasu [29-31]. Sections were immunogold labelled as described by Tokuyasu [31] using a PLIN5 antibody (\#GP31; Guinea pig polyclonal; Progen Biotechnik, Heidelberg, Germany) in a 1:100 dilution and protein A-gold (20 nm particles) [32]. Guinea pig normal serum (Santa Cruz Biotechnology, Tebu-bio, Heerhugowaard, The Netherlands) was used as a negative control.

\section{Oil-red-O stainings and immunofluorescence}

Neutral lipids, mitochondria and PLIN5 in muscle sections were stained with a modified Oil-red-O staining for fluorescence microscopy as previously described [33] using antibodies against PLIN5 (\#GP31; Progen Biotechnik, Heidelberg, Germany), laminin (L9393; Sigma, St. Louis, USA), and OXPHOS (MS601; MitoSciences, Eugene, OR, USA) and the appropriate secondary Alexa-fluor conjugated antibodies (Invitrogen, Groningen, The Netherlands). Fluorescent images of Alexa-350 (laminin), Alexa-488 (PLIN5), Alexa-647 (OXPHOS), and Oil-red-O (visible in the red -594- channel) were acquired using an imaging system consisting of an IX81 inverted microscope (Olympus, Hamburg, Germany), an Xcite fluorescent light source (Lumen Dynamics group, Mississauga, Ontario, Canada), Fview II CCD camera (OSIS, Münster, Germany) and the Cell^F imaging software (OSIS). Fluorescent photomicrographs were made from Z-stacks consisting of 30-40 images with a distance of $0.28 \mu \mathrm{m}$ using the maximum intensity projection method in the ImageJ software (Rasband, W.S., ImageJ, U. S. National Institutes of Health, Bethesda, Maryland, USA, http://rsb.info.nih.gov/ij/, 1997-2009). 


\section{PLIN5 localizes to muscle mitochondria}

\section{Western blots}

Western blots were performed in protein lysates from whole muscle homogenates or mitochondrial fractions. Muscle samples and mitochondrial fractions were homogenized in ice-cold PBS containing $1 \%$ Nonidet-P40, $0.5 \%$ sodium dodecyl sulfate, $0.1 \mathrm{mM}$ phenylmethylsulfonyl fluoride, complete inhibitor (Roche, Almere, The Netherlands) and processed for standard SDS-PAGE and Western blotting. Protein concentration was determined and equal amounts of protein were loaded per lane. The nitrocellulose membranes were incubated with antibodies against PLIN5 (GP31; Progen Biotechnik, Heidelberg, Germany), PLIN2 (GP40; Progen Biotechnik, Heidelberg, Germany), OXPHOS

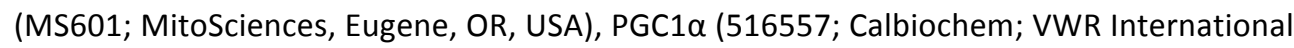
BV, Amsterdam, The Netherlands), VDAC (SC-8828; Santa Cruz Biotechnology, Tebu-bio, Heerhugowaard, The Netherlands), and SR-actin (A-2172; Sigma, St. Louis, USA).

Blots incubated with PLIN5, PLIN2, OXPHOS, PGC1 $\alpha$, VDAC and sr-actin were probed with appropriate IRDye800-conjugated or IRDye700-conjugated secondary antibodies (Rockland, Tebu-bio, Heerhugowaard, The Netherlands, and LICOR Biosciences, Westburg, Leusden, The Netherlands), and bands at a molecular weight corresponding to the control samples were quantified using the Odyssey infrared imaging system (LICOR Biosciences, Westburg, Leusden, The Netherlands).

\section{Statistical analysis}

Results are presented as mean \pm SE. Differences between groups were evaluated with paired T-tests. Outcomes were considered statistically significant when $\mathrm{P}<0.05$ (twotailed). Pearson's correlation coefficients were used to describe the linear association between variables. All analyses were performed using the Statistical Package for the Social Sciences (SPSS 16.0, Nieuwegein, The Netherlands) software for Mac 16.0.

\section{RESULTS}

\section{Skeletal muscle PLIN5 protein content correlates with oxidative capacity}

In order to explore the role of PLIN5 in skeletal muscle, we measured PLIN5 protein content in muscle biopsies of vastus lateralis muscle of young healthy male subjects. PLIN5 protein content correlated strongly with the protein content of structural components of the individual complexes of the electron transport chain; OXPHOS complexes I ( $r=0.721$, $\mathrm{P}=0.012)$, III ( $\mathrm{r}=0.810, \mathrm{P}=0.003)$, IV $(\mathrm{r}=0.704, \mathrm{P}=0.016)$ and $\mathrm{V}(\mathrm{r}=0.606, \mathrm{P}=0.048)$ but not with protein content of VDAC, an outermitochondrial membrane protein without a recognized role in (fat) oxidation $(r=0.148, P=0.664)(n=11)$ (Table 1$)$.

These observations indirectly suggest a role of PLIN5 in mitochondrial fat oxidative metabolism. This led us to investigate the relationship between PLIN5 protein content in whole muscle homogenates with respiration rates of isolated muscle mitochondria on a fat-derived substrate (palmitoyl-CoA). Thus, we analyzed correlations of skeletal muscle PLIN5 protein expression with mitochondrial function in a model of progressive 
myocellular fat deposition, the maturing Zucker diabetic fatty (ZDF) rats (fa/fa). In this model, PLIN5 protein content tracks with intramyocellular lipid content [6].

Table 1. Correlation of PLIN5 protein expression with OXPHOS complexes in human vastus lateralis muscle.

\begin{tabular}{lllllll}
\hline & VDAC & OXPHOS & OXPHOS II & OXPHOS III & OXPHOS IV & OXPHOS V \\
\hline Pearson Correlation & -0.148 & $.721^{*}$ & 0.455 & $.810^{*}$ & $.704^{*}$ & $.606^{*}$ \\
$P$ & 0.664 & 0.012 & 0.159 & 0.003 & 0.016 & 0.048 \\
\hline
\end{tabular}

We examined the correlation between PLIN5 content in whole muscle homogenates and intrinsic mitochondrial function in mitochondria isolated from these muscles by classical mitochondrial respirometry using palmitoyl-CoA as a FA-derived substrate. In these rats, PLIN5 protein content, but importantly not PLIN2 protein content, positively correlated with ADP-driven state 3 respiration $(r=0.713, P<0.001)$ as well as respiration under maximal FCCP-mediated uncoupled conditions (state $U, r=0.663, P=0.001$ ) (Table 2). These observations may indicate that in muscles in which PLIN5 protein content scales with LD content, PLIN5 is involved in facilitating increased mitochondrial fat oxidation.

Table 2. Correlation of PLIN5 protein expression with respiration of mitochondria isolated from skeletal muscle of fatty ZDF rats.

\begin{tabular}{llcc}
\hline & & \multicolumn{2}{c}{ Palmitoyl-CoA } \\
\hline PLIN5 & Pearson Correlation & State 3 & State U \\
& $\mathrm{P}$ & $.713^{*}$ & $.663^{*}$ \\
& $\mathrm{n}$ & $<0.001$ & 0.001 \\
PLIN2 & Pearson Correlation & 23 & 23 \\
& $\mathrm{P}$ & 0.343 & 0.182 \\
& $\mathrm{n}$ & 0.1 & 0.396 \\
& 24 & 24 \\
\hline
\end{tabular}

\section{Perilipin 5 localizes to lipid droplets as well as to mitochondria in cardiac and skeletal muscle}

The strong correlation of PLIN5 protein content with OXPHOS complexes and mitochondrial respiration on a FA-derived substrate led us to examine whether PLIN5, next to its recognized localisation to LD, is also present in mitochondria. Thus, we measured PLIN5 protein content in total muscle protein lysates as well as in mitochondrial fractions from rat skeletal muscle (Fig. 1A). A double band representing PLIN5 was observed in whole muscle lysates and more strikingly also in isolated mitochondria. To exclude the ability that the PLIN5 signal detected in the mitochondria originated from contamination of the mitochondrial fraction with ER or LD derived membrane fractions we examined protein expression of ADRP/PLIN2 in our mitochondrial fractions (Fig. 1B). The absence of an ADRP/PLIN2 band indicates that the mitochondrial fractions used were 


\section{PLIN5 localizes to muscle mitochondria}

devoid of ER or LD membrane structures, substantiating our notion that PLIN5 indeed localizes to mitochondria.

We further substantiated mitochondrial localisation of PLIN5 using immunogold electron microscopy, the gold standard methodology for subcellular localisation studies of single proteins. In all muscles examined (soleus, EDL and cardiac muscle) PLIN5 was present on the LDs, at the interface of LDs with mitochondria, as well as in the mitochondria (Fig. 1C and 1D), whereas other structures were almost completely devoid of gold particles. Negative controls by omission of the primary antibody or by using nonimmune serum did not show any immunogold staining. Immunogold staining using the ADRP/PLIN2 antibody only revealed staining associated with LD (data not shown).

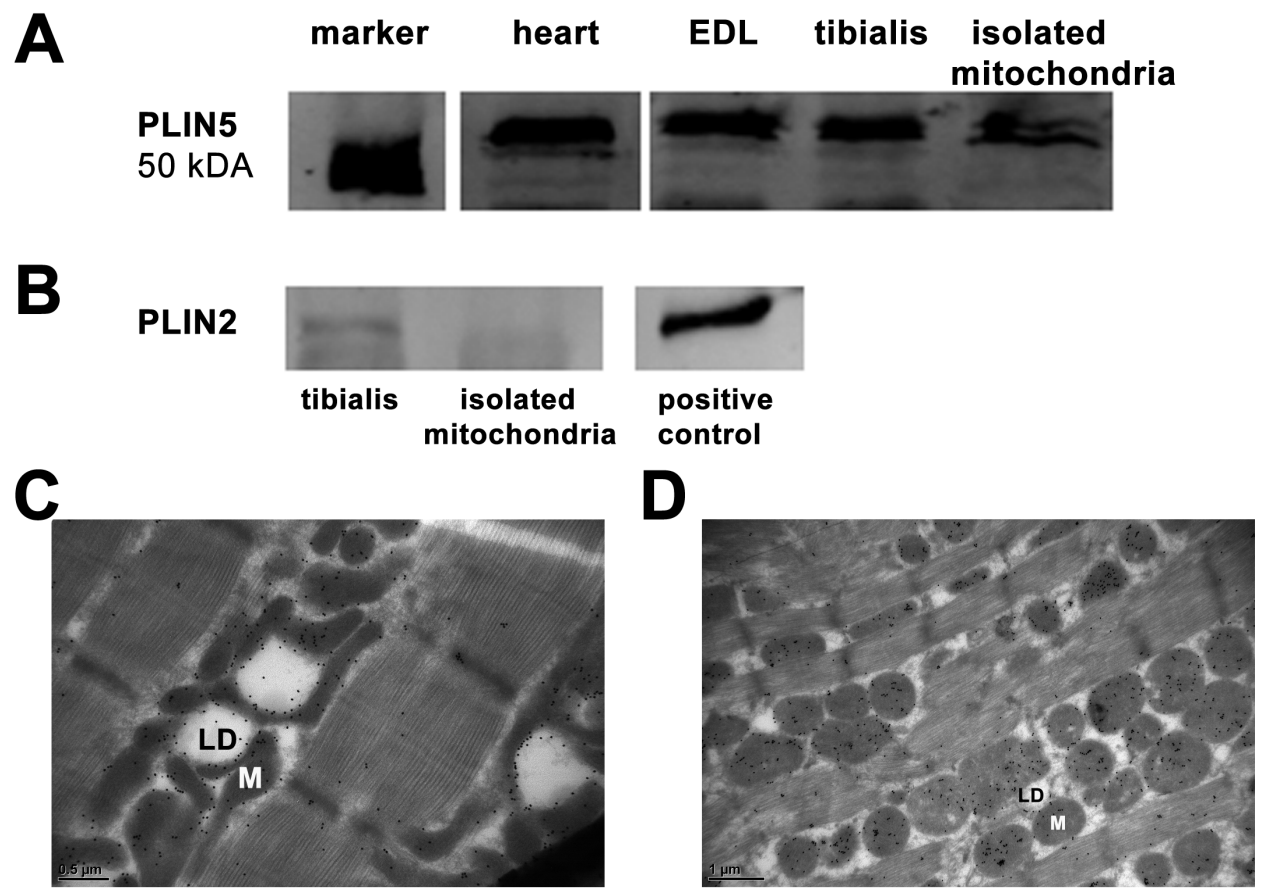

Figure 1. Perilipin 5 protein expression in whole muscle homogenates, isolated mitochondria and muscle sections. (A) Western blotting of perilipin 5 in whole skeletal muscle lysates from heart muscle, extensor digitorum longus (EDL) and tibialis anterior muscles and mitochondria isolated from tibialis anterior muscle. (B) Western blots incubated with the PLIN2 antibody did not show any bands in isolated mitochondria, indicating that the mitochondrial fraction was devoid of lipid droplets and was not contaminated with fragments of the ER. HEK cells transfected with PLIN2 plasmid were used as positive control. (C) PLIN5 immunogold labeling in rat soleus muscle. PLIN5 coats the lipid droplets and is present at mitochondria but not at myofibrils. (D) PLIN5 immunogold labeling in rat left ventricle showing mitochondrial localization of PLIN5.

LD: lipid droplet, M: mitochondrion. 


\section{PLIN5 overexpression in rat tibialis anterior muscle}

To examine the effect of overexpression of PLIN5 on its subcellular localisation, a CMVdriven full-length PLIN5 construct was used for unilateral overexpression of PLIN5 in rat tibialis anterior muscle by gene electroporation using the contralateral empty vectorelectroporated leg as an internal control. Upon transfection in HEK cells the construct used resulted in the anticipated double band on the Western, representing two PLIN5 isoforms (Fig. 2A).
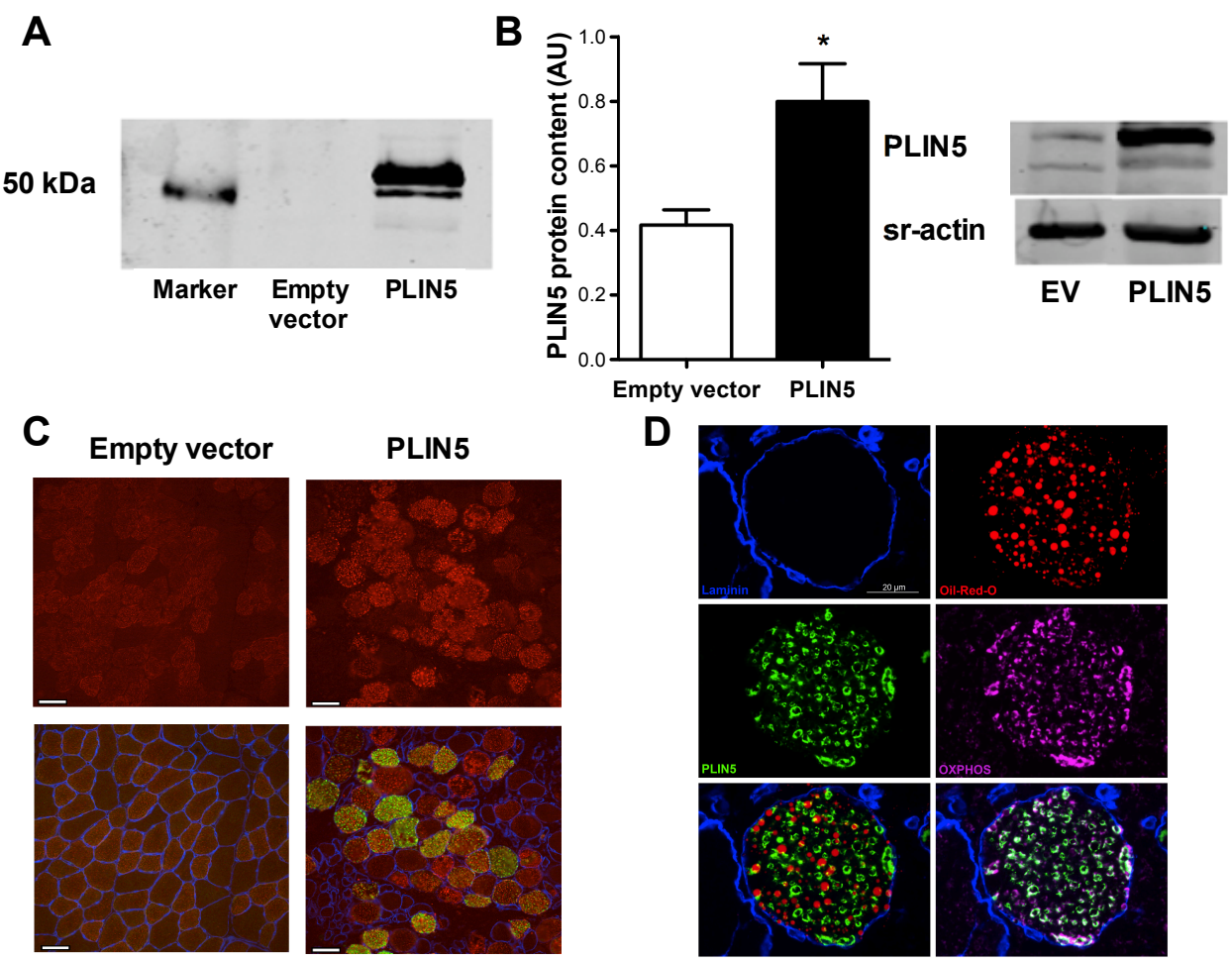

Figure 2. PLIN5 overexpression (gene electroporation) in rat muscle using an empty vector as internal control. (A) Specificity of the PLIN5 antibody (Progen). A full length PLIN5 vector was transfected in cells without endogenous PLIN5 expression (HEK cells), this resulted in ectopic expression of PLIN5. (B) PLIN5 protein content in protein lysates from electroporated tibialis anterior muscle $(n=16)$. Error bars represent SEM, ${ }^{*} P<0.01$. The samples were derived from the same experiment and were simultaneously processed in random order on two gels/blots. EV: empty vector. (C) Shows the effect of PLIN5 overexpression on lipid storage (upper right hand panel) and PLIN5 content (lower right hand panel) compared to the empty vector control (upper and lower left hand panels). LDs are stained in red), PLIN5 in green and cell membranes in blue. Bars represent 100 $\mu \mathrm{m}$. (D) Overlay of PLIN5 and mitochondrial proteins upon PLIN5 overexpression. PLIN5 overexpression increases LD (in red) and PLIN5 (in green) content (upper right hand and middle left hand panel, respectively). Mitochondria are shown in magenta (middle left hand panel). The lower left hand panel shows LD decorated with PLIN5 while the lower right hand panel shows PLIN5 interaction with mitochondria. The bar represents $20 \mu \mathrm{m}$. Representative image are shown. 


\section{PLIN5 localizes to muscle mitochondria}

In rat tibialis anterior muscle, PLIN5 overexpression doubled PLIN5 protein content in whole muscle homogenates $(\mathrm{P}=0.0006, \mathrm{n}=14$, paired T-test) (Fig. 2B). Consistent with results obtained in vitro [4, 5], PLIN5 overexpression profoundly augmented intramyocellular lipid storage in the transfected muscle (Fig. 2C). Immunohistochemistry revealed that PLIN5 was present on LDs and showed punctuate mitochondrial localisation. Double immunofluorescence using an antibody cocktail against structural components of all 5 OXPHOS complexes confirmed co-localisation of PLIN5 with mitochondria (Fig. 2D). Ultrastructural analysis by electron microscopy confirmed the light microscopy based observation of augmented lipid storage upon PLIN5 overexpression and clearly showed increased LD size (Fig. 3). In addition, almost all LD appear to interact tightly with mitochondria in the PLIN5-overexpressing muscle and sometimes even appear to envelop the lipid droplets (Fig. 3). Immunogold labelling of PLIN5 in electroporated muscle confirmed the localization of PLIN5 in mitochondria, on LDs and on the LD-mitochondrial interface (Fig. 4).

\section{PLIN5 overexpression does not affect mitochondrial density}

To examine the putative effect of PLIN5 overexpression on mitochondrial density, we measured in whole muscle homogenates the protein content of PGC1 $\alpha$ (Fig. 5A), VDAC (Fig. 5B) and 5 distinct structural components of subunits of the individual OXPHOS complexes (complex I subunit NDUFB8, complex II subunit 30kDa, complex III subunit Core 2, complex IV subunit I and complex V ATP sythase subunit alpha (Fig. 5C). Although we observed a non-significant $(p=0.14)$ increase in $P G C 1 \alpha$, a key co-activator for mitochondrial biogenesis, protein content of VDAC and OXPHOS complexes remained unaltered, indicating that 8 days after overexpressing PLIN5 mitochondrial density was not affected.

A

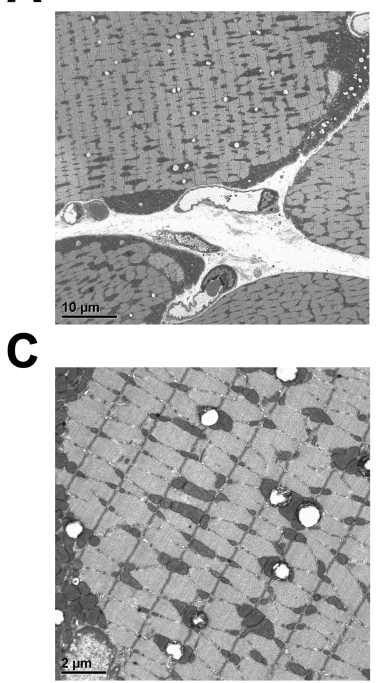

B

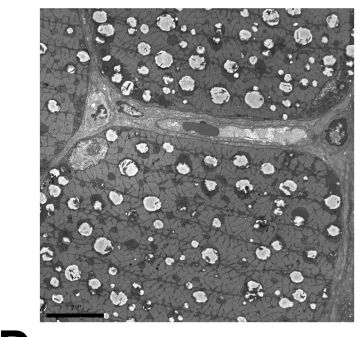

D

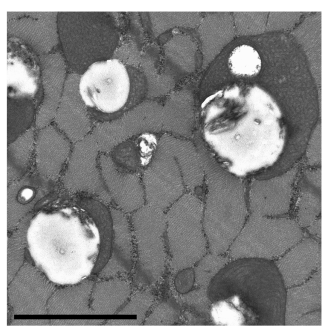

Figure 3. PLIN5 overexpression results in large LDs. Left hand panels ( $\mathbf{A}$ and $\mathbf{C}$ ) show empty vector control data, right hand panels (B and D) show PLIN5 overexpression data. Note the apparent larger LD size upon PLIN5 overexpression. Bar represents $10 \mu \mathrm{m}$ in the upper panel and $2 \mu \mathrm{m}$ in the lower panels. 


\section{PLIN5 overexpression does not improve respiration of isolated mitochondria}

Mitochondrial respirometry assays in the mitochondria isolated from PLIN5 overexpressing muscles relative to muscles isolated from empty vector electroporated muscles did not reveal significant differences in respiration, neither on pyruvate (empty vector vs. PLIN5 $15.98 \pm 1.17$ vs. $15.48 \pm 1.18$ state 3 / state $2, P=0.83 ; 22.53 \pm 0.88$ vs. $22.29 \pm 1.44$ state $\mathrm{U} /$ state $2, \mathrm{P}=0.68$ ), nor on palmitoyl-CoA (empty vector vs. PLIN5 $6.76 \pm$ 0.38 vs. $7.36 \pm 0.30$ state 3 / state $2, P=0.23 ; 8.56 \pm 0.63$ vs. $9.14 \pm 0.49$ state $U /$ state 2 , $\mathrm{P}=0.37$ ) (Fig. 6A and 6B). Thus, in a system in which PLIN5-coated LDs are dissociated from the mitochondria, PLIN5 overexpression does not augment mitochondrial (fat) oxidative capacity.

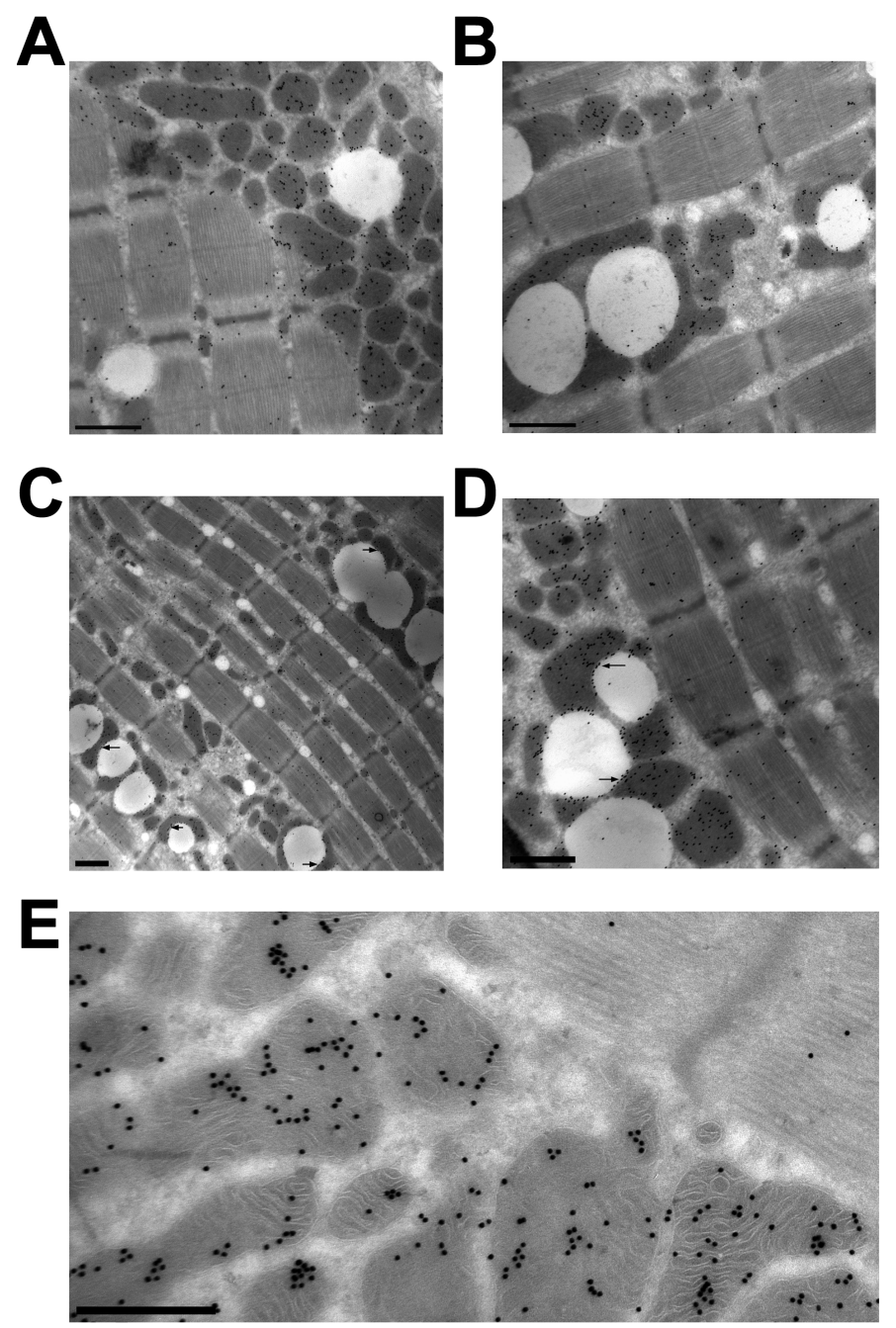

Figure 4. PLIN5 labeling in mitochondria and on the LDs. Immunogold staining of PLIN5 in tibialis anterior muscle of empty vector (control) (A) or PLIN5electroporated muscle (B). PLIN5 overexpression (B, C and $\mathbf{D})$ resulted in larger LDs and intimate interaction of LDs with mitochondria at PLIN5 positive sites (see arrowheads in $\mathbf{C}$ and $\mathbf{D}$ ). Bars represent $1 \mu \mathrm{m}$. (E) Intramitochondrial PLIN5 labeling. Bar represents $0.5 \mu \mathrm{m}$. 
A
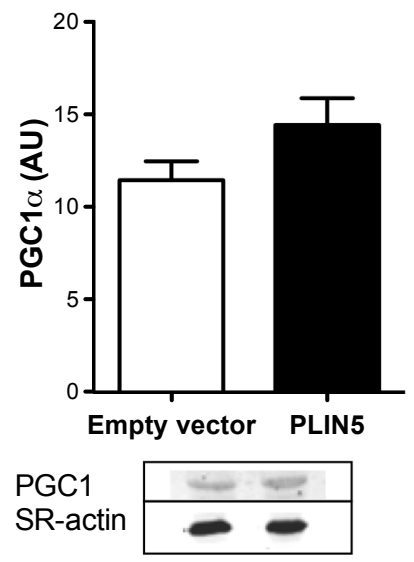

C

\begin{tabular}{lcc}
\hline & Empty vector & PLIN5 \\
\hline Complex I & $1.86 \pm 0.36$ & $2.40 \pm 0.46$ \\
Complex II & $6.64 \pm 0.58$ & $7.85 \pm 0.70$ \\
Complex III & $17.7 \pm 1.71$ & $19.5 \pm 2.19$ \\
Complex IV & $16.8 \pm 2.64$ & $19.2 \pm 3.96$ \\
Complex V & $64.2 \pm 3.71$ & $63.6 \pm 3.71$ \\
\hline
\end{tabular}

B
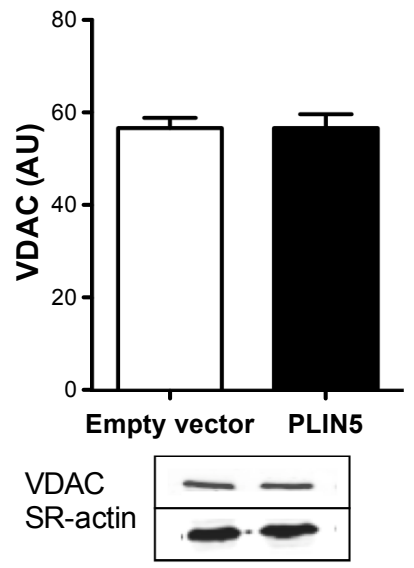

D

Complex V

Complex III

Complex IV

Complex II

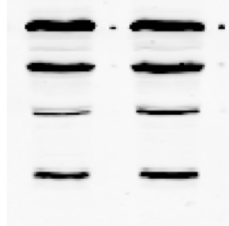

Complex I

Figure 5. Abundance of mitochondrial proteins upon PLIN5 overexpression. Western blots were performed for expression of PGC1 $\alpha$ (A), VDAC (B) and 5 distinct structural components of the OXPHOS complexes (C) in lysates from whole muscle homogenates $(n=14)$. Error bars represent $\mathrm{SEM},{ }^{*}=\mathrm{P}<0.01$. The samples were derived from the same experiment and were simultaneously processed in random order.

\section{PLIN5 overexpression improved ${ }^{14} \mathrm{C}$-palmitate-oxidation}

Given the intimate association of LDs with mitochondria we performed complementary measurements of fat oxidation using ${ }^{14} \mathrm{C}$-palmitate in whole muscle homogenates when LDs and mitochondria were not dissociated. Total ${ }^{14} \mathrm{C}$-palmitate-oxidation was not changed (empty vector $0.71 \pm 0.06 \mathrm{nmol} / 2 \mathrm{~h} / \mathrm{mg}$ protein, PLIN5 $0.71 \pm 0.03 \mathrm{nmol} / 2 \mathrm{~h} / \mathrm{mg}$ protein, $\mathrm{P}=0.99$ ) (Fig. $6 \mathrm{C}$ ). However, oxidation of ${ }^{14} \mathrm{C}$-palmitate to ${ }^{14} \mathrm{CO}_{2}$ increased by $44.8 \%$ (empty vector $0.05 \pm 0.008$, PLIN5 $0.07 \pm 0.012{ }^{14} \mathrm{CO}_{2} /$ total ${ }^{14} \mathrm{C}$-palmitate oxidation, $\mathrm{P}=0.05$ ) (Fig. 6D). The respiration data in isolated mitochondria and in muscle homogenates jointly indicate that overexpression of PLIN5 does not augment mitochondrial fat oxidative capacity per se but rather creates a situation in which shuttling of FAs towards mitochondria becomes more efficient, thereby protecting mitochondria against the deleterious effects of lipid overflow. 
A

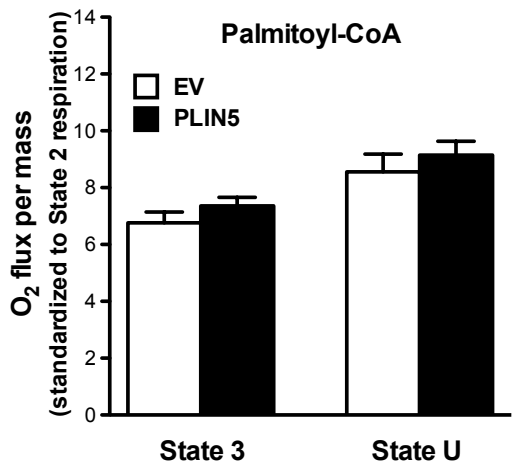

C

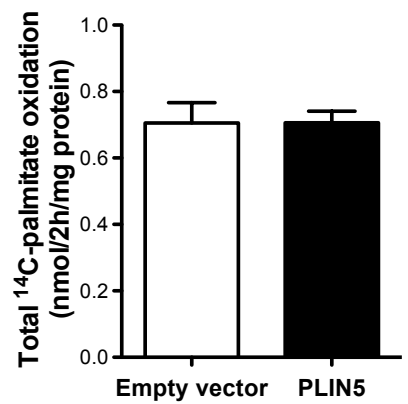

B

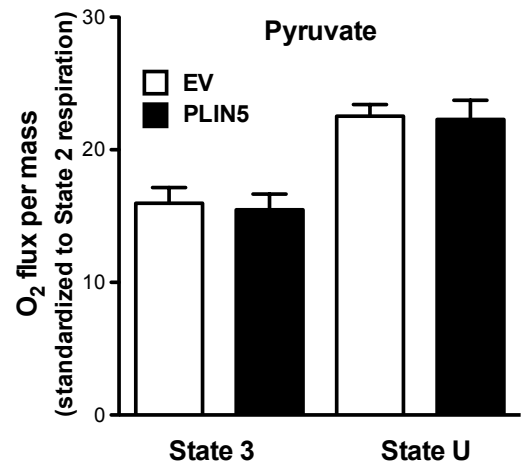

D

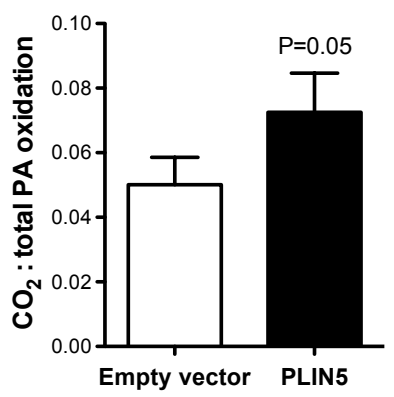

Figure 6. Effects of PLIN5 overexpression on mitochondrial respiration and FA oxidation. (A and $\mathbf{B}$ ) State 3 (coupled) and state $U$ (uncoupled) respiration on palmitoyl-CoA (A) or pyruvate (B), values are standardized to state 2 respiration (background respiration in the absence of $A D P)(n=9)$. (C) Total ${ }^{14} \mathrm{C}$-palmitate oxidation in muscle homogenates $\left(\mathrm{CO}_{2}\right.$ plus $\left.\mathrm{ASMs}\right)$. (D) The ratio of $\mathrm{CO}_{2}$ production (complete oxidation) to total palmitate (PA) oxidation $\left(\mathrm{CO}_{2}\right.$ plus acid soluble metabolites) $(n=7)$. Error bars represent SEM, P-values were derived from paired T-tests.

\section{DISCUSSION}

PLIN5 was recently identified as a member of the perilipin family of lipid droplet coating proteins and was considered to be an exchangeable LD coat protein; unlike perilipins 1 and 2, PLIN5 is not exclusively found in the LD-coat but also cytosolically [3-5]. Using a variety of validated techniques, however, we here show that PLIN5 in muscle is found at the LDs as well as in mitochondria, this in contrast to PLIN2, the other major LD coat protein found in muscle. PLIN5 positive mitochondria were detected in oxidative (soleus), glycolytic (EDL), and mixed (TA) muscles as well as in cardiac muscle. Both subsarcolemmal mitochondria and intramyofibrillar mitochondria contained PLIN5. Gene electroporation mediated overexpression of PLIN5 doubled PLIN5 protein content and resulted in more numerous and apparently larger LDs in intimate interaction with mitochondria. Functional assays revealed no direct involvement of PLIN5 in mitochondrial respiration, as respiration 


\section{PLIN5 localizes to muscle mitochondria}

in isolated mitochondria was not affected by PLIN5 overexpression. Interestingly though, fatty acid oxidation rates were higher in whole muscle homogenates of PLIN5 overexpressing muscles, suggesting a facilitating role of PLIN5 in augmenting fat oxidation situations when LDs are physically interconnected to the mitochondrial reticulum, possibly by shuttling or chaperoning of LD-derived FAs towards mitochondria for oxidation.

Recent reports have shown that PLIN5 localised to LDs in tissues rich in mitochondria [3-5], that overexpressing PLIN5 in OP-9 and COS-7 cells promoted fat oxidation [4] and that the proteome of LDs contained multiple mitochondrial proteins [34]. In addition, PLIN5 interaction with ATGL on LDs and on undefined intracellular structures lacking neutral lipids [8] has been reported. This has led us to investigate the possibility that PLIN5 also localizes to mitochondria.

Thus, we observed that PLIN5 protein content in vastus lateralis muscle of healthy young male subjects correlated positively and tightly with structural components of all five complexes of the electron transport chain, but not with mitochondrial proteins without a recognised role in fat oxidation. The lack of associations of PLIN5 with VDAC, a mitochondrial protein not involved in (fat) oxidation, narrows the interpretation of previous observations of PLIN5 being abundant in mitochondria rich tissues [3-5] and may hint towards a more direct involvement of PLIN5 in mitochondrial fat oxidation. Hence, we studied ADP-driven respiration rates on palmitoyl-CoA in mitochondria isolated from tibialis anterior muscles of ZDF rats with a range in myocellular fat content. We previously observed that muscles of these rats have increased PLIN5 and PLIN2 protein content which tracked with intramyocellular fat content [6]. Fascinatingly, coupled respiration and maximal respiration on palmitoyl-CoA correlated tightly with muscle PLIN5 content but interestingly not with PLIN2 content. Thus, only PLIN5 paralleled changes in mitochondrial fat oxidative capacity. Upon Western blotting isolated mitochondria with a specific PLIN5 antibody, we were able to unmask PLIN5 as a mitochondrial protein. The mitochondrial isolation protocol used results in a very clean mitochondrial homogenate without contamination of other membrane structures of remnants of LD membranes. This was substantiated by the observation that the mitochondrial isolation was negative for PLIN2, while showing clear PLIN5 bands in mitochondria isolated from a variety of skeletal and cardiac muscles. To further substantiate these findings we performed double immunofluorescence microscopy with PLIN5 along with an antibody against structural components of the electron transport chain in rat tibialis anterior muscles. Confocal analysis of tissue sections indeed localised PLIN5 to the LD, but also to the mitochondria. For a more detailed confirmation of PLIN5 being expressed in mitochondria we applied post-embedding immunogold electron microscopy, the gold standard for high-resolution subcellular localisation studies of proteins [35]. Thus, we identified PLIN5 to the LD membrane as well as in mitochondria in sections from rat glycolytic (EDL), oxidative (soleus) and cardiac muscle. PLIN5 was consistently present in subsarcolemmal as well as in intermyofibrillar mitochondria of all muscle types examined. Again, no such observations were made for PLIN2, the other major LD coat protein in muscle. Except for LDs, other organelles and myofibrillar structures were almost devoid of any PLIN5 signal. 
Having identified PLIN5 in mitochondria we set out to investigate the effect of PLIN5 overexpression on PLIN5 subcellular distribution and myocellular ultrastructure. We deliberately choose unilateral gene electroporation as the in vivo approach to overexpress PLIN5 in the tibialis anterior muscle of a rat. Thus, we were able to avoid lifelong adaptive responses while creating the ability to use the contralateral leg as an internal control. This resulted in a two-fold overexpression of PLIN5. Immunofluorescence microscopy and immunogold electron microscopy in tibialis anterior samples of the control and the overexpressing muscle confirmed specific localisation of PLIN5 to mitochondria and lipid droplets. No apparent changes in the subcellular distribution of PLIN5 were observed, i.e., subsarcolemmal and intermyofibrillar mitochondria pools both remained PLIN5 positive and qualitative examination of electron microscopical images did not indicate selective upregulation of PLIN5 at the LD site or at mitochondria. Using a variety of mitochondrial proteins we did not obverse indications of increased mitochondrial density upon PLIN5 overexpression during the 8 day time span of PLIN5 overexpression.

Moreover, PLIN5 overexpression augmented intramyocellular lipid storage and LD size, possibly reflecting the involvement of PLIN5 in ATGL-mediated lipolysis $[8,10]$. The localization of PLIN5 on the LDs and in mitochondria suggests a role for PLIN5 in directing or binding fatty acids -or fatty acid derivatives- for mitochondrial oxidation. Measurements of respiration in isolated mitochondria did not reveal any differences between mitochondria derived from the sham- and the PLIN5-electroporated muscle, which does not support a direct role for PLIN5 in mitochondrial respiration. Interestingly though, when examining ${ }^{14} \mathrm{C}$-palmitate oxidation in muscle homogenates -when mitochondria are not examined in isolation but in context of their native subcellular milieu- we observed increased complete oxidation of ${ }^{14} \mathrm{C}$-palmitate to $\mathrm{CO}_{2}$. This occurred in the absence of an increase in accumulation of acid soluble metabolites, indicating that the supply of fatty acids and/or the rate of ß-oxidation were better matched with the capacity for downstream FA oxidative metabolism. It should be noted that, albeit unlikely, we cannot exclude the possibility that, during the isolation of mitochondria, the stronger physical interaction between mitochondria and lipid droplets upon PLIN5 overexpression resulted in a loss of mitochondria intimately connected to the large lipid droplets. This could explain the discrepancy in the results of the experiments in muscle homogenates and isolated mitochondria. Nevertheless, the increase ${ }^{14} \mathrm{C}$-palmitate to $\mathrm{CO}_{2}$ points towards a beneficial effect of PLIN5 overexpression on mitochondrial fatty acid oxidation.

Thus, given the dual localization of PLIN5 to the LD and to mitochondria, it is tempting to speculate that next to a role for PLIN5 in releasing fatty acids from the LD by co-regulating lipolysis, PLIN5 is also involved in shuttling/chaperoning/binding fatty acids or fatty acid derivatives from LD origin to mitochondria for sake of oxidation. While this suggestion clearly needs further experimental substantiation, it is well in line with previous observations by others that overexpressing PLIN5 augmented fat oxidation [4]. In the process of finalizing this manuscript, Wang et al. [36] showed that PLIN5 is an important mediator of the release of fatty acids for mitochondrial $\beta$-oxidation in liver cells. Upon PKA stimulation, PLIN5 increases LD hydrolysis thus making fatty acids available for 


\section{PLIN5 localizes to muscle mitochondria}

downstream mitochondrial metabolism [36]. Whether the same holds true for muscle deserves further investigation.

Although our data clearly support mitochondrial localization of PLIN5 it remains to be solved how PLIN5 gets into mitochondria. We were unable to find evidence for an $\mathrm{N}$ terminal mitochondrial targeting pre-sequence following targeted database searches using PSORT [37] and SignalP [38]. Although such a pre-sequence is common for many mitochondrial proteins [39], it should be noted that a variety of other mitochondrial proteins do not contain such a pre-sequence either [40]. Rather, the mitochondrial localization of these proteins is determined by structural characteristics of the protein. It has been postulated that protein localization to LDs is determined by basic and hydrophobic domains, with remarkable similarities to the signals that target proteins to mitochondria [41]. Interestingly, we did find structural homology of PLIN5 with the alpha and beta chains of the mitochondrial protein ATP synthase (PropSearch) [42], providing additional support for structural characteristics in the PLIN5 sequence that could determine mitochondrial localization. Proteome analysis of the LD coat interestingly revealed that the mitochondrial protein ATP synthase was present in LD fractions of lipolytically stimulated adipocytes [34]. Thus, PLIN5 would not be the first protein localised to mitochondria and lipid droplets while lacking a mitochondrial targeting pre-sequence. Moreover, recent work revealed that the last 20 amino acids of the C-terminal end of the protein were identified to be essential for recruitment of mitochondria to the lipid droplet surface [36].

In conclusion, we provide evidence that PLIN5 is abundantly expressed in subsarcolemmal and intermyofibrillar mitochondria of glycolytic, oxidative and cardiac muscle as well as on the interface of mitochondria and lipid droplets. PLIN5 overexpression augmented fat oxidation in muscle homogenates containing both LDs and mitochondria but not in isolated mitochondria. These findings unmask PLIN5 as a protein localised to LD and mitochondria with a putative role in channelling LD derived fatty acids towards mitochondrial oxidation. Interaction of PLIN5 coated LD with mitochondria appears more frequent and more intimate upon skeletal muscle PLIN5 overexpression.

\section{REFERENCES}

1. Bickel PE, Tansey JT, and Welte MA. PAT proteins, an ancient family of lipid droplet proteins that regulate cellular lipid stores. Biochim Biophys Acta 2009; 1791: 419-440.

2. Brasaemle DL. Thematic review series: adipocyte biology. The perilipin family of structural lipid droplet proteins: stabilization of lipid droplets and control of lipolysis. J Lipid Res 2007; 48: 2547-59.

3. Yamaguchi T, Matsushita S, Motojima K, Hirose F, and Osumi T. MLDP, a novel PAT family protein localized to lipid droplets and enriched in the heart, is regulated by peroxisome proliferator-activated receptor $\alpha$. J Biol Chem 2006; 281: 14232-40.

4. Wolins NE, Quaynor BK, Skinner JR, Tzekov A, Croce MA, Gropler MC, Varma V, Yao-Borengasser A, Rasouli $\mathrm{N}$, Kern PA, Finck BN, and Bickel PE. OXPAT/PAT-1 is a PPAR-induced lipid droplet protein that promotes fatty acid utilization. Diabetes 2006; 55: 3418-28.

5. Dalen KT, Dahl T, Holter E, Arntsen B, Londos C, Sztalryd C, and Nebb HI. LSDP5 is a PAT protein specifically expressed in fatty acid oxidizing tissues. Biochim Biophys Acta 2007; 1771: 210-27. 
6. Minnaard R, Schrauwen P, Schaart G, Jorgensen JA, Lenaers E, Mensink M, and Hesselink MKC. Adipocyte differentiation-related protein and OXPAT in rat and human skeletal muscle: involvement in lipid accumulation and type 2 diabetes mellitus. J Clin Endocrinol Metab 2009; 94: 4077-85.

7. Lass A, Zimmermann R, Haemmerle G, Riederer M, Schoiswohl G, Schweiger M, Kienesberger P, Strauss JG, Gorkiewicz G, and Zechner R. Adipose triglyceride lipase-mediated lipolysis of cellular fat stores is activated by CGI-58 and defective in Chanarin-Dorfman Syndrome. Cell Metab 2006; 3: 309-319.

8. Granneman JG, Moore H-PH, Mottillo EP, Zhu Z, and Zhou L. Interactions of perilipin-5 (PLIN5) with adipose trigylceride lipase (ATGL). J Biol Chem 2011; 286: 5126-5135.

9. Granneman JG, Moore HP, Mottillo EP, and Zhu Z. Functional interactions between MLDP (LSDP5) and ABHD5 in the control of intracellular lipid accumulation. J Biol Chem 2009; 284: 3049-57.

10. Wang H, Bell M, Sreenevasan U, Hu H, Liu J, Dalen K, Londos C, Yamaguchi T, Rizzo MA, Coleman R, Gong $D$, Brasaemle D, and Sztalryd C. Unique regulation of adipose triglyceride lipase (ATGL) by perilipin 5, a lipid droplet-associated protein. J Biol Chem 2011; 286: 15707-15.

11. Blanchette-Mackie EJ, Dwyer NK, Barber T, Coxey RA, Takeda T, Rondinone CM, Theodorakis JL, Greenberg AS, and Londos C. Perilipin is located on the surface layer of intracellular lipid droplets in adipocytes. J Lipid Res 1995; 36: 1211-1226.

12. Cohen AW, Razani B, Schubert W, Williams TM, Wang XB, Iyengar P, Brasaemle DL, Scherer PE, and Lisanti MP. Role of caveolin-1 in the modulation of lipolysis and lipid droplet formation. Diabetes 2004; 53: 12611270.

13. Hoppeler H. Skeletal muscle substrate metabolism. Int J Obes Relat Metab Disord 1999; 23 Suppl 3: S7-10.

14. Hoppeler $H$, Luthi $P$, Claassen $H$, Weibel ER, and Howald $H$. The ultrastructure of the normal human skeletal muscle. A morphometric analysis on untrained men, women and well-trained orienteers. Pflugers Arch 1973; 344: 217-32.

15. Stone SJ, Levin MC, Zhou P, Han J, Walther TC, and Farese RV, Jr. The endoplasmic reticulum enzyme DGAT2 is found in mitochondria-associated membranes and has a mitochondrial targeting signal that promotes its association with mitochondria. J Biol Chem 2009; 284: 5352-5361.

16. Hammond LE, Gallagher PA, Wang S, Hiller S, Kluckman KD, Posey-Marcos EL, Maeda N, and Coleman RA. Mitochondrial glycerol-3-phosphate acyltransferase-deficient mice have reduced weight and liver triacylglycerol content and altered glycerolipid fatty acid composition. Mol Cell Biol 2002; 22: 8204-8214.

17. Lewin TM, Schwerbrock NMJ, Lee DP, and Coleman RA. Identification of a new glycerol-3-phosphate acyltransferase isoenzyme, mtGPAT2, in mitochondria. Journal of Biological Chemistry 2004; 279: 1348813495.

18. Ellis JM, Frahm JL, Li LO, and Coleman RA. Acyl-coenzyme A synthetases in metabolic control. Curr Opin Lipidol 2010; 21: 212-217 10.1097/MOL.0b013e32833884bb.

19. Wang $\mathrm{H}$ and Sztalryd C. Oxidative tissue: perilipin 5 links storage with the furnace. Trends Endocrinol Metab 2011; 22:

20. Bergstrom J. Percutaneous needle biopsy of skeletal muscle in physiological and clinical research. Scand J Clin Lab Invest 1975; 35: 609-16.

21. Lenaers E, De Feyter HM, Hoeks J, Schrauwen P, Schaart G, Nabben M, Nicolay K, Prompers JJ, and Hesselink MKC. Adaptations in mitochondrial function parallel, but fail to rescue, the transition to severe hyperglycemia and hyperinsulinemia: a study in Zucker diabetic fatty rats. Obesity 2010; 18: 1100-1107.

22. Bruce CR, Brolin C, Turner N, Cleasby ME, van der Leij FR, Cooney GJ, and Kraegen EW. Overexpression of carnitine palmitoyltransferase $\mathrm{I}$ in skeletal muscle in vivo increases fatty acid oxidation and reduces triacylglycerol esterification. Am J Physiol Endocrinol Metab 2007; 292: E1231-1237.

23. Bruce CR, Hoy AJ, Turner N, Watt MJ, Allen TL, Carpenter K, Cooney GJ, Febbraio MA, and Kraegen EW. Overexpression of carnitine palmitoyltransferase-1 in skeletal muscle is sufficient to enhance fatty acid oxidation and improve high fat diet-induced insulin resistance. Diabetes 2009; 58: 550-558.

24. Tonkonogi $M$ and Sahlin K. Rate of oxidative phosphorylation in isolated mitochondria from human skeletal muscle: effect of training status. Acta Physiol Scand 1997; 161: 345-53.

25. Udenfriend S, Stein S, Bohlen P, Dairman W, Leimgruber W, and Weigele M. Fluorescamine: a reagent for assay of amino acids, peptides, proteins, and primary amines in the picomole range. Science $1972 ; 178$ : $871-2$. 


\section{PLIN5 localizes to muscle mitochondria}

26. Hoeks J, Briedé JJ, de Vogel J, Schaart G, Nabben M, Moonen-Kornips E, Hesselink MKC, and Schrauwen P. Mitochondrial function, content and ROS production in rat skeletal muscle: Effect of high-fat feeding. FEBS Lett 2008; 582: 510-516.

27. Frisard MI, McMillan RP, Marchand J, Wahlberg KA, Wu Y, Voelker KA, Heilbronn L, Haynie K, Muoio B, Li L, and Hulver MW. Toll-like receptor 4 modulates skeletal muscle substrate metabolism. Am J Physiol Endocrinol Metab 2010; 298: E988-E998.

28. Kim JY, Koves TR, Yu GS, Gulick T, Cortright RN, Dohm GL, and Muoio DM. Evidence of a malonyl-CoAinsensitive carnitine palmitoyltransferase I activity in red skeletal muscle. Am J Physiol Endocrinol Metab 2002; 282: E1014-E1022.

29. Tokuyasu KT. A technique for ultracryotomy of cell suspensions and tissues. J Cell Biol 1973; 57: 551-65.

30. Tokuyasu KT. Immunochemistry on ultrathin frozen sections. Histochem J 1980; 12: 381-403.

31. Tokuyasu KT. Application of cryoultramicrotomy to immunocytochemistry. J Microsc 1986; 143: 139-49.

32. Slot JW and Geuze HJ. Sizing of protein A-colloidal gold probes for immunoelectron microscopy. J Cell Biol 1981; 90: 533-536.

33. Koopman R, Schaart G, and Hesselink M. Optimisation of oil red O staining permits combination with immunofluorescence and automated quantification of lipids. Histochem Cell Biol 2001; 116: 63-68.

34. Brasaemle DL, Dolios G, Shapiro L, and Wang R. Proteomic analysis of proteins associated with lipid droplets of basal and lipolytically stimulated 3T3-L1 adipocytes. J Biol Chem 2004; 279: 46835-46842.

35. Zuber C, Fan J, Guhl B, and Roth J. Applications of immunogold labeling in ultrastructural pathology. Ultrastruct Pathol 2005; 29: 319-330.

36. Wang H, Sreenevasan U, Hu H, Saladino A, Polster BM, Lund LM, Gong D-W, Stanley WC, and Sztalryd C. Perilipin 5, a lipid droplet associated protein, provides physical and metabolic linkage to mitochondria. J Lipid Res 2011; 52: 2159-2168.

37. Horton P, Park K-J, Obayashi T, Fujita N, Harada H, Adams-Collier CJ, and Nakai K. WoLF PSORT: protein localization predictor. Nucleic Acids Res 2007; 35: W585-W587.

38. Bendtsen JD, Nielsen H, von Heijne G, and Brunak S. Improved prediction of signal peptides: SignalP 3.0. J Mol Biol 2004; 340: 783-795.

39. Van der Laan M, Hutu DP, and Rehling P. On the mechanism of preprotein import by the mitochondrial presequence translocase. Biochim Biophys Acta 2010; 1803: 732-739.

40. Dukanovic J and Rapaport D. Multiple pathways in the integration of proteins into the mitochondrial outer membrane. Biochim Biophys Acta 2011; 1808: 971-980.

41. Ingelmo-Torres M, Elena G-M, Adam K, Michael H-B, Francesc T, Albert H, Thomas G, John FH, Carlos E, Marta B, Steven PG, Robert GP, and Albert P. Hydrophobic and basic domains target proteins to lipid droplets. Traffic 2009; 10: 1785-1801.

42. Hobohm U and Sander C. A sequence property approach to searching protein databases. J Mol Biol 1995; 251: 390-399. 


\section{CHAPTER 7}

Overexpression of PLIN5 in skeletal muscle promotes oxidative gene expression and intramyocellular lipid content without compromising insulin sensitivity

Madeleen Bosma, Lauren M. Sparks, Guido Hooiveld, Johanna Jorgensen, Sander Houten, Patrick Schrauwen, Sander Kersten, Matthijs K.C. Hesselink

Biochimica et Biophysica Acta-Molecular and Cell Biology of Lipids; in press 


\begin{abstract}
While lipid deposition in skeletal muscle is considered to be involved in obesity-associated insulin resistance, neutral intramyocellular lipid (IMCL) accumulation per se does not necessarily induce insulin resistance. We previously demonstrated that overexpression of the lipid droplet coat protein perilipin 2 augments intramyocellular lipid content while improving insulin sensitivity. Another member of the perilipin family, perilipin 5 (PLIN5), is predominantly expressed in oxidative tissues like skeletal muscle. Here we investigated the effects of PLIN5 overexpression - in comparison with effects of PLIN2 - on skeletal muscle lipid levels, gene expression profiles and insulin sensitivity.

Gene electroporation was used to overexpress PLIN5 in tibialis anterior muscle of rats fed a high fat diet. Eight days after electroporation, insulin-mediated glucose uptake in skeletal muscle was measured by means of a hyperinsulinemic euglycemic clamp. Electron microscopy, fluorescence microscopy and lipid extractions were performed to investigate IMCL accumulation. Gene expression profiles were obtained using microarrays.

TAG storage and lipid droplet size increased upon PLIN5 overexpression. Despite the higher IMCL content, insulin sensitivity was not impaired and DAG and acylcarnitine levels were unaffected. In contrast to the effects of PLIN2 overexpression, microarray data analysis revealed a gene expression profile favoring FA oxidation and improved mitochondrial function. In conclusion, both PLIN2 and PLIN5 increase neutral IMCL content without impeding insulin-mediated glucose uptake. As opposed to the effects of PLIN2 overexpression, overexpression of PLIN5 in skeletal muscle promoted expression of a cluster of genes under control of PPAR $\alpha$ and PGC1 $\alpha$ involved in FA catabolism and mitochondrial oxidation.
\end{abstract}




\section{INTRODUCTION}

Obesity is associated with increased lipid supply to skeletal muscle resulting in increased intramyocellular lipid (IMCL) storage. Accumulation of $\mathrm{IMCL}$ is associated with the development of insulin resistance. However, IMCL accumulation per se does not necessarily induce insulin resistance (reviewed in [1]). Recent studies suggest that increasing the capacity for triacylglycerol (TAG) storage in lipid droplets (LDs) creates a sink for storage of fatty acids (FAs) in the form of neutral lipids thereby sequestering FAs and protecting against lipotoxicity [2-5].

By regulating processes like LD synthesis, breakdown, fusion, intracellular transport and interorganelle interactions, LD coat proteins are determinants of the highly dynamic nature of LDs (reviewed in [6, 7]). One of the major lipid droplet coat protein families characterized to date is the perilipin family. Perilipin 2 (PLIN2), PLIN3 and PLIN5 are considered the major perilipins in skeletal muscle. Indeed, we have recently shown that PLIN2 overexpression in muscle results in massive fat accumulation in muscle, while insulin-mediated glucose uptake was only modestly increased [2]. Furthermore, PLIN2 overexpression also blunted high fat diet-induced induction of expression of OXPHOS protein complexes [2], which may indicate that in the long run oxidative capacity will no longer keep track with intramyocellular lipid content in this situation.

Why skeletal muscle expresses both PLIN2 and PLIN5 is still unknown. We and others $[8,9]$ recently found that PLIN5 not only localizes to LDs, but also to mitochondria. Thus, the putative role of PLIN5 is most likely not limited to the regulation of lipolysis. Putatively, PLIN5 may also be involved in shuttling of FAs to mitochondria for oxidation. In line with this we observed that PLIN5 overexpression also augmented intramyocellular LD content in parallel with improved oxidation of palmitate to $\mathrm{CO}_{2}$ [8]. Here, we aimed to further investigate the effects of PLIN5 overexpression - in comparison with effects of PLIN2 - on lipid storage, transcriptomic oxidative gene profiles, and insulin sensitivity.

\section{METHODS}

\section{Study design}

8-week old male Wistar rats were purchased from Harlan (Horst, The Netherlands). Rats were housed individually on a 12:12 h light-dark cycle (light from 7:00 am to 7:00 pm), at room temperature $\left(21-22{ }^{\circ} \mathrm{C}\right)$ with ad libitum access to tap water. Rats were fed a high fat diet (45\% energy from fat, D01060502, Research Diets, New Brunswick, NJ, USA) for the duration of the 3-week intervention. The Institutional Animal Care and Use Committee of Maastricht University approved the experiments. During the experiments all efforts were made to minimize suffering of the animals. 


\section{Electroporation}

Two weeks after the start of the diet, overexpression of Plin5 in either the right or left tibialis anterior (TA) muscle of the rat was accomplished by an in vivo DNA electrotransfer technique to achieve overexpression of PLIN5 in one leg; the contralateral TA served as a sham-electroporated internal control. Plin5 was electroporated randomly in the left or the right TA. DNA electroporation was performed under isoflurane anaesthesia. TA muscles were transcutaneously injected with either $150 \mu \mathrm{g}(2 \mu \mathrm{g} / \mu \mathrm{l})$ pcDNA3.1-CMV-Plin5 or pcDNA3.1-empty vector in $0.9 \%$ sterile saline. Within 15 seconds after the last injection 5 electric pulses were applied by two stainless steel plate electrodes placed the ventral and dorsal side of the leg. One high voltage pulse of $800 \mathrm{~V} / \mathrm{cm}$ and four low voltage pulses of $80 \mathrm{~V} / \mathrm{cm}$ at $1 \mathrm{~Hz}$ were generated by an ECM 830 electroporator (BTX, San Diego, CA, USA) as described previously $[10,11]$. Rats were killed 8 days post-electroporation. TA muscles were quickly dissected and processed for mitochondrial isolations and morphological analysis. The remainder of the TA was rapidly frozen in melting isopentane for further analyses.

\section{Cannulation and hyperinsulinemic euglycemic clamps}

Throughout the entire study, rats were handled daily for familiarisation. Indwelling catheters were placed in the right jugular vein (for the sampling of blood) and the left carotid artery (for the infusion of insulin and glucose) under isoflurane anaesthesia and aseptic conditions, two weeks before the hyperinsulinemic euglycemic clamp was performed. The venous catheter was extended to the level of the right atrium and the arterial catheter within the aortic arch. Both catheters were tunnelled subcutaneously and exteriorized at the top of the head, where they were attached in dentist cement between 2-3 screws onto a 90--bend needle. The catheters were filled with a mixture of $85 \%$ glycerol (Merck, Darmstadt, Germany) and $500 \mathrm{U} / \mathrm{ml}$ heparin (Leo Pharma BV, Breda, The Netherlands) to maintain patency. All rats regained pre-surgery body mass within 3 days.

Hyperinsulinemic euglycemic clamps of conscious rats were performed after a $6 \mathrm{~h}$ fast. Insulin stimulated glucose disposal in vivo within the individual tibialis anterior muscles was studied according to a previously described method [12]. A primed continuous infusion of insulin (Actrapid HM; Novo Nordisk, Copenhagen, Denmark) was administered at a rate of $13 \mathrm{mU} / \mathrm{kg} / \mathrm{min}$ for $120 \mathrm{~min}$. Blood glucose values were monitored at 10-min intervals throughout the clamp. The glucose infusion rate (GIR) was adjusted to maintain blood glucose concentration within the range of 3.5-4.5 mM. Rats were conscious during the entire clamp. $45 \mathrm{~min}$ before completion of the clamp, a bolus of $140 \mu \mathrm{Ci} / \mathrm{kg}$ of the non-metabolizable glucose analogue 2-[3H(N)]-deoxy-D-glucose (Perkin Elmer, Waltham, Massachusetts, USA) was administered to measure insulin-stimulated glucose disposal in the individual TA muscles. Upon completion of the clamp, the rats were sacrificed with an overdose of sodium pentobarbital and tibialis anterior muscles were quickly dissected and frozen in liquid nitrogen-cooled isopentane and stored at -80 ㅇ C until further analyses. 


\section{${ }^{3} \mathrm{H}$-Deoxyglucose measurements}

Frozen TA muscle sections were ground to powder under liquid nitrogen, homogenized in MilliQ water, and eluted on columns filled with DOWEX ion-exchange resin (Sigma, St. Louis, Missouri, USA) using elution buffer ( $0.3 \mathrm{M}$ ammonium acetate and $1.25 \%$ formic acid in $\mathrm{H} 2 \mathrm{O}, \mathrm{pH} 4.9$ ). Ionizing radiation counts were determined by scintillation counting.

\section{Electron microscopy procedures}

Ultrastructural morphology was examined using transmission electron microscopy. Muscle tissue sections were fixed in $2.5 \%$ glutaraldehyde in $0.1 \mathrm{M}$ phosphate buffer ( $\mathrm{pH} 7.4$ ). Postfixation was performed in $1 \%$ osmium tetroxide in $0.1 \mathrm{M}$ cacodylate buffer $(\mathrm{pH} 7.4)$ supplemented with $1.5 \%$ potassium ferrocyanide. The samples were then dehydrated and embedded in epon. Ultrathin sections were examined using a Philips CM100 electron microscope. Electron microscopy pictures were available from 4 rats. 5-10 images per muscle sample were taken randomly. LD size was measured using the freehand selection tool of ImageJ [13].

\section{Oil-red-O staining and immunofluorescence}

Neutral lipids were stained in muscle sections with a modified Oil-red-O staining along with immunofluorescence to study PLIN5 and laminin using antibodies against PLIN5 (\#GP31; Progen Biotechnik, Heidelberg, Germany) and laminin (L-9393; Sigma, St. Louis, USA) as previously described [14] and visualised with appropriate secondary Alexa-fluor conjugated antibodies (Invitrogen, Groningen, The Netherlands).

\section{Lipid profiles}

Intramyocellular TAG levels were measured using the method of Schwartz and Wolins [15]. DAG [2] and acylcarnitine [16] levels were measured as described previously.

\section{Western blots}

Western blots were performed with muscle homogenates in RIPA-lysis buffer mixed 1:1 with Laemmli sample buffer (Bio-Rad, Mississauga, Ontario, Canada) using antibodies directed against PLIN2 (GP40; Progen, Heidelberg, Germany), PLIN3 (SC-14726, Santa Cruz Biotechnology, Heidelberg, Germany), PLIN5 (GP31; Progen, Heidelberg, Germany), ATGL (2138, Cell Signaling, Boston, USA), CGI-58 (NB110-41576, Novus Biologicals, Littleton, USA), and HSL (4107, Cell Signalling, Boston, USA). Secondary antibodies for PLIN2, PLIN3 PLIN5, ATGL and SR-actin contained a fluorescent tag (IRDye800- or IRDye700-conjugated secondary antibodies (Rockland, Tebu-bio, Heerhugowaard, The Netherlands, and LICOR Biosciences, Westburg, Leusden, The Netherlands). Protein quantification was performed by scanning on an Odyssey Infrared Imaging system (LI-COR Biotechnology, Lincoln, Nebraska, USA). CGI-58 and HSL were detected using an HRP-conjugated antibody and ECL 
detection. Protein expression values were standardized against sr-actin protein expression (Sigma, St. Louis, USA) and expressed in arbitrary units (AU).

\section{RNA isolation and microarray gene expression analysis}

Total RNA from rat tibialis anterior muscle was extracted and purified with the RNeasy kit for fibrous tissue (Qiagen, Venlo, The Netherlands). RNA quality was assessed on an Agilent 2100 bioanalyzer (Agilent Technologies, Amsterdam, The Netherlands) with 6000 Nano Chips using the Eukaryote Total RNA Nano assay. RNA was judged as suitable for array hybridization only if samples showed intact bands corresponding to the $28 \mathrm{~S}$ and $18 \mathrm{~S}$ rRNA subunits, displayed no chromosomal peaks or RNA degradation products, and had a RIN (RNA integrity number) above 8.0. RNA samples from 6 rats were pooled. Five micrograms of RNA were used for one cycle cRNA synthesis (Affymetrix, Santa Clara, CA). Hybridization, washing and scanning of Affymetrix rat arrays was carried out according to standard Affymetrix protocols. To adjust for non-specific hybridization and optical noise, the array expression data were normalized with RMA (robust multichip analysis, a package of the Bioconductor project [17] in the R environment. Functional analysis of the array data was performed by a method based on enrichment of gene sets (Gene Ontology (GO) classes using the application GSEA [18] and gene set clustering analysis using Cytoscape [19]. Microarray data have been submitted to Gene Expression Omnibus (GEO number pending).

\section{Statistical analysis}

Results are presented as mean \pm SEM. Differences between groups were evaluated with paired T-tests. Outcomes were considered statistically significant when $\mathrm{P}<0.05$ (twotailed). Analyses were performed using the Statistical Package for the Social Sciences (SPSS 16.0, Nieuwegein, The Netherlands) software for Mac 16.0. For microarray data, normalized enrichment scores (NES) and false discovery rates (q-values), calculated by the application GSEA, were reported. Q-values $<0.05$ were considered statistically significant. In Cytoscape, cut-off values were set at $\mathrm{P}<0.005$ and $\mathrm{q}<0.1$.

\section{RESULTS}

\section{PLIN5 overexpression increases intramyocellular lipid storage}

PLIN5 electroporation resulted in a 2.8-fold overexpression of PLIN5 (empty vector muscle lysates $0.81 \pm 0.19$, PLIN5 muscle $2.28 \pm 0.42 \mathrm{AU}, \mathrm{P}<0.05, \mathrm{n}=9$ ) (Fig $1 \mathrm{~A}$ ). The overexpression of PLIN5 gave rise to a pronounced increase in IMCL levels (Fig. 1B-C). Lipid droplet size was increased; the LD size distribution shifted from LDs of up to $1.2 \mu \mathrm{m}^{2}$ in size in the empty vector-electroporated muscle fibers to LDs of up to $5.8 \mu^{2}$ in the PLIN5 overexpressing fibers (Fig. 1D). The average LD size increased more than five-fold $(P<0.01)$ (Fig. 1D). The increase in LD size occurred in parallel with a 3-fold increase in intramyocellular triacylglycerol (TAG) levels (Fig. 2A). Diacylglycerol (DAG) levels (Fig. 2B) 
were unchanged. Acylcarnitines are formed in mitochondria when $\beta$-oxidation rates outpace the capacity of the TCA cycle [20] and have been implemented in development of insulin resistance. Free carnitine (Fig. 2C) and acylcarnitine levels (Fig. 2D) were not different in the PLIN5-electroporated muscle versus the empty vector control. Additionally, the FA-composition of the DAG fraction was not significantly changed and the individual acylcarnitine species did not show a different profile in empty-vector versus PLIN5-electroporated muscles (Supplemental Tables S1 and S2, respectively).

A
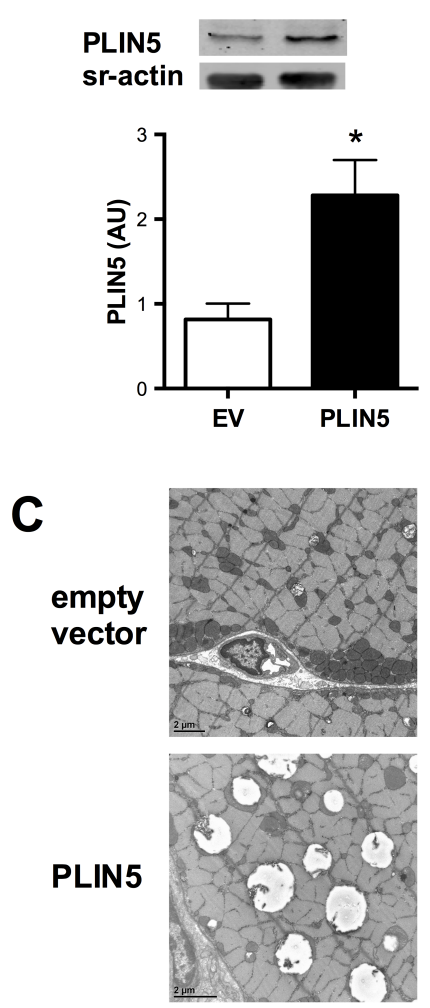
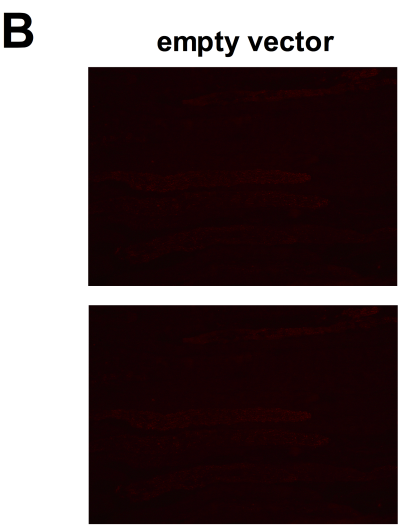

D

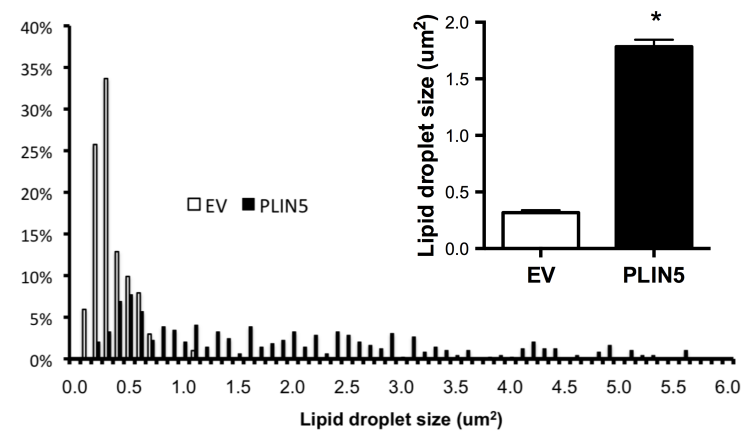

Figure 1. PLIN5 overexpression increases intramyocellular lipid accumulation and lipid droplet size. (A) PLIN5 protein content in protein lysates from electroporated tibialis anterior muscle. (B) Shows the effect of PLIN5 overexpression on PLIN5 content (lower right hand panel) and lipid storage (upper right hand panel) compared to the empty vector control (upper and lower left hand panels). LDs are stained in red, PLIN5 in green and cell membranes in blue. Bars represent $100 \mu \mathrm{m}$. (C) Electron microscopy showing skeletal muscle ultrastructure. (D) Lipid droplet size distribution and average $L D$ size. EV: empty vector, ${ }^{*} \mathrm{P}<0.05$, error bars represent $S E M$. 
A

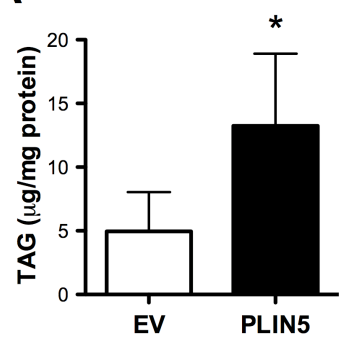

C

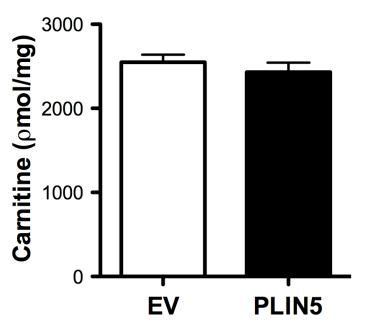

B

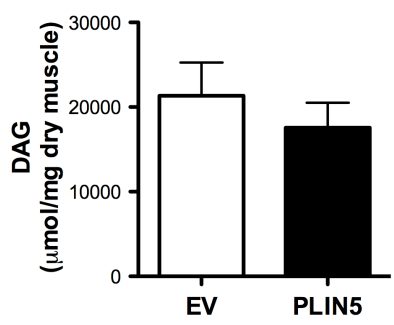

D

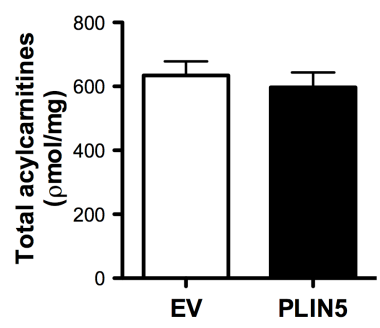

Figure 2. PLIN5 overexpression results in increased TAG accumulation. (A) Skeletal muscle TAG levels (ug/ $\mathrm{mg}$ protein). (B) DAG content $(\mu \mathrm{mol} / \mathrm{mg}$ dry weight). (C) Free carnitine ( $\rho \mathrm{mol} / \mathrm{mg}$ protein). (D) Acylcarnitine levels ( $\rho \mathrm{mol} / \mathrm{mg}$ protein). EV: empty vector. ${ }^{*} \mathrm{P}<0.05$, error bars represent SEM.

\section{Increased ATGL protein content in PLIN5 overexpressing muscle}

PLIN5 overexpression was not paralleled by compensatory changes in PLIN2 and PLIN3 protein content (Fig. 3A and B). ATGL protein content was significantly increased by $16 \%$ $(\mathrm{P}=0.047)$ (Fig. $3 \mathrm{C})$, while $\mathrm{CGI}-58$ protein content showed a trend towards downregulation $(P=0.10)$ (Fig. 3D). HSL protein content was similar in empty vector and PLIN5electroporated muscle (Fig. 3E). 
A PLIN2 sr-actin

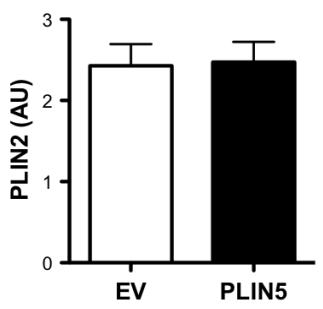

C ATGL sr-actin

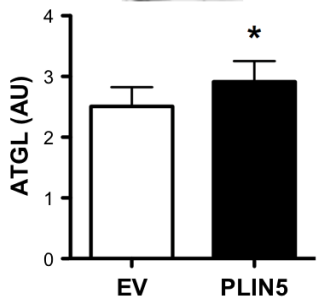

E HSL

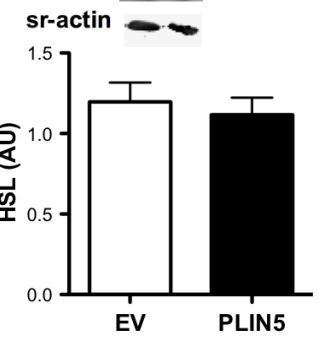

B

PLIN3

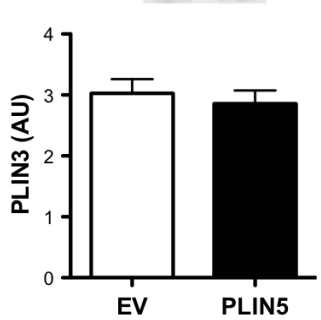

D ${ }_{\text {sr-actin }}^{\text {CGI-58 }}-$

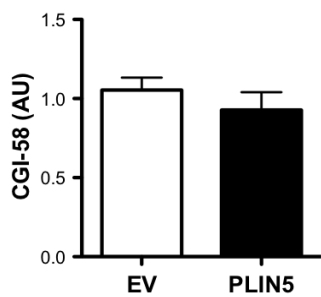

Figure 3. PLIN5 overexpression increased ATGL protein content. (AD) Western blots for PLIN2 (A), PLIN3 (B), ATGL (C), CGI-58 (D) and HSL (E) in whole muscle protein lysates $(n=17)$.

PLIN5 overexpression results in a gene expression pattern favoring FA oxidative metabolism

Upon PLIN5 overexpression, 775 genes were upregulated, 1042 genes were downregulated (fold change cut-off value 1.3). Table 1 gives the gene expression profiles for a selection of genes, the complete microarray dataset can be found as supporting document online (Supplemental Table S3). Gene class enrichment analyses revealed that PLIN5 overexpression resulted in increased expression of genes involved in FA $\beta$-oxidation, the TCA cycle, the electron transport chain and mitochondrion organization (Table 2). Genes involved in immune processes were downregulated (Table 3). 


\section{PLIN5 overexpression promotes oxidative gene expression}

Table 1. Heat map. Fold changes in gene expression for a selection of genes are given for PLIN5 versus empty-vector (EV) electroporated muscles.

\begin{tabular}{|c|c|c|c|}
\hline Gene name & Entrez ID & Description & Fold change \\
\hline Pla2g $4 c$ & 691810 & Phospholipase A2, group IVC (cytosolic, calcium-independent) & 2.94 \\
\hline Acsm5 & 361637 & Acyl-CoA synthetase medium-chain family member 5 & 2.17 \\
\hline Scand3 & 288622 & SCAN domain containing 3 & 2.17 \\
\hline LOC679586 & 679586 & Similar to ATP synthase, $\mathrm{H}^{+}$transporting, mitochondrial F0 complex, subunit $\mathrm{G}$ & 1.89 \\
\hline Atp5h/1 & 306478 & ATP synthase, $\mathrm{H}^{+}$transporting, mitochondrial F0 complex, subunit d-like 1 & 1.78 \\
\hline Dync2li1 & 298767 & Dynein cytoplasmic 2 light intermediate chain 1 & 1.77 \\
\hline Acat3 & 308100 & Acetyl-Coenzyme A acetyltransferase 3 & 1.70 \\
\hline$R f k$ & 499328 & Riboflavin kinase & 1.70 \\
\hline Angpt/4 & 362850 & Angiopoietin-like 4 & 1.68 \\
\hline Atp6v1a & 685232 & ATPase, $\mathrm{H}^{+}$transporting, lysosomal $\mathrm{V} 1$ subunit $\mathrm{A}$ & 1.63 \\
\hline$H s d 3 b$ & 682974 & $3 \beta$-hydroxysteroid dehydrogenase $/ \Delta 5-4$ isomerase type II & 1.59 \\
\hline Fabp4 & 79451 & Fatty acid binding protein 4 & 1.58 \\
\hline$A \cot 3$ & 314304 & Acyl-CoA thioesterase 3 & 1.57 \\
\hline Acnat1 & 681043 & Acyl-coenzyme $\mathrm{A}$ amino acid $\mathrm{N}$-acyltransferase 1 & 1.55 \\
\hline LOC689271 & 689271 & $\begin{array}{l}\text { Similar to ATP synthase, } \mathrm{H}^{+} \text {transporting, mitochondrial F0 complex, subunit } \mathrm{f} \text {, } \\
\text { isoform } 2\end{array}$ & 1.54 \\
\hline$C d 36$ & 29184 & Cd36 molecule & 1.49 \\
\hline RGD1559672 & 500650 & Similar to translocase of inner mitochondrial membrane 23 homolog & 1.48 \\
\hline Nkain3 & 689576 & $\mathrm{Na}^{+} / \mathrm{K}^{+}$transporting ATPase interacting 3 & 1.47 \\
\hline Ehhadh & 171142 & Enoyl-CoA, hydratase/3-hydroxyacyl CoA dehydrogenase & 1.45 \\
\hline Atp6v1b1 & 312488 & ATPase, $\mathrm{H}^{+}$transporting, lysosomal V1 subunit B1 & 1.41 \\
\hline Atp6v1g3 & 289407 & ATPase, $\mathrm{H}^{+}$transporting, lysosomal V1 subunit $\mathrm{G} 3$ & 1.38 \\
\hline Fads6 & 303671 & Fatty acid desaturase domain family, member 6 & 1.35 \\
\hline Mrps27 & 361883 & Mitochondrial ribosomal protein S27 & 1.34 \\
\hline Acox2 & 252898 & Acyl-CoA oxidase 2 , branched chain & 1.33 \\
\hline RGD1561341 & 502769 & Similar to translocase of outer mitochondrial membrane 20 homolog & 1.33 \\
\hline Pld6 & 287366 & Phospholipase D family, member 6 & 1.33 \\
\hline Atp5s & 362749 & ATP synthase, $\mathrm{H}^{+}$transporting, mitochondrial FO complex, subunit s (factor $\mathrm{B}$ ) & 1.32 \\
\hline S/c27a3 & 295219 & Solute carrier family 27 (fatty acid transporter), member 3 & -2.98 \\
\hline Pparg & 25664 & Peroxisome proliferator-activated receptor $\gamma$ & -1.89 \\
\hline Gk5 & 367146 & Glycerol kinase 5 (putative) & -1.79 \\
\hline Ppt1 & 29411 & Palmitoyl-protein thioesterase 1 & -1.70 \\
\hline $\sin$ & 367086 & Sarcolipin & -1.68 \\
\hline Pla2g2a & 29692 & Phospholipase A2, group IIA & -1.66 \\
\hline Smpd3 & 94338 & Sphingomyelin phosphodiesterase 3 , neutral membrane & -1.56 \\
\hline Pltp & 296371 & Phospholipid transfer protein & -1.45 \\
\hline Slc37a2 & 500973 & Solute carrier family 37 (glycerol-3-phosphate transporter), member 2 & -1.38 \\
\hline
\end{tabular}




\begin{tabular}{llll} 
Chn2 & 84031 & Chimerin 2 & -1.38 \\
Prkcd & 170538 & Protein kinase C, $\delta$ & -1.35 \\
Ldhal6b & 369018 & Lactate dehydrogenase A-like 6B & -1.35 \\
Scd & 83792 & Stearoyl-CoA desaturase (49-desaturase) & -1.31 \\
\hline
\end{tabular}

To investigate if these gene expression profiles were specific for PLIN5-induced lipid accumulation, we compared these results with overexpression of PLIN2. As described previously [2], PLIN2 overexpression increased IMCL levels concurrent with a gene expression profile favoring lipid storage rather than oxidation. Figure 4 displays the effects of PLIN5 and PLIN2 electroporation (versus the corresponding empty vector controls) on gene sets involved in fatty acid oxidation and mitochondrial function. Interestingly, PLIN5 has opposite effects on transcription levels of genes involved in FA oxidation compared to PLIN2. Our data indicate that - as opposed to PLIN2 overexpression - PLIN5 overexpression is associated with induction of a transcriptional program favoring FA catabolism and subsequent mitochondrial oxidation. These changes in gene expression were functionally reflected in increased ${ }^{14} \mathrm{C}$-palmitate oxidation to $\mathrm{CO}_{2}$ after PLIN5 overexpression which we observed previously (empty vector $0.05 \pm 0.008$, PLIN5 $0.07 \pm$ $0.012{ }^{14} \mathrm{CO}_{2} /$ total ${ }^{14} \mathrm{C}$-palmitate oxidation, $\left.P=0.05\right)[8]$.

Table 2. PLIN5 overexpression increased expression of genes involved in mitochondrial function and fatty acid oxidation. Microarray gene expression profiles for PLIN5 overexpression were clustered in Gene Ontology (GO) classes using GSEA (Gene Set Enrichment Analysis). This table shows the GO classes that were enriched in the set of upregulated genes. All upregulated GO classes with a false discovery rate (FDR) q-value $<0.05$ are shown. NES: normalized enrichment score.

\begin{tabular}{llrr}
\hline GO & Name & NES & FDR q-value \\
\hline GO:0005759 & Mitochondrial matrix & 4.01 & $<1.00 \mathrm{E}-06$ \\
GO:0044455 & Mitochondrial membrane part & 3.60 & $<1.00 \mathrm{E}-06$ \\
GO:0045333 & Cellular respiration & 3.59 & $<1.00 \mathrm{E}-06$ \\
GO:0005743 & Mitochondrial inner membrane & 3.50 & $<1.00 \mathrm{E}-06$ \\
GO:0019866 & Organelle inner membrane & 3.30 & $<1.00 \mathrm{E}-06$ \\
GO:0030964 & NADH dehydrogenase complex & 3.29 & $<1.00 \mathrm{E}-06$ \\
GO:0045271 & Respiratory chain complex I & 3.28 & $<1.00 \mathrm{E}-06$ \\
GO:0005747 & Mitochondrial respiratory chain complex I & 3.26 & $<1.00 \mathrm{E}-06$ \\
GO:0005746 & Mitochondrial respiratory chain & 3.01 & $<1.00 \mathrm{E}-06$ \\
GO:0022900 & Electron transport chain & 2.98 & $<1.00 \mathrm{E}-06$ \\
GO:0070469 & Respiratory chain & 2.90 & $4.52 \mathrm{E}-05$ \\
GO:0006084 & Acetyl-CoA metabolic process & 2.88 & $1.29 \mathrm{E}-04$ \\
GO:0072329 & Monocarboxylic acid catabolic process & 2.79 & $2.74 \mathrm{E}-04$ \\
GO:0006091 & Generation of precursor metabolites and energy & 2.76 & $4.48 \mathrm{E}-04$ \\
GO:0009060 & Aerobic respiration & 2.74 & $5.01 \mathrm{E}-04$ \\
GO:0015980 & Energy derivation by oxidation of organic compounds & 2.71 & $6.28 \mathrm{E}-04$ \\
GO:0022904 & Respiratory electron transport chain & 2.67 & $1.04 \mathrm{E}-03$ \\
GO:0009062 & Fatty acid catabolic process & 2.58 & $2.97 \mathrm{E}-03$
\end{tabular}




\begin{tabular}{|c|c|c|c|}
\hline GO:0046356 & Acetyl-CoA catabolic process & 2.55 & $3.86 \mathrm{E}-03$ \\
\hline GO:0006119 & Oxidative phosphorylation & 2.48 & 7.09E-03 \\
\hline GO:0046395 & Carboxylic acid catabolic process & 2.46 & 7.23E-03 \\
\hline GO:0003954 & NADH dehydrogenase activity & 2.43 & $8.80 \mathrm{E}-03$ \\
\hline GO:0016054 & Organic acid catabolic process & 2.42 & $9.12 \mathrm{E}-03$ \\
\hline GO:0048037 & Cofactor binding & 2.42 & $9.01 \mathrm{E}-03$ \\
\hline GO:0007005 & Mitochondrion organization and biogenesis & 2.40 & $1.01 \mathrm{E}-02$ \\
\hline GO:0050662 & Coenzyme binding & 2.39 & $1.08 \mathrm{E}-02$ \\
\hline GO:0006099 & Tricarboxylic acid cycle & 2.39 & $1.08 \mathrm{E}-02$ \\
\hline GO:0051187 & Cofactor catabolic process & 2.38 & 1.10E-02 \\
\hline GO:0051186 & Cofactor metabolic process & 2.37 & $1.20 \mathrm{E}-02$ \\
\hline GO:0006732 & Coenzyme metabolic process & 2.37 & $1.18 \mathrm{E}-02$ \\
\hline GO:0006637 & Acyl-CoA metabolic process & 2.37 & 1.16E-02 \\
\hline GO:0009109 & Coenzyme catabolic process & 2.34 & $1.55 \mathrm{E}-02$ \\
\hline GO:0016655 & $\begin{array}{l}\text { Oxidoreductase activity, acting on NADH or NADPH, quinone or similar } \\
\text { compound as acceptor }\end{array}$ & 2.32 & $1.70 \mathrm{E}-02$ \\
\hline GO:0051262 & Protein tetramerization & 2.32 & 1.77E-02 \\
\hline GO:0035383 & Thioester metabolic process & 2.32 & $1.76 \mathrm{E}-02$ \\
\hline GO:0008137 & NADH dehydrogenase (ubiquinone) activity & 2.31 & $1.76 \mathrm{E}-02$ \\
\hline GO:0042773 & ATP synthesis coupled electron transport & 2.29 & $2.11 \mathrm{E}-02$ \\
\hline GO:0050136 & NADH dehydrogenase (quinone) activity & 2.29 & $2.11 \mathrm{E}-02$ \\
\hline GO:0016651 & Oxidoreductase activity & 2.27 & $2.27 \mathrm{E}-02$ \\
\hline GO:0051087 & Chaperone binding & 2.27 & $2.23 \mathrm{E}-02$ \\
\hline GO:0019395 & Fatty acid oxidation & 2.24 & $2.84 \mathrm{E}-02$ \\
\hline GO:0006635 & Fatty acid beta-oxidation & 2.23 & $3.02 \mathrm{E}-02$ \\
\hline GO:0034440 & Lipid oxidation & 2.23 & 3.09E-02 \\
\hline GO:0016469 & Proton-transporting two-sector ATPase complex & 2.22 & 3.16E-02 \\
\hline GO:0005777 & Peroxisome & 2.21 & $3.39 \mathrm{E}-02$ \\
\hline GO:0042579 & Microbody & 2.19 & $3.74 \mathrm{E}-02$ \\
\hline GO:0015985 & Energy coupled proton transport, down electrochemical gradient & 2.19 & $3.96 \mathrm{E}-02$ \\
\hline GO:0015986 & ATP synthesis coupled proton transport & 2.18 & 4.24E-02 \\
\hline GO:0006818 & Hydrogen transport & 2.17 & $4.52 \mathrm{E}-02$ \\
\hline GO:0000062 & Fatty-acyl-CoA binding & 2.16 & 4.49E-02 \\
\hline GO:0031968 & Organelle outer membrane & 2.16 & 4.54E-02 \\
\hline
\end{tabular}


Table 3. PLIN5 overexpression lowers expression of genes involved in immune processes. Microarray gene expression profiles for PLIN5 overexpression were clustered in Gene Ontology (GO) classes using GSEA (Gene Set Enrichment Analysis). This table shows the GO classes that were enriched in the set of downregulated genes. All downregulated GO classes with a false discovery rate (FDR) qvalue $<0.05$ are shown. NES: normalized enrichment score.

\begin{tabular}{|c|c|c|c|c|}
\hline \multirow[b]{2}{*}{ GO } & \multirow[b]{2}{*}{ Name } & \multicolumn{3}{|l|}{ No. of genes } \\
\hline & & in the set & NES & FDR q-val \\
\hline GO:0002252 & Immune effector process & 249 & -2.99 & $1.60 \mathrm{E}-03$ \\
\hline GO:0004428 & Inositol or phosphatidylinositol kinase activity & 31 & -2.97 & $1.15 \mathrm{E}-03$ \\
\hline GO:0002768 & $\begin{array}{l}\text { Immune response-regulating cell surface receptor signaling } \\
\text { pathway }\end{array}$ & 66 & -2.94 & $1.40 \mathrm{E}-03$ \\
\hline GO:0002429 & $\begin{array}{l}\text { Immune response-activating cell surface receptor signaling } \\
\text { pathway }\end{array}$ & 63 & -2.92 & $1.41 \mathrm{E}-03$ \\
\hline GO:0002274 & Myeloid leukocyte activation & 78 & -2.83 & $2.03 \mathrm{E}-03$ \\
\hline GO:0005765 & Lysosomal membrane & 61 & -2.82 & $1.99 \mathrm{E}-03$ \\
\hline GO:0016050 & Vesicle organization & 74 & -2.80 & 2.03E-03 \\
\hline GO:0009897 & External side of plasma membrane & 177 & -2.68 & $5.10 \mathrm{E}-03$ \\
\hline GO:0000323 & Lytic vacuole & 189 & -2.61 & 7.09E-03 \\
\hline GO:0002443 & Leukocyte mediated immunity & 146 & -2.52 & $1.18 \mathrm{E}-02$ \\
\hline GO:0005096 & GTPase activator activity & 138 & -2.51 & $1.25 \mathrm{E}-02$ \\
\hline GO:0050776 & Regulation of immune response & 297 & -2.49 & $1.34 \mathrm{E}-02$ \\
\hline GO:0046488 & Phosphatidylinositol metabolic process & 72 & -2.49 & $1.29 \mathrm{E}-02$ \\
\hline GO:0005100 & Rho GTPase activator activity & 22 & -2.47 & $1.41 \mathrm{E}-02$ \\
\hline GO:0002449 & Lymphocyte mediated immunity & 118 & -2.47 & $1.36 \mathrm{E}-02$ \\
\hline GO:0046649 & Lymphocyte activation & 310 & -2.47 & $1.32 \mathrm{E}-02$ \\
\hline GO:0042110 & T cell activation & 212 & -2.46 & $1.32 \mathrm{E}-02$ \\
\hline GO:0005764 & Lysosome & 188 & -2.44 & $1.44 \mathrm{E}-02$ \\
\hline GO:0001727 & Lipid kinase activity & 26 & -2.39 & $1.91 \mathrm{E}-02$ \\
\hline GO:0035586 & Purinergic receptor activity & 31 & -2.39 & $1.93 \mathrm{E}-02$ \\
\hline GO:0050852 & T cell receptor signaling pathway & 34 & -2.32 & $2.43 \mathrm{E}-02$ \\
\hline GO:0046854 & Phosphatidylinositol phosphorylation & 15 & -2.32 & $2.38 \mathrm{E}-02$ \\
\hline GO:0006909 & Phagocytosis & 64 & -2.32 & $2.36 \mathrm{E}-02$ \\
\hline GO:0050851 & Antigen receptor-mediated signaling pathway & 54 & -2.32 & $2.35 \mathrm{E}-02$ \\
\hline GO:0006044 & $\mathrm{N}$-acetylglucosamine metabolic process & 16 & -2.28 & $2.68 \mathrm{E}-02$ \\
\hline GO:0044420 & Extracellular matrix part & 103 & -2.27 & $2.70 \mathrm{E}-02$ \\
\hline GO:0045058 & T cell selection & 21 & -2.25 & $2.85 \mathrm{E}-02$ \\
\hline GO:0002460 & $\begin{array}{l}\text { Adaptive immune response based on somatic recombination of } \\
\text { immune receptors built from immunoglobulin superfamily } \\
\text { domains }\end{array}$ & 121 & -2.24 & $2.86 \mathrm{E}-02$ \\
\hline GO:0019724 & B cell mediated immunity & 68 & -2.23 & 3.17E-02 \\
\hline GO:0001614 & Purinergic nucleotide receptor activity & 27 & -2.22 & $3.13 \mathrm{E}-02$ \\
\hline GO:0046633 & Alpha-beta T cell proliferation & 20 & -2.21 & $3.23 \mathrm{E}-02$ \\
\hline GO:0006041 & Glucosamine metabolic process & 16 & -2.20 & $3.28 \mathrm{E}-02$ \\
\hline GO:0016502 & Nucleotide receptor activity & 27 & -2.19 & $3.48 \mathrm{E}-02$ \\
\hline GO:0010717 & Regulation of epithelial to mesenchymal transition & 24 & -2.17 & $3.85 \mathrm{E}-02$ \\
\hline GO:0002250 & Adaptive immune response & 124 & -2.16 & 3.85E-02 \\
\hline GO:0007173 & Epidermal growth factor receptor signaling pathway & 39 & -2.15 & $4.24 \mathrm{E}-02$ \\
\hline GO:0005581 & Collagen & 24 & -2.14 & 4.24E-02 \\
\hline GO:0000139 & Golgi membrane & 265 & -2.14 & 4.19E-02 \\
\hline
\end{tabular}




\section{PLIN5 overexpression promotes oxidative gene expression}

\begin{tabular}{llrrr} 
GO:0050778 & Positive regulation of immune response & 228 & -2.14 & $4.29 \mathrm{E}-02$ \\
GO:0002062 & Chondrocyte differentiation & 45 & -2.12 & $4.70 \mathrm{E}-02$ \\
GO:0006040 & Amino sugar metabolic process & 21 & -2.11 & $4.87 \mathrm{E}-02$ \\
GO:0045061 & Thymic T cell selection & 16 & -2.10 & $4.99 \mathrm{E}-02$ \\
GO:0007229 & Integrin-mediated signaling pathway & 46 & -2.10 & $4.95 \mathrm{E}-02$ \\
GO:0045309 & Protein phosphorylated amino acid binding & 21 & -2.10 & $4.89 \mathrm{E}-02$ \\
\hline
\end{tabular}
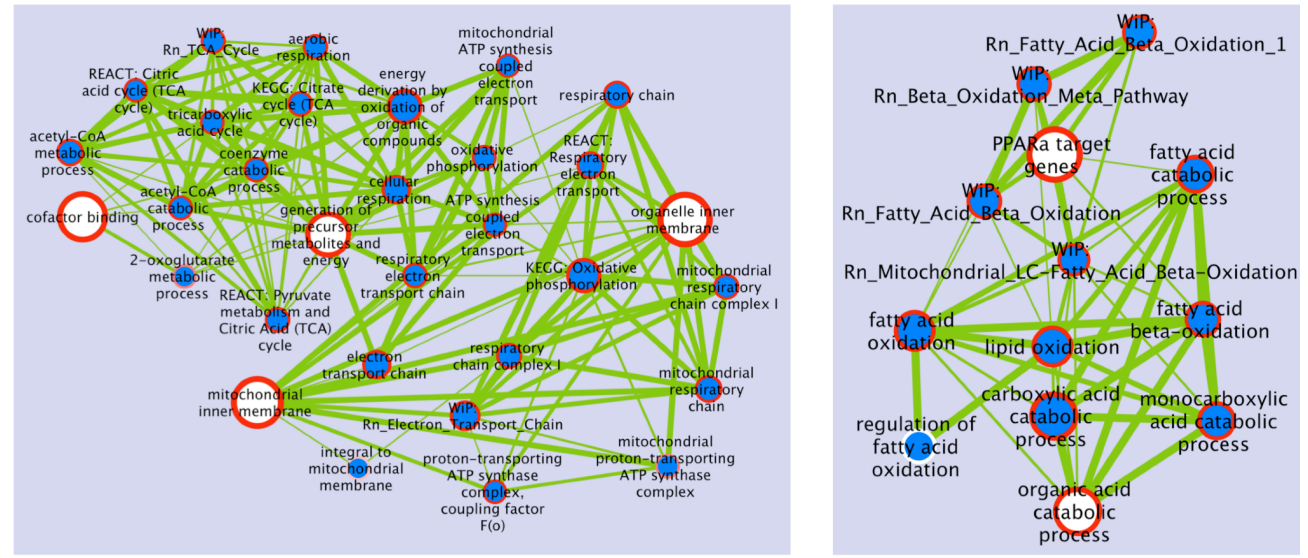

Figure 4. Gene expression profiles of PLIN5 overexpression were markedly different from those obtained after overexpression of PLIN2. Cytoscape gene set clustering (two selected clusters are shown). The cluster on the left shows gene sets involving mitochondrial function including the TCA cycle and the electron transport chain. The cluster on the right hand side shows gene sets linked to FA oxidative metabolism. Gene expression levels in the PLIN2 and PLIN5 electroporated legs were both compared to the corresponding empty vector legs. The inner circle color corresponds to the effect of PLIN2 overexpression, the circle border represents the effects of PLIN5 overexpression. Blue: downregulation, red: upregulation, white: no change. The lines indicate overlap between gene sets. The gene sets included the GO classes, KEGG pathways, REACT, and WiP gene sets.

\section{Despite increased IMCL content, PLIN5 overexpression did not impair insulin sensitivity}

Skeletal muscle insulin sensitivity was measured under stable clamp conditions (Supplemental Figure 1). Despite the pronounced effect of PLIN5 overexpression on intramyocellular lipid storage and LD size, ${ }^{3} \mathrm{H}$-deoxyglucose uptake was similar in empty vector and PLIN5-electroporated muscle (Fig. 5), indicating that PLIN5-induced intramyocellular lipid storage did not impair insulin mediated glucose uptake. 


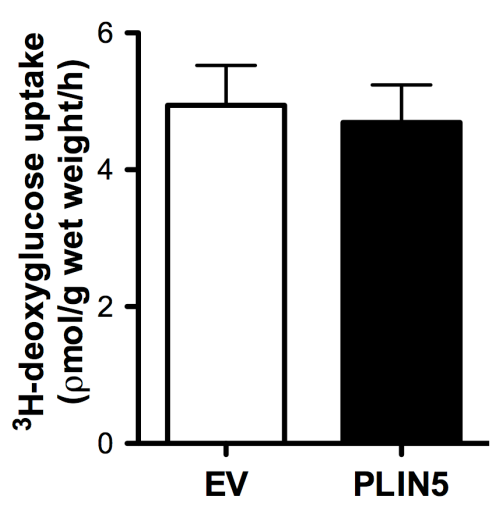

Figure 5. PLIN5 overexpression- induced intramyocellular lipid accumulation did not affect insulin sensitivity. ${ }^{3} \mathrm{H}$-labeled deoxyglucose uptake ( $\rho \mathrm{mol} / \mathrm{g}$ wet weight/h) in empty vector (EV) and PLIN5-electroporated tibialis anterior muscle $(n=9)$. Error bars represent SEM.

\section{DISCUSSION}

Elevated IMCL levels have been associated with the development of insulin resistance [2123], however data from the last decade indicates that the relation between IMCL and insulin sensitivity may be less straightforward than originally proposed [3, 4, 24]. In recent years, PLINs have been identified as important regulators of skeletal muscle lipid metabolism. Skeletal muscle-specific PLIN2 overexpression improved insulin sensitivity despite increased IMCL levels [2]. Here we show that the augmented IMCL storage as a result of PLIN5 electroporation did not impair insulin-stimulated glucose uptake, consistent with effects of PLIN2 overexpression. Yet, in striking contrast to the effects of PLIN2 overexpression [2], PLIN5 electroporation resulted in a gene expression profile favoring fatty acid catabolism and mitochondrial function. This profile of high PLIN5 levels, augmented IMCL storage, increased oxidative gene expression and fat oxidative capacity without a negative impact on skeletal muscle insulin-mediated glucose uptake mimics observations in master athletes [25].

Both PLIN2 and PLIN5 overexpression resulted in increased LD size, consistent with in vitro studies [9, 26, 27]. When compared to PLIN2-induced LD expansion [2], LDs in PLIN5overexpressing muscle were approximately 1.3-fold larger in size. While large LDs have previously been suggested to be more detrimental with respect to insulin sensitivity than small LDs [28-30], we here demonstrate that augmenting LD size by overexpressing PLIN5 did not impede insulin-mediated glucose uptake - or compromise mitochondrial function measured as fat oxidative capacity within the time frame of our studies.

One mechanism by which PLINs and an increase in LD size may prevent lipid-induced insulin resistance is by sequestering bioactive lipids. Indeed, PLIN5 overexpression increased intramyocellular TAG storage without affecting the accumulation of the potentially insulin desensitizing and mitotoxic lipid intermediates DAG and acylcarnitines. These effects parallel observations upon PLIN2 overexpression [2], when IMCL content was also augmented while fatty acid intermediates remained unchanged. Thus, both 


\section{PLIN5 overexpression promotes oxidative gene expression}

PLIN2 and PLIN5 overexpression augmented neutral TAG accumulation in a manner that did not impede insulin-mediated glucose uptake.

While the effects of PLIN2 and PLIN5 on IMCL content and insulin sensitivity appear alike, marked differences were observed in gene expression profiles. In striking contrast to the effects of PLIN2 overexpression, which results in lowered expression of genes and proteins involved in oxidative metabolism [2], PLIN5 overexpression resulted in a transcriptomic profile representing improved oxidative capacity. Our unbiased microarray approach raised the opportunity to study gene expression patterns across the whole genome. Gene set enrichment analysis revealed overrepresentation of upregulated genes in a multiple gene sets involved in FA $\beta$-oxidation, the TCA cycle, the electron transport chain and mitochondrion organization. Consistent with our data, ectopic expression of PLIN5 in COS cells increased expression of genes involved in FA oxidation [31]. Whilst short-term (one week) PLIN2 overexpression was beneficial to insulin sensitivity [2], it is anticipated that in the long run, PLIN2 overexpression may result in a mismatch between lipid storage and oxidative capacity. In contrast, PLIN5 overexpression results in increased IMCL storage paralleled with increased oxidative capacity, observations similar to endurance trained athletes who have high PLIN5 and IMCL levels, are insulin sensitive [25] and are protected against lipid-induced insulin resistance [32].

Since acylcarnitine accumulation has been suggested to reflect an imbalance between $\beta$-oxidation and TCA cycle activity [33], the lack of an induction of acylcarnitine accumulation further confirms that PLIN5 overexpression results in neutral IMCL storage matched with downstream catabolic metabolism. Moreover, genes involved in immuneprocesses associated with insulin resistance were downregulated upon PLIN5 overexpression. Though, whether increased PLIN5 expression is beneficial in the long term, remains to be investigated.

How PLIN5 overexpression promotes oxidative gene expression is currently unknown. It is however of interest to note that the vast majority of the genes induced is under control of the PPAR-PGC1 $\alpha$ complex. PPAR-PGC1 $\alpha$ mediated gene expression requires fatty acids as ligands. Recent studies in mice lacking the ATGL gene revealed that fatty acids which serve as ligands for PPARs have to originate from LD lipolysis; lack of ATGL leads to severe reduction of oxidative gene expression [34-36]. Consistently, we showed that ectopic overexpression of PLIN1 in cultured myotubes abolished AGTL mediated lipolysis and downregulated oxidative gene expression [37], which could not be rescued by adding exogenous fatty acids to the medium. This indicates that reduced intramyocellular LD lipolysis modulates gene expression by affecting ligand release from the LD. Along the same lines, one may speculate that overexpression of PLIN5 induces a reversed process. In contrast to overexpressing PLIN1 in muscle, overexpressing PLIN5 may promote liberation of fatty acids from the LD as ligands to promote oxidative gene expression and fat oxidative capacity.

Interestingly, PLIN5 appears to have a dual effect on LD lipolysis. Under basal conditions PLIN5 inhibits lipolysis while under stimulated conditions PLIN5 appears to 
facilitate lipolysis [38-41]. In the present study PLIN5 overexpression resulted in increased ATGL protein content. Thus, a higher availability of both PLIN5 and ATGL may translate into increased lipolytic capacity under stimulated conditions and promotes liberation of fatty acids as ligands for the PPAR-PGC1 $\alpha$ complex [34]. With that, PLIN5 overexpression might induce a feed-forward loop, since skeletal muscle PGC1 $\alpha$ activation is known to affect both oxidative capacity and intracellular lipid storage [42-44]. On the other hand, we also observed that overexpression of PLIN5 resulted in a profound increase in LD size and TAG content. Which could reflect a state of decreased ATGL-mediated lipolysis and hence blunted availability of fatty acids as ligands. Therefore, it can not be excluded that PLIN5 may activate PPAR/PGC1 via other mechanisms. Based upon subcellular distribution of PLIN5 and its interaction with mitochondria we previously hypothesized a role for PLIN5 as a chaperone protein shuttling fatty acids towards mitochondria for oxidation [8]. Similarly, PLIN5 may also be involved in shuttling LD-derived fatty acids towards nuclei to serve as ligands for PPAR/PGC1. In that respect it is of relevance to note that PLIN5 was shown to localize to small, high dense lipid droplets and to be involved in lipid trafficking [26].

Based on previous reports and our current data of improved gene expression of oxidative genes, we propose that PLIN5 is an important player in matching intramyocellular lipid storage capacity with the ability to regulate oxidative gene expression on the one hand and facilitating release of fatty acids from the LD as substrates for mitochondrial oxidation on the other hand.

In summary, PLIN2 and PLIN5 both increase neutral IMCL content without negatively impacting on insulin sensitivity. Interestingly, as opposed to the transcriptomic profile upon PLIN2 overexpression, we here report that overexpression of PLIN5 in skeletal muscle promoted expression of a cluster of genes under control of PPAR $\alpha$ and PGC1 $\alpha$ involved in fatty acid catabolism and mitochondrial oxidation. This suggests a role of PLIN5, either directly or indirectly, in mediating skeletal muscle oxidative gene expression.

\section{REFERENCES}

1. Bosma M, Kersten S, Hesselink MKC, and Schrauwen P. Re-evaluating lipotoxic triggers in skeletal muscle: Relating intramyocellular lipid metabolism to insulin sensitivity. Prog Lipid Res 2012; 51: 36-49.

2. Bosma M, Hesselink MKC, Sparks LM, Timmers S, Ferraz MJ, Mattijssen F, van Beurden D, Schaart G, de Baets $\mathrm{MH}$, Verheyen FK, Kersten S, and Schrauwen P. Perilipin 2 improves insulin sensitivity in skeletal muscle despite elevated intramuscular lipid levels. Diabetes 2012; 61: 2679-2690.

3. Liu L, Shi X, Choi CS, Shulman GI, Klaus K, Nair KS, Schwartz GJ, Zhang Y, Goldberg IJ, and Yu YH. Paradoxical coupling of triglyceride synthesis and fatty acid oxidation in skeletal muscle overexpressing DGAT1. Diabetes 2009; 58: 2516-2524.

4. Schenk S and Horowitz JF. Acute exercise increases triglyceride synthesis in skeletal muscle and prevents fatty acid-induced insulin resistance. J Clin Invest 2007; 117: 1690-1698.

5. Timmers S, de Vogel-van den Bosch J, Hesselink MKC, van Beurden D, Schaart G, Ferraz MJ, Losen M, Martinez-Martinez P, De Baets MH, Aerts JMFG, and Schrauwen P. Paradoxical increase in TAG and DAG content parallel the insulin sensitizing effect of unilateral DGAT1 overexpression in rat skeletal muscle. PLOS ONE 2011; 6: e14503. 


\section{PLIN5 overexpression promotes oxidative gene expression}

6. Beller M, Thiel K, Thul PJ, and Jäckle H. Lipid droplets: A dynamic organelle moves into focus. FEBS Lett 2010; 584: 2176-82.

7. Walther TC and Farese Jr RV. The life of lipid droplets. Biochim Biophys Acta 2009; 1791: 459-66.

8. Bosma M, Minnaard R, Sparks LM, Schaart G, Losen M, De Baets MH, Duimel H, Kersten S, Bickel PE, Schrauwen $P$, and Hesselink MKC. The lipid droplet coat protein perilipin 5 also localizes to muscle mitochondria. Histochem Cell Biol 2012; 137: 205-216.

9. Wang H, Sreenevasan U, Hu H, Saladino A, Polster BM, Lund LM, Gong DW, Stanley WC, and Sztalryd C. Perilipin 5, a lipid droplet associated protein, provides physical and metabolic linkage to mitochondria. J Lipid Res 2011; 52: 2159-2168.

10. Bruce CR, Brolin C, Turner N, Cleasby ME, van der Leij FR, Cooney GJ, and Kraegen EW. Overexpression of carnitine palmitoyltransferase $\mathrm{I}$ in skeletal muscle in vivo increases fatty acid oxidation and reduces triacylglycerol esterification. Am J Physiol Endocrinol Metab 2007; 292: E1231-1237.

11. Bruce CR, Hoy AJ, Turner N, Watt MJ, Allen TL, Carpenter K, Cooney GJ, Febbraio MA, and Kraegen EW. Overexpression of carnitine palmitoyltransferase-1 in skeletal muscle is sufficient to enhance fatty acid oxidation and improve high fat diet-induced insulin resistance. Diabetes 2009; 58: 550-558.

12. James $D E$, Jenkins $A B$, and Kraegen EW. Heterogeneity of insulin action in individual muscles in vivo: euglycemic clamp studies in rats. Am J Physiol Endocrinol Metab 1985; 248: E567-574.

13. Abramoff MD, Magalhaes PJ, and Ram SJ. Image Processing with ImageJ. Biophotonics Int. 2004; 11 : 36-42.

14. Koopman R, Schaart G, and Hesselink M. Optimisation of oil red O staining permits combination with immunofluorescence and automated quantification of lipids. Histochem Cell Biol 2001; 116: 63-68.

15. Schwartz DM and Wolins NE. A simple and rapid method to assay triacylglycerol in cells and tissues. J Lipid Res 2007; 48: 2514-2520.

16. Van Vlies N, Tian L, Overmars H, Bootsma AH, Kulik W, Wanders RJ, Wood PA, and Vaz FM. Characterization of carnitine and fatty acid metabolism in the long-chain acyl-CoA dehydrogenasedeficient mouse. Biochem J 2005; 387: 185-93.

17. Gentleman R, Carey V, Bates D, Bolstad B, Dettling M, Dudoit S, Ellis B, Gautier L, Ge Y, Gentry J, Hornik K, Hothorn T, Huber W, lacus S, Irizarry R, Leisch F, Li C, Maechler M, Rossini A, Sawitzki G, Smith C, Smyth G, Tierney L, Yang J, and Zhang J. Bioconductor: open software development for computational biology and bioinformatics. Genome Biol 2004; 5: R80.

18. Subramanian A, Tamayo P, Mootha VK, Mukherjee S, Ebert BL, Gillette MA, Paulovich A, Pomeroy SL, Golub TR, Lander ES, and Mesirov JP. Gene set enrichment analysis: A knowledge-based approach for interpreting genome-wide expression profiles. Proc Natl Acad Sci 2005; 102: 15545-15550.

19. Lopes CT, Franz M, Kazi F, Donaldson SL, Morris Q, and Bader GD. Cytoscape Web: an interactive webbased network browser. Bioinformatics 2010; 26: 2347-2348.

20. Koves TR, Ussher JR, Noland RC, Slentz D, Mosedale M, Ilkayeva O, Bain J, Stevens R, Dyck JRB, Newgard $\mathrm{CB}$, Lopaschuk GD, and Muoio DM. Mitochondrial overload and incomplete fatty acid oxidation contribute to skeletal muscle insulin resistance. Cell Metab 2008; 7: 45-56.

21. Aguer C, Foretz M, Lantier L, Hebrard S, Viollet B, Mercier J, and Kitzmann M. Increased FAT/CD36 cycling and lipid accumulation in myotubes derived from obese type 2 diabetic patients. PLoS ONE 2011; 6: e28981.

22. Goodpaster BH, Theriault R, Watkins SC, and Kelley DE. Intramuscular lipid content is increased in obesity and decreased by weight loss. Metabolism 2000; 49: 467-472.

23. Pan DA, Lillioja S, Kriketos AD, Milner MR, Baur LA, Bogardus C, Jenkins AB, and Storlien LH. Skeletal muscle triglyceride levels are inversely related to insulin action. Diabetes 1997; 46: 983-8.

24. Dubé JJ, Amati F, Stefanovic-Racic M, Toledo FGS, Sauers SE, and Goodpaster BH. Exercise-induced alterations in intramyocellular lipids and insulin resistance: the athlete's paradox revisited. Am J Physiol Endocrinol Metab 2008; 294: E882-888.

25. Amati F, Dube JJ, Alvarez-Carnero E, Edreira MM, Chomentowski P, Coen PM, Switzer GE, Bickel PE, Stefanovic-Racic M, Toledo FGS, and Goodpaster BH. Skeletal muscle triglycerides, diacylglycerols, and ceramides in insulin resistance: another paradox in endurance-trained athletes? Diabetes 2011; 60: 25882597.

26. Bartholomew SR, Bell EH, Summerfield T, Newman LC, Miller EL, Patterson B, Niday ZP, Ackerman Iv WE, 
and Tansey JT. Distinct cellular pools of perilipin 5 point to roles in lipid trafficking. Biochim Biophys Acta 2012; 1821: 268-278.

27. Imamura M, Inoguchi T, Ikuyama S, Taniguchi S, Kobayashi K, Nakashima N, and Nawata H. ADRP stimulates lipid accumulation and lipid droplet formation in murine fibroblasts. Am J Physiol Endocrinol Metab 2002; 283: E775-783.

28. Fraenkel M, Weiss R, Leizerman I, Anaby D, Golomb E, Leibowitz G, and Kaiser N. Scanning electron microscopic analysis of intramyocellular lipid droplets in an animal model of type 2 diabetes. Obesity 2008; 16: 695-699.

29. He J, Goodpaster BH, and Kelley DE. Effects of weight loss and physical activity on muscle lipid content and droplet size. Obesity 2004; 12: 761-769.

30. Molero JC, Lee S, Leizerman I, Chajut A, Cooper A, and Walder K. Effects of rosiglitazone on intramyocellular lipid accumulation in Psammomys obesus. Biochim Biophys Acta 2010; 1802: 235-9.

31. Wolins NE, Quaynor BK, Skinner JR, Tzekov A, Croce MA, Gropler MC, Varma V, Yao-Borengasser A, Rasouli $\mathrm{N}$, Kern PA, Finck BN, and Bickel PE. OXPAT/PAT-1 is a PPAR-induced lipid droplet protein that promotes fatty acid utilization. Diabetes 2006; 55: 3418-28.

32. Phielix E, Meex R, Ouwens DM, Sparks L, Hoeks J, Schaart G, Moonen-Kornips E, Hesselink MKC, and Schrauwen $\mathrm{P}$. High oxidative capacity due to chronic exercise training attenuates lipid-induced insulin resistance. Diabetes 2012;

33. Muoio DM. Intramuscular triacylglycerol and insulin resistance: guilty as charged or wrongly accused? Biochim Biophys Acta 2009; 1801: 281-288.

34. Haemmerle G, Moustafa T, Woelkart G, Buttner S, Schmidt A, van de Weijer T, Hesselink M, Jaeger D, Kienesberger PC, Zierler K, Schreiber R, Eichmann T, Kolb D, Kotzbeck P, Schweiger M, Kumari M, Eder S, Schoiswohl G, Wongsiriroj N, Pollak NM, Radner FPW, Preiss-Landl K, Kolbe T, Rulicke T, Pieske B, Trauner M, Lass A, Zimmermann R, Hoefler G, Cinti S, Kershaw EE, Schrauwen P, Madeo F, Mayer B, and Zechner R. ATGL-mediated fat catabolism regulates cardiac mitochondrial function via PPAR- $\alpha$ and PGC-1. Nat Med 2011; 17: 1076-1085.

35. Mottillo EP, Bloch AE, Leff T, and Granneman JG. Lipolytic products activate peroxisome proliferatoractivated receptor (PPAR) $\alpha$ and $\delta$ in brown adipocytes to match fatty oxidation with supply. J Biol Chem 2012; 287: 25038-25048.

36. Ong KT, Mashek MT, Bu SY, Greenberg AS, and Mashek DG. Adipose triglyceride lipase is a major hepatic lipase that regulates triacylglycerol turnover and fatty acid signaling and partitioning. Hepatology 2011; 53: 116-126.

37. Koves TR, Sparks LM, Kovalik JP, Mosedale M, Arumugam R, Debalsi KL, Everingham K, Thorne L, Phielix E, Meex RC, Kien CL, Hesselink MKC, Schrauwen P, and Muoio DM. PPARy coactivator-1 $\alpha$ contributes to exercise-induced regulation of intramuscular lipid droplet programming in mice and humans. J Lipid Res; in press.

38. Granneman JG, Moore HPH, Mottillo EP, Zhu Z, and Zhou L. Interactions of perilipin-5 (PLIN5) with adipose trigylceride lipase (ATGL). J Biol Chem 2011; 286: 5126-5135.

39. Granneman JG, Moore HP, Mottillo EP, and Zhu Z. Functional interactions between MLDP (LSDP5) and ABHD5 in the control of intracellular lipid accumulation. J Biol Chem 2009; 284: 3049-57.

40. Kuramoto K, Okamura T, Yamaguchi T, Nakamura TY, Wakabayashi S, Morinaga H, Nomura M, Yanase T, Otsu K, Usuda N, Matsumura S, Inoue K, Fushiki T, Kojima Y, Hashimoto T, Sakai F, Hirose F, and Osumi T. Perilipin 5, a lipid droplet-binding protein, protects the heart from oxidative burden by sequestering fatty acid from excessive oxidation. J Biol Chem 2012; 287: 23852-63.

41. Wang H, Bell M, Sreenevasan U, Hu H, Liu J, Dalen K, Londos C, Yamaguchi T, Rizzo MA, Coleman R, Gong D, Brasaemle D, and Sztalryd C. Unique regulation of adipose triglyceride lipase (ATGL) by perilipin 5, a lipid droplet-associated protein. J Biol Chem 2011; 286: 15707-15.

42. Espinoza DO, Boros LG, Crunkhorn S, Gami H, and Patti M-E. Dual modulation of both lipid oxidation and synthesis by peroxisome proliferator-activated receptor- $\gamma$ coactivator- $1 \alpha$ and $-1 \beta$ in cultured myotubes. FASEB J 2010; 24: 1003-1014.

43. Mormeneo E, Jimenez-Mallebrera C, Palomer X, De Nigris V, Vázquez-Carrera M, Orozco A, Nascimento A, Colomer J, Lerín C, and Gómez-Foix AM. PGC-1 $\alpha$ induces mitochondrial and myokine transcriptional 
programs and lipid droplet and glycogen accumulation in cultured human skeletal muscle cells. PLoS ONE 2012; 7: e29985.

44. Summermatter S, Baum O, Santos G, Hoppeler H, and Handschin C. Peroxisome proliferator-activated receptor $\gamma$ coactivator $1 \alpha(P G C-1 \alpha)$ promotes skeletal muscle lipid refueling in vivo by activating de novo lipogenesis and the pentose phosphate pathway. J Biol Chem 2010; 285: 32793-32800. 


\section{SUPPLEMENTAL INFORMATION}

Supplemental Table 1. Content of the individual FA-species in the DAG fraction ( $\mu \mathrm{mol} / \mathrm{g}$ ). Data are mean \pm SEM.

\begin{tabular}{lrrr}
\hline FA & \multicolumn{1}{c}{ EV } & \multicolumn{1}{c}{ PLIN5 } & P-value \\
\hline $14: 0$ & $0.49 \pm 0.13$ & $0.46 \pm 0.09$ & 0.81 \\
$15: 0$ & $0.19 \pm 0.07$ & $0.10 \pm 0.04$ & 0.34 \\
$16: 0$ & $12.73 \pm 1.58$ & $11.99 \pm 1.95$ & 0.72 \\
$16: 1 n-7$ tr & $0.20 \pm 0.07$ & $0.21 \pm 0.06$ & 0.94 \\
$16: 1 n-7$ & $0.80 \pm 0.36$ & $0.43 \pm 0.10$ & 0.31 \\
$18: 0$ & $5.05 \pm 0.87$ & $4.46 \pm 0.68$ & 0.53 \\
$18: 1$ tr & $0.23 \pm 0.08$ & $0.20 \pm 0.07$ & 0.60 \\
$18: 1 n-9$ & $11.72 \pm 3.07$ & $8.87 \pm 1.64$ & 0.38 \\
$18: 1 n-7$ & $0.27 \pm 0.14$ & $0.45 \pm 0.19$ & 0.47 \\
$18: 2 n-6$ tr & $0.16 \pm 0.07$ & $0.08 \pm 0.04$ & 0.34 \\
$18: 2 n-6$ & $7.14 \pm 2.38$ & $4.84 \pm 1.09$ & 0.38 \\
$20: 0$ & $0.11 \pm 0.02$ & $0.07 \pm 0.02$ & 0.29 \\
$18: 3 n-6$ & $0.22 \pm 0.12$ & $0.07 \pm 0.05$ & 0.32 \\
$20: 1 n-9$ & $0.17 \pm 0.05$ & $0.14 \pm 0.03$ & 0.55 \\
$18: 3 n-3$ & $0.26 \pm 0.15$ & $0.13 \pm 0.04$ & 0.41 \\
$18: 4 n-3$ & $0.11 \pm 0.04$ & $0.04 \pm 0.03$ & 0.25 \\
$20: 2 n-6$ & $0.28 \pm 0.07$ & $0.30 \pm 0.08$ & 0.82 \\
$20: 3 n-6$ & $0.02 \pm 0.01$ & $0.09 \pm 0.03$ & 0.06 \\
$20: 4 n-6$ & $1.14 \pm 0.19$ & $0.98 \pm 0.23$ & 0.52 \\
$23: 0$ & $0.10 \pm 0.05$ & $0.00 \pm 0.00$ & 0.07 \\
$22: 2 n-6$ & $0.23 \pm 0.07$ & $0.16 \pm 0.06$ & 0.39 \\
$24: 1 n-9$ & $0.25 \pm 0.09$ & $0.26 \pm 0.08$ & 0.91 \\
$22: 4 n-6$ & $0.21 \pm 0.05$ & $0.15 \pm 0.04$ & 0.38 \\
$22: 5 n-3$ & $0.18 \pm 0.10$ & $0.22 \pm 0.21$ & 0.88 \\
$22: 6 n-3$ & $0.41 \pm 0.08$ & $0.42 \pm 0.12$ & 0.94 \\
Sum Saturated & $18.67 \pm 2.18$ & $17.09 \pm 2.68$ & 0.56 \\
Sum Unsaturated & $23.99 \pm 6.06$ & $18.05 \pm 3.31$ & 0.35 \\
Total DAG & $35.13 \pm 5.87$ & 0.37 \\
\hline & & &
\end{tabular}


Supplemental Table 2. Skeletal muscle content of the individual acylcarnitine species ( $\rho \mathrm{mol} / \mathrm{mg})$. Data are mean \pm SEM.

\begin{tabular}{|c|c|c|c|}
\hline Species & EV & PLIN5 & P-value \\
\hline $\mathrm{C} 2$ & $391.6 \pm 19.3$ & $374.3 \pm 19.4$ & 0.52 \\
\hline C3 & $4.53 \pm 0.35$ & $4.58 \pm 0.44$ & 0.90 \\
\hline $\mathrm{C} 4$ & $12.0 \pm 1.41$ & $12.8 \pm 1.92$ & 0.59 \\
\hline C5:1 & $0.40 \pm 0.07$ & $0.43 \pm 0.06$ & 0.82 \\
\hline C5 & $2.65 \pm 0.41$ & $2.37 \pm 0.39$ & 0.41 \\
\hline $\mathrm{C} 4-3 \mathrm{OH}$ & $8.61 \pm 0.77$ & $8.81 \pm 0.99$ & 0.79 \\
\hline C6 & $3.50 \pm 0.47$ & $3.56 \pm 0.54$ & 0.87 \\
\hline $\mathrm{C} 5-\mathrm{OH}$ & $2.11 \pm 0.11$ & $2.15 \pm 0.16$ & 0.81 \\
\hline C8:1 & $0.24 \pm 0.03$ & $0.32 \pm 0.06$ & 0.15 \\
\hline C16:1 & $8.98 \pm 1.66$ & $8.63 \pm 1.50$ & 0.83 \\
\hline C16 & $47.3 \pm 10.3$ & $41.1 \pm 7.69$ & 0.45 \\
\hline $\mathrm{C} 16: 2-\mathrm{OH}$ & $0.57 \pm 0.13$ & $0.52 \pm 0.09$ & 0.57 \\
\hline $\mathrm{C} 16: 1-\mathrm{OH}$ & $1.02 \pm 0.16$ & $1.05 \pm 0.16$ & 0.83 \\
\hline $\mathrm{C} 16-\mathrm{OH}$ & $0.71 \pm 0.11$ & $0.73 \pm 0.13$ & 0.88 \\
\hline C18:3 & $1.62 \pm 0.36$ & $1.36 \pm 0.26$ & 0.34 \\
\hline C18:2 & $25.0 \pm 5.87$ & $21.3 \pm 4.14$ & 0.44 \\
\hline C18:1 & $48.1 \pm 10.5$ & $42.6 \pm 8.41$ & 0.50 \\
\hline C18 & $16.7 \pm 3.22$ & $14.9 \pm 2.64$ & 0.53 \\
\hline $\mathrm{C} 18: 2-\mathrm{OH}$ & $0.57 \pm 0.08$ & $0.57 \pm 0.13$ & 0.97 \\
\hline C18:1-OH & $0.71 \pm 0.10$ & $0.85 \pm 0.19$ & 0.44 \\
\hline $\mathrm{C} 18-\mathrm{OH}$ & $0.35 \pm 0.05$ & $0.35 \pm 0.07$ & 0.97 \\
\hline C20:4 & $1.51 \pm 0.39$ & $1.34 \pm 0.28$ & 0.57 \\
\hline C20:2 & $1.86 \pm 0.35$ & $1.84 \pm 0.42$ & 0.95 \\
\hline C20:1 & $2.07 \pm 0.35$ & $2.27 \pm 0.51$ & 0.65 \\
\hline $\mathrm{C} 20$ & $0.46 \pm 0.07$ & $0.47 \pm 0.09$ & 0.90 \\
\hline $\mathrm{C} 20: 2-\mathrm{OH}$ & $0.09 \pm 0.02$ & $0.09 \pm 0.03$ & 0.89 \\
\hline $\mathrm{C} 20: 1-\mathrm{OH}$ & $0.10 \pm 0.03$ & $0.06 \pm 0.02$ & 0.23 \\
\hline $\mathrm{C} 20-\mathrm{OH}$ & $0.22 \pm 0.06$ & $0.21 \pm 0.05$ & 0.92 \\
\hline $\mathrm{C} 22: 2$ & $0.08 \pm 0.02$ & $0.09 \pm 0.03$ & 0.83 \\
\hline C22:1 & $0.12 \pm 0.02$ & $0.15 \pm 0.03$ & 0.24 \\
\hline $\mathrm{C} 22$ & $0.07 \pm 0.02$ & $0.06 \pm 0.02$ & 0.68 \\
\hline $\mathrm{C} 22: 1-\mathrm{OH}$ & $0.03 \pm 0.01$ & $0.05 \pm 0.02$ & 0.37 \\
\hline $\mathrm{C} 22-\mathrm{OH}$ & $0.03 \pm 0.01$ & $0.07 \pm 0.03$ & 0.25 \\
\hline C24:2 & $0.01 \pm 0.01$ & $0.02 \pm 0.01$ & 0.16 \\
\hline C24:1 & $0.09 \pm 0.02$ & $0.09 \pm 0.03$ & 0.82 \\
\hline Total & $634.3 \pm 44.3$ & $596.9 \pm 47.0$ & 0.44 \\
\hline
\end{tabular}

Supplemental Table 3.

Can be found as supporting datasheet with this paper online. 
A

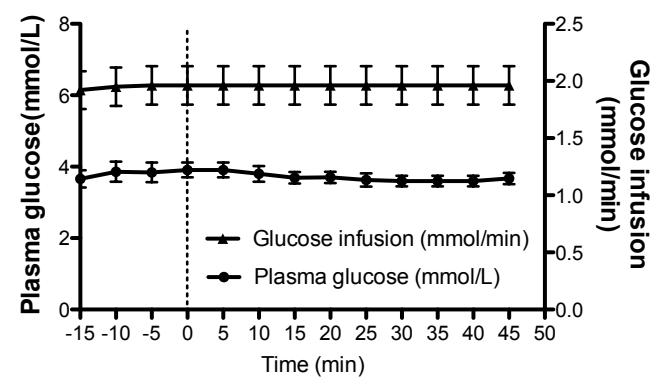

B

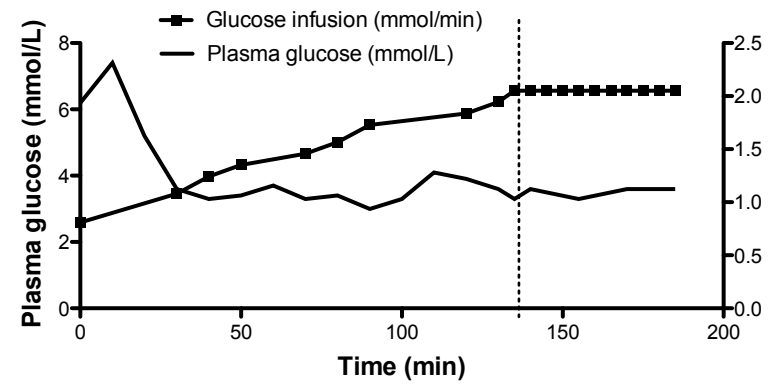

Supplemental Figure 1.

(A) Plasma glucose levels and glucose infusion rates (GIR) $15 \mathrm{~min}$. before and during the 45-min clamp. Mean $\pm \operatorname{SEM}(n=9)$. (B) Representative graph of the complete clamp procedure for 1 rat (run in phase and the $45 \mathrm{~min}$. stable phase after the injection of the ${ }^{3} \mathrm{H}$ deoxyglucose bolus). The dotted line indicates the timepoint of the injection of the ${ }^{3} \mathrm{H}$-deoxyglucose bolus. 


\section{CHAPTER 8}

Modifying the myocellular lipid droplet phenotype by exercise training in obese and type 2 diabetic subjects contributes to metabolic flexibility

Ruth C.R. Meex, Madeleen Bosma, Cedric Moro, Dominique Langin, Gert Schaart, Esther Moonen-Kornips, Patrick Schrauwen, Matthijs K.C. Hesselink

In preparation 


\begin{abstract}
We studied the hypothesis that proteins involved in lipid droplet (LD) assembly, maturation and localization, and mobilization contribute to exercise mediated improvements in insulin sensitivity and concomitant metabolic flexibility. Eighteen male type 2 diabetics (T2D) and twenty BMI- and age-matched normoglycemic control subjects (C) exercise-trained for 12 weeks. Myocellular LDs, LD coating proteins, indices of muscle lipolysis and the putative LD mitochondria anchoring protein OPA1 were measured before and after training, and evaluated in the light of changes in insulin sensitivity and substrate selection.

Pre-training, protein contents of PLIN3 and OPA1 were significantly lower in T2D, along with similar LD content, PLIN2, PLIN5, TAG-hydrolysis and ATGL. Training restored PLIN3 and OPA1 in T2D towards $C$ levels. Post-training LD content only modestly $(P=0.10)$ increased, while PLIN2 and PLIN5 protein content increased $\sim 2$-fold in $C$ and T2D $(P<0.05)$. Pre-training PLIN5 content correlated with OPA1, and ectopically overexpressing PLIN5 in rat muscle increased OPA1 and blunted lipotoxicity. Changes in LD coating proteins correlated with changes in substrate selection under basal and insulin-stimulated conditions.

In conclusion, T2D subjects restored their capacity to mature nascent LD by restoration of PLIN3. Restoration of OPA1 upon training may promote LD mitochondrial interaction and reduce lipotoxicity. Exercise-training increased PLIN2 and PLIN5 and hence reduced TAG hydrolase activity despite increased ATGL content. Correlative analysis revealed that these changes may be implicated in regulating exercise- and insulin-mediated changes in substrate selection.
\end{abstract}




\section{INTRODUCTION}

Lipid droplets (LDs) are lipid dense organelles present in virtually all eukaryotic cells. While originally viewed as relatively inert organelles sequestering fatty acids for triacylglycerol (TAG) storage, research over the past two decades unveiled LDs as highly dynamic organelles with a key role in orchestrated uptake and release of fatty acids. Fatty acids released from the LD serve as substrates for (mitochondrial) oxidation, as signalling molecules or as precursors for phospholipid synthesis [1]. Dysregulation of storage and hydrolysis of lipids in the LD is associated with multiple disease states, including insulin resistance and type 2 diabetes (T2D) (reviewed in [2-5]).

The identification of a family of LD associated proteins -the PLIN proteins- has been pivotal to our understanding of the regulation of LD turnover. At present the PLIN protein family comprises five members with shared homology in the N-terminal domain [6]: PLIN1 (perilipin), PLIN2 (ADRP), PLIN3 (TIP47), PLIN4 (S3-12) and PLIN5 (OXPAT) [7]. PLIN proteins are scaffolding proteins with a regulatory role in adipose triglyceride lipase (ATGL) mediated TAG hydrolysis [8-10] and may hence give rise to bioactive lipid species with insulin desensitizing properties. Of these PAT proteins, PLIN2, 3 and 5 are most abundant in skeletal muscle, the organ responsible for $\sim 80 \%$ of post-prandial glucose uptake [11]. The observation that LD content negatively associates with insulin-stimulated glucose uptake $[12,13]$ and the ability of PLIN proteins to affect lipolysis has put myocellular LD central stage in studies towards muscle insulin resistance and type 2 diabetes.

We previously studied the role of PLIN2 and PLIN5 in insulin-mediated glucose uptake, in rat skeletal muscle upon gene electroporation mediated overexpression of PLIN2 or PLIN5. Despite a massive increase in LD content upon PLIN2 and PLIN5 overexpression, insulin-mediated glucose uptake in the overexpressing muscles was maintained, or even modestly improved $[14,15]$. Intriguingly, trained athletes also have lots of myocellular LD, whilst being very insulin sensitive $[12,16]$. In line with our PLIN5 overexpression study in rats, a cross-sectional human study revealed that, despite having significantly higher LD content than controls, older (65 years), trained athletes were significantly more insulin sensitive than controls of the same age [17]. In these athletes, PLIN5 protein content correlated positively with insulin sensitivity [17]. Likewise, we recently observed that in young lean trained athletes protein content of PLIN2 and PLIN5 in muscle was up and stepwise regression analysis identified PLIN5 as a dominant predictor of insulin-mediated glucose uptake [18]. Moreover, we observed that acute exercise in rats promotes gene expression of PLIN2 and PLIN5. This indicates that the cross-sectional observation of trained humans having higher myocellular PLIN5 content may originate from sustained exercise training and unmasks PLIN5 as a putative player in the insulin sensitizing effect of exercise training.

Another characteristic of insulin resistant muscle is metabolic inflexibility, i.e. a reduced ability to adjust substrate selection to substrate availability $[19,20]$. During low intensity physical exercise and in the fasted state, fatty acid oxidation normally prevails 
over glucose oxidation while in the post-prandial state and upon increasing exercise intensity, glucose oxidation becomes more prominent. The transition between fasting and feeding can experimentally be mimicked during a hyperinsulinemic euglycemic clamp. In trained humans, muscle ATGL content was identified as a significant predictor of metabolic flexibility under clamp conditions [18]. In addition, it has been shown that during exercise fatty acids required to fuel muscle contraction at least partly originate from myocellular LD [21] and that mainly droplets coated with PLIN2 become depleted post-exercise [22].

At present, however, it is not known if, and to what extent, adaptive responses of proteins involved in LD assembly, maturation and localization, and mobilization are involved in the insulin sensitizing effect of exercise training in type 2 diabetic patients. Therefore we studied the hypothesis that proteins involved in LD degradation and synthesis contribute to exercise-mediated improvements in insulin sensitivity and concomitant metabolic flexibility.

\section{RESEARCH DESIGN AND METHODS}

\section{Subjects}

Male type 2 diabetic subjects (T2D, n=18) and normoglycemic control subjects (,$n=20)$ matched for body weight, body mass index (BMI) and age were included. All diabetic patients had well-controlled diabetes $(\mathrm{HbA} 1 \mathrm{c}=7.2 \pm 0.2 \%)$ diagnosed for at least one year. Drug use to promote glycemic control was restricted to oral anti-diabetic agents (metformin only, or in combination with SU derivatives). Body composition was measured by hydrostatic weighing and maximal work load and oxygen uptake was assessed during a graded cycling test until exhaustion. The ethical committee of the Maastricht University Medical Centre approved the study. All subjects gave written informed consent before participation.

\section{Exercise training protocol}

Subjects adhered to a 12-week individually supervised progressive exercise training program in small groups $(n=3-4)$. Prior to the training protocol maximal workload capacity was determined twice, the first test served as a familiarisation trial, while the second test was used to determine the workload during the training program [23]. All tests were performed under standardized conditions and substrate oxidation measurements were performed (indirect calorimetry) during the steady-state phase of submaximal stages at 75 and 125 Watt. To ensure the progressive nature of the training program, maximal workload (Wmax) was determined again after 6 weeks of training and workload was adjusted accordingly.

During the 12 weeks of training, cycling ergometer exercise was performed twice a week for 30 minutes at 55\% Wmax. Resistance exercise was performed once a week and comprised 1 series of 8 repetitions at 55\% of previously determined maximal voluntary 
contraction (MVC) [23] and 2 series of 8 repetitions at 75\% MVC and focused on large muscle groups. The MVC test to assess maximal work load was preceded by a familiarization trial. Every 4 weeks, MVC was reassessed and training loads was readjusted accordingly. Training sessions were preceded and ended with 5 minutes of warming up/cooling down on the cycling ergometer at $45 \% \mathrm{Wmax}$.

\section{Hyperinsulinemic-euglycemic clamp}

A $6 \mathrm{~h}$ hyperinsulinemic-euglycemic insulin clamp $\left(40 \mathrm{mU} / \mathrm{m}^{2} / \mathrm{min}\right)$ was performed before and after the training period after an overnight fast as described previously [23]. Antidiabetic medication was discontinued 7 days prior to the clamp. Subjects refrained from any physical exercise at least 48 hours prior to the clamp. Rates of glucose disposal $(R \mathrm{~d})$ was determined using $\left[6,6-{ }^{2} \mathrm{H}_{2}\right]$ glucose and used to calculate the insulin sensitivity index (Si). In the final 30 minutes of the non-insulin stimulated period ( $t=150-180)$ and under steady hyperinsulinemic conditions ( $t=330-360)$, substrate selection was assessed by indirect calorimetry. Needle muscle biopsies were obtained from the vastus lateralis before and after the training program 30 minutes before the onset of the clamp. Biopsies were freed from visible detectable fat and connective tissue and snap frozen in melting isopentane and stored at $-80^{\circ} \mathrm{C}$ for further analyses.

\section{Blood sample analysis}

Arterialised blood samples were collected in EDTA coated tubes, from a hot-box heated hand vein. Plasma free fatty acids (FFAs) and glucose were measured with enzymatic assays automated on a Cobas Fara/Mira (FFA: Wako Nefa C test kit; Wako Chemicals, Neuss, Germany) (glucose: hexokinase method; LaRoche, Basel, Switzerland). Plasma insulin levels were measured by a radioimmunoassay (Linco Research, St. Charles, MO).

\section{Lipid droplet content}

Intramyocellular lipid content was assessed histochemically in muscle cross-sections using a modified oil-red-O staining for fluorescence microscopy [24]. Lipid droplets were binned and the area fraction of the LD relative to muscle cell area was computed. Thus, LD content can be measured accurately. Due to limitations in the optical resolution, this method does not allow valid statements on the change in LD size. For each subject a minimum of 150 muscle fibers were examined pre- and post-training. Representative histological slides are presented in Figure 1.

\section{Western blotting}

Muscle samples were homogenized in ice-cold PBS containing 1\% Nonidet-P40, $0.5 \%$ sodium dodecyl sulfate, $0.1 \mathrm{mM}$ phenylmethylsulfonyl fluoride, and complete inhibitor (Roche, Almere, The Netherlands) and processed for standard SDS-PAGE and Western blotting. Gels were loaded with equal amounts of protein of pre- and posttraining lysates 
of 2 control and 2 type diabetic subjects per gel to allow valid comparison between preand posttraining samples.

Membranes were incubated with antibodies against FIT1 and FIT2 (kindly provided by Dr. David Silver, Duke - National University of Singapore, Singapore); FSP27 (kindly provided by dr. Vishu Puri, Boston University School of Medicine, USA); PLIN2 (GP40, Progen, Heidelberg, Germany); PLIN3 (GP30, Progen); PLIN5 (GP31, Progen); ATGL (2138, Cell Signalling Technology, Leiden, The Netherlands); CGI58 (NB110-41576, Novus Biologicals, Littleton, CO, USA); OPA1 (612606, BD Biosciences, Breda, The Netherlands); and SR-actin as the loading control, A-2172; Sigma, St. Louis, USA.

Blots incubated with FITs, FSP27, PLINs, and OPA1 were probed with appropriate IRDye800-conjugated secondary antibodies (Rockland, Gilbertsville, PA, USA and LICOR Biosciences, Westburg, Leusden, The Netherlands), and bands at a molecular weight corresponding to the control samples were quantified using the Odyssey infrared imaging system (LICOR Biosciences, Westburg, the Netherlands). Blots detecting ATGL and CGI58 were probed with the appropriate horseradish-conjugated antibodies and after incubation specific protein bands were visualized by chemiluminescence and analyzed by Chemidoc XRS system (Bio-Rad, Veenendaal, the Netherlands). Protein content was expressed as arbitrary units (AU).

\section{TAG and DAG hydrolase activity}

TAG and DAG hydrolase activities were measured in muscle tissue homogenates as previously described [25]. Briefly, triolein and 1(3)-mono-oleyl-2-O-mono-oleylglycerol were emulsified with phospholipids by sonication. Triolein is a triglyceride containing three oleic acid specifically used to determine TAG hydrolase activity. 1(3)-Mono-oleyl-2$O$-mono-oleylglycerol is a DAG analog used to measure specifically the DAG hydrolase activity, since it is not a substrate for monoacylglycerol lipase. Lipase activity data were normalized to total protein content determined in each sample and expressed in $\mathrm{nmol} / \mathrm{min} / \mathrm{mg}$.

\section{Electroporation study}

A total of 18 8-week old male Wistar rats were purchased from Charles River (Wilmington, Massachusetts, USA). Rats were housed individually on a 12:12 h light-dark cycle (light from 7:00 am to 7:00 pm), at room temperature $\left(21-22^{\circ} \mathrm{C}\right)$ with ad libitum access to tap water. Rats were fed a high fat diet (45\% energy from fat, D01060502, Research Diets, New Brunswick, NJ, USA) for the duration of the 3-week intervention. The Animal Care and Use Committee of Maastricht University approved the experiments.

Two weeks after the start of the diet, overexpression of mouse Plin5 in either the right or left tibialis anterior (TA) muscle of the rat was accomplished by an in vivo DNA electrotransfer technique to obtain overexpression of mouse perilipin 5 in one leg; the contralateral TA served as a sham-electroporated internal control. Plin5 was electroporated in the left or the right TA on a random basis to eliminate bias. DNA 
electroporation was performed under isoflurane anaesthesia. TA muscles were transcutaneously injected with either $150 \mu \mathrm{g}(2 \mu \mathrm{g} / \mu \mathrm{l})$ pcDNA3.1-CMV-Plin5 or pcDNA3.1empty vector in $0.9 \%$ sterile $\mathrm{NaCl}$. Within 15 seconds after the last injection 5 electric pulses were applied by two stainless steel plate electrodes placed at the ventral and dorsal side of the leg. One high voltage pulse of $800 \mathrm{~V} / \mathrm{cm}$ and four low voltage pulses of $80 \mathrm{~V} / \mathrm{cm}$ at $1 \mathrm{~Hz}$ were generated by an ECM 830 electroporator (BTX, San Diego, CA, USA) as described previously $[26,27]$. Rats were sacrificed 8 days postelectroporation.

\section{Oxygen consumption in isolated mitochondria}

After excision, the right and left TA muscles were placed into ice-cold medium containing $100 \mathrm{mM}$ sucrose, $100 \mathrm{mM} \mathrm{KCl}, 50 \mathrm{mM}$ Tris- $\mathrm{HCl}, 1 \mathrm{mM} \mathrm{KH}_{2} \mathrm{PO}_{4}, 0.1 \mathrm{mM} \mathrm{EGTA}$, and $0.2 \%$ (wt/vol) FA-free bovine serum albumin ( $\mathrm{pH}$ 7.4). The TA was immediately processed for mitochondrial isolation, essentially according to Tonkonogi and Sahlin [28]. The protein concentration in the mitochondrial pellet was measured using fluorescamine (Fluram; Fluka, Zwijndrecht, the Netherlands) with bovine serum albumin as a standard [29]. Freshly isolated mitochondria were used immediately for mitochondrial respirometry.

FA-induced respiration uncoupled from ATP synthesis was determined as a marker for FAinduced uncoupling. Thus, $0.2 \mathrm{mg}$ mitochondria in the presence of $5 \mathrm{mM}$ pyruvate as a substrate and oligomycin $(1 \mu \mathrm{g} / \mathrm{ml})$ to block ATP synthesis (state 40 respiration), were automatically titrated with increasing levels of palmitate by a titration pump (OROBOROS ${ }^{\circledR}$ Instruments, Innsbruck, Austria) while respiration was monitored. The free concentrations of palmitate were calculated using the equation described [30] for the binding of palmitate to $\mathrm{BSA}$ at $37^{\circ} \mathrm{C}$. Data for FA concentration-response curves were analyzed with the four parameter logistic curve fit option of the Sigmaplot 8.0 application (Systat Software, Erkrath, Germany). All substrates were dissolved in double distilled water except palmitate and FCCP/oligomycin, which were dissolved in 50\% and $96 \%$ ethanol, respectively.

\section{Statistics}

Results are presented as mean \pm SEM. Statistical analyses were performed using SPSS for Windows 15.0 software (SPSS, Chicago, IL). Statistical comparisons between conditions (pre- and posttraining) were performed using paired T-tests. Correlations reported were computed as Spearman correlation coefficients. The level of statistical significance was set at $\mathrm{P}<0.05$.

\section{RESULTS}

\section{Subject characteristics}

Control subjects (C) and type 2 diabetic patients (T2D) were carefully matched for body weight, BMI and age (Table 1). Body composition was similar between T2D and C and was unaffected by training (Table 1). Maximal workload capacity and concomitant oxygen 
uptake before training was comparable prior to training and increased similarly upon training in both groups ( $+6.4 \pm 2.6 \%$; $\mathrm{P}=0.04$ in $\mathrm{C}$ and $+11.3 \pm 2.2 \% ; \mathrm{P}<0.01$ in $\mathrm{T} 2 \mathrm{D})$. Fasting plasma free fatty acid (FFA) levels were similar across groups and were unaffected by training (Table 1).

\section{Insulin sensitivity index}

The insulin sensitivity index $(\mathrm{Si}, \mu \mathrm{mol} / \mathrm{kg} / \mathrm{min} / \mathrm{mU})$ was considerably lower in T2D compared with $\mathrm{C}$ (Table 2). Exercise training significantly $(\mathrm{P}<0.01)$ improved insulin sensitivity in T2D and C (Table 2).

\section{Lipid oxidation}

Under insulin stimulation, suppression of lipid oxidation was less pronounced in T2D than in $\mathrm{C}$ before training (metabolic inflexibility). After training, suppression of lipid oxidation in T2D restored to levels similar to age- and BMI matched control subjects (Table 2), reflecting restoration of metabolic flexibility. Lipid oxidation during submaximal exercise (at 75 and $125 \mathrm{~W}$ ) was comparable in $\mathrm{C}$ and T2D before training $(2.06 \pm 0.49$ and $2.26 \pm$ $0.47 \mathrm{mmol} / \mathrm{kg} / \mathrm{min}$ at 75 watt in $\mathrm{C}$ and $\mathrm{T} 2 \mathrm{D}$, respectively; $1.76 \pm 0.39$ and $1.63 \pm 0.57$ $\mathrm{mmol} / \mathrm{kg} / \mathrm{min}$ at 125 watt in $\mathrm{C}$ and T2D, respectively). Training improved lipid oxidation in $\mathrm{C}$ and T2D at 75 Watts ( $3.25 \pm 0.34$ in $\mathrm{C} ; \mathrm{P}<0.01$ and $3.99 \pm 0.43$ in T2D; $\mathrm{P}<0.01)$ as well as at 125 Watts ( $2.86 \pm 0.57$ in $C ; P<0.05$ and $3.13 \pm 0.42$ in $T 2 D ; P<0.01)$.

Table 1. Subject characteristics.

\begin{tabular}{lcccc}
\hline & \multicolumn{2}{c}{ C } & \multicolumn{2}{c}{ T2D } \\
\hline & Pre-training & Post-training & Pre-training & Post-training \\
\hline Age (years) & $59.0 \pm 0.8$ & $/$ & $59.4 \pm 1.1$ & $/$ \\
Years since diagnosis & $/$ & $/$ & $3.9 \pm 0.9$ & $/$ \\
Weight (kg) & $94.7 \pm 2.7$ & $93.6 \pm 2.7$ & $93.8 \pm 2.9$ & $92.8 \pm 3.1$ \\
Height (cm) & $179 \pm 1.3$ & $/$ & $177 \pm 1.3$ & $/$ \\
BMI (kg/m $)$ & $29.7 \pm 0.8$ & $29.4 \pm 0.8$ & $30.0 \pm 0.8$ & $29.8 \pm 0.9$ \\
Body fat (\%) & $31.5 \pm 1.4$ & $30.6 \pm 1.6$ & $31.1 \pm 1.4$ & $29.9 \pm 1.3^{*}$ \\
FM (kg) & $30.0 \pm 1.8$ & $29.2 \pm 2.0$ & $29.4 \pm 1.9$ & $28.0 \pm 1.8^{*}$ \\
FFM (kg) & $64.6 \pm 2.0$ & $65.4 \pm 2.0$ & $64.3 \pm 1.7$ & $64.8 \pm 1.8$ \\
VO2max (ml/min/kg) & $28.8 \pm 1.0$ & $30.2 \pm 1.2^{*}$ & $27.5 \pm 1.2$ & $31.1 \pm 1.2^{*}$ \\
Wmax (Watt) & $207 \pm 10$ & $236 \pm 9^{*}$ & $202 \pm 9$ & $233 \pm 9 *$ \\
Average strength (kg) & $85.8 \pm 3.2$ & $104.0 \pm 3.5^{*}$ & $83.7 \pm 3.5$ & $102.4 \pm 4.2^{*}$ \\
Fasting glucose (mmol/l) & $5.9 \pm 0.1$ & $5.5 \pm 0.1^{*}$ & $9.0 \pm 0.4 \#$ & $9.0 \pm 0.4 \#$ \\
HbA1c (\%) & $5.8 \pm 0.1$ & $5.7 \pm 0.1^{*}$ & $7.2 \pm 0.2 \#$ & $7.2 \pm 0.2 \#$ \\
Triacylglycerol (mmol/l) & $1.52 \pm 0.13$ & $1.49 \pm 0.15$ & $1.77 \pm 0.16$ & $1.68 \pm 0.14$ \\
Type 1 muscle fibers (\%) & $40.0 \pm 2.3$ & $39.5 \pm 2.8$ & $40.0 \pm 3.9$ & $36.5 \pm 2.5$ \\
Type 2 muscle fibers (\%) & $60.0 \pm 2.3$ & $60.5 \pm 2.8$ & $60.0 \pm 3.9$ & $63.5 \pm 2.5$ \\
\hline
\end{tabular}

Data are expressed as mean \pm SEM, ${ }^{\#}$ T2D significantly different from control group, *post-training significantly different from pre-training. 
Table 2. Substrate kinetics pre- and post training.

\begin{tabular}{|c|c|c|c|c|}
\hline & \multicolumn{2}{|c|}{ C } & \multicolumn{2}{|c|}{ T2D } \\
\hline & Pre-training & Post training & Pre-training & Post training \\
\hline \multicolumn{5}{|l|}{ Plasma insulin (mU/I) } \\
\hline Basal & $18.1 \pm 2.4$ & $16.1 \pm 2.1^{*}$ & $16.4 \pm 1.2$ & $14.6 \pm 0.8^{*}$ \\
\hline Clamp & $112.5 \pm 5.4$ & $112.1 \pm 5.5$ & $107.6 \pm 4.8$ & $103.1 \pm 2.7$ \\
\hline \multicolumn{5}{|l|}{ Plasma FFA $(\mu \mathrm{mol} / \mathrm{l})$} \\
\hline Basal & $479.0 \pm 22.9$ & $454.9 \pm 28.3$ & $519.4 \pm 25.3$ & $500.1 \pm 34.1$ \\
\hline Clamp & $84.7 \pm 7.2$ & $67.5 \pm 6.9^{*}$ & $107.1 \pm 8.7$ & $87.6 \pm 8.7^{*}$ \\
\hline $\mathrm{Si}(\mu \mathrm{mol} / \mathrm{kg} / \mathrm{min} / \mathrm{mU})$ & $0.029 \pm 0.005$ & $0.034 \pm 0.005^{*}$ & $0.013 \pm 0.002 \#$ & $0.023 \pm 0.003 *$ \\
\hline \multirow{2}{*}{\multicolumn{5}{|c|}{$\begin{array}{l}\text { Lipid oxidation } \\
\text { ( } \mu \mathrm{mol} / \mathrm{kg} / \mathrm{min})\end{array}$}} \\
\hline & & & & \\
\hline Basal & $1.08 \pm 0.05$ & $1.03 \pm 0.05$ & $1.08 \pm 0.05$ & $1.09 \pm 0.05$ \\
\hline Clamp & $0.63 \pm 0.04$ & $0.55 \pm 0.04$ & $0.75 \pm 0.04 \#$ & $0.59 \pm 0.05^{*}$ \\
\hline Delta & $-0.46 \pm 0.05$ & $-0.48 \pm 0.06$ & $-0.32 \pm 0.06$ & $-0.49 \pm 0.06^{*}$ \\
\hline
\end{tabular}

$\mathrm{Si}=$ insulin sensitivity index. Data are expressed as mean \pm SEM., "T2D significantly different from control group, *post-training significantly different from pre-training.

\section{Muscle LD content and contents of LD-coat proteins}

Immunohistochemical analyses of percentage $\mathrm{MHCl}$ and $\mathrm{MHCll}$ positive muscle fibers was similar at baseline and did not change significantly upon training (Table 1 and Figure 1). Pre-training, LD content was comparable in both (BMI matched) groups (1.36 \pm 0.20 and $1.49 \pm 0.20$ in $C$ and T2D, respectively; $P=0.65)$ and was unaffected in $C(1.36 \pm 0.20$ vs. $1.33 \pm 0.23$ pre- and post-training; $P=0.89$ ), whereas in $T 2 \mathrm{D}$ a near significant and modest increase in LD content was observed (from $1.49 \pm 0.20$ to $1.91 \pm 0.34 ; P=0.10$ ). Representative images of the combined LD and fiber typing are shown in Figure 1. Content of LD coat proteins involved in LD assembly were not different between groups nor were significantly affected by exercise training (FIT1 $1.24 \pm 0.17$ in C vs. $0.89 \pm 0.16$ in T2D pretraining and $0.86 \pm 0.17$ in C vs. $1.01 \pm 0.12$ in T2D post-training, FIT2 $1.14 \pm 0.16$ in $\mathrm{C}$ vs. $0.99 \pm 0.18$ in T2D pre- training and $0.97 \pm 0.23$ in C vs. $0.91 \pm 0.11$ in T2D post-training, FSP27 $1.00 \pm 0.08$ in C vs. $1.02 \pm 0.12$ in T2D pre- training and $0.88 \pm 0.10$ in C vs. $1.10 \pm$ 0.13 in $\mathrm{T} 2 \mathrm{D}$ post-training). 

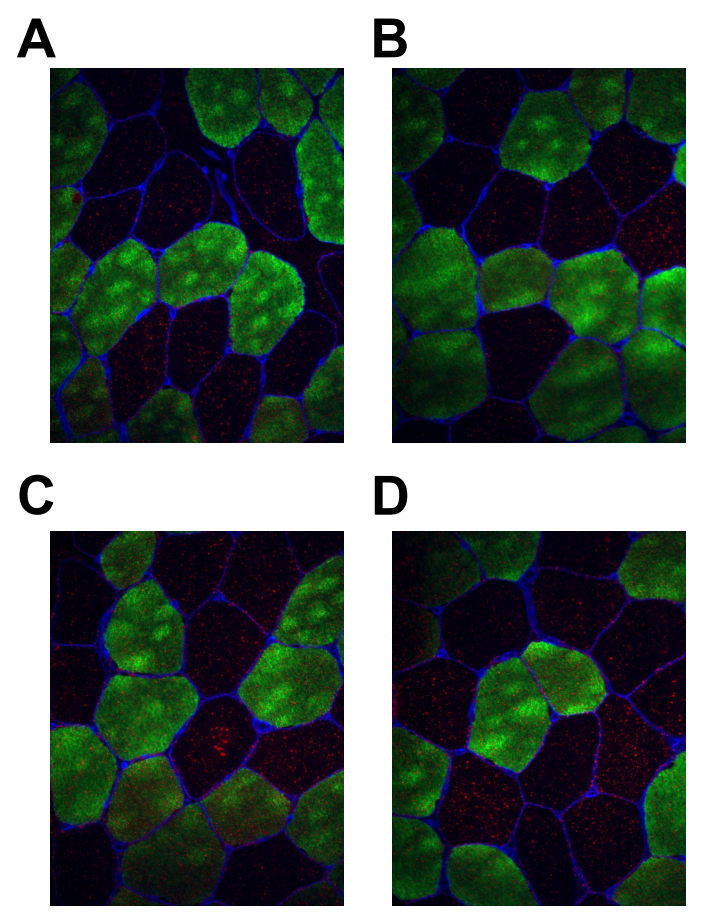

Figure 1. (A-D) Representative images of lipid droplet content (red) with type 1 muscle fibers (green) in control subjects pre- and post training ( $\mathbf{A}$ and $\mathbf{B}$ ) and in type 2 diabetic (T2D) subjects pre- and post training (C and $\mathbf{D})$.

Of the myocellular members of the perilipin family (PLIN2, PLIN3 and PLIN5), protein content of PLIN2 and PLIN5 were similar in C and T2D pre-training (PLIN2: $0.59 \pm 0.06$ and $0.71 \pm 0.09$ in $C$ and T2D respectively; PLIN5: $0.70 \pm 0.14$ and $0.70 \pm 0.10$ in $C$ and T2D respectively, Figure $2 \mathrm{~A}$ and $\mathrm{B}$ ) while pre-training PLIN3 was significantly down in T2D (1.10 \pm 0.11 and $0.81 \pm 0.08$ in $C$ and $T 2 D$ respectively; $P=0.04$, Figure $2 C$ ). The training intervention augmented protein content of all members of the perilipin family, indicative of active remodelling of the LD. Thus, protein content of PLIN2 and PLIN5 approximately doubled after exercise training in $C$ and T2D (PLIN2: from $0.59 \pm 0.06$ to $1.17 \pm 0.14$; $P<0.01$ in $C$ and from $0.71 \pm 0.09$ to $1.55 \pm 0.20 ; P<0.01$ in T2D, PLIN5: from $0.70 \pm 0.14$ to $1.29 \pm 0.19 ; P=0.03$ in $C$ and from $0.70 \pm 0.10$ to $1.27 \pm 0.20 ; P=0.01$ in $T 2 D$, Figure $2 A$ and $B)$, while in T2D patients protein content of PLIN3 restored to pre-training levels observed in $C(1.09 \pm 0.09$ and $1.00 \pm 0.08$ in $C$ and $T 2 D$ respectively, Figure $2 C)$. Training-induced changes in PLIN2 and PLIN5 protein abundance correlated $(r=0.476, \mathrm{P}=0.007)$ and the change in PLIN2 post-training correlated positively with the training-induced change in resting fat oxidation $(r=0.519, \mathrm{P}=0.003)$ and negatively with glucose oxidation $(r=-0.546$, $\mathrm{P}=0.002$ ). 

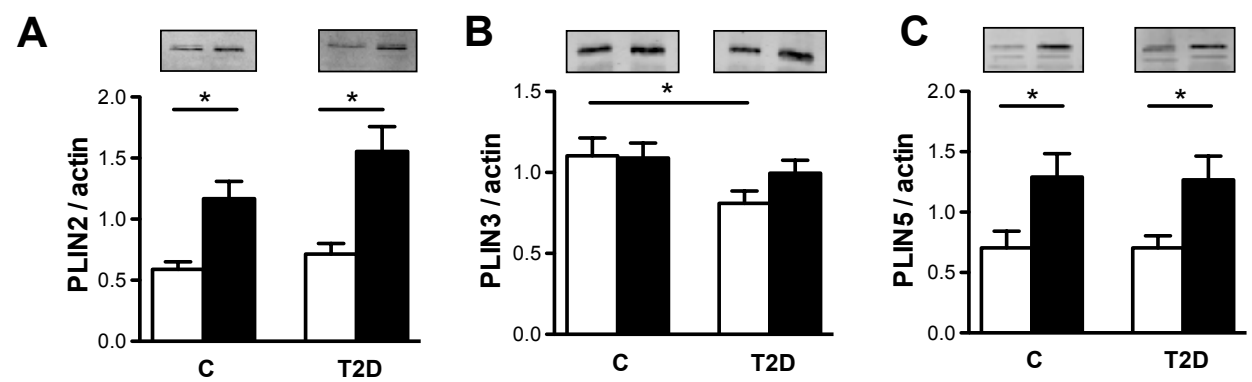

Figure 2. Protein expression of PLIN2 (A), PLIN3 (B) and PLIN5 (C) in vastus lateralis muscle, before (white bars) and after training (black bars). Data are expressed as mean (in arbitrary units, AU) \pm SEM. ${ }^{*} \mathrm{P}<0.05$.

A series of recent papers prompted us to zoom deeper into the role of PLIN5 in the exercise-mediated adaptations in LD assembly and mobilization. Thus, trained athletes have very high levels of PLIN5 $[17,18]$ and myocellular overexpression of PGC1 $\alpha$, a promiscuous transcriptional co-activator with a prominent role in driving the adaptive response to exercise profoundly induces PLIN5 [18]. Furthermore, PLIN5 has also been observed in mitochondria [31,32] and overexpression of PLIN5 promotes oxidative gene expression [15] and interactions of mitochondria with LDs [32]. Thus, we examined if PLIN5 content pre-training correlated with abundance of proteins of the oxidative phosphorylation system (OXPHOS). Indeed, we observed that post-training content of complex I subunit NDUFB8, complex II subunit $30 \mathrm{kDa}$ and complex V ATP synthase subunit alpha correlated significantly with PLIN5 ( $r=0.391, \mathrm{P}=0.029 ; r=0.379, \mathrm{P}=0.035$ and $r=0.447, \mathrm{P}=0.012$, respectively).

Moreover, it has recently been shown that a mitochondrial innermembrane protein optic atrophy 1 (OPA1) involved in mitochondrial fusion, interacts with PLIN1 in adipose tissue to regulate adipocyte lipolysis [33]. If extrapolation to muscle is valid, OPA1 may interact with PLIN5 to regulate lipolysis of myocellular LD. Therefore, we examined OPA1 in muscle biopsies of $\mathrm{C}$ and T2D pre- and post-training. Interestingly, we observed that OPA1 was significantly down in patients with T2D $(1.40 \pm 0.15$ and $1.04 \pm 0.12$ pre-training in $C$ and T2D respectively; $P=0.04$, Figure $3 A$ ) and that training restored values in $T 2 D$ to control levels $1.27 \pm 0.14$ and $1.51 \pm 0.10$ post-training in $C$ and $T 2 D$ respectively, Figure $3 A)$. Moreover, pre-training levels of PLIN5 correlated with OPA1 ( $r=0.361, P=0.046)$. 
A
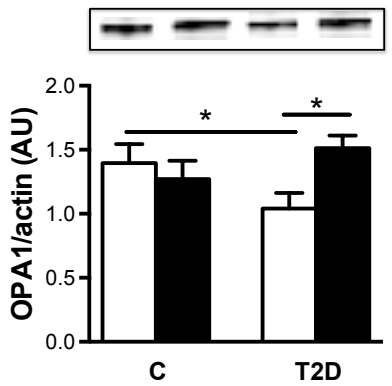

C

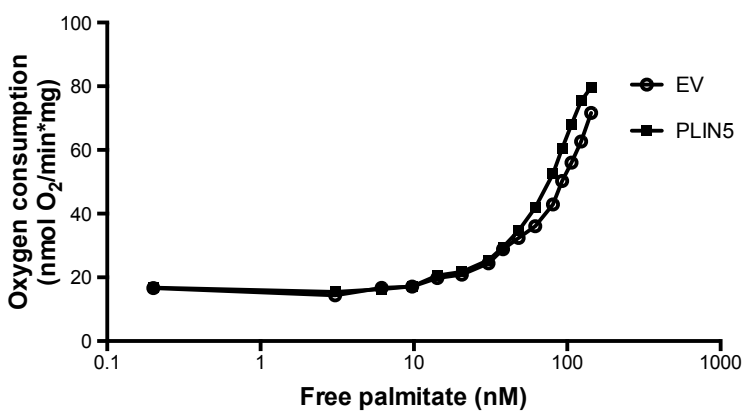

D

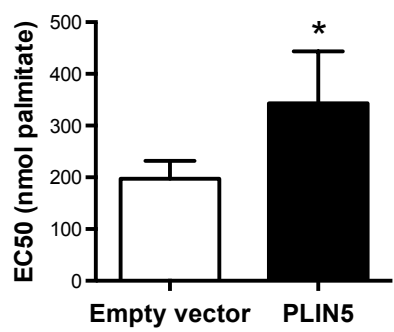

B

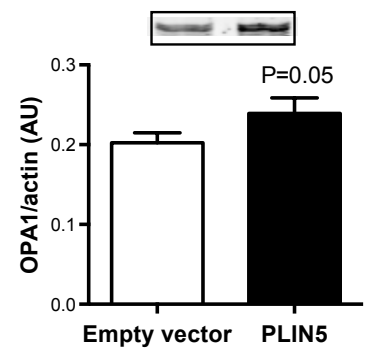

E

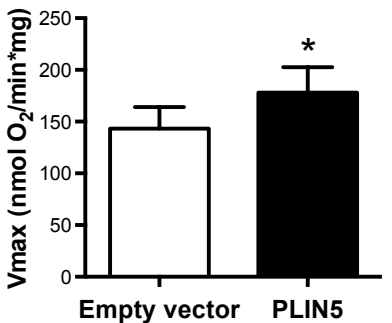

Figure 3. (A) OPA1 protein content before (white bars) and after training (black bars). (B) OPA1 protein content in empty vector and PLIN5electroporated tibialis anterior muscle of rats $(n=18)$. (C) Palmitateinduced uncoupling. Oxygen consumption in isolated mitochondria from empty vector (EV) or PLIN5-

electroporated muscle upon titration with palmitate $(n=10)$. (D-E) EC50 (D) and Vmax (E) for palmitate titrationinduced oxygen consumption $(n=10)$. Data are expressed as mean \pm SEM. ${ }^{*} P<0.05$.

To shed more light on this issue, we overexpressed PLIN5 using unilateral gene electroporation in rats in vivo [31]. Thus, we showed that doubling the protein content of PLIN5 upon electroporation coincided with a significant increase in OPA1 content (Figure 3B). Titration of fatty-acids to mitochondria isolated from the PLIN5 overexpressing muscles with simultaneous measurement of mitochondrial respiration suggest a protective effect of PLIN5 overexpression and concomitant increase of OPA1 to fatty-acid induced uncoupling and lipotoxicity (Figure $3 \mathrm{C}$ and D).

\section{Lipase activities and contents of ATGL and CGI-58}

Contents of the major triacylglycerol lipase ATGL and its indispensable co-activator CGI58 were comparable between groups pre-training (ATGL: $0.73 \pm 0.14$ and $0.87 \pm 0.20$ in C and 
T2D, CGI58: $1.09 \pm 0.11$ and $0.81 \pm 0.10$ in $C$ and T2D, Figure $4 A$ and $B$ ). Training tended to increase ATGL content in T2D (towards $1.70 \pm 0.34, P=0.06$, Figure $4 A$ ), while this increase was absent in $C(0.73 \pm 0.14$ vs. $0.77 \pm 0.20 ; P=0.85$ Figure $4 A$, pre- and post-training, respectively), hence $A T G L$ content post-training was significantly higher in T2D compared to $C(P=0.02)$. While content of $C G I-58$ was not significantly affected by training, $C G I-58$ protein content post-training was significantly lower in $T 2 D$ than in $C(P=0.03$, Figure $4 B$ ). Moreover, the training-induced increase in ATGL and PLIN5 content correlated positively with improvement in insulin mediated suppression in fat oxidation $(r=0.364, P=0.048$ and $r=0.438, P=0.022$, respectively) and negatively with the change in insulin-stimulated glucose oxidation ( $r=-0.364, \mathrm{P}=0.048$ and $r=-0.347, \mathrm{P}=0.083$, respectively), indicative of improved metabolic flexibility.

A
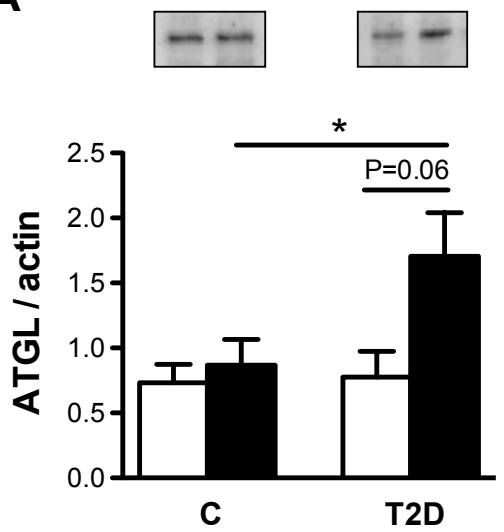

B

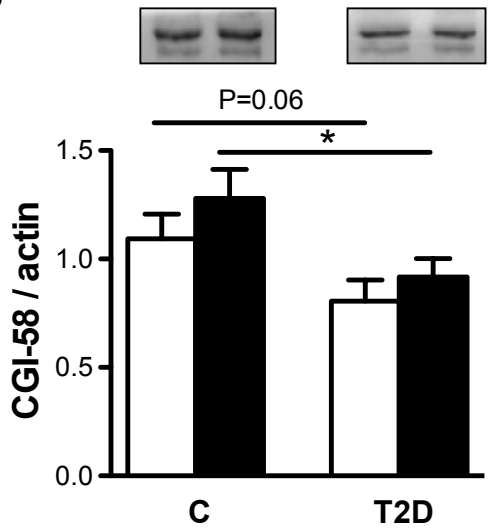

Figure 4. Protein expression of ATGL (A) and CGI-58 (B) in in vastus lateralis muscle, before (white bars) and after training (black bars). Data are expressed as mean (in arbitrary units, AU) \pm SEM. $* P<0.05$.

To examine if the response in PLINs, ATGL and CGI58 translated in altered lipolytic capacity, we performed ex vivo TAG and DAG hydrolase activity assays. TAG hydrolase capacity pre-training was similar in $C$ and T2D $(0.85 \pm 0.16 \mathrm{nmol} / \mathrm{mg} / \mathrm{h}$ and $0.90 \pm 0.11$ $\mathrm{nmol} / \mathrm{mg} / \mathrm{h}$ in $\mathrm{C}$ and $\mathrm{T} 2 \mathrm{D}$ respectively; $\mathrm{P}=0.78$, Figure $5 \mathrm{~A}$ ). Interestingly, post-training lipolytic activity decreased similarly in both groups (towards $0.59 \pm 0.11 \mathrm{nmol} / \mathrm{mg} / \mathrm{h}$ in C; $\mathrm{P}=0.03$, and towards $0.72 \pm 0.10 \mathrm{nmol} / \mathrm{mg} / \mathrm{h}$ in T2D; $\mathrm{P}=0.048$, Figure $5 \mathrm{~A}$ ). DAG hydrolase activity was comparable between groups before training $(10.57 \pm 1.47$ and $12.08 \pm 1.02$ $\mathrm{nmol} / \mathrm{mg} / \mathrm{h}$ in $\mathrm{C}$ and $T 2 \mathrm{D}$ respectively; $\mathrm{P}=0.41$, Figure $5 \mathrm{~B})$ and was not significantly $(\mathrm{P}=0.13$ for $C, P=0.12$ for $T 2 D$ ) affected by training (Figure $5 B$ ). 
A

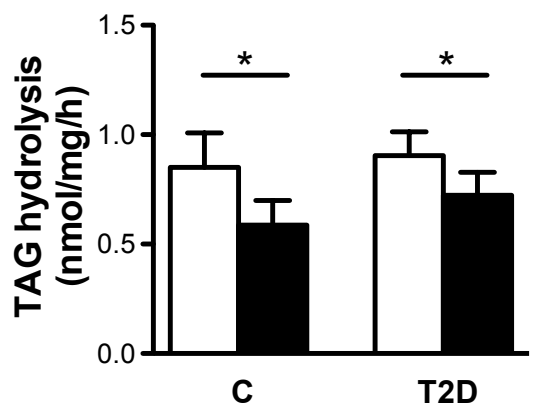

B

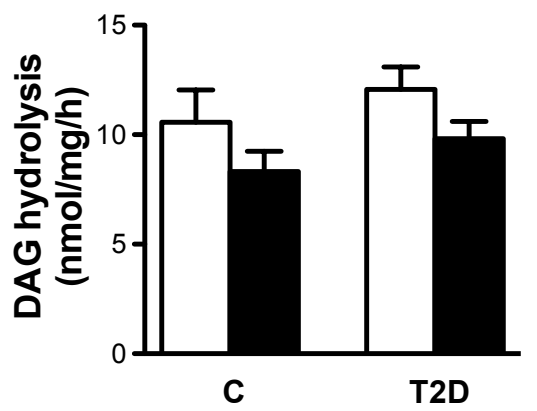

Figure 5. TAG hydrolase (A) and DAG hydrolase (B) activity in vastus lateralis muscle, before (white bars) and after training (black bars). Data are expressed as mean (in arbitrary units) \pm SEM. ${ }^{*} P<0.05$.

\section{DISCUSSION}

In light of our previous observations that myocellular overexpression of either PLIN2 or PLIN5 resulted in massive accretion of fat in the muscle while maintaining muscle insulin sensitivity $[14,15]$ and the cross sectional observation that trained athletes have high LD content with high PLIN5 levels whilst being very insulin sensitive, we set-out to measure contents of proteins involved in LD assembly, maturation, localization and mobilization in obese normoglycemic subjects and subjects with T2D. Moreover, we examined the putative involvement of these proteins in metabolic flexibility and training mediated improvements herein. As we previously observed that the quantity of LD coat proteins in animal models tracked with the LD content [34] and LD content associates with BMI, subjects were carefully matched for BMI.

Thus, we were able to show that in the face of similar myocellular LD content, the protein content of the nascent LD coating protein PLIN3 and of OPA1, a protein putatively involved in facilitating LD mitochondrial interaction [33], were significantly lower in T2D patients compared to obese normoglycemic control subjects (C). While training did not affect abundance of proteins involved in LD assembly (FIT1, FIT2 or FSP27), profound increases in the perilipins (PLIN2, 3 and 5) were observed in both C and T2D. Post-training, the major lipase ATGL was significantly higher in T2D compared with $C$. The proteins which were down in T2D pre-training (PLIN3 and OPA1) restored to levels observed in C after the training program. Ex vivo, these adaptations translated into a reduced TAG hydrolase activity which occurred in face of improved insulin mediated glucose uptake and metabolic flexibility in vivo. Correlative analyses underpin the suggestion that adaptive induction of a LD program by exercise training contributes to the improvements in substrate selection upon altered substrate availability and/or demand.

The observation that PLIN3 is the only LD coat protein which was down in T2D is intriguing. While the precise role of PLIN3 has not yet been identified, knockdown of PLIN3 
in Hela cells prevents nascent LDs from maturation, hence sequestering of fatty-acids (or their insulin desensitizing derivatives) into LDs and maturation of LDs is blunted [35]. Training restored PLIN3 content in T2D to levels similar to age- and BMI matched control. This adaptive response may facilitate the maturation of nascent LDs.

The essentially similar level of PLIN2 and PLIN5 in muscle from C and T2D patients is compatible with previous findings from our lab [34]. Given the lack of differences in content of PLIN2 and PLIN5, it is not likely that these proteins mediate flaws in fatty acid sequestering or lipolytic control responsible for the obvious differences in insulinmediated glucose uptake between $C$ and T2D. On the other hand, we previously observed that myocellular overexpression of either PLIN2 or PLIN5 both ameliorated lipid-induced insulin resistance $[14,15]$. This indicates that augmenting PLIN2 and PLIN5 content contributes to preserving muscle insulin sensitivity.

Although PLIN2 and PLIN5 are both present in muscle and share a high homology [6, 36], overexpression of either protein has differential effects. Evidently, overexpressing PLIN2 or PLIN5 both result in increased myocellular LD content. Despite a profound increase in LD content, PLIN2 overexpression did not promote PLIN5 content and inversely PLIN5 overexpression did not affect PLIN2 content [14, 15]. Overexpressing PLIN2 resulted in a gene expression profile favoring efficient myocellular fat storage as triacylglycerol rather than promoting fatty acid oxidation, while overexpression of PLIN5 in muscle promoted expression of a cluster of genes under control of PPAR $\alpha$ and PGC1 $\alpha$ involved in fatty acid catabolism and mitochondrial oxidation [15]. Recently, we reported that PGC1 $\alpha$, a recognized player in mediating the adaptive response to exercise training, not only plays a prominent role in regulating mitochondrial biogenesis and oxidative metabolism but is also involved in orchestrating the response to exercise of a LD program. While in a cell autonomous system, overexpression of PGC1 $\alpha$ profoundly induced PLIN5 but not PLIN2, muscle specific overexpression of PGC1 $\alpha$ in vivo promoted LD content with a concomitant increase both PLIN2 and PLIN5 [18], suggesting joint regulation of PLIN2 and PLIN5. This suggestion is substantiated by our observation that training induced a similar increase in PLIN2 and PLIN5 protein content in C and T2D and by the observation that the change in these proteins correlated tightly.

Although the precise role of PLIN2 and PLIN5 in muscle remains to be elucidated, overexpression of PLIN2 reduces TAG hydrolase activity by inhibiting accessibility of ATGL to the LD [9, 37]. ATGL, in turn, requires CGI58 to exert its full lipolytic capacity [38]. While CGI58 clearly is indispensable for LD lipolysis, levels of CGI58 appeared not to be ratelimiting for either basal or stimulated lipolysis in mouse adipose tissue [39]. Thus, the decline we observed in TAG hydrolase activity in response to training matches with the concomitant increase in PLIN2 levels in C and T2D. While CGI58 levels tended to be lower in patients with T2D pre- and posttraining, ATGL levels were significantly higher in T2D than in $C$ after the training program. The divergent response of ATGL to exercise training in T2D compared to $C$ may originate from the significant drop in insulin (a negative regulator of ATGL expression [40]) post-training in T2D. 
Data in exercising mice lacking ATGL in skeletal muscle indicate that ATGL is obligatory to liberate fatty acids for mitochondrial oxidation from intramyocellular LD during exercise $[41,42]$. Interestingly, PLIN5 has recently also been implicated in oxidative lipolysis; PLIN5 retains fatty acids within LD by inhibiting lipolysis under basal conditions while upon stimulated LD lipolysis, fatty acids are released for oxidation [8, 10, 43]. These findings nicely match with our observation that pre-exercise PLIN5 content correlates with training-mediated increases in multiple structural components of the oxidative phosphorylation system. Furthermore, PLIN5 was shown to facilitate fatty acid oxidation by recruiting mitochondria to LDs [32] possibly via OPA1 [33] to reduce lipotoxic effects of fatty acids. Thus, we examined OPA1 content and fascinatingly observed significantly reduced OPA1 content in T2D which remarkably restored to control levels upon training. Moreover, pre-training levels of PLIN5 correlated with OPA1, suggesting a functional link between PLIN5 and OPA1. Although we did not observe correlations between traininginduced changes in markers of mitochondrial density and OPA1, it could be argued that the change in OPA1 after exercise training merely reflects mitochondrial density and is not related to changes in PLIN5 levels. Thus, by promoting PLIN5 content in rat skeletal muscle by gene electroporation we observed that a two-fold increase in PLIN5 content significantly increased OPA1 content without significant effects on mitochondrial mass, indicating that PLIN5 and OPA1 may functionally interact to protect lipotoxicity if LD lipolysis does not match mitochondrial fat oxidation. This is in line with our observation that mitochondria isolated from PLIN5 overexpressing muscle are less sensitive to lipotoxicity. These observations may indicate that exercise training in $C$ and T2D, by promoting PLIN2 and PLIN5 content and restoring PLIN3 and OPA1, results in a LD phenotype characterized by increased capacity to sequester fatty acids in LD which are shielded for uncontrolled basal lipolysis but at the same time are equipped to promote oxidative LD lipolysis upon increased energy demand.

While we have no hard data on the functional consequences of these adaptive responses in vivo, it is of interest to know that training-induced increases in PLIN2 and changes in resting fat and carbohydrate oxidation rates correlate tightly, indicating that PLIN2 is somehow involved in substrate selection and may balance the release of fatty acids from the LD with mitochondrial fat oxidation rates. Interestingly, putative involvement of PLIN proteins in substrate switching extends to insulin-mediated substrate switching (metabolic flexibility) and the training-induced improvement herein. Thus, the increase in PLIN2 and PLIN5 content correlated positively with the training-induced improvement in insulin mediated suppression in fat oxidation and negatively with the change in insulin-stimulated glucose oxidation.

Altogether the present study shows that exercise training results in adaptive responses in PLIN proteins, OPA1 and ATGL, priming the muscle to increase lipolytic flux in times of increased demand. At the same time these adaptive responses may contribute to improved control on basal lipolysis and post-prandial substrate selection. While pretraining data of the PLIN proteins or indices of muscle lipolysis indicate that these proteins 
are unlikely to have direct effects on reduced insulin sensitivity in T2D patients, trainingmediated changes render a favourable myocellular LD phenotype facilitating changes in substrate selection during submaximal exercise and improved metabolic flexibility under insulin-stimulated conditions, both of which are mediators of insulin sensitivity.

\section{REFERENCES}

1. Wang $\mathrm{H}$ and Sztalryd C. Oxidative tissue: perilipin 5 links storage with the furnace. Trends Endocrinol Metab 2011; 22: 197-203.

2. Bosma M, Kersten S, Hesselink MKC, and Schrauwen P. Re-evaluating lipotoxic triggers in skeletal muscle: Relating intramyocellular lipid metabolism to insulin sensitivity. Prog Lipid Res 2012; 51: 36-49.

3. Greenberg AS, Coleman RA, Kraemer FB, McManaman JL, Obin MS, Puri V, Yan QW, Miyoshi H, and Mashek DG. The role of lipid droplets in metabolic disease in rodents and humans. J Clin Invest 2011; 121: 2102-2110.

4. Le Lay S and Dugail I. Connecting lipid droplet biology and the metabolic syndrome. Prog Lipid Res 2009; 48: 191-195.

5. Meex RCR, Schrauwen P, and Hesselink MKC. The modulation of myocellular fat stores; lipid droplet dynamics in health and disease. Am J Physiol Regul Integr Comp Physiol 2009; 91053.2008.

6. Bickel PE, Tansey JT, and Welte MA. PAT proteins, an ancient family of lipid droplet proteins that regulate cellular lipid stores. Biochim Biophys Acta 2009; 1791: 419-440.

7. Kimmel AR, Brasaemle DL, McAndrews-Hill M, Sztalryd C, and Londos C. Adoption of PERILIPIN as a unifying nomenclature for the mammalian PAT-family of intracellular, lipid storage droplet proteins. J Lipid Res 2009; 51: 468-471.

8. Granneman JG, Moore HPH, Mottillo EP, Zhu Z, and Zhou L. Interactions of perilipin-5 (PLIN5) with adipose trigylceride lipase (ATGL). J Biol Chem 2011; 286: 5126-5135.

9. Listenberger LL, Ostermeyer-Fay AG, Goldberg EB, Brown WJ, and Brown DA. Adipocyte differentiationrelated protein reduces the lipid droplet association of adipose triglyceride lipase and slows triacylglycerol turnover. J Lipid Res 2007; 48: 2751-2761.

10. Wang H, Bell M, Sreenevasan U, Hu H, Liu J, Dalen K, Londos C, Yamaguchi T, Rizzo MA, Coleman R, Gong $D$, Brasaemle D, and Sztalryd C. Unique regulation of adipose triglyceride lipase (ATGL) by perilipin 5, a lipid droplet-associated protein. J Biol Chem 2011; 286: 15707-15.

11. DeFronzo RA. Lilly lecture 1987. The triumvirate: beta-cell, muscle, liver. A collusion responsible for NIDDM. Diabetes 1988; 37: 667-87.

12. Goodpaster BH, He J, Watkins S, and Kelley DE. Skeletal muscle lipid content and insulin resistance: evidence for a paradox in endurance-trained athletes. J Clin Endocrinol Metab 2001; 86: 5755-5761.

13. Goodpaster $\mathrm{BH}$ and Wolf D. Skeletal muscle lipid accumulation in obesity, insulin resistance, and type 2 diabetes. Pediatr Diabetes 2004; 5: 219-226.

14. Bosma M, Hesselink MKC, Sparks LM, Timmers S, Ferraz MJ, Mattijssen F, van Beurden D, Schaart G, de Baets $\mathrm{MH}$, Verheyen FK, Kersten S, and Schrauwen P. Perilipin 2 improves insulin sensitivity in skeletal muscle despite elevated intramuscular lipid levels. Diabetes 2012; 61: 2679-2690.

15. Bosma M, Sparks LM, Hooiveld G, Jorgensen J, Houten SM, Schrauwen P, Kersten S, and Hesselink MKC. Overexpression of PLIN5 in skeletal muscle promotes oxidative gene expression and intramyocellular lipid content without compromising insulin sensitivity. Biochim Biophys Acta; in press.

16. Van Loon LC and Goodpaster B. Increased intramuscular lipid storage in the insulin-resistant and endurance-trained state. Pflügers Arch 2006; 451: 606-616.

17. Amati F, Dube JJ, Alvarez-Carnero E, Edreira MM, Chomentowski P, Coen PM, Switzer GE, Bickel PE, Stefanovic-Racic M, Toledo FGS, and Goodpaster BH. Skeletal muscle triglycerides, diacylglycerols, and ceramides in insulin resistance: another paradox in endurance-trained athletes? Diabetes 2011; 60: 25882597. 


\section{Perilipins in type 2 diabetic muscle before and after exercise training}

18. Koves TR, Sparks LM, Kovalik JP, Mosedale M, Arumugam R, DeBalsi KL, Everingham K, Thorne L, Phielix E, Meex RC, Kien CL, Hesselink MKC, Schrauwen P, and Muoio DM. PPAR y coactivator-1 $\alpha$ contributes to exercise-induced regulation of intramuscular lipid droplet programming in mice and humans. J Lipid Res; in press, doi: 10.1194/jlr.P028910.

19. Kelley DE and Mandarino $L$. Fuel selection in human skeletal muscle in insulin resistance: a reexamination. Diabetes 2000; 49: 677-683.

20. Storlien L, Oakes ND, and Kelley DE. Metabolic flexibility. Proc Nutr Soc 2004; 63: 363-8.

21. van Loon LJ, Koopman R, Stegen JH, Wagenmakers AJ, Keizer HA, and Saris WH. Intramyocellular lipids form an important substrate source during moderate intensity exercise in endurance-trained males in a fasted state. J Physiol 2003; 553: 611-25.

22. Shepherd SO, Cocks M, Tipton KD, Ranasinghe AM, Barker TA, Burniston JG, Wagenmakers AJM, and Shaw CS. Preferential utilisation of perilipin 2 associated intramuscular triglycerides during one hour of moderate intensity endurance-type exercise. Exp Physiol 2012; 97: 970-980.

23. Meex RCR, Schrauwen-Hinderling VB, Moonen-Kornips E, Schaart G, Mensink M, Phielix E, van de Weijer T, Sels JP, Schrauwen P, and Hesselink MKC. Restoration of muscle mitochondrial function and metabolic flexibility in type 2 diabetes by exercise training is paralleled by increased myocellular fat storage and improved insulin sensitivity. Diabetes 2010; 59: 572-579.

24. Koopman R, Schaart G, and Hesselink M. Optimisation of oil red O staining permits combination with immunofluorescence and automated quantification of lipids. Histochem Cell Biol 2001; 116: 63-68.

25. Moro C, Galgani JE, Luu L, Pasarica M, Mairal A, Bajpeyi S, Schmitz G, Langin D, Liebisch G, and Smith SR. Influence of gender, obesity, and muscle lipase activity on intramyocellular lipids in sedentary individuals. J Clin Endocrinol Metab 2009; 94: 3440-3447.

26. Bruce CR, Brolin C, Turner N, Cleasby ME, van der Leij FR, Cooney GJ, and Kraegen EW. Overexpression of carnitine palmitoyltransferase $\mathrm{I}$ in skeletal muscle in vivo increases fatty acid oxidation and reduces triacylglycerol esterification. Am J Physiol Endocrinol Metab 2007; 292: E1231-1237.

27. Bruce CR, Hoy AJ, Turner N, Watt MJ, Allen TL, Carpenter K, Cooney GJ, Febbraio MA, and Kraegen EW. Overexpression of carnitine palmitoyltransferase-1 in skeletal muscle is sufficient to enhance fatty acid oxidation and improve high fat diet-induced insulin resistance. Diabetes 2009; 58: 550-558.

28. Tonkonogi $M$ and Sahlin K. Rate of oxidative phosphorylation in isolated mitochondria from human skeletal muscle: effect of training status. Acta Physiol Scand 1997; 161: 345-53.

29. Udenfriend S, Stein S, Bohlen P, Dairman W, Leimgruber W, and Weigele M. Fluorescamine: a reagent for assay of amino acids, peptides, proteins, and primary amines in the picomole range. Science 1972; 178: 871-2.

30. Richieri GV, Ogata RT, and Kleinfeld AM. The measurement of free fatty acid concentration with the fluorescent probe ADIFAB: A practical guide for the use of the ADIFAB probe. Mol Cell Biochem 1999; 192: 87-94.

31. Bosma M, Minnaard R, Sparks LM, Schaart G, Losen M, De Baets MH, Duimel H, Kersten S, Bickel PE, Schrauwen $P$, and Hesselink MKC. The lipid droplet coat protein perilipin 5 also localizes to muscle mitochondria. Histochem Cell Biol 2012; 137: 205-216.

32. Wang H, Sreenevasan U, Hu H, Saladino A, Polster BM, Lund LM, Gong DW, Stanley WC, and Sztalryd C. Perilipin 5, a lipid droplet associated protein, provides physical and metabolic linkage to mitochondria. J Lipid Res 2011; 52: 2159-2168.

33. Pidoux G, Witczak O, Jarnaess E, Myrvold L, Urlaub H, Stokka AJ, Kuntziger T, and Tasken K. Optic atrophy 1 is an A-kinase anchoring protein on lipid droplets that mediates adrenergic control of lipolysis. EMBO J 2011; 30: 4371-4386.

34. Minnaard R, Schrauwen P, Schaart G, Jorgensen JA, Lenaers E, Mensink M, and Hesselink MKC. Adipocyte differentiation-related protein and OXPAT in rat and human skeletal muscle: involvement in lipid accumulation and type 2 diabetes mellitus. J Clin Endocrinol Metab 2009; 94: 4077-85.

35. Bulankina AV, Deggerich A, Wenzel D, Mutenda K, Wittmann JG, Rudolph MG, Burger KNJ, and Honing S. TIP47 functions in the biogenesis of lipid droplets. J Cell Biol 2009; 185: 641-655.

36. Dalen KT, Dahl T, Holter E, Arntsen B, Londos C, Sztalryd C, and Nebb HI. LSDP5 is a PAT protein specifically expressed in fatty acid oxidizing tissues. Biochim Biophys Acta 2007; 1771: 210-27. 


\section{Chapter 8}

37. Prats C, Donsmark M, Qvortrup K, Londos C, Sztalryd C, Holm C, Galbo H, and Ploug T. Decrease in intramuscular lipid droplets and translocation of HSL in response to muscle contraction and epinephrine. J Lipid Res 2006; 47: 2392-9.

38. Lass A, Zimmermann R, Haemmerle G, Riederer M, Schoiswohl G, Schweiger M, Kienesberger P, Strauss JG, Gorkiewicz G, and Zechner R. Adipose triglyceride lipase-mediated lipolysis of cellular fat stores is activated by CGI-58 and defective in Chanarin-Dorfman Syndrome. Cell Metab 2006; 3: 309-319.

39. Caviglia JM, Betters JL, Dapito D-H, Lord CC, Sullivan S, Chua S, Yin T, Sekowski A, Mu H, Shapiro L, Brown $\mathrm{JM}$, and Brasaemle DL. Adipose-selective overexpression of ABHD5/CGI-58 does not increase lipolysis or protect against diet-induced obesity. J Lipid Res 2011; 52: 2032-2042.

40. Kershaw EE, Hamm JK, Verhagen LAW, Peroni O, Katic M, and Flier JS. Adipose triglyceride lipase: function, regulation by insulin, and comparison with adiponutrin. Diabetes 2006; 55: 148-157.

41. Huijsman E, van de Par C, Economou C, van der Poel C, Lynch GS, Schoiswohl G, Haemmerle G, Zechner R, and Watt MJ. Adipose triacylglycerol lipase deletion alters whole body energy metabolism and impairs exercise performance in mice. Am J Physiol Endocrinol Metab 2009; 297: E505-513.

42. Schoiswohl G, Schweiger M, Schreiber R, Gorkiewicz G, Preiss-Landl K, Taschler U, Zierler KA, Radner FPW, Eichmann TO, Kienesberger PC, Eder S, Lass A, Haemmerle G, Alsted TJ, Kiens B, Hoefler G, Zechner R, and Zimmermann R. Adipose triglyceride lipase plays a key role in the supply of the working muscle with fatty acids. J Lipid Res 2010; 51: 490-499.

43. Granneman JG, Moore HP, Mottillo EP, and Zhu Z. Functional interactions between MLDP (LSDP5) and ABHD5 in the control of intracellular lipid accumulation. J Biol Chem 2009; 284: 3049-57. 
CHAPTER 9

General discussion 
The current obesity epidemic warrants further research into the mechanisms involved in the etiology of obesity-associated comorbidities like type 2 diabetes (T2D). Obesity is associated with increased lipid supply to skeletal muscle and this intramyocellular lipid (IMCL) accumulation correlates with insulin resistance in sedentary obese individuals [1, 2]. Yet, the exact mechanistic link between IMCL accumulation and impairments in insulin signaling is unclear (reviewed in chapter 2). Skeletal muscle is the largest contributor to glucose clearance in the postprandial state. Furthermore, insulin resistance in skeletal muscle has been hypothesized to serve as underlying cause for hyperlipidemia and hepatic steatosis [3, 4]. Elevated lipid supply, increased skeletal muscle fatty acid uptake, disturbed lipid metabolism (lipid storage and lipid turnover) and reduced oxidative capacity have been identified as underlying factors for the development of skeletal muscle insulin resistance (reviewed in chapter 2 and $[5,6]$ ). Therefore, improvements in skeletal muscle lipid handling may potentially result in improvements in insulin sensitivity.

Lipid droplets (LDs) serve as dynamic intramyocellular lipid depots. These lipid reservoirs provide quickly accessible pools of substrates in periods of energy demand. Moreover, LDs serve as storage depots for lipids needed as building blocks for membrane synthesis [7] and bioactive lipids that function as intracellular messengers [8, 9]. Therefore, impairments in LD dynamics affect many important intracellular metabolic processes. LDs consist of a neutral lipid core surrounded by a phospholipid monolayer. Sufficient provision of phospholipids is essential for LD synthesis and growth [10]. The phospholipid monolayer is decorated with proteins. These LD coat proteins modulate LD dynamics, including LD synthesis and degradation, motility and interorganelle interactions $[11,12]$. Furthermore, LD coat proteins regulate lipid metabolism. The discovery of proteins in the LD coat as modulators of lipid storage and metabolism [13] opened new doors for research into mechanisms involved in lipid-induced insulin resistance and may provide targets for intervention.

The aim of the research presented in this thesis was to investigate the role of the LD coat proteins perilipin (PLIN) 2 and 5 in skeletal muscle lipid metabolism and insulin resistance. In this chapter the results are interpreted and discussed in the light of recent advances in the field. The following research questions will be discussed: (9.1) does an increased capacity for intramyocellular neutral lipid storage protect against lipid-induced insulin resistance?; (9.2) are the lipid droplet coat proteins PLIN2 and PLIN5 involved in neutral lipid storage in skeletal muscle?; (9.3) are PLIN2 and PLIN5 involved in the regulation of oxidative fatty acid metabolism?; and (9.4) does a higher availability of PLINs protect against lipid-induced insulin resistance?. General conclusions and future perspectives are presented in paragraph 9.5.

\subsection{Neutral lipid storage versus lipid intermediate accumulation}

On the basis of chemical classification, neutral lipids encompass TAG, diacylglycerol (DAG) and cholesterol(-esters). The LD is the main storage site for neutral lipids. TAG is the inert storage form for lipids and is the major storage form for lipids in LDs [14]. The data 
presented in chapter 3 show that individuals with a larger increase in storage of IMCL in LDs after a prolonged fast become less insulin resistant. This suggests that under acute conditions of high lipid supply an increased storage of neutral lipids protects against lipidinduced insulin resistance. Furthermore, a lower incorporation of fatty acids (FAs) into neutral lipids was shown in skeletal muscle from obese T2D compared to BMI-matched controls both ex vivo and in vitro (chapter 4). Myotubes established from satellite cells mainly reflect the profile of the donor. Therefore, the fact that this reduced capacity to store FAs as neutral lipids is retained in vitro suggests that neutral lipid storage capacity is an intrinsic characteristic of muscle cells and may be considered one of the explanations for the fact that not all (severely) obese subjects develop insulin resistance [15]. Hence, expanding the neutral lipid storage capacity in skeletal muscle may be a strategy to prevent obesity-associated insulin resistance.

In chapter $\mathbf{8}$ we show that a 12-week training program in type 2 diabetic individuals improves insulin sensitivity in parallel with modestly increased IMCL storage, consistent with the paper of Dubé et al. [16], in which it was furthermore reported that the increased IMCL storage upon training mainly consisted of TAG storage [16]. This is in harmony with earlier reports describing the athlete's paradox: endurance-trained athletes have elevated IMCL levels, despite being highly insulin sensitive $[2,17]$. By use of in vivo infusion of ${ }^{13} \mathrm{C}-$ palmitate, Bergman et al. [18] showed that palmitate incorporation into skeletal muscle TAG was increased in endurance trained athletes compared with sedentary controls. Further support for the proposed beneficial role for the neutral lipid storage capacity came from Schenk et al. [19], who showed that one exercise session protects against lipidinduced insulin resistance by channeling FAs towards TAG synthesis [19]. Collectively, the findings reported in this thesis and earlier and more recent literature in this area indicate that IMCL accumulation is not per se detrimental and that a high capacity to channel FAs towards intramyocellular neutral lipid storage protects against lipid-induced insulin resistance.

Besides storage of FAs in the form of inert TAG, FAs can accumulate in the form of lipid intermediates like FA-CoA, acylcarnitines, ceramides and diacylglycerol (DAG). Animal and cell studies demonstrated that these lipid intermediates have the potential to induce insulin resistance, but human studies show conflicting and merely correlative results (reviewed in chapter 2). Moreover, interventions that result in elevated lipid intermediate accumulation do not necessarily result in insulin resistance. For example, we (chapter 5) and others [20] have shown that interventions that are associated with increased ceramide levels do not necessarily impair insulin sensitivity. The results reported in this thesis mainly reflect a beneficial role for neutral lipid storage in LDs in general, rather than that levels of individual lipid species would determine insulin resistance. For example, skeletal muscle of T2D subjects did not show an increased channeling of FAs towards accumulation in the form of DAG when compared to BMI-matched controls. Furthermore, muscle cells from obese nondiabetic donors showed increased channeling of FAs towards the total neutral lipid pool which could not solely be accounted for by the increased channeling towards TAG (chapter 4). An important question to be answered is whether 


\section{General discussion}

lipid intermediates stored in the LD (as opposed to lipid intermediates stored in/near cellular and organellar membranes) can affect cellular function. In order to interfere with insulin signaling, lipid intermediates in the LD should be capable of activating a second messenger that will translocate to the plasma membrane to interfere with insulin signaling. This phenomenon was recently described for DAG-induced insulin resistance [21]. However, further support for this hypothesis is lacking and the question arises how lipids in the LD can pass through the phospholipid monolayer to activate the second messenger. Furthermore, this hypothesis contrasts with the findings of Bergman et al. [22], who demonstrated that DAG accumulation in the membranes was associated with insulin resistance. Furthermore, it was shown that athletes have higher DAG levels compared to sedentary controls [23], but that athletes accumulate less DAG in/near membranes [22], indicating that not DAG accumulation in LDs but accumulation in the membrane is linked to insulin resistance. Additionally, it was recently demonstrated that 1,2-DAG, the DAG-isoform that activates PKCs thereby impairing insulin signaling, is not produced by lipolysis [24]. Therefore, DAG released from the LD by lipolysis is an unlikely candidate to activate PKCs. Because of the inconsistencies [25] and the scarce information available, further studies on lipid intermediate subspecies and their intracellular localization are warranted.

In general, lipid intermediate levels are merely snap-shots of highly complex and dynamic processes. These lipid intermediates are important intracellular messengers and are precursors for membrane lipids [26-29]. Therefore, increases in lipid intermediate levels may represent increased lipid turnover and activation of intracellular signaling pathways. Furthermore, one may speculate that lipid intermediate storage in the LD - as opposed to accumulation in cellular and organellar membranes - will reduce its lipotoxic potential. Likewise, numerous studies have shown that lipid intermediate build-up is not necessarily detrimental (reviewed in chapter 2). On the other hand, a disbalance in skeletal muscle lipid influx, lipid metabolism and oxidative capacity may result in excess lipid intermediate accumulation ultimately resulting in the development of lipotoxicity and insulin resistance. Restoring this balance is advantageous and may involve creation of neutral lipid storage depots. Approaches to increase neutral lipid storage capacity include increasing the channeling of FAs towards neutral lipid synthesis, inhibiting (uncontrolled) lipolysis, and expanding the storage space by increasing LD number, -size and/or stability.

\subsection{The role of PLIN2 and PLIN5 in intramyocellular neutral lipid storage}

\subsubsection{Lipid droplet coat proteins in skeletal muscle}

A unique characteristic of LDs in comparison with other organelles is the fact that cells harbor a heterogeneous population of LDs with different metabolic fates and hence varying proteins in the LD coat. While the skeletal muscle LD proteome contains more than 300 different proteins [30], little is known to date about the function of the individual LD proteins in skeletal muscle. The perilipin (PLIN) protein family was the first identified family of LD coat proteins [13]. PLIN2 and PLIN5 are abundantly expressed in skeletal muscle [31-35], but information on their function is still limited. The research presented in 
this thesis advances the knowledge on the function of PLIN2 and PLIN5 in skeletal muscle. PLIN2 is an LD coat protein expressed in the majority of nonadipose tissues [36, 37]. In human skeletal muscle about $60 \%$ of the LDs are coated with PLIN2 [32]. PLIN5 is expressed in tissues with a high fat oxidative capacity, including brown adipose tissue, heart and skeletal muscle [38, 39]. PLIN2 expression is strongly induced in vitro by increased FA supply (chapter 5 and [40-42]. PLIN2 protein content increased with FA loading of myotubes and with in vivo interventions in mice that increase IMCL levels (consumption of a high fat diet and fasting) (chapter 5). Contrastingly, PLIN5 is expressed at very low levels in cultured cells exposed to FAs and high fat feeding increases PLIN5 expression only modestly in skeletal muscle [39]. Both PLIN2 and PLIN5 contain a PPRE in their promotor region and hence are PPAR target genes [41, 43-45]. In hepatocytes and macrophages, induction of PLIN2 expression by unsaturated FAs requires both PPAR and AP-1 activation [41, 46]. Similarly, an oral gavage with the PPAR $\alpha$ agonists Wy14,643 or fenofibrate induced PLIN5 but not PLIN2 expression in mouse skeletal muscle (Appendix 1). Thus, PLIN5 is a PPAR $\alpha$ target gene in skeletal muscle (Appendix 1 and [39]), PLIN2 expression in skeletal muscle is mainly induced by increased supply of (unsaturated) FAs, which is partly mediated by PPAR signaling. The role of PLIN2 and PLIN5 in skeletal muscle lipid metabolism is discussed below.

\subsubsection{PLIN2 and intramyocellular lipid storage}

In chapter $\mathbf{5}$ we show that PLIN2 is essential for intramyocellular TAG accumulation. Knockdown of PLIN2 prevented oleate-induced intramyocellular TAG accumulation and LD storage. In the absence of PLIN2, LD accumulation was restricted to a few LDs per myotube. Moreover, overexpression of PLIN2 in vitro and in vivo resulted in elevated neutral IMCL levels. These data indicate that PLIN2 is involved in LD synthesis and/or LD stability and neutral lipid (TAG) storage. Consistently, Bell et al. [47] showed that PLIN2 knockdown in liver cells decreased LD number. The fundamental role of PLIN2 in neutral lipid storage has been firmly established in a range of in vivo and in vitro studies [47-53]. Furthermore, it was suggested that PLIN2 might be involved in budding of LDs from the endoplasmic reticulum [54]. Moreover, PLIN2 overexpression increased expression profiles of genes involved in lipid synthesis (chapter 5), consistent with findings in other models [55] and indicating that PLIN2 builds fat stores. In addition, PLIN2 overexpression was shown to be associated with increased FA uptake [56], while PLIN2 knockdown was paralleled with decreased FA uptake [51]. We did not observe changes in short-term FA uptake rates upon PLIN2 knockdown and overexpression (Appendix 2), arguing against a direct role for PLIN2 in FA uptake. On the other hand, total incorporation into lipids was lower in the PLIN2 knockdown cells, while FA oxidation only tended to be modestly increased (chapter 5). This may indicate that feedback mechanisms exist that synchronize lipid storage capacity with FA uptake in the longer term.

Besides influencing lipid synthesis and storage, modulation of lipolysis is an alternative way of influencing $\mathrm{IMCL}$ storage and lipid (intermediate) accumulation. The results presented in chapter $\mathbf{5}$ indicate that PLIN2 is involved in both lipid (droplet) 


\section{General discussion}

synthesis and inhibition of lipolysis. Consistently, PLIN2 was shown to inhibit lipolysis in several cell models $[47,57,58]$. Nonetheless, ATGL-inhibition by the compound BEL was not sufficient to restore TAG levels upon oleate incubation (Appendix 3), indicating that PLIN2-mediated IMCL accumulation is not solely mediated by a decrease in lipolysis and that PLIN2 availability is essential for TAG storage. Shepherd et al. [34] showed that PLIN2associated lipid droplets were preferentially depleted upon acute exercise [34]. Moreover, PLIN2 was shown to colocalize with and bind to CGI-58 [59, 60] and HSL [61]. HSL translocates to PLIN2-coated LDs upon muscle contraction [62]. Therefore, the energy demand may govern whether PLIN2 inhibits lipolysis. The findings described in this thesis in combination with relevant literature indicate that PLIN2 is an important facilitator of $\mathrm{IMCL}$ storage by influencing both LD storage and stability as well as (uncontrolled) lipolysis.

\subsubsection{PLIN5 and intramyocellular lipid accumulation}

Consistent with the effects of PLIN2, PLIN5 overexpression resulted in elevated neutral lipid content mainly consisting of TAG (chapter 7). This is consistent with findings in other cell types [39, 63, 64]. It remains unclear exactly which mechanisms explain the increased IMCL accumulation upon PLIN5 overexpression (chapters 6 and 7). The increased LD size and TAG storage upon PLIN5 overexpression (chapter 7) may serve as an indication for inhibition of lipolysis by PLIN5. Likewise, PLIN5 was described to inhibit lipolysis under basal conditions in heart and liver $[59,63,65]$. On the other hand, PLIN5 was shown to be essential for ATGL-mediated lipolysis $[64,66]$ and was demonstrated to stimulate ATGLmediated lipolysis in hepatocytes specifically upon PKA stimulation [59]. This may imply that the higher availability of both PLIN5 and ATGL upon PLIN5 overexpression (chapter 7) results in a higher lipolytic capacity in conditions of increased energy demand. Therefore, the function of PLIN5 in regulating lipolysis in skeletal muscle appears complex and deserves further attention. Additionally, the increased TAG storage upon PLIN5 overexpression presumably does not solely result from inhibition of lipolysis. It was shown in liver cells that PLIN5 overexpression increased the incorporation of palmitate into TAG [67]. Furthermore, in our in vivo gene electroporation studies, gene expression of the FA transporter CD36 was increased 1.5-fold upon PLIN5 overexpression. Moreover, PLIN5 overexpression resulted in increased expression of genes under control of PGC1 $\alpha$ (chapter 7). PGC1 $\alpha$ activation is known to stimulate both oxidative capacity and IMCL synthesis [6871]. Therefore, PLIN5 is likely to be involved in the induction of a feed-forward loop, increasing both lipid storage and the capacity to liberate and oxidize FA. The regulatory role of PLIN5 in FA oxidative metabolism is discussed below.

\subsection{PLINs 2 and 5 \& oxidative capacity}

\subsubsection{PLIN5 and interorganelle interactions}

Classical studies in the sixties [72] and seventies [73] already showed interaction of LDs with mitochondria in skeletal muscle. More recent publications indicated that the 
proteome of isolated LDs contains many mitochondrial proteins, which provides further support for regular interactions between these cellular organelles [30, 74]. Nonetheless, little is known about how these interactions are regulated. The close proximity of LDs and mitochondria facilitates shuttling of FAs towards mitochondrial oxidation, thus maintaining low cellular concentrations of FAs, which are potentially toxic. Training increases the number of LDs in contact with mitochondria [75]. Additionally, older adults have larger intramyocellular LDs, fewer mitochondria, and a lower proportion of LDs in contact with mitochondria [76]. In chapter 6 we show that PLIN5 localizes to both LDs and mitochondria. PLIN5 overexpression resulted in more intimate interactions between these two organelles; almost all LDs in PLIN5 overexpressing muscle were in contact with mitochondria. Mitochondria in PLIN5 overexpressing muscle sometimes even appeared to envelop the LD (chapter 6). It should however be noted that this is a qualitative finding based on ultrastructural analysis by electron microscopy. Yet, consistent with our findings, Wang et al. [67] demonstrated that PLIN5 recruits mitochondria to the LD surface in a range of different cell types and that mitochondria in interaction with PLIN5-coated LDs are not as mobile and dynamic as mitochondria in cells with PLIN2-coated LDs, providing further support for the notion that PLIN5 is involved in interactions between mitochondria and LDs. Using immunogold electron microscopy, we showed that PLIN5 was present at the interface of LDs with mitochondria as well as in the mitochondria (chapter 6). FA oxidation was improved, indicating that these more intimate interactions between LDs and mitochondria do not negatively impact on mitochondrial function. Further research is warranted to study the function of PLIN5 in interactions of mitochondria with LDs, primarily the exact localization of PLIN5 (inner- or outermitochondrial membranes or matrix) and its interaction partners. PLIN5 was shown to form homo-oligomers [64]. One may speculate that the formation of oligomeric protein complexes, by interactions between PLIN5 molecules on LDs and mitochondria is important for interactions between LDs and mitochondria. Furthermore, the interactions with lipolytic enzymes, would then ensure that lipases are targeted to the right subcellular location hence ensuring lipid delivery at the right place and preventing unnecessary FA-intermediate accumulation.

\subsubsection{PLINs and oxidative capacity}

PLIN5 is expressed in tissues with a high fat oxidative capacity, including brown adipose tissue, heart and skeletal muscle $[38,39]$. Furthermore, PLIN5 overexpression in vitro was shown to increase FA oxidation [39]. In chapter 6 we show that PLIN5 correlates with markers for oxidative capacity, including mitochondrial function and mitochondrial density. The latter was confirmed by Peters et al. [77] and indicates that increased abundance of PLIN5 is associated with improved oxidative capacity. Recently, Kuramoto et al. [65] described the phenotype of PLIN5 knockout mice. These mice lacked detectable LDs in the heart, LDs in skeletal muscle were smaller and less abundant compared to wildtype mice. Cultured cardiomyocytes from PLIN5 knockout mice showed a higher rate of FA oxidation, but this likely reflects compensation for the lack of LD stability and storage capacity as a result of the increased lipase activity. Yet, the increased FA oxidation 


\section{General discussion}

was associated with increased accumulation of acid soluble metabolites (metabolites originating from $\beta$-oxidation and the TCA-cycle) and reactive oxygen species as well as impaired cardiac function [65]. In chapter 6 we show that PLIN5 overexpression in tibialis anterior muscle was associated with increased complete $\mathrm{FA}$ oxidation towards $\mathrm{CO}_{2}$ in the absence of an increased accumulation of acid soluble metabolites, indicating that an increased abundance of PLIN5 results in improved FA oxidation.

Furthermore, PLIN5 overexpression resulted in a transcriptomic profile suggesting improved oxidative capacity (chapter 7). In normal physiology, ectopic lipid storage, lipolysis and $\beta$-oxidation are well coupled thus preventing lipid intermediate build-up [78]. Type 2 diabetes development is associated with reduced oxidative capacity [79]. Moreover, strategies that improve skeletal muscle oxidative capacity and mitochondrial function improve insulin sensitivity [80-82]. Interestingly, strategies to improve oxidative capacity in skeletal muscle usually go hand in hand with increased neutral lipid storage [68-70, 81]. This indicates that storage of lipids in LDs and downstream metabolism are highly interrelated and share regulatory processes. The major regulator of skeletal muscle oxidative capacity is the transcriptional coactivator PGC1 $\alpha$ [83], which is exerciseresponsive and regulates both mitochondrial FA oxidative capacity and LD dynamics [71]. PLIN2 and PLIN5 are induced upon PGC1 $\alpha$ activation [71]. The induction of PLIN2 is likely to be solely associated - either regulatory or as a consequence of increased PLIN2 stability by increased lipid storage - with the expansion of the lipid stores upon training/PGC1 $\alpha$ activation, since we do not have any indications for involvement of PLIN2 in FA oxidative metabolism. Interestingly, we show in chapter 7 that PLIN5 overexpression promoted expression of a cluster of genes under control of PPARs/PGC1 $\alpha$, indicative of a feedforward loop of PGC1 $\alpha$-activation by a downstream target. It remains unclear how PLIN5 overexpression leads to increased expression of PGC1 $\alpha$ target genes. Possibilities include involvement of PLIN5 in liberation of PPAR ligands, ligand transport to the nucleus or direct interaction with PGC1 $\alpha$. Nevertheless, PLIN5 overexpression resulted in increased neutral lipid storage paralleled with a transcriptional profile representing increased oxidative capacity. Furthermore, PLIN5 overexpression resulted in more intimate interactions between mitochondria and LDs (chapter 6). Hence, the capacity for FA liberation and FA oxidation is utilized in the most efficient way. PLIN5 expression is induced upon acute exercise [71] and its activity is regulated by PKA phosphorylation [67]. Therefore, PLIN5 appears to have the potential to be a key player in regulating cellular metabolism upon energy demand by regulating lipolysis and interactions between LDs and mitochondria. Moreover, by indirectly or directly promoting expression of genes involved in FA oxidative metabolism and mitochondrial function, PLIN5 could potentially balance intramyocellular lipid load with downstream catabolic machinery thus enhancing the fat oxidative capacity. Therefore, based on our data in combination with the relevant literature, one could speculate that PLIN5 induces a feed-forward loop to match the capacity to store IMCL with the ability to liberate and oxidize FA. 


\subsection{PLIN2 and PLIN5 availability in relation to skeletal muscle lipid metabolism and insulin sensitivity}

\subsubsection{PLINs and insulin sensitivity}

As discussed above, PLIN2 and PLIN5 facilitate neutral lipid storage. Hence, these proteins may protect against lipid-induced insulin resistance. Indeed, our mechanistic studies show that increased PLIN2 or PLIN5 levels facilitate neutral lipid storage in skeletal muscle without impairing insulin sensitivity (chapters 5 and 7). Consistent with our findings in skeletal muscle (chapter 5), PLIN2 overexpression in liver improved insulin sensitivity [53]. Furthermore, skeletal muscle PLIN2 and PLIN5 protein content is increased after insulinsensitizing strategies like exercise (both PLIN2 and PLIN5) (chapter 8 and [33, 77]), weight loss and metformin treatment (PLIN2, no data available on PLIN5) [84]. Coen et al. showed a lower PLIN2 gene expression in muscle of T2D subjects compared with BMI-matched controls [85]. Yet, a low PLIN2 protein content does not seem to be a general characteristic of T2D muscle (chapter 8 and [31, 84] and PLIN2 and PLIN5 expression does not necessarily correlate with insulin sensitivity (chapters $\mathbf{3}$ and $\mathbf{8}$ ). Nevertheless, in chapter $\mathbf{3}$ it is shown that individuals with high PLIN2 protein content store more lipids in LDs upon an increased plasma lipid load (fasting) (chapter 3). Additionally, PLIN2 and PLIN5 expression are markedly increased in endurance-trained athletes in comparison with sedentary BMI-matched controls $[23,71]$. Therefore, PLIN2 and PLIN5 expression can be considered components of a profile reflecting improved intramyocellular lipid metabolism. Interestingly, PLIN5 was shown to be a strong predictor for insulin sensitivity in endurance-trained young men [71]. One may argue that a balance in LD coat protein expression facilitating sufficient neutral lipid storage space and dynamic lipid metabolism may protect against lipid-induced insulin resistance. PLIN2 and PLIN5 are two examples of proteins facilitating neutral IMCL storage, other candidates may include enzymes involved in TAG synthesis and proteins involved in lipid incorporation into the LD, LD synthesis and LD stability. Hence, a genetic profile facilitating a high protein expression and/or activity of proteins facilitating intramyocellular neutral lipid storage may protect against lipidinduced insulin resistance. Likewise, in chapter 4 we observed both ex vivo and in vitro that T2D subjects have a lower capacity of channeling FAs towards neutral lipid storage compared with obese nondiabetics, indicating that impaired neutral lipid storage capacity is an intrinsic characteristic of the type 2 diabetic myotube and may determine predisposition towards the development of obesity-associated type 2 diabetes.

\subsubsection{Strategies to improve intramyocellular lipid storage}

Given the beneficial effects of increasing neutral lipid storage capacity and PLIN2 and PLIN5 expression, it is tempting to investigate which strategies are effective in improving these parameters. An obvious candidate strategy is exercise training. Indeed, in chapter 8 we show that PLIN2 and PLIN5 protein expression are increased after a 12-week endurance training program in obese men, consistent with previously published findings $[33,77,86]$. Acute exercise induces channeling of FAs towards neutral lipid storage [19] 


\section{General discussion}

and induces gene expression of multiple genes involved in TAG synthesis and LD assembly and mobilization in mouse skeletal muscle [71]. Regular exercise induces lipid turnover and the increase in LD and neutral lipid synthesis upon acute exercise allows the muscle to better cope with a subsequent lipid load [19]. Interestingly, it was demonstrated that in endurance-trained muscle, pre-exercise $\mathrm{IMCL}$ levels determine the degree of $\mathrm{IMCL}$ depletion [87]. Furthermore, subjecting sedentary subjects to an endurance training program was shown to enhance muscle reliance on local lipids [88]. One may speculate that lipid depletion during exercise and increased lipid turnover upon exercise training may result in mobilization and catabolism of lipid intermediates that under sedentary conditions would not have been preferentially utilized. Moreover, exercise training results in a balanced system of neutral lipid storage capacity and downstream mitochondrial machinery.

Another approach to influence skeletal muscle lipid metabolism is diet composition. Low calorie diets improve skeletal muscle insulin sensitivity even in lean insulin resistant subjects [89]. Interestingly, this improvement in insulin sensitivity with weight loss was paralleled by an increase in LD density, while IMCL storage was decreased [89], indicating a remodeling of intramyocellular lipid metabolism. Additionally, it was shown that a weight loss intervention in obese subjects resulted in increased PLIN2 protein content [84]. In addition to low-calorie diets, the fat composition of the diet may influence skeletal muscle lipid metabolism. That is, in addition to availability of the glycerol backbone [90, 91], long chain unsaturated FAs like oleate should be available in sufficient amounts to build TAG stores [92]. Oleate treatment results in increased LD size and recruits PLIN2 to the LDs [92]. Hence, oleate increases neutral lipid storage and TAG synthesis. The coincubation of muscle cells with oleate and palmitate increases the channeling of the saturated FA palmitate towards storage in the form of TAG thereby rescuing the palmitate-induced lipotoxicity [93-96]. Interestingly, the differential effects of oleate and palmitate on PLIN2 expression in C2C12 myotubes even exceed the difference in TAG accumulation (chapter 5 ) and PLIN2 expression is primarily induced in mouse skeletal muscle upon consumption of a diet rich in monounsaturated fatty acids (Appendix 4). Thus, based on the above and following the general lifestyle guidelines, a combination of exercise and diet composition in addition to the genetic profile determines the muscle neutral lipid storage capacity.

Pharmacological and nutraceutical approaches targeting AMPK, thereby influencing the cellular energy status, offer a third strategy to improve skeletal muscle lipid handling. The thiazolidinediones are insulin-sensitizing drugs serving as agonists for PPAR $\gamma$, but also target AMPK [97]. The thiazolidinedione rosiglitazone was shown to increase lipid accumulation in the form of TAG and to decrease saturation status of FAs in the neutral lipid fraction of mouse skeletal muscle [98]. Yet, rosiglitazone treatment for 8 weeks downregulated PLIN2 and PLIN5 expression in human skeletal muscle [31]. In contrast, a 3-month treatment period with troglitazone, another thiazolidinedione, was shown to increase skeletal muscle PLIN2 protein content in parallel with improvements in insulin sensitivity [84]. PPARy agonists have been used in the treatment of type 2 diabetes, but 
are -except for pioglitazone - currently no longer prescribed because they increase the risk for heart failure [99]. Metformin, another AMPK activator and the primary drug used in the treatment of type 2 diabetes, also increases PLIN2 protein content in skeletal muscle [84] and leads to neutral lipid accumulation in human primary myotubes [100]. Thus, several lifestyle and pharmaceutical approaches have the potential to improve skeletal muscle neutral lipid storage capacity and lipid handling.

\subsection{Conclusions and future perspectives}

Overall, the findings described in this thesis indicate that creating neutral lipid storage capacity protects against obesity-associated insulin resistance. Both PLIN2 and PLIN5 increase neutral lipid storage space without negatively impacting on insulin sensitivity, at least on the short term. Given the beneficial effects of increasing neutral lipid storage capacity in skeletal muscle, further research into nutraceutical and pharmacological strategies to improve PLIN function and LD dynamics is promising with respect to metabolic health.

Several questions arise which may be addressed in future research:

1. We show that promoting intramyocellular neutral lipid content is associated with improved insulin sensitivity. Ultimately, lipid turnover will need to be matched with the increased IMCL storage to ensure continuous storage space for excess lipids. Further mechanistic research should be directed towards characterizing key regulators of intramyocellular lipid storage capacity and lipid turnover. In addition, the question arises whether sufficient provision of phospholipids and LD coat proteins is a limiting factor for neutral lipid storage capacity. Furthermore, future research may elucidate how lipids enter LDs, whether strategies exist to target FA metabolites towards storage in the LD and whether creation of lipid storage space also creates space for inert storage of lipid intermediates.

2. It would be valuable to study intramyocellular LD dynamics in vivo. Technical advances, for instance multiphoton microscopy, may make this possible at least in animal models. LD dynamics could then be studied in situations of increased lipid supply and/or increased energy demand. This would also provide the opportunity to investigate whether LD dynamics are altered in models of obesity and diabetes as compared to healthy and/or trained muscle. For example one may question whether lipid oversupply results in accumulation of LDs with a low turnover rate.

Alternatively, establishing primary human myotubes offers the opportunity to extensively study intramyocellular lipid dynamics from the perspective of the genetic background of the donor (chapter 4). Challenging these myotubes with an energy demand and silencing and overexpression strategies could provide further mechanistic insight into skeletal muscle lipid handling. Furthermore, novel compound testing could provide potential therapeutics improving intramyocellular lipid handling to be validated in vivo. 


\section{General discussion}

3. With regard to PLIN2, it will need to be established what the exact function is of PLIN2 in TAG storage and LD synthesis. We showed that PLIN2 is essential for intramyocellular TAG storage, but it remains unclear whether the presence of PLIN2 on the ER and/or the LD is a prerequisite for TAG and LD synthesis. PLIN2 may interact with enzymes involved in neutral lipid synthesis. On the other hand, TAG may quickly be degraded in the absence of PLIN2. Furthermore, since regulatory factors of PLIN2 expression and stabilization remain unclear, future research may be dedicated to the transcriptional and posttranslational regulation of PLIN2 expression in skeletal muscle. Additionally, we demonstrated that short-term (7 day) increases in PLIN2 abundance were beneficial, although high fat diet-induced induction of oxidative capacity was reduced. It remains to be investigated whether increased PLIN2 abundance is advantageous with respect to intramyocellular lipid handling and insulin sensitivity in the long term.

4. Concerning PLIN5, its intramitochondrial localization and function and interaction partners will need to be examined. This could lead to identification of the function of mitochondrial PLIN5. In addition, the mechanism behind the increased expression levels of PGC1 $\alpha$ target genes deserves further attention. Following up on that aspect, it would be interesting to study PLIN5 function in situations of increased energy demand. PGC1 $\alpha$ was shown to improve skeletal muscle insulin sensitivity in an activity-dependent manner [101]. Subjecting muscle-specific PLIN5 knockout mice to acute exercise and exercise training could point out whether PLIN5 is essential for provision of energy from fat stores and whether PLIN5 plays a vital role in the feedforward mechanism of PGC1 $\alpha$ function in response to training.

5. Interactions between LDs and mitochondria are presumably very important for substrate provision for skeletal muscle oxidative metabolism. Exercise training increases the proportion of LDs in contact with mitochondria [73]. Interestingly, it was shown that LDs and mitochondria appear to share portions of the same membrane [102]. It remains to be investigated how these interactions are regulated and whether membrane fusions are in fact involved. Furthermore, little is known about organelle trafficking and its stimulatory and regulatory factors. Moreover, the question arises whether the interaction between LDs and mitochondria is reversible and acutely regulated by energy demand. 


\section{REFERENCES}

1. Pan DA, Lillioja S, Kriketos AD, Milner MR, Baur LA, Bogardus C, Jenkins AB, and Storlien LH. Skeletal muscle triglyceride levels are inversely related to insulin action. Diabetes 1997; 46: 983-8.

2. Goodpaster BH, He J, Watkins S, and Kelley DE. Skeletal muscle lipid content and insulin resistance: evidence for a paradox in endurance-trained athletes. J Clin Endocrinol Metab 2001; 86: 5755-5761.

3. Flannery C, Dufour S, Rabø| R, Shulman GI, and Petersen KF. Skeletal muscle insulin resistance promotes increased hepatic de novo lipogenesis, hyperlipidemia, and hepatic steatosis in the elderly. Diabetes 2012; 61:2711-2717.

4. Rabø| R, Petersen KF, Dufour S, Flannery C, and Shulman GI. Reversal of muscle insulin resistance with exercise reduces postprandial hepatic de novo lipogenesis in insulin resistant individuals. Proc Natl Acad Sci 2011; 108: 13705-13709.

5. Glatz JFC, Luiken JJFP, and Bonen A. Membrane fatty acid transporters as regulators of lipid metabolism: implications for metabolic disease. Physiol Rev 2010; 90: 367-417.

6. Morino K, Petersen KF, and Shulman GI. Molecular mechanisms of insulin resistance in humans and their potential links with mitochondrial dysfunction. Diabetes 2006; 55: S9-S15.

7. Zehmer JK, Huang Y, Peng G, Pu J, Anderson RG, and Liu P. A role for lipid droplets in inter-membrane lipid traffic. Proteomics 2009; 9:914-921.

8. Fang $\mathrm{Y}$, Vilella-Bach $\mathrm{M}$, Bachmann $\mathrm{R}$, Flanigan $\mathrm{A}$, and Chen J. Phosphatidic acid-mediated mitogenic activation of mTOR signaling. Science 2001; 294: 1942-1945.

9. Haemmerle G, Moustafa T, Woelkart G, Buttner S, Schmidt A, van de Weijer T, Hesselink M, Jaeger D, Kienesberger PC, Zierler K, Schreiber R, Eichmann T, Kolb D, Kotzbeck P, Schweiger M, Kumari M, Eder S, Schoiswohl G, Wongsiriroj N, Pollak NM, Radner FPW, Preiss-Landl K, Kolbe T, Rulicke T, Pieske B, Trauner M, Lass A, Zimmermann R, Hoefler G, Cinti S, Kershaw EE, Schrauwen P, Madeo F, Mayer B, and Zechner R. ATGL-mediated fat catabolism regulates cardiac mitochondrial function via PPAR- $\alpha$ and PGC-1. Nat Med 2011; 17: 1076-1085.

10. Krahmer N, Guo Y, Wilfling F, Hilger M, Lingrell S, Heger K, Newman HW, Schmidt-Supprian M, Vance DE, Mann M, Farese RV Jr, and Walther TC. Phosphatidylcholine synthesis for lipid droplet expansion is mediated by localized activation of CTP:phosphocholine cytidylyltransferase. Cell Metab 2011; 14: 504515.

11. Beller M, Thiel K, Thul PJ, and Jäckle H. Lipid droplets: A dynamic organelle moves into focus. FEBS Lett 2010; 584: 2176-82.

12. Walther TC and Farese Jr. RV. Lipid droplets and cellular lipid metabolism. Ann Rev Biochem 2012; 81:687714.

13. Greenberg AS, Egan JJ, Wek SA, Garty NB, Blanchette-Mackie EJ, and Londos C. Perilipin, a major hormonally regulated adipocyte-specific phosphoprotein associated with the periphery of lipid storage droplets. J Biol Chem 1991; 266: 11341-11346.

14. DiAugustine RP, Schaefer JM, and Fouts JR. Hepatic lipid droplets. Isolation, morphology and composition. Biochem J 1973; 132: 323-7.

15. Nguyen N, Nguyen XM, Lane J, and Wang P. Relationship between obesity and diabetes in a US Adult population: findings from the national health and nutrition examination survey, 1999-2006. Obes Surg 2011; 21: 351-355.

16. Dubé J, Amati F, Toledo F, Stefanovic-Racic M, Rossi A, Coen P, and Goodpaster B. Effects of weight loss and exercise on insulin resistance, and intramyocellular triacylglycerol, diacylglycerol and ceramide. Diabetologia 2011; 54: 1147-1156.

17. Van Loon LIC and Goodpaster B. Increased intramuscular lipid storage in the insulin-resistant and endurance-trained state. Pflügers Arch 2006; 451: 606-616.

18. Bergman BC, Perreault L, Hunerdosse DM, Koehler MC, Samek AM, and Eckel RH. Increased intramuscular lipid synthesis and low saturation relate to insulin sensitivity in endurance-trained athletes. J Appl Physiol 2010; 108: 1134-1141. 


\section{General discussion}

19. Schenk S and Horowitz JF. Acute exercise increases triglyceride synthesis in skeletal muscle and prevents fatty acid-(0)induced insulin resistance. J Clin Invest 2007; 117: 1690-1698.

20. Brown JM, Betters JL, Lord C, Ma Y, Han X, Yang K, Alger HM, Melchior J, Sawyer J, Shah R, Wilson MD, Liu X, Graham MJ, Lee R, Crooke R, Shulman GI, Xue B, Shi H, and Yu L. CGI-58 knockdown in mice causes hepatic steatosis but prevents diet-induced obesity and glucose intolerance. J Lipid Res 2010; 51: 33063315.

21. Kumashiro N, Erion DM, Zhang D, Kahn M, Beddow SA, Chu X, Still CD, Gerhard GS, Han X, Dziura J, Petersen KF, Samuel VT, and Shulman GI. Cellular mechanism of insulin resistance in nonalcoholic fatty liver disease. Proc Natl Acad Sci 2011; 108: 16381-16385.

22. Bergman B, Hunerdosse D, Kerege A, Playdon M, and Perreault L. Localisation and composition of skeletal muscle diacylglycerol predicts insulin resistance in humans. Diabetologia 2012; 55:1140-1150.

23. Amati F, Dube JJ, Alvarez-Carnero E, Edreira MM, Chomentowski P, Coen PM, Switzer GE, Bickel PE, Stefanovic-Racic M, Toledo FGS, and Goodpaster BH. Skeletal muscle triglycerides, diacylglycerols, and ceramides in insulin resistance: another paradox in endurance-trained athletes? Diabetes 2011; 60: 25882597.

24. Eichmann TO, Kumari M, Haas JT, Farese RV, Zimmermann R, Lass A, and Zechner R. Studies on the substrate and stereo/regioselectivity of adipose triglyceride lipase, hormone-sensitive lipase, and diacylglycerol-O-acyltransferases. J Biol Chem 2012.

25. Farese Robert V, Zechner R, Newgard Christopher B, and Walther Tobias C. The problem of establishing relationships between hepatic steatosis and hepatic insulin resistance. Cell Metab 2012; 15: 570-573.

26. Faergeman NJ and Knudsen J. Role of long-chain fatty acyl-CoA esters in the regulation of metabolism and in cell signalling. Biochem J 1997; 323:1-12.

27. Gibellini F and Smith TK. The Kennedy pathway-De novo synthesis of phosphatidylethanolamine and phosphatidylcholine. IUBMB Life 2010; 62: 414-428.

28. Grösch S, Schiffmann S, and Geisslinger G. Chain length-specific properties of ceramides. Prog Lipid Res 2012; 51: 50-62.

29. van Blitterswijk WJ and Houssa B. Properties and functions of diacylglycerol kinases. Cell Signal 2000; 12: 595-605.

30. Zhang H, Wang Y, Li J, Yu J, Pu J, Li L, Zhang H, Zhang S, Peng G, Yang F, and Liu P. Proteome of skeletal muscle lipid droplet reveals association with mitochondria and apolipoprotein A-I. J Proteome Res 2011; 10: 4757-4768.

31. Minnaard R, Schrauwen P, Schaart G, Jorgensen JA, Lenaers E, Mensink M, and Hesselink MKC. Adipocyte differentiation-related protein and OXPAT in rat and human skeletal muscle: involvement in lipid accumulation and type 2 diabetes mellitus. J Clin Endocrinol Metab 2009; 94: 4077-85.

32. Shaw $C$, Sherlock $M$, Stewart $P$, and Wagenmakers $A$. Adipophilin distribution and colocalisation with lipid droplets in skeletal muscle. Histochem Cell Biol 2009; 131: 575-581.

33. Shaw CS, Shepherd SO, Wagenmakers AJM, Hansen D, Dendale P, and van Loon LJC. Prolonged exercise training increases intramuscular lipid content and perilipin 2 expression in type I muscle fibres of patients with type 2 diabetes. Am J Physiol Endocrinol Metab 2012.

34. Shepherd SO, Cocks M, Tipton KD, Ranasinghe AM, Barker TA, Burniston JG, Wagenmakers AJM, and Shaw CS. Preferential utilisation of perilipin 2 associated intramuscular triglycerides during one hour of moderate intensity endurance-type exercise. Exp Physiol 2012; 97:970-980.

35. Shepherd SO, Cocks M, Tipton KD, Ranasinghe AM, Barker TA, Burniston JG, Wagenmakers AJM, and Shaw CS. Sprint interval and traditional endurance training increase net intramuscular triglyceride breakdown and expression of perilipin 2 and 5. J Physiol, in press; doi:10.1113/jphysiol.2012.240952.

36. Heid HW, Moll R, Schwetlick I, Rackwitz H-R, and Keenan TW. Adipophilin is a specific marker of lipid accumulation in diverse cell types and diseases. Cell Tissue Res 1998; 294: 309-321.

37. Jiang HP and Serrero G. Isolation and characterization of a full-length cDNA coding for an adipose differentiation-related protein. Proc Natl Acad Sci 1992; 89: 7856-7860.

38. Dalen KT, Dahl T, Holter E, Arntsen B, Londos C, Sztalryd C, and Nebb HI. LSDP5 is a PAT protein specifically expressed in fatty acid oxidizing tissues. Biochim Biophys Acta 2007; 1771: 210-27. 
39. Wolins NE, Quaynor BK, Skinner JR, Tzekov A, Croce MA, Gropler MC, Varma V, Yao-Borengasser A, Rasouli $\mathrm{N}$, Kern PA, Finck BN, and Bickel PE. OXPAT/PAT-1 is a PPAR-induced lipid droplet protein that promotes fatty acid utilization. Diabetes 2006; 55: 3418-28.

40. Grasselli E, Voci A, Pesce C, Canesi L, Fugassa E, Gallo G, and Vergani L. PAT protein mRNA expression in primary rat hepatocytes: effects of exposure to fatty acids. Int J Mol Med 2010; 25: 505-12.

41. Fan B, Ikuyama S, Gu J-QIU, Wei P, Oyama J-i, Inoguchi T, and Nishimura J. Oleic acid-induced ADRP expression requires both AP-1 and PPAR-response elements, and is reduced by Pycnogenol through mRNA degradation in NMuLi liver cells. Am J Physiol Endocrinol Metab 2009; 297: E112-23.

42. Gao J and Serrero HYG. Stimulation of adipose differentiation related protein (ADRP) expression in adipocyte precursors by long-chain fatty acids. Journal of Cellular Physiology 2000; 182: 297-302.

43. Dalen KT, Ulven SM, Arntsen BM, Solaas K, and Nebb HI. PPARalpha activators and fasting induce the expression of adipose differentiation-related protein in liver. J Lipid Res 2006; 47: 931-43.

44. Yamaguchi T, Matsushita S, Motojima K, Hirose F, and Osumi T. MLDP, a novel PAT family protein localized to lipid droplets and enriched in the heart, is regulated by peroxisome proliferator-activated receptor $\alpha$. J Biol Chem 2006; 281: 14232-40.

45. Targett-Adams P, McElwee MJ, Ehrenborg E, Gustafsson MC, Palmer CN, and McLauchlan J. A PPAR response element regulates transcription of the gene for human adipose differentiation-related protein. Biochim Biophys Acta 2005; 1728: 95-104.

46. Wei P, Taniguchi S, Sakai Y, Imamura M, Inoguchi T, Nawata H, Oda S, Nakabeppu Y, Nishimura J, and Ikuyama S. Expression of Adipose Differentiation-Related Protein (ADRP) Is Conjointly Regulated by PU.1 and AP-1 in Macrophages. J Biochem 2005; 138: 399-412.

47. Bell M, Wang H, Chen H, McLenithan JC, Gong D-W, Yang R-Z, Yu D, Fried SK, Quon MJ, Londos C, and Sztalryd C. Consequences of lipid droplet coat protein downregulation in liver cells: abnormal lipid droplet metabolism and induction of insulin resistance. Diabetes 2008; 57: 2037-2045.

48. Chang BH, Li L, Paul A, Taniguchi S, Nannegari V, Heird WC, and Chan L. Protection against fatty liver but normal adipogenesis in mice lacking adipose differentiation-related protein. Mol Cell Biol 2006; 26: 106376.

49. Imai Y, Varela GM, Jackson MB, Graham MJ, Crooke RM, and Ahima RS. Reduction of hepatosteatosis and lipid levels by an adipose differentiation-related protein antisense oligonucleotide. Gastroenterology 2007; 132: 1947-54.

50. Imamura M, Inoguchi T, Ikuyama S, Taniguchi S, Kobayashi K, Nakashima N, and Nawata H. ADRP stimulates lipid accumulation and lipid droplet formation in murine fibroblasts. Am J Physiol Endocrinol Metab 2002; 283: E775-783.

51. Faleck D, Ali K, Roat R, Graham MJ, Crooke RM, Battisti R, Garcia E, Ahima RS, and imai Y. Adipose differentiation-related protein regulates lipids and insulin in pancreatic islet. Am J Physiol Endocrinol Metab 2010; 299: E249-E257.

52. Fukushima M, Enjoji M, Kohjima M, Sugimoto R, Ohta S, Kotoh K, Kuniyoshi M, Kobayashi K, Imamura M, Inoguchi T, Nakamuta $M$, and Nawata $H$. Adipose differentiation related protein induces lipid accumulation and lipid droplet formation in hepatic stellate cells. In Vitro Cell Dev Biol Anim 2005; 41: 321324.

53. Sun Z, Miller RA, Patel RT, Chen J, Dhir R, Wang H, Zhang D, Graham MJ, Unterman TG, Shulman GI, Sztalryd C, Bennett MJ, Ahima RS, Birnbaum MJ, and Lazar MA. Hepatic Hdac3 promotes gluconeogenesis by repressing lipid synthesis and sequestration. Nat Med 2012; 18:934-942.

54. Robenek H, Hofnagel O, Buers I, Robenek MJ, Troyer D, and Severs NJ. Adipophilin-enriched domains in the ER membrane are sites of lipid droplet biogenesis. J Cell Sci 2006; 119: 4215-4224.

55. McIntosh AL, Senthivinayagam S, Moon KC, Gupta S, Lwande JS, Murphy CC, Storey SM, and Atshaves BP. Direct interaction of Plin2 with lipids on the surface of lipid droplets: A live cell FRET analysis. Am J Physiol Cell Physiol 2012.

56. Gao J and Serrero G. Adipose differentiation related protein (ADRP) expressed in transfected COS-7 cells selectively stimulates long chain fatty acid uptake. J Biol Chem 1999; 274: 16825-16830. 


\section{General discussion}

57. Listenberger LL, Ostermeyer-Fay AG, Goldberg EB, Brown WJ, and Brown DA. Adipocyte differentiationrelated protein reduces the lipid droplet association of adipose triglyceride lipase and slows triacylglycerol turnover. J Lipid Res 2007; 48: 2751-2761.

58. Sapiro JM, Mashek MT, Greenberg AS, and Mashek DG. Hepatic triacylglycerol hydrolysis regulates PPAR- $\alpha$ activity. J Lipid Res 2009; 50: 1621-9.

59. Wang H, Bell M, Sreenevasan U, Hu H, Liu J, Dalen K, Londos C, Yamaguchi T, Rizzo MA, Coleman R, Gong D, Brasaemle D, and Sztalryd C. Unique regulation of adipose triglyceride lipase (ATGL) by perilipin 5, a lipid droplet-associated protein. J Biol Chem 2011; 286: 15707-15.

60. Yamaguchi T, Omatsu N, Omukae A, and Osumi T. Analysis of interaction partners for perilipin and ADRP on lipid droplets. Mol Cell Biochem 2006; 284: 167-173.

61. Wang H, Hu L, Dalen K, Dorward H, Marcinkiewicz A, Russel D, Gong D, Londos C, Yamaguchi T, Holm C, Rizzo MA, Brasaemle D, and Sztalryd C. Activation of hormone-sensitive lipase requires two steps: protein phosphorylation and binding to the PAT-1 domain of lipid droplet coat proteins. J Biol Chem 2009; M109.006726.

62. Prats C, Donsmark M, Qvortrup K, Londos C, Sztalryd C, Holm C, Galbo H, and Ploug T. Decrease in intramuscular lipid droplets and translocation of HSL in response to muscle contraction and epinephrine. J Lipid Res 2006; 47: 2392-9.

63. Li H, Song Y, Zhang L, Gu Y, Li FF, Pan SY, Jiang LN, Liu F, Ye J, and Li Q. LSDP5 enhances triglyceride storage in hepatocytes by influencing lipolysis and fatty acid $\beta$-oxidation of lipid droplets. PLoS ONE 2012; 7: e36712.

64. Granneman JG, Moore HPH, Mottillo EP, Zhu Z, and Zhou L. Interactions of perilipin-5 (PLIN5) with adipose trigylceride lipase (ATGL). J Biol Chem 2011; 286: 5126-5135.

65. Kuramoto K, Okamura T, Yamaguchi T, Nakamura TY, Wakabayashi S, Morinaga H, Nomura M, Yanase T, Otsu K, Usuda N, Matsumura S, Inoue K, Fushiki T, Kojima Y, Hashimoto T, Sakai F, Hirose F, and Osumi T. Perilipin 5, a lipid droplet-binding protein, protects the heart from oxidative burden by sequestering fatty acid from excessive oxidation. J Biol Chem 2012; 287: 23852-63.

66. Granneman JG, Moore HPH, Krishnamoorthy R, and Rathod M. Perilipin controls lipolysis by regulating the interactions of AB-hydrolase containing 5 (Abhd5) and adipose triglyceride lipase (Atgl). J Biol Chem 2009; 284: 34538-34544.

67. Wang H, Sreenevasan U, Hu H, Saladino A, Polster BM, Lund LM, Gong DW, Stanley WC, and Sztalryd C. Perilipin 5, a lipid droplet associated protein, provides physical and metabolic linkage to mitochondria. J Lipid Res 2011; 52: 2159-2168.

68. Espinoza DO, Boros LG, Crunkhorn S, Gami H, and Patti ME. Dual modulation of both lipid oxidation and synthesis by peroxisome proliferator-activated receptor- $\gamma$ coactivator- $1 \alpha$ and $-1 \beta$ in cultured myotubes. FASEB J 2010; 24: 1003-1014.

69. Mormeneo E, Jimenez-Mallebrera C, Palomer X, De Nigris V, Vázquez-Carrera M, Orozco A, Nascimento A, Colomer J, Lerín C, and Gómez-Foix AM. PGC-1 $\alpha$ induces mitochondrial and myokine transcriptional programs and lipid droplet and glycogen accumulation in cultured human skeletal muscle cells. PLoS ONE 2012; 7: e29985.

70. Summermatter S, Baum O, Santos G, Hoppeler H, and Handschin C. Peroxisome proliferator-activated receptor $y$ coactivator $1 \alpha(\mathrm{PGC}-1 \alpha)$ promotes skeletal muscle lipid refueling in vivo by activating de novo lipogenesis and the pentose phosphate pathway. J Biol Chem 2010; 285: 32793-32800.

71. Koves TR, Sparks LM, Kovalik JP, Mosedale M, Arumugam R, Debalsi KL, Everingham K, Thorne L, Phielix E, Meex RC, Kien CL, Hesselink M, Schrauwen P, and Muoio D. PPAR $\gamma$ coactivator- $1 \alpha$ contributes to exerciseinduced regulation of intramuscular lipid droplet programming in mice and humans. J Lipid Res 2012, in press; doi: 10.1194/jlr.P028910.

72. Stein $O$ and Stein Y. Lipid synthesis, intracellular transport, and storage: III. Electron microscopic radioautographic study of the rat heart perfused with tritiated oleic acid. J Cell Biol 1968; 36: 63-77.

73. Hoppeler $\mathrm{H}$, Luthi $\mathrm{P}$, Claassen $\mathrm{H}$, Weibel ER, and Howald $\mathrm{H}$. The ultrastructure of the normal human skeletal muscle. A morphometric analysis on untrained men, women and well-trained orienteers. Pflugers Arch 1973; 344: 217-32.

74. Brasaemle DL, Dolios G, Shapiro L, and Wang R. Proteomic analysis of proteins associated with lipid droplets of basal and lipolytically stimulated 3T3-L1 adipocytes. J Biol Chem 2004; 279: 46835-46842. 
75. Tarnopolsky MA, Rennie CD, Robertshaw HA, Fedak-Tarnopolsky SN, Devries MC, and Hamadeh MJ. Influence of endurance exercise training and sex on intramyocellular lipid and mitochondrial ultrastructure, substrate use, and mitochondrial enzyme activity. Am J Physiol Regul Integr Comp Physiol 2007; 292: R1271-1278.

76. Crane JD, Devries MC, Safdar A, Hamadeh MJ, and Tarnopolsky MA. The effect of aging on human skeletal muscle mitochondrial and intramyocellular lipid ultrastructure. J Gerontol A Biol Sci Med Sci 2010; 65A: 119-128.

77. Peters SJ, Samjoo IA, Devries MC, Stevic I, Robertshaw HA, and Tarnopolsky MA. Perilipin family (PLIN) proteins in human skeletal muscle: the effect of sex, obesity, and endurance training. Appl Physiol Nutr Metab 2012; 724-735.

78. Moro C, Bajpeyi S, and Smith SR. Determinants of intramyocellular triglyceride turnover: implications for insulin sensitivity. Am J Physiol Endocrinol Metab 2008; 294: E203-13.

79. Hoeks $J$ and Schrauwen P. Muscle mitochondria and insulin resistance: a human perspective. Trends Endocrinol Metab 2012; 23: 444-450.

80. Benton CR, Nickerson JG, Lally J, Han XX, Holloway GP, Glatz JFC, Luiken JJFP, Graham TE, Heikkila JJ, and Bonen A. Modest PGC-1 $\alpha$ overexpression in muscle in vivo is sufficient to increase insulin sensitivity and palmitate oxidation in subsarcolemmal, not intermyofibrillar, mitochondria. J Biol Chem 2008; 283: 42284240 .

81. Timmers S, Konings E, Bilet L, Houtkooper Riekelt H, van de Weijer T, Goossens Gijs H, Hoeks J, van der Krieken S, Ryu D, Kersten S, Moonen-Kornips E, Hesselink Matthijs KC, Kunz I, SchrauwenHinderling Vera B, Blaak EE, Auwerx J, and Schrauwen P. Calorie restriction-like effects of 30 days of resveratrol supplementation on energy metabolism and metabolic profile in obese humans. Cell Metab 2011; 14: 612-622.

82. Toledo FGS, Menshikova EV, Azuma K, Radiková Z, Kelley CA, Ritov VB, and Kelley DE. Mitochondrial capacity in skeletal muscle is not stimulated by weight loss despite increases in insulin action and decreases in intramyocellular lipid content. Diabetes 2008; 57: 987-994.

83. Wu Z, Puigserver P, Andersson U, Zhang C, Adelmant G, Mootha V, Troy A, Cinti S, Lowell B, Scarpulla RC, and Spiegelman BM. Mechanisms controlling mitochondrial biogenesis and respiration through the thermogenic coactivator PGC-1. Cell 1999; 98: 115-124.

84. Phillips SA, Choe CC, Ciaraldi TP, Greenberg AS, Kong AP, Baxi SC, Christiansen L, Mudaliar SR, and Henry RR. Adipocyte differentiation-related protein in human skeletal muscle: relationship to insulin sensitivity. Obes Res 2005; 13: 1321-9.

85. Coen PM, Dubé JJ, Amati F, Stefanovic-Racic M, Ferrell RE, Toledo FGS, and Goodpaster BH. Insulin resistance is associated with higher intramyocellular triglycerides in type I but not type II myocytes concomitant with higher ceramide content. Diabetes 2009; 59: 80-8.

86. Gjelstad IMF, Haugen F, Gulseth HL, Norheim F, Jans A, Bakke SS, Raastad T, Tjønna AE, Wisløff U, Blaak EE, Risérus U, Gaster M, Roche HM, Birkeland KI, and Drevon CA. Expression of perilipins in human skeletal muscle in vitro and in vivo in relation to diet, exercise and energy balance. Arch Physiol Biochem 2012; 118: 22-30.

87. Vermathen P, Saillen P, Boss A, Zehnder M, and Boesch C. Skeletal muscle $1 \mathrm{H}$ MRSI before and after prolonged exercise. I. muscle specific depletion of intramyocellular lipids. Magnetic Resonance in Medicine 2012; 68: 1357-1367.

88. Hurley BF, Nemeth PM, Martin WH, Hagberg JM, Dalsky GP, and Holloszy JO. Muscle triglyceride utilization during exercise: effect of training. J Appl Physiol 1986; 60: 562-567.

89. Petersen KF, Dufour S, Morino K, Yoo PS, Cline GW, and Shulman GI. Reversal of muscle insulin resistance by weight reduction in young, lean, insulin-resistant offspring of parents with type 2 diabetes. Proc Natl Acad Sci 2012; 109: 8236-8240.

90. Hakimi P, Yang J, Casadesus G, Massillon D, Tolentino-Silva F, Nye CK, Cabrera ME, Hagen DR, Utter CB, Baghdy Y, Johnson DH, Wilson DL, Kirwan JP, Kalhan SC, and Hanson RW. Overexpression of the cytosolic form of phosphoenolpyruvate carboxykinase (GTP) in skeletal muscle repatterns energy metabolism in the mouse. J Biol Chem 2007; 282: 32844-32855.

91. Miranda DA, Koves TR, Gross DA, Chadt A, Al-Hasani H, Cline GW, Schwartz GJ, Muoio DM, and Silver DL. Re-patterning of skeletal muscle energy metabolism by Fat storage-Inducing Transmembrane protein 2. J Biol Chem 2011; 286.

92. Peng G, Li L, Liu Y, Pu J, Zhang S, Yu J, Zhao J, and Liu P. Oleate blocks palmitate-induced abnormal lipid distribution, endoplasmic reticulum expansion and stress, and insulin resistance in skeletal muscle. Endocrinology 2011; 152: 2206-2218. 


\section{General discussion}

93. Coll T, Eyre E, Rodriguez-Calvo R, Palomer X, Sanchez RM, Merlos M, Laguna JC, and Vazquez-Carrera M. Oleate reverses palmitate-induced insulin resistance and inflammation in skeletal muscle cells. J Biol Chem 2008; 283: 11107-16.

94. Montell E, Turini M, Marotta M, Roberts M, Noe V, Ciudad CJ, Mace K, and Gomez-Foix AM. DAG accumulation from saturated fatty acids desensitizes insulin stimulation of glucose uptake in muscle cells. Am J Physiol Endocrinol Metab 2001; 280: E229-37.

95. Sabin MA, Stewart CE, Crowne EC, Turner SJ, Hunt LP, Welsh GI, Grohmann MJ, Holly JM, and Shield JP. Fatty acid-induced defects in insulin signalling, in myotubes derived from children, are related to ceramide production from palmitate rather than the accumulation of intramyocellular lipid. J Cell Physiol 2007; 211: 244-252.

96. Yuzefovych L, Wilson G, and Rachek L. Different effects of oleate vs. palmitate on mitochondrial function, apoptosis, and insulin signaling in L6 skeletal muscle cells: role of oxidative stress. Am J Physiol Endocrinol Metab 2010; 299: E1096-E1105.

97. LeBrasseur NK, Kelly M, Tsao T-S, Farmer SR, Saha AK, Ruderman NB, and Tomas E. Thiazolidinediones can rapidly activate AMP-activated protein kinase in mammalian tissues. Am J Physiol Endocrinol Metab 2006; 291: E175-E181.

98. Chabowski A, Żendzian-Piotrowska M, Nawrocki A, and Górski J. Not only accumulation, but also saturation status of intramuscular lipids is significantly affected by PPARY activation. Acta Physiol 2012; 205: 145-158.

99. Nissen SE and Wolski K. Effect of rosiglitazone on the risk of myocardial infarction and death from cardiovascular causes. N Engl J Med 2007; 356: 2457-2471.

100. Kitzmann M, Lantier L, Hébrard S, Mercier J, Foretz M, and Aguer C. Abnormal metabolism flexibility in response to high palmitate concentrations in myotubes derived from obese type 2 diabetic patients. Biochim Biophys Acta 2011; 1812: 423-430.

101. Summermatter S, Shui G, Maag D, Santos G, Wenk MR, and Handschin C. PGC-1 $\alpha$ improves glucose homeostasis in skeletal muscle in an activity-dependent manner. Diabetes 2012; 62:85-95.

102. Pu J, Ha C, Zhang S, Jung J, Huh WK, and Liu P. Interactomic study on interaction between lipid droplets and mitochondria. Protein Cell 2011; 2: 487-496. 
APPENDIX 
A

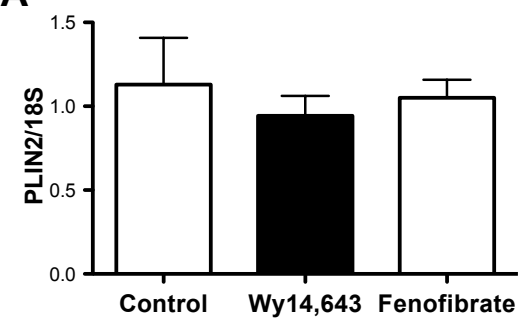

B

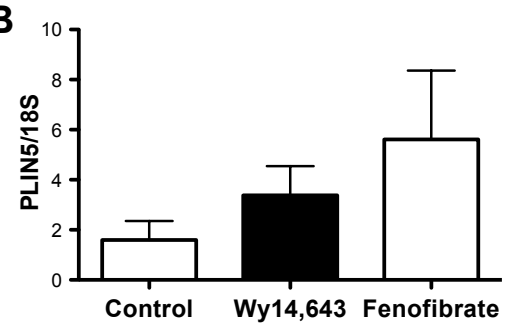

A

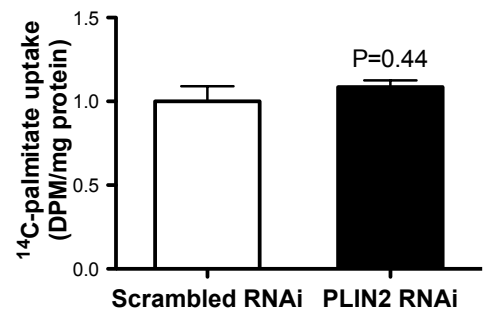

B

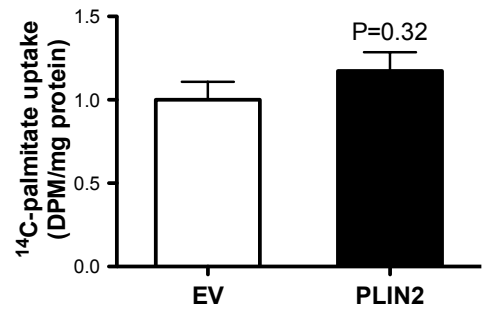

Appendix 1. Effects of an oral gavage of Wy14,643 or fenofibreate (PPAR $\alpha$ agonists). The animals were fasted for 4 hours, followed by the intragastric gavage. WY14,643 and fenofibrate were given as $10 \mathrm{mg} / \mathrm{ml}$ suspension in $0.5 \%$ carboxymethyl cellulose, which also served as control treatment $(400 \mu \mathrm{l})$. The mice were killed 6 hours thereafter.

Appendix 2. (A) ${ }^{14} \mathrm{C}$-palmitate uptake in C2C12 myotubes transfected with scrambled control or PLIN2 RNAi. (B) ${ }^{14} \mathrm{C}$ palmitate uptake in $\mathrm{C} 2 \mathrm{C} 12$ myotubes transfected with empty vector (EV) or PLIN2 plasmid. Mean \pm SEM, $n=3-4$. 


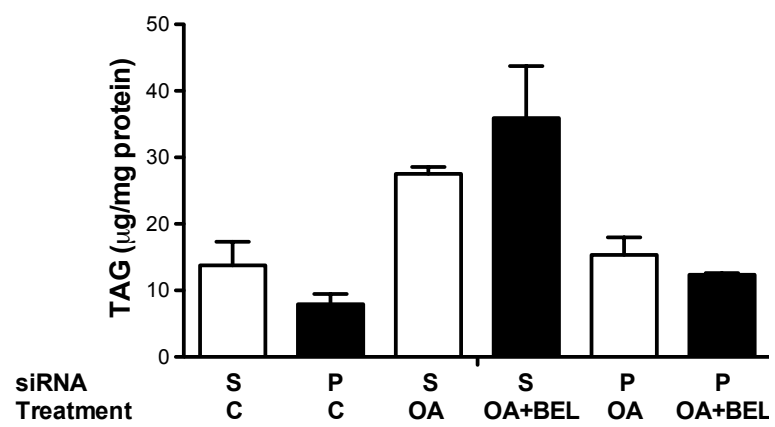

Appendix 3. Inhibition of ATGL by the compound bromoenol lactone (BEL) does not rescue TAG storage in PLIN2knockdown myotubes. S: scrambled siRNA, P: PLIN2 siRNA, OA: oleate (bound to BSA), C: control (BSA).

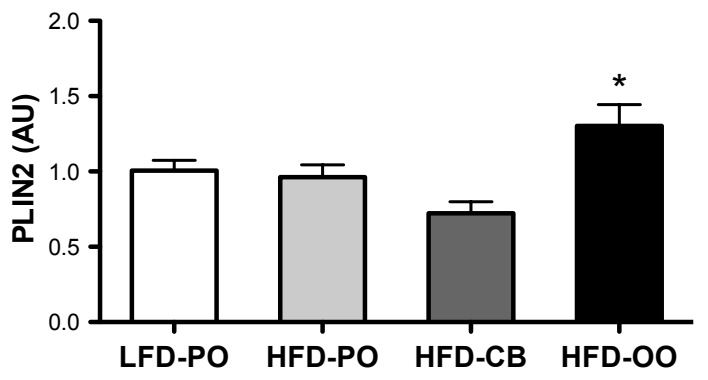

Appendix 4. PLIN2 protein abundance in tibialis anterior muscle of C57BI6 mice fed a low fat diet containing palm oil (LFD$\mathrm{PO}$ ) or one of the high fat diets (HFD) for 8 weeks; PO: palm oil, CB: cacao butter, OO: olive oil. Mean \pm SEM, $\quad * P<0.05$ vs. LFD-PO. 
SUMMARY \& SAMENVATTING 


\section{SUMMARY}

Western style diets, excess calorie intake and low physical activity levels have resulted in a strong increase in the prevalence of obesity. This obesity epidemic is currently affecting more than one in ten of the world's population and the epidemic is still expanding dramatically in adults as well as in children. Obesity is associated with a range of comorbidities. One of the major complications of obesity is impaired glucose tolerance, which may deteriorate towards type 2 diabetes. Impaired glucose tolerance is characterized by insulin resistance - an impaired ability of the hormone insulin to stimulate glucose disposal by skeletal muscle and liver and to inhibit hepatic glucose production - and a reduced secretion of insulin by the pancreas. This reduced glucose tolerance may deteriorate towards type 2 diabetes, which is characterized by $\beta$-cell dysfunction and hyperglycemia, reflecting the disability of the pancreatic $\beta$-cells to compensate for the peripheral insulin resistance. Approximately 90 percent of type 2 diabetics are overweight. Yet, the fact that 'only' approximately 30 percent of obese people have type 2 diabetes indicates that genetic and/or epigenetic predisposition plays an important role in the etiology of obesity-associated insulin resistance and progression towards type 2 diabetes.

The skeletal muscle accounts for more than 80 percent of the postprandial whole body glucose uptake and therefore plays an important role in glucose homeostasis. Skeletal muscle lipid levels - intramyocellular lipids (IMCL) - correlate negatively with insulin sensitivity in a sedentary population and hence were considered predictive for insulin resistance and causative in obesity-associated insulin resistance. However, endurance athletes also have high IMCL levels despite being highly insulin sensitive, which indicates that not the level of IMCL accumulation per se, but rather the characteristics of this intramyocellular fat determine whether it negatively affects insulin signaling.

Upon entrance of the cell, fatty acids can be converted to different types of lipids for storage. Triacylglycerol (TAG) consists of three fatty acids bound to a glycerol molecule and is considered the most neutral and harmless type of intracellular lipid storage. The majority of the IMCL that is stored in muscle cells of endurance-trained athletes consists of TAG. Besides, fatty acids can be converted to lipid intermediates like diacylglycerol (DAG), ceramides and fatty acyl-CoAs. These lipid intermediates can impair insulin signaling, which is referred to as lipid-induced insulin resistance and lipotoxicity. Intramyocellular lipids are mainly stored in lipid droplets, the organelles for fat storage. Initially, these lipid droplets were considered to merely serve as fat depots, but since the discovery in the nineties of proteins in the lipid droplet coat that regulate lipid droplet dynamics and lipid metabolism, lipid droplets are seen as highly dynamic organelles that play a very important role in the regulation of intracellular lipid storage and lipid metabolism.

This thesis focuses on two lipid droplet coat proteins: the perilipins (PLINs) 2 and 5 . The perilipin family was the first characterized group of lipid droplet coat proteins, but their 
function is mainly studied in adipose tissue and liver. The general goal of the research presented in this thesis was to investigate the potential role of these lipid droplet coat proteins in the regulation of skeletal muscle lipid metabolism and the protection against lipid-induced insulin resistance by creation of synthesis- and storage capacity for lipids. This thesis project encompasses a series of cell, animal and human studies - as well as a combination of in vivo, ex vivo, and in vitro techniques.

Chapter 2 gives an overview and interpretation of the recent literature on the relationship between intramyocellular lipid storage and insulin resistance. This review focuses on the evidence from human studies, in combination with supporting mechanistic information obtained from cell- and animal studies. Evidently, lipid accumulation in skeletal muscle is an important parameter in the development of obesity-associated type 2 diabetes. Accumulation of the lipid intermediates diacylglycerol, ceramides and fatty acyl-CoAs is associated with insulin resistance. However, the results of the human studies are inconsistent. Moreover, increased levels of these intermediates in skeletal muscle do not necessarily result in insulin resistance. Rather, the results of the array of human studies performed to date indicate that there are different routes towards lipid-induced insulin resistance. Besides augmented synthesis and accumulation of lipid intermediates, probably also the intracellular localization - in lipid droplets or in/near membranes - and lipid metabolism (lipid turnover) are of importance.

Increased lipid supply to muscle is considered to be one of the explanations for the increased intramyocellular lipid storage in obese individuals. Storage of lipids in lipid droplets may prevent that lipid intermediates interfere with the insulin signaling cascade in/near the cell membranes. The capacity for lipid storage in intramyocellular lipid droplets and the abundance of lipid droplet coat proteins may therefore determine interindividual variation in sensitivity for the development of insulin resistance in situations of increased lipid supply. Fasting and consumption of a high fat diet are two human models for increased fatty acid supply to the muscle. In chapter $\mathbf{3}$ the effects of fasting for 60 hours and consumption of a high fat diet for three weeks on intramyocellular lipid accumulation, insulin sensitivity and the expression of lipid droplet coat proteins are discussed. Fasting resulted in a pronounced increase in plasma free fatty acid levels, intramyocellular lipid accumulation and insulin resistance. However, a larger increase in lipid storage in intramyocellular lipid droplets upon fasting was associated with a lower reduction in insulin sensitivity. This phenomenon was not apparent in the high fat diet intervention, which indicates that the protective role of lipid storage capacity in lipid droplets is specifically of importance under acute conditions of high lipid supply. PLIN2 and PLIN5 levels were not increased after fasting, in contrast to animal studies. In both interventions, PLIN2 levels correlated positively with intramyocellular lipid content in lipid droplets.

Increased fatty acid uptake, reduced oxidative capacity and disturbances in intramyocellular lipid metabolism have been suggested as explanations for lipotoxicity resulting in insulin resistance. In chapter 4, intramyocellular lipid metabolism was 


\section{Summary}

explored in skeletal muscle of obese individuals with type 2 diabetes compared with BMIand age-matched control subjects. Lipid metabolism was investigated ex vivo in muscle biopsy tissue and in vitro in cultured muscle cells (myotubes). These muscle cells are cultured from satellite cells and therefore mainly represent the genetic profile of the donor. With this study set up we were able to investigate both acquired disturbances in skeletal muscle lipid metabolism as a consequence of lifestyle and diabetes development and genetic differences in lipid metabolism that could potentially explain the susceptibility for type 2 diabetes development. Ex vivo fatty acid oxidation and incorporation of fatty acids into TAG were lower in type 2 diabetics compared with control subjects. In contrast, in vitro fatty acid oxidation was similar in myotubes established from diabetics and controls. Similar to the ex vivo findings, in vitro incorporation of fatty acids into TAG was significantly lower in the type 2 diabetics. Fatty acid uptake was similar in the two groups. These results show that a reduced capacity for storage of fatty acids in the form of TAG is an inherent characteristic of the diabetic muscle cell.

These first chapters indicate that an increased capacity for storage of fatty acids in the form of TAG is associated with higher insulin sensitivity. Lipid droplet coat proteins are involved in the regulation of intracellular lipid storage. Yet, little is known about the role of lipid droplet coat proteins in skeletal muscle. Chapter $\mathbf{5}$ shows that PLIN2 facilitates neutral lipid storage in skeletal muscle. PLIN2 is essential for intramyocellular TAG storage; knockdown of PLIN2 in cultured myotubes by means of siRNA resulted into lower TAG levels, reduced incorporation of fatty acids into TAG and a lower number of lipid droplets. Overexpression of PLIN2 in vitro in cultured myotubes and in vivo in rat tibialis anterior muscle resulted in increased intramyocellular neutral lipid storage while insulin sensitivity was improved. In conclusion, PLIN2 facilitates the storage of potentially toxic fatty acids in the form of neutral TAG hence improving insulin sensitivity.

Chapter 6 describes the subcellular localization of PLIN5. PLIN5 not only localizes to lipid droplets, but also to mitochondria. Skeletal muscle PLIN5 content correlates with markers for oxidative capacity. Unilateral overexpression of PLIN5 overexpression in rat tibialis anterior muscle resulted in increased intramyocellular lipid content and increased fatty acid oxidation. Chapter 7 builds on the previous chapter and further identifies effects of PLIN5 overexpression - in comparison with effects of PLIN2 - on skeletal muscle lipid accumulation, insulin sensitivity and gene expression profiles. Both PLIN2 and PLIN5 overexpression resulted in increased neutral intramyocellular lipid content without negatively impacting on insulin sensitivity. Interestingly, as opposed to the effects of PLIN2 overexpression, overexpression of PLIN5 promoted expression of a cluster of genes under control of PPAR $\alpha$ and PGC1 $\alpha$ involved in fatty acid catabolism and mitochondrial oxidation. This suggests a role for PLIN5, either directly or indirectly, in mediating skeletal muscle oxidative gene expression.

Insulin-sensitizing strategies may involve adaptations in intramyocellular lipid droplet dynamics. In chapter $\mathbf{8}$ the effects of an endurance training program on intramyocellular lipid storage and PLIN protein expression are described. Eighteen male type 2 diabetics and twenty BMI- and age-matched normoglycemic controls exercise-trained for 12 weeks. 
Intramyocellular lipid content was modestly increased after the training period, while the skeletal muscle protein content of PLIN2 and PLIN5 was doubled.

In conclusion, the findings described in this thesis indicate that creating intramyocellular neutral lipid storage capacity protects against obesity-associated insulin resistance in skeletal muscle. Both PLIN2 and PLIN5 increase intramyocellular neutral lipid storage space without negatively impacting on insulin sensitivity, at least on the short term. Given the beneficial effects of increasing neutral lipid storage capacity in skeletal muscle, further research into nutraceutical and pharmacological strategies to improve PLIN function and LD dynamics is promising with respect to metabolic health. 


\section{SAMENVATTING}

Het veranderde voedingspatroon, overmatige calorie-inname en de verminderde fysieke activiteit hebben de afgelopen decennia geresulteerd in een sterke toename in de prevalentie van obesitas. Momenteel leidt een op de tien volwassenen wereldwijd aan obesitas en deze epidemie is nog altijd exponentieel aan het toenemen. Obesitas is geassocieerd met een scala aan comorbiditeiten, waaronder type 2 diabetes.

Een verminderde glucosetolerantie is een voorstadium van type 2 diabetes en wordt gekenmerkt door insulineresistentie; een verminderde gevoeligheid van weefsels voor het hormoon insuline - insuline faciliteert de opname van glucose in de perifere weefsels waaronder de spier en remt de glucose productie in de lever - en een verlaagde secretie van insuline door de pancreas. Deze verminderde glucose tolerantie kan zich uiteindelijk ontwikkelen richting type 2 diabetes, wat gekenmerkt wordt door verhoogde glucose niveaus in het bloed doordat het lichaam de glucosespiegels niet meer voldoende kan reguleren. Ongeveer 90 procent van de type 2 diabetes patiënten heeft overgewicht. Echter, 'slechts' 30 procent van de personen die lijden aan obesitas heeft type 2 diabetes, wat impliceert dat genetische aanleg zeer waarschijnlijk een rol speelt bij de ontwikkeling van type 2 diabetes.

De skeletspieren zijn verantwoordelijk voor 80 procent van de postprandiale glucose opname in het lichaam en spelen daarom een belangrijke rol bij de glucosehuishouding. Vetstapeling in de spier wordt in verband gebracht met de ontwikkeling van insulineresistentie. Obesitas gaat gepaard met vetstapeling in de spier als gevolg van verhoogde vetzuurniveaus in de bloedbaan en een verminderde vetopslagcapaciteit in het vetweefsel. Echter, ook duurgetrainde atleten hebben een grote mate van vetopslag in de spieren, terwijl atleten juist zeer insulinegevoelig zijn, wat suggereert dat niet de mate van vetstapeling, maar de eigenschappen van dit vet bepalen of het de insulinesignalering hindert.

Vetzuren kunnen in de cel worden opgeslagen in verschillende vormen. Triacylglycerol (TAG) bestaat uit een glycerol molecuul met daaraan 3 vetzuren gebonden en wordt beschouwd als de meest neutrale en onschadelijke vorm van intracellulaire vetopslag. De spiercellen van duurgetrainde atleten bevatten veel TAG. Daarnaast kunnen vetzuren omgezet worden in onder andere diacylglycerol (DAG), ceramiden en vetzuurCoAs, de zogeheten lipidintermediairen. Deze lipidintermediaren kunnen de insulinesignalering negatief beïnvloeden, wat omschreven wordt als lipid-geïnduceerde insulineresistentie en lipotoxiciteit. Vetten (lipiden) in de spiercel zijn voor het merendeel opgeslagen in lipidendruppels, de organellen voor vetopslag. Initieel werd aangenomen dat deze lipidendruppels enkel dienen als vetdepots, maar sinds de ontdekking in de jaren '90 van eiwitten op de lipidendruppel die de dynamiek van lipidendruppels en het vetmetabolisme reguleren, worden deze lipidendruppels gezien als dynamische organellen die een zeer belangrijke rol spelen in de regulatie van vetopslag en vetmetabolisme. 
In dit proefschrift is staan twee lipidendruppel-eiwitten centraal: de perilipines (PLIN) 2 en 5. De perilipine familie was de eerste groep eiwitten gekarakteriseerd als lipidendruppeleiwitten, maar de functie van deze eiwitten is tot op heden voornamelijk bestudeerd in vetweefsel en lever. De algemene doelstelling van het onderzoek beschreven in dit proefschrift was het inventariseren van de potentiële rol van deze lipidendruppel-eiwitten in de regulatie van het vetmetabolisme in de spier en de bescherming tegen insuline resistentie door middel van het creëren van synthese- en opslagcapaciteit voor lipiden. Dit proefschrift is gebaseerd op een translationele benadering, het is een combinatie van cel, dier- en, humane studies alsmede in vivo, ex vivo en in vitro technieken.

In hoofdstuk 2 wordt een overzicht en interpretatie van de recente literatuur op het gebied van de relatie tussen vetstapeling in de spier en insulineresistentie gegeven. Hierin staan de resultaten van humane studies centraal, maar ook de voorgestelde mechanismen ter verklaring van de relatie tussen vetstapeling in de spier en insulineresistentie worden besproken aan de hand van de uitkomsten van cel- en dierstudies. Het is evident dat vetstapeling in de spier een belangrijke factor is in het ontstaan van obesitasgeassocieerde type 2 diabetes. Stapeling van lipidintermediairen zoals diacylglycerol, ceramiden en vetzuur-CoAs wordt in verband gebracht met insulineresistentie. Echter, de resultaten van de humane studies geven geen consistent beeld. Bovendien leiden verhoogde concentraties van deze intermediairen in de skeletspier niet noodzakelijk tot insulineresistentie. Er bestaan waarschijnlijk verschillende routes richting lipidgeïnduceerde insulineresistentie. Naast verhoogde vorming en stapeling van lipidintermediairen spelen hoogstwaarschijnlijk ook de intracellulaire lokalisatie van deze intermediairen - in lipidendruppels of in/nabij membranen - en het lipidenmetabolisme (lipidturnover) een rol.

Een verhoogde vet-toevoer naar de spier, door middel van verhoogde lipidenwaarden in het bloed, wordt beschouwd als een van de onderliggende verklaringen voor de toegenomen vetstapeling in de spier bij obesitas. Opslag van lipiden in lipidendruppels zou mogelijk kunnen voorkomen dat lipidenintermediaren de insulinesignaleringscascade in de celmembranen hinderen. De capaciteit voor vetopslag in lipidendruppels in de spier en de mate van aanwezigheid van lipidendruppel-eiwitten zou daarom de interindividuele verschillen in gevoeligheid voor het ontwikkelen van insulineresistentie bij verhoogde vettoevoer kunnen verklaren. Twee modellen voor een verhoogde vettoevoer zijn vasten en een dieet rijk in vet. In hoofdstuk 3 worden de effecten van vasten (60 uur) en consumptie van een dieet rijk in vet gedurende drie weken op vetstapeling in de spier, insulinegevoeligheid en expressieniveaus van lipidendruppeleiwitten besproken. Vasten leidde tot sterk verhoogde vetzuurniveaus in de bloedbaan, vetstapeling in de spier en insulineresistentie. Echter, een grotere toename in de vetstapeling in lipidendruppels na vasten was geassocieerd met een verminderde inductie van insulineresistentie. Dit fenomeen was niet van kracht in de hoog vet-dieet interventie, wat impliceert dat de beschermende rol van de vetstapelingscapaciteit in lipidendruppels met name van kracht is in acute condities van verhoogde vettoevoer. PLIN2 en PLIN5 


\section{Samenvatting}

niveaus waren niet verhoogd na vasten in humaan spierweefsel, in tegenstelling tot de resultaten van dierstudies. In beide studies correleerden PLIN2 niveaus met de hoeveelheid vetstapeling in lipidendruppels.

Een verhoogde vetzuuropname, een verlaagde vet-oxidatieve capaciteit (afbraak van vetten voor energievoorziening) en verstoringen in het lipidenmetabolisme in de spiercel zijn gesuggereerd als verklaringen voor lipotoxiciteit resulterend in insulineresistentie. In hoofdstuk 4 is het lipidenmetabolisme in de spier van obese personen met type 2 diabetes vergeleken met obese controle personen. In deze studie hebben we gekeken naar het lipidenmetabolisme in spierbiopten (ex vivo), maar ook in gekweekte spiercellen (in vitro). Deze spiercellen worden gekweekt vanuit satellietcellen en representeren daarom voornamelijk het genetische profiel van de donor. Met deze studieopzet konden we daarom kijken naar zowel verworven defecten in spier-lipidenmetabolisme als gevolg van de leefstijl en diabetesontwikkeling alsmede genetische verschillen in lipidenmetabolisme die potentieel de aanleg voor de ontwikkeling van obesitasgeassocieerde type 2 diabetes kunnen verklaren. Ex vivo hadden de type 2 diabeten een lagere vetzuur oxidatie en een lagere incorporatie van vetzuren in TAG in het spierweefsel. In vitro echter, was de vetzuur oxidatiecapaciteit gelijk in spiercellen van diabeten en de obese controles, terwijl de incorporatie van vetzuren in TAG zowel ex vivo als in vitro lager was in de groep diabeten. De vetzuuropname was gelijk in de twee groepen. Deze resultaten tonen aan dat een gereduceerde capaciteit voor het opslaan van vetzuren in de vorm van TAG een intrinsiek kenmerk is van de diabete spiercel.

De bovenstaande hoofstukken laten zien dat een verhoogde capaciteit voor opslag van vetten in de vorm van TAG in lipidendruppels geassocieerd is met een hogere insulinegevoeligheid. Lipidendruppel-coatende eiwitten zijn betrokken bij het reguleren van intracellulaire vetopslag. Echter, er is nog weinig bekend over de rol van lipidendruppel-eiwitten in de skeletspier. In hoofdstuk $\mathbf{5}$ is aangetoond dat het lipidendruppel-eiwit PLIN2 neutrale vetopslag in de spier faciliteert. PLIN2 is essentieel voor opslag van TAG in de spiercel; het verminderen van de PLIN2 eiwitniveaus in gekweekte spiercellen door middel van siRNA zorgde voor lagere TAG niveaus, verminderde incorporatie van vetzuren in TAG en een lager aantal lipidendruppels in de spiercellen. Verhogen van de aanwezigheid van PLIN2 in vitro in gekweekte spiercellen en in vivo in rat spier leidde tot verhoogde vetstapeling in de spiercel, terwijl de insulinegevoeligheid was toegenomen. In conclusie, PLIN2 faciliteert de opslag van potentieel toxische vetzuren in de vorm van het neutrale TAG en verbetert daardoor de insulinegevoeligheid.

Hoofdstuk 6 beschrijft de lokalisatie van PLIN5. Naast de aanwezigheid op de lipidendruppel, tonen wij aan dat PLIN5 ook aanwezig is in skeletspier mitochondriën. De hoeveelheid PLIN5 correleerde met markers voor oxidatieve capaciteit. Het verhogen van de aanwezigheid van PLIN5 in de spier door middel van genelectroporatie leidde tot een verhoogde vetstapeling in de spier en een verhoogde vetzuuroxidatie. Hoofdstuk 7 geeft hieraan een vervolg. In dit hoofdstuk worden de effecten van PLIN5 overexpressie - een verhoogde aanwezigheid van PLIN5 in de skeletspier tibialis anterior - vergeleken met de 
effecten van PLIN2 overexpressie op het niveau van stapeling van verschillende typen lipiden, insulinegevoeligheid en genexpressie profielen. Zowel overexpressie van PLIN2 als van PLIN5 verhoogden de stapeling van TAG in de spier en deze verhoogde vetstapeling leidde in beide gevallen niet tot verminderde insulinegevoeligheid. Een interessant contrast was echter, dan PLIN2 leidde tot een verlaagde expressie van genen betrokken bij vetzuuroxidatie, terwijl overexpressie van PLIN5 leidde tot een verhoogde expressie van genen betrokken bij vetzuuroxidatie en mitochondriële functie.

Strategieën ter verbetering van de insulinegevoeligheid, zoals training, zouden hand in hand kunnen gaan met een verbeterd lipidendruppelmetabolisme. In hoofdstuk 8 worden de effecten beschreven van een trainingsprogramma van 12 weken (een combinatie van kracht- en duursport) in obese personen en type 2 diabeten op vetstapeling in de spier en het expressieniveau van een cluster lipidendruppel-eiwitten. De vetopslag in lipidendruppels in de spier was licht verhoogd na de trainingsperiode, terwijl de expressie van PLIN2 en PLIN5 was verdubbeld.

In conclusie, de resultaten van deze serie studies tonen aan dat het creëren van opslagcapaciteit voor neutrale lipiden beschermt tegen obesitas-geassocieerde insuline resistentie in de spier. Een verhoogde aanwezigheid van PLIN2 of PLIN5 leidt tot een verhoogde vetstapeling in lipidendruppels zonder de insulinegevoeligheid van de spier negatief te beïnvloeden. Verder onderzoek naar interventies die de PLIN functie en lipidendruppeldynamiek positief beïnvloeden - zoals farmacologische-, voedings- en bewegingsstrategieën - is daarom veelbelovend in het kader van de preventie en behandeling van type 2 diabetes. 
DANKWOORD 
Hier is 't dan; mijn proefschrift. Ik had mij nooit gerealiseerd hoe zwaar een promotietraject kan zijn. Maar hoe zwaar ook, het eindresultaat is daar en ik kan zeggen dat ik naast wetenschappelijke kennis en ervaring heel veel geleerd heb over mijzelf en mijn omgeving, wat zo'n traject nog waardevoller maakt. De laatste twee jaar duurden lang, maar het enorme plezier in het bedrijven van wetenschap is altijd blijven bestaan. Zonder doorzettingsvermogen had ik dit proefschrift nooit binnen 4 jaar afgerond, maar dat was natuurlijk ook nooit gelukt zonder de hulp van velen. Waarvoor mijn grote dank!

Beste Patrick, Matthijs en Sander, heren professoren, ontzettend bedankt voor de begeleiding van mijn promotietraject! Jullie vormden een promotieteam met een mooie combinatie van expertises. Het was een ontzettend leerzame periode. Ik wil jullie bedanken voor het feit dat ik echt mijn eigen stempel heb kunnen drukken op dit project en dat ik ervaring op heb kunnen doen met vele technieken. Bedankt voor het in mij gestelde vertrouwen; met name in de eerste 2 jaar had ik min of meer de vrije hand om de PLIN experimenten en mijn promotie-traject vorm te geven. Ik heb goede herinneringen aan de meetings met $z^{\prime} n$ vieren, maar ik heb eigenlijk nog meer gehad aan de interacties met elk van jullie. Ik heb het heel waardevol gevonden dat ik zoveel van jullie heb kunnen leren.

Patrick: jij was als eerste begeleider het meest betrokken bij dit project. We zaten regelmatig niet op dezelfde lijn, maar dat leidde dan meestal wel weer tot de juiste compromissen en eigenlijk denk ik ook dat het goed is dat je het in de wetenschap niet altijd eens bent, want juist door die discussies kom je tot nieuwe inzichten en strategieën. Op de momenten dat ik een discussie probeerde te omzeilen door mee te gaan in plaats van er tegenin dan werkte dat ook vaak niet, want acteertalent heb ik niet. Maar het heeft geresulteerd in een mooi project. Bedankt voor alle begeleiding, zowel op het gebied van mijn promotietraject als op carrière vlak!

Matthijs: jouw enthousiasme voor het lipidendruppel-onderzoek was aanstekelijk. wij begrepen elkaar niet altijd, maar ook dat is inzichtelijk geweest. Ik kan me ons tripje naar Steamboat Springs van 2,5 jaar geleden nog goed herinneren, dat is echt een van de hoogtepunten geweest van mijn promotietraject. Die congresweek bood uitdaging en inspiratie. Stiekem vind ik het toch wel een beetje jammer dat ik het lipidendruppelveld ga verlaten (al blijf ik nog wel wat onderzoek doen op dat vlak). Het is een ontzettend leuk en relevant onderzoeksgebied dat nog vele mogelijkheden biedt!

Sander: jij was meer op de achtergrond aanwezig, maar zeker een hele waardevolle kracht in het promotorenteam! De meetings met $z$ 'n vieren die we een paar keer per jaar hielden waren voor mij heel inzichtelijk en overzichtelijk en jouw moleculair-biologische kennis bood dan weer inspiratie voor de te kiezen vervolgstappen. Al tijdens mijn master in Wageningen heb jij mij weten te inspireren tot het zoeken van uitdagingen. Mijn stage in New York was daarvoor een belangrijke stap. Wat mij ook altijd bij zal blijven is dat jij, maar zeker ook Guido, mij destijds hebben aangeraden steeds op zoek te gaan naar personen om je heen waarvan je kunt leren en die je inspireren. Dat is het pad dat ik nog altijd probeer te volgen. Bedankt voor alle adviezen gedurende de afgelopen jaren! 
Prof. dr. Glatz, Prof. dr. Biessen, Prof. dr. Havekes, Prof. dr. Karpe and dr. Shiri-Sverdlov: thank you very much for evaluating my thesis.

Lieve Karina, ik ben heel blij dat jij deze dag achter mij staat als paranimf! Onze vriendschap heeft zich de afgelopen jaren ontwikkeld tot een zeer hechte band. Wat hebben we samen veel meegemaakt de afgelopen jaren. Ik kan bij jou altijd terecht voor goede gesprekken, afleiding en vooral ook samen genieten van het goede leven. Ontzettend bedankt voor alle steun en betrokkenheid de afgelopen jaren!

Lieve Silvie, ik vond het heel speciaal om jouw paranimf te mogen zijn en ik vind het super dat jij ook mij bijstaat tijdens mijn verdediging! Ik waardeer het enorm dat ik altijd bij je terecht kan voor steun, overleg en gezelligheid. Je bent al heel goed op weg richting een mooie carrière in de wetenschap. Ik hoop dat we in de toekomst ook op afstand nog altijd bij elkaar terecht kunnen!

Collega's HB en BW: naast alle praktische hulp, bedankt voor alle gezelligheid; de praatjes bij het koffiezetapparaat, de borrels en etentjes. Al heb ik al best wat van de wereld gezien, wonen in Limburg voelde voor mij regelmatig als buitenlandervaring. De cultuur is nooit de mijne geworden, maar ik heb kennis kunnen maken met carnaval en heb genoten van het bourgondische leven. Jos: bedankt voor het organiseren van de borrels! Ook de uitstapjes en weekenden waren altijd super gezellig!

Collega's en oud-collega's van het SHOCk-team: heel hartelijk bedankt voor de samenwerking en de inspirerende meetings. De wekelijkse meetings en journalclubs waren altijd nuttig en inzichtelijk, waardoor ik ook buiten mijn onderzoeksgebied veel heb kunnen leren. Allemaal heel hartelijk bedankt! Lauren, you were involved in most of my projects, so a special thanks to you!

Kamergenoten: Anja, Hazibe, Bianca, Guy en Lisje, bedankt voor de fijne tijd op kamer 2.306! Anja, bedankt voor alle support en gezelligheid tijdens mijn opstartfase. Hazibe, bedankt voor 4 jaar betrokkenheid en gezelligheid! Bianca, bedankt voor alles, zowel op het werk als daarbuiten en wat hebben we samen mooie reizen gemaakt! Guy, ook jij bedankt voor de gezelligheid en betrokkenheid, ik heb enorm veel respect voor jouw ambities en werkwijze. Lisje, het was kort maar heel gezellig!

Ik wil ook graag de secretaresses en analisten van $\mathrm{HB}$ en BW en de medewerkers van het RNL en het CPV bedanken voor alle hulp. In het bijzonder wil ik Gert, Esther, Johanna en Denis heel graag bedanken voor alle hulp maar ook zeker voor de goede sfeer in het lab! Daarnaast, alle coauteurs: heel hartelijk bedankt voor jullie bijdrages aan de artikelen! 
Pontus: thanks for the giving me the opportunity to start as a postdoc in your research group. I already knew for more than 6 months that I would be joining the lab and finally the time has come. This is the challenging and inspiring research environment that I was looking for as the next step in my career!

Colleagues of Boström/Andersson lab, many thanks for the warm welcome! It's great to work in such a strong and enthusiastic team.

Anke, Annemarie, Eline, Frederike, Geerke, Marijke, Nynke en Sietske: geweldig dat wij elkaar nog zo regelmatig zien! Ik heb hele goede herinneringen aan mijn studententijd in Wageningen en de jaren daarna, waarin we zoveel met elkaar hebben beleefd. Bedankt voor alles. Waar ter wereld we ook wonen en hoe onze levens er ook uit zien, de sterke band blijft bestaan, super!

Else, Mirjam en Victoria: super dat onze vriendschap al ruim 13 jaar stand houdt terwijl onze levens inmiddels sterk uiteen lopen!

Familie: bedankt voor alles; de getoonde interesse, gezelligheid en betrokkenheid. Robert, Almer en Lisa in het bijzonder; bedankt voor alle steun en gezelligheid!

Leave heit en mem, tige tank foar alles, woorden schieten natuurlijk tekort om uit te drukken hoeveel dank ik jullie verschuldigd ben. Fijn om altijd terug te kunnen vallen op een stabiele, fijne basis. Bedankt voor de hulp bij alle verhuizingen en ontzettend bedankt voor alle steun op moeilijke momenten. Super dat jullie mij onvoorwaardelijk steunen in alle keuzes die ik maak! 
LIST OF PUBLICATIONS 


\section{Published papers and papers accepted for publication:}

M. Bosma, L. Sparks, S. Timmers, S. Houten, G. Hooiveld, S. Kersten, P. Schrauwen, M. Hesselink. Overexpression of PLIN5 in skeletal muscle promotes oxidative gene expression and intramyocellular lipid content without compromising insulin sensitivity. Biochim Biophys Acta; in press, doi: 10.1016/j.bbalip.2013.01.007.

T. van de Weijer, B. Havekes, J. Hoeks, L. Bilet, L. Sparks, M. Bosma, S. Paglialunga, J. Jorgensen, M. Janssen, G. Schaart, H. Sauerwein, J. Smeets, R. Zechner, V. SchrauwenHinderling, M.K.C. Hesselink, P. Schrauwen. Effects of bezafibrate treatment in two sisters with mutations in the PNPLA2 gene, causing Neutral Lipid Storage Disease with Myopathy (NLSDM). Circ Res; in press.

M. Bosma, M.K.C. Hesselink, L.M. Sparks, S. Timmers, J. Ferraz, F. Mattijssen, D. van Beurden, G. Schaart, M.H. De Baets, F. Verheyen, S. Kersten, and P. Schrauwen. Perilipin 2 improves insulin sensitivity in skeletal muscle despite elevated intramuscular lipid levels. Diabetes 2012; 61:2679-2690.

S. Timmers, M. Nabben, M. Bosma, B. van Bree, E. Lenaers, D. van Beurden, G. Schaart, M. Westerterp-Plantenga, W. Langhans, M.K.C. Hesselink, V. Schrauwen-Hinderling, P. Schrauwen. Augmenting muscle diacylglycerol and triacylglycerol content by blocking fatty acid oxidation does not impede insulin sensitivity. Proc Natl Acad Sci 2012; 109:1171111716.

M. Bosma, S. Kersten, M.K.C. Hesselink, P. Schrauwen. Re-evaluating lipotoxic triggers in skeletal muscle: relating intramyocellular lipid metabolism to insulin sensitivity. Prog Lipid Res 2012; 51:46-49.

M. Bosma, R. Minaard, L.M. Sparks, G. Schaart, M. Losen, M. de Baets, H. Duimel, S. Kersten, P. Schrauwen, M. Hesselink. The lipid droplet coat protein perilipin 5 also localizes to muscle mitochondria. Histochem Cell Biol 2012; 137:205-216.

S. Paglialunga, B. van Bree, M. Bosma, P. Valdecantos, E. Amengual-Cladera, J. Jorgensen, D. van Beurden, G. den Hartog, M. Ouwens, J. Briedé, P. Schrauwen, J. Hoeks. Targeting mitochondrial ROS production does not avert lipid-induced insulin resistance in muscle. Diabetologia 2012; 55:2759-2768. 


\section{Manuscripts submitted or in preparation:}

M. Bosma, J. Hoeks, N. van Herpen, J. Jorgensen, E. Kornips, M.K.C. Hesselink, P. Schrauwen. Increased intramyocellular lipid storage capacity is associated with lower fasting-induced insulin resistance. Submitted.

M. Bosma*, L.M. Sparks*, G. Schaart, T. van de Weijer, B. Brouwers, M.K.C. Hesselink, P. Schrauwen. Reduced incorporation of fatty acids into triacylglycerol in myotubes established from obese individuals with type 2 diabetes. In preparation.

* These authors contributed equally.

R. Meex, M. Bosma, C. Moro, D. Langin, G. Schaart, E. Moonen-Kornips, P. Schrauwen, M.K.C. Hesselink. Modifying the myocellular lipid droplet phenotype by exercise training in obese and type 2 diabetic subjects contributes to metabolic flexibility. In preparation.

A. Taube, B. Platzbecker, A. Schober, G. van Echten-Deckert, M. Bosma, J. Weiss, P. Schrauwen, K. Jeruschke, K. Eckardt, J. Eckel. Adipokines promote lipotoxic effects of low levels of palmitic acid but not oleic acid by reducing fatty acid oxidation and increasing diacylglycerol. Submitted.

N. Billecke, G. Rago, M. Bosma, M.K.C. Hesselink, M. Bonn, S.H. Parekh. CARS microscopy for local analysis of lipid droplets in skeletal muscle tissue. In preparation.

L. Sparks, M. Bosma, A. Gemmink, J. Jorgensen, P. Schrauwen, J. Hoeks. Examining the role of adenine nucleotide translocase 1 (ANT1) in mild uncoupling of skeletal muscle. In preparation. 


\section{Published abstracts and chapters:}

M. Bosma, J. Hoeks, N. van Herpen, J. Jorgensen, E. Kornips, M.K.C. Hesselink, P. Schrauwen. Increased intramyocellular lipid storage capacity is associated with lower fasting-induced insulin resistance. Nederlands Tijdschrift voor Diabetologie 2012; 10(3): p.117.

M. Bosma, L. Sparks, S. Timmers, S. Houten, G. Hooiveld, S. Kersten, P. Schrauwen, M. Hesselink. The lipid droplet coat protein perilipin 5 increases intramyocellular lipid accumulation without affecting insulin sensitivity. Lipotox symposium Graz (Austria), 2012.

M. Bosma, R. Minnaard, L.M. Sparks, G. Schaart, M. Losen, M.H. de Baets, H. Duimel, S. Kersten, P.E. Bickel, P. Schrauwen, M.K.C. Hesselink. The lipid droplet coat protein perilipin 5 also localizes to muscle mitochondria. Nederlands Tijdschrift voor Diabetologie 2011; 9(3): p.139.

M. Bosma, M.K.C. Hesselink, L.M. Sparks, S. Timmers, D. van Beurden, G. Schaart, M.H. De Baets, F. Verheyen, S. Kersten, and P. Schrauwen. ADRP is essential for lipid droplet storage in skeletal muscle and protects against insulin resistance. FASEB Summer Research Conference 'Lipid droplets: metabolic consequences of the storage of neutral lipids', Colorado (USA), 2010.

M. Bosma, R. Minnaard, S. Kersten, M.K.C. Hesselink, P. Schrauwen. Muscular lipid droplet dynamics: ADRP and OXPAT protein expression upon lipid loading in cultured myotubes. European Association for the Study of Diabetes Annual Meeting, Vienna (Austria). Diabetologia 2009; 52: S277-S277.

M. Bünger, P. de Groot, L. Sanderson, L. Singh, M. Bosma, S. Hannenhalli, S. Kersten, M. Müller, G. Hooiveld. Organ-specific function of PPAR $\alpha$ as revealed by gene expression profiling. Book chapter PhD thesis (Wageningen University 2008). 
CURRICULUM VITAE 
Madeleen Bosma was born in Heerenveen, The Netherlands, on November $16^{\text {th }}, 1984$. In 2003, she finished pre-university secondary education at the Bornego College in Heerenveen. Subsequently, she started with the bachelor Nutrition and Health at Wageningen University and graduated cum laude in 2006.

She then continued with the master Nutrition and Health at the same university and specialized in both 'Molecular Nutrition' and 'Nutritional Physiology'. As part of her MSc training she performed a thesis project Metabolism and Nutrigenomics at the department of Human Nutrition investigating the effects of PPAR $\alpha$ activation in small intestine and liver under the supervision of Dr. Guido Hooiveld and Prof. dr. Michael Müller. Her second thesis project at the department of Human and Animal Physiology was a combination of a study investigating the bioavailability of lysine from sources subjected to the Maillard reaction and a study on the cannabinoid system in the small intestine, under supervision of Dr. Gert-Jan Geerse, Dr. Joost van den Borne and Prof. dr. Katja Teerds. Subsequently, she was awarded several grants, among which a student grant from the Dutch Heart Foundation ('De Hartstichting') for an internship at the department of Preventive Medicine and Nutrition, College of Physicians and Surgeons, Columbia University in New York City (USA), under supervision of Dr. Konstantinos Drosatos, Prof. Ira Goldberg and Prof. dr. Sander Kersten (Wageningen University), investigating mechanisms involved in lipotoxicity in the heart. She graduated cum laude in November 2008.

In December 2008, she accepted a VLAG/NUTRIM PhD-student position the department of Human Biology at Maastricht University, under supervision of Prof. dr. Patrick Schrauwen, Prof. dr. Matthijs Hesselink and Prof. dr. Sander Kersten (Wageningen University). She investigated the role of the lipid droplet coat proteins perilipin 2 and 5 in relation to skeletal muscle lipid metabolism and insulin sensitivity. She was involved in cell, animal and human studies, with a focus on ex vivo and in vitro techniques related to gene manipulation and lipid- and glucose metabolism. In 2010, she received the Foppe ten Hoor Young Investigator award at the NWO-Nutrition conference.

Madeleen Bosma is currently working as a postdoctoral researcher in the research group of Dr. Pontus Boström at the department of Cell and Molecular Biology at the Karolinska Institute in Stockholm, Sweden. This position allows her to extend her knowledge on and experience in molecular biology techniques. She is involved in several projects on exerciseinduced myokine signaling. She is currently investigating the physiological regulation and function of the myokine FNDC4 and is studying the effects of exercise-induced myokines on (cardio)myocellular lipid metabolism and the immune system. 

It is through science that we prove, but through intuition that we discover

(Jules Henri Poincare) 